\title{
PREVENTING FALLS IN OLDER PEOPLE
}

Simon Paul Conroy MB ChB MRCP

A thesis submitted in partial fulfilment of the requirements for the degree of Doctor of Philosophy

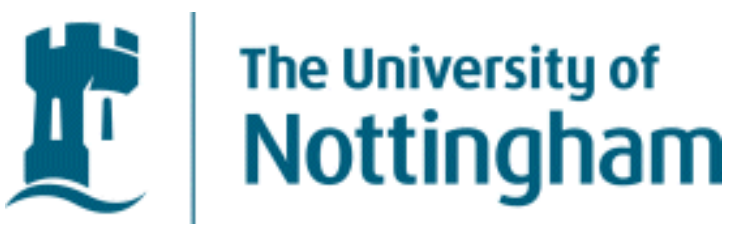

December 2008, revised February 2009 


\title{
UNIVERSITY OF NOTTINGHAM
}

\author{
ABSTRACT \\ Preventing falls in older people \\ Simon Conroy
}

Falls are a major cause of injury fear of falling and death affecting $24 \%$ of older people annually. Falls have a major impact on hospital services, and are an important cause of carer strain and admission to long term care. Multifactorial interventions delivered to fallers are effective in reducing falls rates by $25 \%$. However, no UK studies have evaluated the role of screening older people living in the primary care setting and offering those at high risk a falls prevention programme. This work describes two studies - the evaluation of a postal falls risk screening tool, and a randomised controlled trial assessing the benefits of offering a falls prevention programme to those identified as being at high risk.

335 older people were recruited into the screening study, using a modified version of the Falls Risk Assessment Tool. The sensitivity was 79\%, specificity $58 \%$, positive predictive value $50 \%$ and the negative predictive value $83 \%$.

In the RCT, 364 community-dwelling older people at high risk of falls were randomised into a pragmatic, multicentre trial evaluating falls prevention programmes. 181 were allocated to the control group and 183 to the intervention.

The primary outcome was the rate of falls; the adjusted IRR was 0.73 $(0.51-1.03), p=0.071$. There were no significant differences between the groups in terms of the proportion of fallers, recurrent fallers, medically verified falls, injurious falls, time to first fall or time to second fall. Nor 
were there significant differences in terms of institutionalisation, mortality, basic or extended activities of daily living, or fear of falling.

Further work on the acceptability and implementation of falls prevention interventions is required, but subject to these conditions being met and a supportive cost-effectiveness analysis, the totality of the evidence suggests that screening and intervening for individuals at high risk of fall may be effective. 


\section{ACKNOWLEDGMENTS}

There are many people who have helped and supported me during the time I have been working on this thesis. It would be imprudent not to mention first and foremost my long suffering family - Marie-Hélène, Océane, Iléana and Amaël, without whose support none of this would have been possible. To the two angels sitting in my shoulders, John Gladman and Denise Kendrick, thank you for your support and patient guidance, especially Denise in such difficult times.

Someone had to do all of the work, so a huge thank you to Rachael Taylor and Judi Edmans who did such a fantastic job recruiting and retaining the many hundreds of participants, not to mention contacting the many thousands who did not participate. Thank you for the laughter and smiles when it was all getting a bit tough. No more chocolate thank you Rachael... To Tash Masud and Rowan Harwood, the instigators and supporters of this study, my heartfelt thanks and gratitude. Also to all of the other study team members who made the study possible: Dr Carol Coupland, Dr Avril

Drummond, Dr Tracey Sach, Dr Pradeep Kumar, Dr Rob Morris and Dr Jane Youde. A huge thank you to the study participants for their good humoured participation and extraordinarily good diary completion. Also to all of the day hospital staff and general practice staff without whose cooperation the study would not have happened. A big thank you to all of those in the Division of Rehabilitation and Ageing in Nottingham - long live geriatrics! Last, but not least, a big thank you to our funders: Nottinghamshire, Derbyshire and Lincolnshire research alliance, Research into Ageing and the British Geriatrics Society and the Special Trustees of Nottingham University Hospital NHS trust. 
TABLE OF CONTENTS

1 BACKGROUND AND LITERATURE REVIEW............................... 10

1.1 General overview: falls in older people 10

1.2 Epidemiology 10

1.3 The impact of falls $\quad 20$

1.3.1 Fear of falling $\quad 20$

1.3.2 Falls and depression $\quad 22$

1.3.3 Fall related injuries $\quad 23$

1.3.4 Falls and mortality $\quad 24$

1.3.5 The impact of falls on hospital services 24

1.3.6 Falls and carer strain $\quad 26$

1.3.7 Falls and admission to long term care 27

1.3.8 Falls risk factors $\quad 28$

1.3.9 Falls screening tools $\quad 32$

1.4 Why do people fall? $\quad 41$

1.5 Interventions to prevent/reduce falls 42

1.5.1 Compliance 44

1.5.2 Published work on falls prevention since the 2003 NICE guidelines 46

1.6 Setting for interventions $\quad 52$

1.7 Summary of the literature review 53

1.8 Research questions $\quad 54$

1.9 Overview $\quad 54$

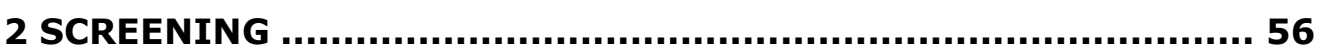

2.1 Definitions 56

2.2 Criteria for a successful screening programme 58

2.2.1 The condition should be an important public health problem 59

2.2.2 There should be an accepted treatment 59

2.2.3 Facilities for diagnosis and treatment should be available $\quad 59$

2.2.4 There should be a recognisable latent stage 60

2.2.5 The natural history of the condition should be understood 60

2.2.6 There should be a suitable and acceptable test 60

2.2.7 There should be an agreed policy on whom to treat 61

2.2.8 The cost of case-finding should be economically balanced 61

2.2.9 Case-finding should be a continuing process 61

2.2.10 Summary 61

2.3 Benefits and adverse effects of screening 62

2.4 Screening terminology 62 
2.4.1 Prevalence and incidence

2.4.2 Measures of effect and impact on populations 64

2.4.3 Sensitivity and specificity $\quad 65$

2.5 Development of a screening tool 66

2.5.1 Developing an item pool 67

$\begin{array}{ll}2.5 .2 \text { Validity } & 67\end{array}$

$\begin{array}{ll}2.5 .3 \text { Reliability } & 70\end{array}$

2.5.4 Development of the screening tool 70

2.6 Evaluation of a falls screening tool - methods 77

$\begin{array}{ll}2.6 .1 \text { Study design } & 77\end{array}$

2.6.2 Population, inclusion and exclusion criteria 78

$\begin{array}{ll}2.6 .3 \text { Recruitment of individual participants } & 79\end{array}$

2.6.4 Outcomes 81

2.6.5 Sample size $\quad 82$

2.6.6 Analyses $\quad 83$

2.7 Evaluation of a falls screening tool - results 86

2.7.1 Recruitment 86

2.7.2 Data cleaning $\quad 89$

2.7.3 Data available for analysis 90

2.7.4 Baseline characteristics 90

2.7.5 Describing the occurrence of falls 91

2.7.6 Predictive properties 93

2.7.7 Sensitivity analyses using imputed data 94

2.7.8 Secondary outcomes 97

$\begin{array}{ll}2.8 \text { Discussion } & 100\end{array}$

$\begin{array}{ll}2.8 .1 \text { Summary } & 100\end{array}$

2.8.2 Strengths and limitations 101

$\begin{array}{ll}\text { 2.8.3 Comparisons with previous studies } & 103\end{array}$

$\begin{array}{ll}2.8 .4 \text { Generalisability } & 104\end{array}$

2.8.5 Interpretation $\quad 104$

3 RANDOMISED CONTROL TRIAL........................................... 106

$\begin{array}{ll}3.1 \text { Overview } & 106\end{array}$

3.2 Design considerations 106

3.2.1 Evaluating complex interventions 106

$\begin{array}{ll}3.2 .2 \text { External comparability } & 107\end{array}$

$\begin{array}{ll}3.2 .3 \text { Internal validity } & 108\end{array}$

$\begin{array}{ll}3.3 \text { Trial design } & 119\end{array}$

$\begin{array}{ll}3.4 \text { Recruitment } & 121\end{array}$ 
3.4.1 Recruitment of general practices 121

3.4.2 Recruitment of day hospitals $\quad 122$

3.4.3 Recruitment of individual participants 123

$\begin{array}{ll}3.4 .4 \text { Retention of study participants } & 128\end{array}$

3.5 Intervention under evaluation $\quad 128$

3.5.1 Medical assessment and treatment 128

3.5.2 Physiotherapy assessment and individualised therapy $\begin{array}{ll}\text { programme } & 129\end{array}$

3.5.3 Occupational therapy assessment and modifications $\quad 129$

3.5.4 Control group 130

$\begin{array}{ll}3.6 \text { Outcome Measures } & 130\end{array}$

3.6.1 Baseline demographic and clinical characteristics 131

3.6.2 Primary outcome: rate of falling over a 12 month period post recruitment 132

$\begin{array}{ll}3.6 .3 \text { Secondary outcomes } & 134\end{array}$

3.6.4 Ascertaining outcome measures 138

3.7 Sample size $\quad 141$

3.7.1 Power calculation and sample size estimates 142

3.8 Study design $\quad 144$

3.9 Randomisation and stratification $\quad 146$

3.10 Blinding 146

3.11 Research governance and ethical considerations 146

3.11.1 International Standard Randomised Control Number $\quad 147$

$\begin{array}{ll}3.12 \text { Process monitoring } & 148\end{array}$

$\begin{array}{ll}3.12 .1 \text { Behavioural mapping } & 148\end{array}$

3.12.2 Adherence to programme 149

$\begin{array}{ll}3.13 \text { Data handling } & 149\end{array}$

$\begin{array}{ll}\text { 3.13.1 Data cleaning } & 149\end{array}$

3.13.2 Handling missing data $\quad 150$

3.14 Data analysis $\quad 152$

3.14.1 General considerations $\quad 152$

3.14.2 Intention to treat analysis 153

3.14.3 Primary outcome: rate of falling 154

3.14.4 Secondary analyses 156

3.15 Results 158

3.15.1 Data Preparation 158

$\begin{array}{ll}3.15 .2 \text { Recruitment } & 159\end{array}$

3.15.3 Randomisation 162 
3.15.4 Baseline data

3.16 Describing the intervention 165

3.16.1 Behavioural mapping 165

3.16.2 Day hospital attendances and logs 165

3.16.3 Describing the primary outcome 169

3.16.4 Adjusted analysis 172

3.16.5 Sub-group analyses 173

$\begin{array}{ll}3.16 .6 \text { Secondary analyses } & 174\end{array}$

3.17 Summary of the findings from the randomised controlled trial 186

3.18 Discussion 188

$\begin{array}{ll}3.18 .1 \text { Inadequate power and chance } & 188\end{array}$

3.18.2 Bias 190

3.18.3 Confounding 192

3.18.4 Insensitive outcomes 192

3.18.5 Reverse causation $\quad 192$

3.18.6 Inadequate intervention 192

3.18.7 Summary 194

3.18.8 External validity 194

3.18.9 Generalisability 195

3.18.10 Implications 195

3.18.11 Overall evidence 198

3.18.12 Recommendations 200

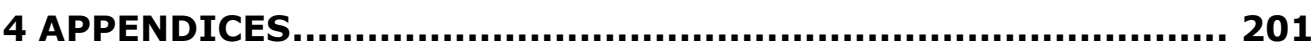

4.1 Literature review - search methods 201

4.1.1 Search terms for falls prevalence and incidence 201

4.1.2 Search terms for falls and admission to long term care 201

4.1.3 Search terms for fear of falling (from 8/2/2003) 202

4.1.4 Search terms for falls and depression 202

4.1.5 Search terms for falls and mortality 202

4.1.6 Search terms for falls and carer burden 203

4.1.7 Search terms for falls risk factors 203

4.1.8 Search terms for falls risk assessment tools 204

4.1.9 Search terms for falls interventions 205

4.1.10 Search terms for day hospital falls interventions 205

4.2 Screening questionnaire 206

4.3 Sample day hospital log 207

4.4 Data checking 4-208

4.5 Model checking results 209 
4.5.1 Primary outcome - negative binomial regression 209

4.6 Meta-analysis of falls prevention trials 211

4.7 Publications and presentations arising $\quad 216$

4.7.1 Publications 216

$\begin{array}{ll}\text { 4.7.2 Presentations } & 216\end{array}$

5 REFERENCES..................................................................... 217

\section{LIST OF FIGURES}

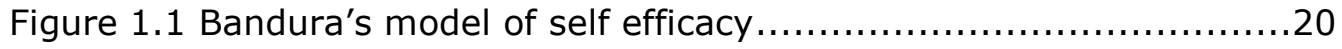

Figure 1.2 Schema for assessing falls (adapted from Lord, $2000^{207}$ ) .......41

Figure 1.3 Factors that contribute to the risk of falls.......................42

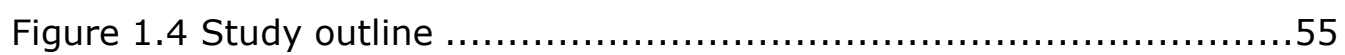

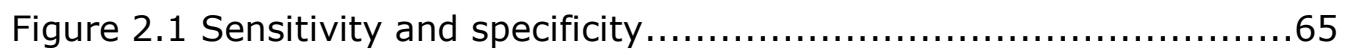

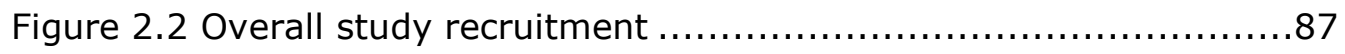

Figure 2.3 Histogram of the number of diaries returned per participant ...90

Figure 2.4 ROC curves comparing risk score and previous fall only.........94

Figure 3.1 Prospective plan of the study ................................ 145

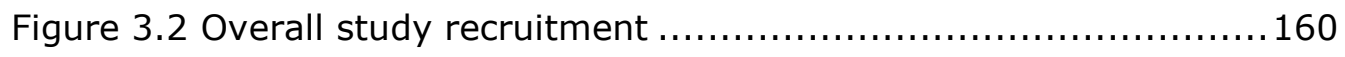

Figure 3.3 RCT participant flow ...................................... 161

Figure 3.4 Number of FPP attendances by day hospital ................... 166

Figure 3.5 Box and whisker plot of individual falls rate by allocation ......170

Figure 3.6 Scatterplot of deviance residuals against study id ..............171

Figure 3.7 Time to first fall by allocation - unadjusted analysis ............178

Figure 3.8 Time to second fall - unadjusted analysis ......................179

Figure 3.9 Bland-Altman plot of mean difference versus average score for

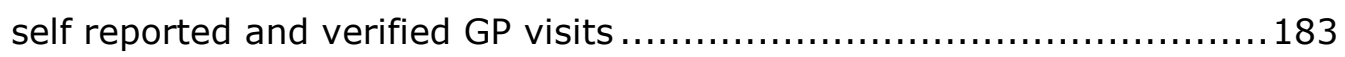

Figure 4.1 Scatterplot of deviance residuals against study id ...............209

Figure 4.2 Scatterplot of Cook's distance against study id .................209

Figure 4.3 Scatterplot of leverage against study id ........................210

Figure 4.4 Scatterplot of predicted mean number of falls against study id

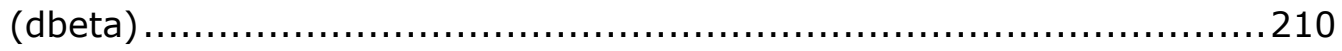

Figure 4.5 Meta-analysis of falls prevention studies using a random-effects

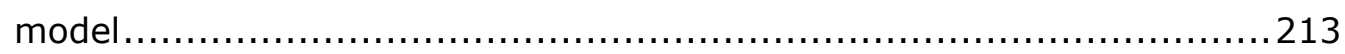

Figure 4.6 Meta-analysis comparing pragmatic versus explanatory falls prevention trials 214

Figure 4.7 Funnel plot of all trials examined in the meta-analysis of falls prevention studies 


\section{BACKGROUND AND LITERATURE REVIEW}

\subsection{General overview: falls in older people}

Falls are one of the 'geriatric giants' ${ }^{1}$. They are a common and potentially serious problem for older people; falls may result in injury, fear of falling, social isolation and death ${ }^{2}$. There is an important relationship between frailty, falls and fractures ${ }^{34}$, with the three sharing risk factors. Falls are a commonly cited factor leading to a care home admission and give rise to a major financial demand on the National Health Service and Social Services ${ }^{5}$.

Several systematic reviews have collated published work on falls $\mathrm{s}^{6-11}$ and show that interventions can reduce falls by up to one-third. Such interventions typically consist of a medical review, home hazards assessment, and strength and balance training. Individual components or combinations of these components have been shown to be effective in hospital, primary care and care home settings, and in many different countries $^{12} 13$.

This work will focus on falls prevention in community dwelling older people.

\subsection{Epidemiology}

Most studies on falls quote the seminal paper by Mary Tinetti - 'one third of those aged over 65 years fall annually, rising to one half of those aged $85^{\prime 14}$, data from 1988 based on a well conducted cohort study of 336 individuals in the United States. Other groups reproduced Tinetti's results at around the same time ${ }^{15} 16$, which led to a focus on falls as a research topic and the recognition of the importance of falls in health planning and policy, not least the highlighting of falls in the United Kingdom (UK) National Service Framework for Older People ${ }^{2}$. However, there have been 
relatively few well conducted studies on the incidence and/or prevalence of falls in the UK in recent years.

Table 1.1 shows a compilation of recent studies (1996-2008) on falls prevalence and incidence in various settings. There is marked heterogeneity in the studies in terms of study design, size, setting and reporting methods, but nevertheless all point towards the high frequency of falls in older people. The UK and European studies indicate an annual falls prevalence of around $24 \%$ for older people ( 70 years old or greater) living in the community ${ }^{17}{ }^{18}$, which is broadly similar to rates in Australia ${ }^{19}$ and the United States ${ }^{20-22}$. A recent survey of older people in England reported falls prevalence of $23 \%$ for men and $29 \%$ for women ${ }^{23}$. One Dutch study reported falls prevalence of $51 \%$ over 10 months ${ }^{24}$, with reasonable reporting methods and a community dwelling older population similar to those studies cited above, which is inconsistent with the bulk of the literature. However, of those originally randomly invited to participate in the study, only $31 \%$ responded, so selection bias is likely.

Worthy of mention is that studies with tighter ascertainment of falls (weekly as opposed to monthly or less frequent diaries), seem to report higher falls prevalence. For example, Snijder ${ }^{25}$ used weekly diaries in a Dutch cohort study of community dwelling older people and found rates of $33 \%$ over one year, which is closer to Tinetti's original study, which used bimonthly phone calls to ascertain falls ${ }^{14}$. This finding was reproduced by Cummings et $\left.a\right|^{26}$ who followed up 325 community dwelling older people over one year using weekly falls diaries; however at one year, $13 \%$ of participants were unable to recall incident falls and a further $7 \%$ recalled falls that were not otherwise corroborated by the diaries (see 3.6.4.1). Falls prevalence in very old ( $>85$ years) community dwelling adults appears to be much higher, nearer the $50 \%$ originally reported by Tinetti. 
For example, the Longitudinal Study on Ageing Amsterdam (LASA) cohort of $85+$ year olds found a 12 month fall prevalence of $44 \%{ }^{27}$.

Few prospective cohort studies have reported falls incidence rates in community dwelling older people, which is in the region of 1.1-1.8 falls per person-year ${ }^{28} 29$, although many intervention trials use incidence as an outcome measure ${ }^{90-36}$. Unpublished work using the THIN database general practises in England has found reported falls rates of 3.6 per 100 personyears ( 0.04 per person-year) in people aged 60 or more, though underreporting is likely.

Rates for recurrent falls (i.e. more than one fall per annum) are more consistent, at around 10-12\% per annum ${ }^{25}$ 37-39 though one Australian study found rates for recurrent falls as high as $22 \%{ }^{19}$, but this was a randomised controlled study, and there is likely to be a degree of selection bias.

By comparison, fall rates in high risk populations, such as those in care homes or geriatric care settings, are consistently higher - $10 \%$ over one week $^{40}, 12 \%$ over three months ${ }^{41}, 20-50 \%$ over six months ${ }^{42-45}$ and 35 $60 \%$ over one year ${ }^{46-49}$.

Fall prevalence appears to be slightly lower in oriental countries, for example rates in Singapore are around $15 \%$ over one year, although this study did include a substantial proportion of younger participants $(<70$ years $)^{50}$. Assantachai et al reported rates of $20 \%$ in community dwelling Thai seniors $(65+)^{51}$, albeit using two monthly diaries to ascertain self reported falls. One study of community dwelling older people from India reported 12 months falls prevalence of $48 \%$, though the recruitment methods (word of mouth) make selection bias highly likely ${ }^{52}$. Falls rates in Turkish older people attending a geriatric outpatient setting are consistent with figures from Western societies $(29 \%)^{53}$. 
However, there are few studies comparing like with like which further explore varying falls rates by country. One study compared fall rates between white and African-American women ${ }^{54}$, but did not find any major difference between the two different ethnic groups. 
Table 1.1 Collated studies on falls epidemiology (1996-2008) - see 4.1.1 for the search methods

\begin{tabular}{|c|c|c|c|c|c|c|c|c|c|}
\hline Study & Study design & $\begin{array}{l}\text { Falls } \\
\text { reporting } \\
\text { method/ } \\
\text { period }\end{array}$ & Ascertainment & Setting & Population & Sample size & Incidence & Prevalence & $\begin{array}{l}\text { Injurious } \\
\text { falls }\end{array}$ \\
\hline $\begin{array}{l}\text { Clough-Gorr } \\
2008^{17}\end{array}$ & Cohort study & $\begin{array}{l}\text { Prospective } \\
12 \text { months }\end{array}$ & Self-reported & $\begin{array}{l}\text { London, UK; } \\
\text { Hamburg, } \\
\text { Germany; } \\
\text { Solothurn, } \\
\text { Switzerland }\end{array}$ & $\begin{array}{l}\text { Community } \\
\text { dwelling older } \\
\text { adults }\end{array}$ & 1644 & & $\begin{array}{l}24 \% \text { over } 12 \\
\text { months }\end{array}$ & \\
\hline Sayer $2006^{18}$ & Cohort study & $\begin{array}{l}\text { Prospective } \\
12 \text { months }\end{array}$ & Self-reported & $\begin{array}{l}\text { United } \\
\text { Kingdom }\end{array}$ & $\begin{array}{l}\text { Community } \\
\text { dwelling older } \\
\text { people }\end{array}$ & 2148 & & $\begin{array}{l}124 / 866 \\
(14 \%) \text { men; } \\
289 / 1282 \\
(23 \%) \\
\text { women }\end{array}$ & \\
\hline Tinetti $2008^{55}$ & Cohort study & $\begin{array}{l}\text { Prospective } \\
3 \text { years }\end{array}$ & $\begin{array}{l}\text { Routine hospital } \\
\text { systems data }\end{array}$ & Unites States & $\begin{array}{l}\text { Older people } \\
\text { attending } \\
\text { hospitals with a } \\
\text { serious injurious } \\
\text { fall }\end{array}$ & $>200,000$ & & & $\begin{array}{l}31-32 \text { per } \\
1000 \\
\text { person- } \\
\text { years }\end{array}$ \\
\hline $\begin{array}{l}\text { Lamoreux } \\
2008^{50}\end{array}$ & Cohort study & $\begin{array}{l}\text { Retrospective } \\
12 \text { months }\end{array}$ & $\begin{array}{l}\text { Self reported } \\
\text { falls over } 12 \\
\text { months }\end{array}$ & Singapore & $\begin{array}{l}\text { Community- } \\
\text { dwelling adults } \\
40 \text { to } 80 \text { years }\end{array}$ & 3266 & & $\begin{array}{l}480 / 3266 \\
(15 \%) \text { over } \\
\text { previous } 12 \\
\text { months }\end{array}$ & \\
\hline
\end{tabular}




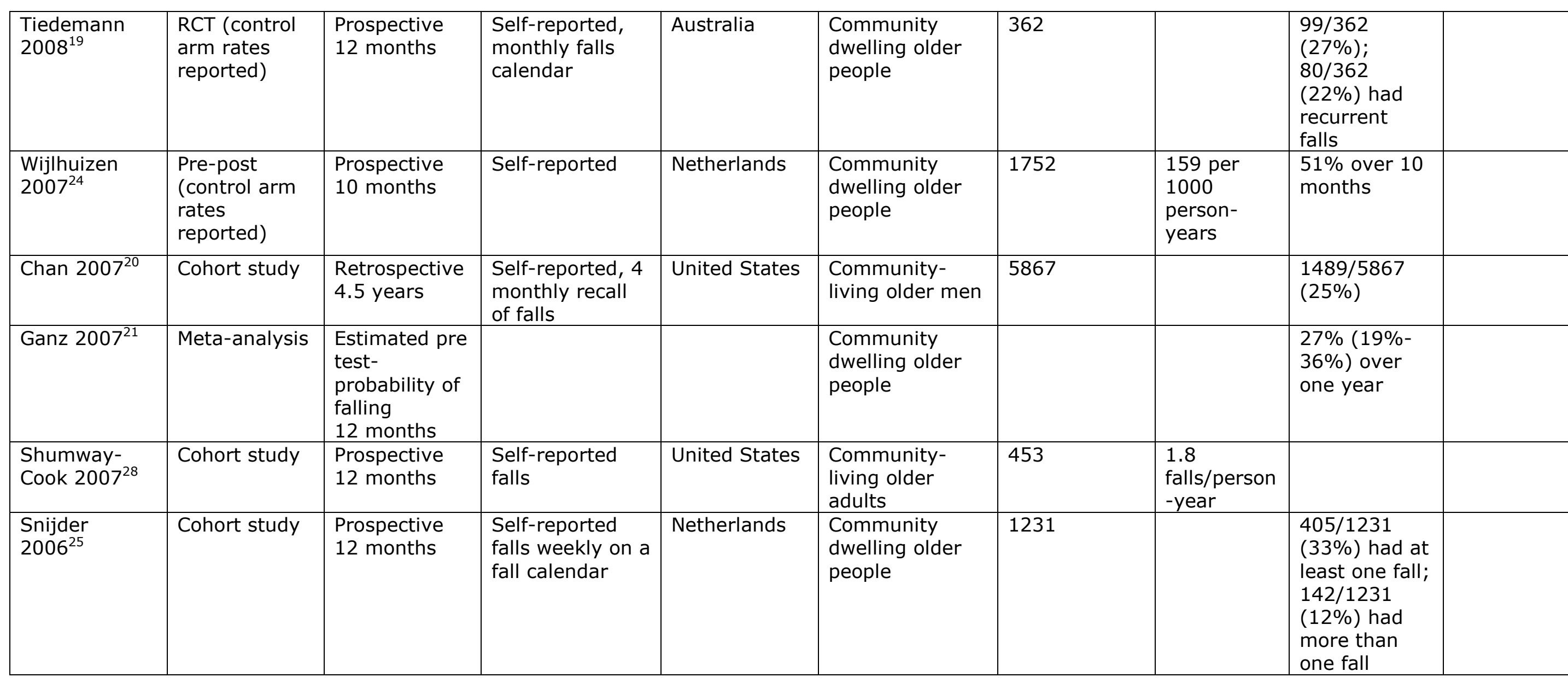




\begin{tabular}{|c|c|c|c|c|c|c|c|c|c|}
\hline Stone $2006^{38}$ & Cohort study & $\begin{array}{l}\text { Retrospective } \\
12 \text { months }\end{array}$ & $\begin{array}{l}\text { Self reported, } 4 \\
\text { monthly diary }\end{array}$ & United States & $\begin{array}{l}\text { Ambulatory, } \\
\text { community- } \\
\text { dwelling women } \\
\text { aged } 65 \text { and } \\
\text { older }\end{array}$ & 8101 & & $\begin{array}{l}10-18 \% \text { for } \\
\text { recurrent } \\
\text { falls over } 12 \\
\text { months }\end{array}$ & \\
\hline $\begin{array}{l}\text { Campbell } \\
2005^{29}\end{array}$ & $\begin{array}{l}\text { RCT (control } \\
\text { arm rates } \\
\text { reported) }\end{array}$ & $\begin{array}{l}\text { Prospective } \\
12 \text { months }\end{array}$ & $\begin{array}{l}\text { Self-reported } \\
\text { monthly } \\
\text { postcard } \\
\text { calendars with } \\
\text { cross check }\end{array}$ & Australia & $\begin{array}{l}\text { Community } \\
\text { dwelling older } \\
\text { people }\end{array}$ & 361 & $\begin{array}{l}1.1 \text { falls per } \\
\text { person- } \\
\text { year }\end{array}$ & $\begin{array}{l}95 / 196 \\
(48 \%)\end{array}$ & $\begin{array}{l}0.6 \text { per } \\
\text { person-year }\end{array}$ \\
\hline $\begin{array}{l}\text { van Bemmel } \\
2005^{27}\end{array}$ & Cohort study & $\begin{array}{l}\text { Retrospective } \\
12 \text { months }\end{array}$ & $\begin{array}{l}\text { Self-reported } \\
\text { recall of falls }\end{array}$ & Netherlands & $\begin{array}{l}\text { Observational } \\
\text { population- } \\
\text { based study }\end{array}$ & 599 & & $\begin{array}{l}212 / 599 \\
(44 \%) \text { over } \\
12 \text { months }\end{array}$ & \\
\hline $\begin{array}{l}\text { Volpato } \\
2005^{39}\end{array}$ & Cohort study & $\begin{array}{l}\text { Retrospective } \\
3 \text { years }\end{array}$ & $\begin{array}{l}\text { Self-reported } \\
\text { recall of falls } \\
\text { every six } \\
\text { months }\end{array}$ & US & $\begin{array}{l}\text { Community } \\
\text { dwelling older } \\
\text { people }\end{array}$ & 878 & & $\begin{array}{l}65 \% \text { over } \\
\text { three years } \\
30 \% \text { had } \\
\text { recurrent } \\
\text { falls }\end{array}$ & \\
\hline Li $2006^{22}$ & Cohort study & $\begin{array}{l}\text { Retrospective } \\
12 \text { months }\end{array}$ & $\begin{array}{l}\text { Self-reported } \\
\text { falls over one } \\
\text { year }\end{array}$ & United States & $\begin{array}{l}\text { Community } \\
\text { dwelling older } \\
\text { people }\end{array}$ & 2193 & & $\begin{array}{l}512 / 2193 \\
(23 \%)\end{array}$ & \\
\hline Tinetti $1988^{14}$ & Cohort study & $\begin{array}{l}\text { Retrospective } \\
12 \text { months }\end{array}$ & $\begin{array}{l}\text { Bimonthly } \\
\text { telephone calls }\end{array}$ & US & $\begin{array}{l}\text { Community } \\
\text { dwelling older } \\
\text { people }\end{array}$ & 336 & & $\begin{array}{l}108 / 336 \\
(32 \%)\end{array}$ & \\
\hline Birks $2004^{56}$ & $\begin{array}{l}\text { RCT (control } \\
\text { arm rates } \\
\text { reported) }\end{array}$ & $\begin{array}{l}\text { Retrospective } \\
\text { Median } 28 \\
\text { months }\end{array}$ & Self reported & UK & $\begin{array}{l}\text { Community } \\
\text { dwelling older } \\
\text { women at risk } \\
\text { of fracture }\end{array}$ & 4169 & & $\begin{array}{l}43 \% \text { over } \\
\text { previous } 12 \\
\text { months }\end{array}$ & \\
\hline $\begin{array}{l}\text { Assantachai } \\
2002^{57}\end{array}$ & $\begin{array}{l}\text { RCT (control } \\
\text { arm rates } \\
\text { reported) }\end{array}$ & $\begin{array}{l}\text { Mixed } \\
12 \text { months }\end{array}$ & $\begin{array}{l}\text { Diary completed } \\
\text { in retrospect } \\
\text { every } 2 \text { months }\end{array}$ & Thailand & $\begin{array}{l}\text { Community } \\
\text { dwelling older } \\
\text { people }\end{array}$ & 1043 & & $\begin{array}{l}20 \% \text { over } 12 \\
\text { months }\end{array}$ & \\
\hline
\end{tabular}




\begin{tabular}{|c|c|c|c|c|c|c|c|c|c|}
\hline $\begin{array}{l}\text { Steinberg } \\
2000^{58}\end{array}$ & Cohort study & $\begin{array}{l}\text { Prospective } \\
12 \text { months }\end{array}$ & $\begin{array}{l}\text { Self reported, } \\
\text { daily calendar }\end{array}$ & Australia & $\begin{array}{l}\text { Community } \\
\text { dwelling older } \\
\text { people }\end{array}$ & 250 & & $\begin{array}{l}6.3-7.0 \text { falls } \\
\text { per } 100 \\
\text { person } \\
\text { months }\end{array}$ & \\
\hline $\begin{array}{l}\text { Bouwen } \\
2008^{42}\end{array}$ & $\begin{array}{l}\text { Cluster RCT } \\
\text { (control arm } \\
\text { rates } \\
\text { reported) }\end{array}$ & $\begin{array}{l}\text { Prospective } \\
6 \text { months }\end{array}$ & $\begin{array}{l}\text { Recorded by } \\
\text { health care } \\
\text { professional }\end{array}$ & Belgium & $\begin{array}{l}\text { Nursing home, } \\
\text { dependant }\end{array}$ & 210 & N/A & $\begin{array}{l}44 / 210 \\
(21 \%) \text { over } 6 \\
\text { months }\end{array}$ & \\
\hline Kerse $2004^{46}$ & $\begin{array}{l}\text { Cluster RCT } \\
\text { (control arm } \\
\text { rates } \\
\text { reported) }\end{array}$ & $\begin{array}{l}\text { Prospective } \\
12 \text { months }\end{array}$ & Staff reported & New Zealand & $\begin{array}{l}\text { Older people in } \\
\text { residential care, } \\
\text { dependant }\end{array}$ & 238 & $\begin{array}{l}2.3 \text { per } \\
\text { person- } \\
\text { year }\end{array}$ & $\begin{array}{l}103 / 238 \\
(43 \%)\end{array}$ & $\begin{array}{l}42 / 238 \\
(18 \%) \\
\text { injurious } \\
\text { falls } \\
1.0 \text { per } \\
\text { person-year }\end{array}$ \\
\hline \multirow[t]{2}{*}{ Jensen $2003^{47}$} & \multirow{2}{*}{$\begin{array}{l}\text { Cluster RCT } \\
\text { (control arm } \\
\text { rates } \\
\text { reported) }\end{array}$} & \multirow[t]{2}{*}{$\begin{array}{l}\text { Prospective } \\
34 \text { weeks }\end{array}$} & \multirow[t]{2}{*}{ Staff reported } & \multirow[t]{2}{*}{ Sweden } & \multirow[t]{2}{*}{$\begin{array}{l}\text { Residential care } \\
\text { facilities }\end{array}$} & $\begin{array}{l}102 \\
\text { MMSE >19 }\end{array}$ & $\begin{array}{l}2.9 \text { per } \\
\text { person- } \\
\text { year }\end{array}$ & $\begin{array}{l}38-54 \% \text { over } \\
\text { six months }\end{array}$ & $\begin{array}{l}0.9 \text { per } \\
\text { person-year }\end{array}$ \\
\hline & & & & & & $\begin{array}{l}79 \\
\text { MMSE } \leq 19\end{array}$ & $\begin{array}{l}3.3 \text { per } \\
\text { person- } \\
\text { year }\end{array}$ & $\begin{array}{l}46-61 \% \text { over } \\
\text { six months }\end{array}$ & $\begin{array}{l}0.9 \text { per } \\
\text { person-year }\end{array}$ \\
\hline Izumi $2002^{59}$ & Cohort study & Unclear & Unclear & Japan & $\begin{array}{l}\text { Rehabilitation } \\
\text { wards, long- } \\
\text { term care } \\
\text { facilities, and } \\
\text { nursing homes }\end{array}$ & 746 & & $\begin{array}{l}13 \% \text { over } \\
\text { three months }\end{array}$ & \\
\hline Kallin $2005^{40}$ & Cohort study & $\begin{array}{l}\text { Retrospective } \\
\text { One week }\end{array}$ & Staff reported & Sweden & $\begin{array}{l}\text { Cognitively } \\
\text { impaired } \\
\text { residents of } \\
\text { geriatric care } \\
\text { settings }\end{array}$ & 2008 & & $\begin{array}{l}189(9 \%) \text { in } \\
\text { previous } \\
\text { week }\end{array}$ & \\
\hline
\end{tabular}




\begin{tabular}{|c|c|c|c|c|c|c|c|c|c|}
\hline Hill $2008^{60}$ & Cohort study & $\begin{array}{l}\text { Retrospective } \\
6 \text { months }\end{array}$ & $\begin{array}{l}\text { Self-reported - } \\
\text { recall over six } \\
\text { months }\end{array}$ & Australia & Falls clinic & 254 & & $\begin{array}{l}78 \% \text { over } \\
\text { previous } 6 \\
\text { months }\end{array}$ & $\begin{array}{l}123 / 254 \\
(51 \%) \\
\text { injurious } \\
\text { falls } \\
8-10 \% \\
\text { fractures } \\
\text { over } 6 \\
\text { months }\end{array}$ \\
\hline $\begin{array}{l}\text { Nowalk } \\
2001^{48}\end{array}$ & $\begin{array}{l}\text { RCT (control } \\
\text { arm rates } \\
\text { reported) }\end{array}$ & $\begin{array}{l}\text { Retrospective } \\
24 \text { months }\end{array}$ & $\begin{array}{l}\text { Self reported } \\
\text { every six } \\
\text { months }\end{array}$ & US & $\begin{array}{l}\text { Long-term care } \\
\text { facilities with } \\
\text { services ranging } \\
\text { from } \\
\text { independent } \\
\text { living to skilled } \\
\text { nursing }\end{array}$ & & & $\begin{array}{l}67 / 110 \\
(61 \%)\end{array}$ & \\
\hline \multirow[t]{2}{*}{$\begin{array}{l}\text { Nyberg } \\
1997^{61}\end{array}$} & \multirow[t]{2}{*}{ Cohort study } & \multirow[t]{2}{*}{$\begin{array}{l}\text { Prospective } \\
\text { Unclear }\end{array}$} & \multirow[t]{2}{*}{ Staff reported } & \multirow[t]{2}{*}{ Sweden } & $\begin{array}{l}\text { Psychogeriatric } \\
\text { clinic }\end{array}$ & & & $\begin{array}{l}171 \text { ( } 146- \\
196) \text { per } \\
10,000 \\
\text { patient days }\end{array}$ & \multirow[t]{2}{*}{$\begin{array}{l}38 \% \\
\text { injurious }\end{array}$} \\
\hline & & & & & $\begin{array}{l}\text { Geriatric } \\
\text { rehabilitation } \\
\text { clinic }\end{array}$ & & & $\begin{array}{l}92(72-112) \\
\text { per } 10,000 \\
\text { patient days }\end{array}$ & \\
\hline $\begin{array}{l}\text { Rosendahl } \\
2008^{43}\end{array}$ & $\begin{array}{l}\text { RCT (control } \\
\text { arm rates } \\
\text { reported) }\end{array}$ & $\begin{array}{l}\text { Prospective } \\
6 \text { months }\end{array}$ & $?$ & Sweden & $\begin{array}{l}\text { Residential care } \\
\text { facilities, } \\
\text { dependant in } \\
\text { ADLs }\end{array}$ & 191 & $\begin{array}{l}4.6 \text { falls per } \\
\text { person- } \\
\text { year }\end{array}$ & $\begin{array}{l}51 \% \text { over } 6 \\
\text { months }\end{array}$ & \\
\hline
\end{tabular}




\begin{tabular}{|c|c|c|c|c|c|c|c|c|c|}
\hline $\begin{array}{l}\text { Sakamoto } \\
2006^{45}\end{array}$ & $\begin{array}{l}\text { RCT (control } \\
\text { arm rates } \\
\text { reported) }\end{array}$ & $\begin{array}{l}\text { Prospective } \\
6 \text { months }\end{array}$ & Staff reported & Japan & $\begin{array}{l}\text { Mixed } \\
\text { community/resi } \\
\text { dential setting - } \\
\text { 'high risk' }\end{array}$ & & & $\begin{array}{l}51 / 212 \\
(24 \%) \text { over } \\
\text { six months }\end{array}$ & \\
\hline $\begin{array}{l}\text { Sjösten } \\
2007^{62}\end{array}$ & $\begin{array}{l}\text { RCT (control } \\
\text { arm rates } \\
\text { reported) }\end{array}$ & $\begin{array}{l}\text { Retrospective } \\
12 \text { months }\end{array}$ & Self-reported & Finland & $\begin{array}{l}\text { People who had } \\
\text { fallen }\end{array}$ & & & $\begin{array}{l}2.3 \text { (aged 65- } \\
74 \text { ) \& } \\
3.1 \text { (aged } \\
75+\text { ) } \\
\text { falls per } \\
\text { person in } \\
\text { previous } 12 \\
\text { months }\end{array}$ & \\
\hline Thapa $1996^{49}$ & Cohort study & $\begin{array}{l}\text { Prospective } \\
\text { Mean } 11 \\
\text { months }\end{array}$ & $\begin{array}{l}\text { Minimum data } \\
\text { set (individual } \\
\text { and staff } \\
\text { reported) }\end{array}$ & United States & $\begin{array}{l}\text { Nursing homes, } \\
\text { dependant }\end{array}$ & 1228 & & $\begin{array}{l}35 \% \text { over } 1 \\
\text { year }\end{array}$ & $\begin{array}{l}6.7 \text { per } 100 \\
\text { person- } \\
\text { years } \\
\text { (ambulatory } \\
\text { ) }\end{array}$ \\
\hline & & & & & & & & & $\begin{array}{l}17.0 \text { per } \\
100 \text { person- } \\
\text { years (non- } \\
\text { ambulatory) }\end{array}$ \\
\hline Ray $2005^{44}$ & $\begin{array}{l}\text { Cluster RCT } \\
\text { (control arm } \\
\text { rates } \\
\text { reported) }\end{array}$ & $\begin{array}{l}\text { Retrospective } \\
12 \text { months }\end{array}$ & $\begin{array}{l}\text { Minimum data } \\
\text { set (individual } \\
\text { and staff } \\
\text { reported) }\end{array}$ & United States & $\begin{array}{l}\text { Nursing home } \\
\text { residents }\end{array}$ & 10558 & $\begin{array}{l}99.5 \text { fall } \\
\text { related } \\
\text { injuries per } \\
1000 \\
\text { person- } \\
\text { years } \\
\end{array}$ & $\begin{array}{l}36 \% \text { in } \\
\text { previous } 180 \\
\text { days }\end{array}$ & $\begin{array}{l}70.1 \text { per } \\
1000 \\
\text { person- } \\
\text { years of } \\
\text { follow up. }\end{array}$ \\
\hline
\end{tabular}




\subsection{The impact of falls}

Falls in older people are undignified, a reminder of vulnerability - in contrast to younger, typically more active individuals in whom falls may be expected and innocuous. For some older people, they are also potentially very serious in terms of health outcomes. Falls are strongly associated with future falls, and recurrent falling can lead to a downwards spiral, leading to fear of falling, reduced activity, deconditioning, more falls, social isolation and depression.

\subsubsection{Fear of falling}

Fear of falling is a well recognised consequence of falling - the 'post-fall syndrome', but also can be anticipatory - 'ptophobia', a phobic reaction to standing or walking ${ }^{10}$. One widely accepted definition of fear of falling is Yow perceived self-efficacy at avoiding falls during the essential, non hazardous activities of daily living 6364 - see Figure 1.1.

Figure 1.1 Bandura's model of self efficacy

The Model of Self-Efficacy (Bandura, 1977)

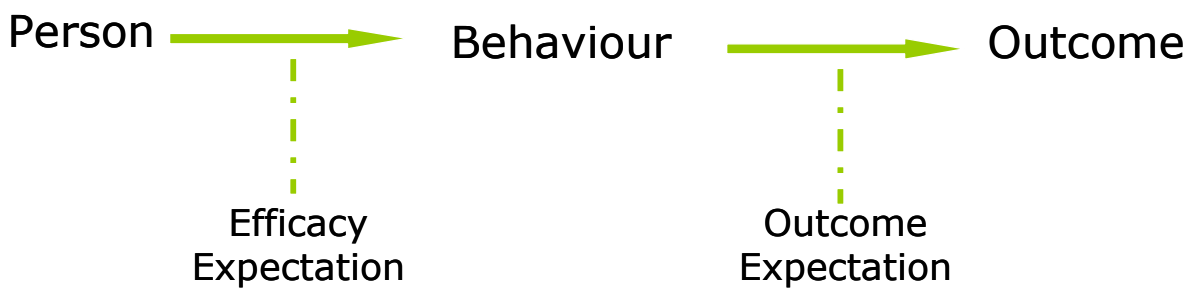

Efficacy Expectation: "conviction that one can successfully execute behaviour required to produce the outcome". Sources: Mastery experience, vicarious experience, social persuasion and emotional arousal. However most influential: Mastery experience and emotional arousal.

Outcome Expectancies: "person's estimate that a given behaviour will lead to certain outcome". 
Applied to falls, Bandura's theory predicts that low self efficacy leads to negative outcome expectations ('I will fall'), or more simply, falls beget falls.

Fear of falling was recently reviewed in the National Institute of Clinical Excellence (NICE) guidelines on the assessment of falls in older people ${ }^{10}$, and this section builds on their findings; see 1.1.1 for search methods.

The main findings from the NICE guidance were that there is considerable overlap between fear of falling and falls in terms of risk factors and associated outcomes. NICE recommended that falls assessments should include a measure of fear of falling, and favoured the Falls Efficacy Scale ${ }^{63}$. Risk factors for fear of falling include: age $>80$ years (relative risk 1.5 ), a sedentary lifestyle (relative risk 2.0), a lack of emotional support (relative risk 2.6) and visual impairment (relative risk 1.4$)^{6566}$. Further falls are associated with fear of falling (relative risk 1.7$)^{65}$, especially after hip fracture associated with a fall ${ }^{67}$.

Other investigators have found an association between increased fear of falling and balance performance ${ }^{68}$, whilst Hellstrom et $a^{69}$ found that falls efficacy was a better predictor of daily function in people recovering from stroke than more objective measures of balance. The association between fear of falling and functional impairment and quality of life has been shown in other studies ${ }^{70} 71$.

Fear of falling is also associated with serious adverse outcomes such as institutionalisation and death in individuals recovering from hips fracture ${ }^{72}$ 7374 .

The striking overlap in underlying risk factors and outcomes between falling and fear of falling make falls prevention programmes an obvious intervention to reduce not only falls but fear of falling ${ }^{65}$. Some investigators 
have found that any reduction in fear of falling is more likely related to improvements in health and functional ability - irrespective of specific nature of the interventions ${ }^{75} 76$. However, conventional exercise classes have not been able to demonstrate a reduction in fear of falling ${ }^{77}$, though it appears that Tai Chi based exercise regimes may be effective. In a randomised controlled trial, Wolf et al showed no fear of falling in $47 \%$ of people undergoing intensive Tai Chi classes, compared to $33 \%$ for those receiving computerised balance training and $41 \%$ for those receiving educational classes at between 7-20 months of follow up, though this was not significant $(p=0.55)^{78}$.

\subsubsection{Falls and depression}

(See 4.1.4 for search methods)

Falls and depression are associated ${ }^{79-85}$ and share common risk factors ${ }^{86}$. There is also an association between depression and fracture, which may be in part mediated through increased falls ${ }^{87}$. Furthermore, depression is independently associated with functional decline after a fall ${ }^{88}$.

There is an association between fear of falling and depression: in a crosssectional study of 540 community dwelling Dutch people aged $70+, 28 \%$ and $26 \%$ with severe fear of falling had feelings of anxiety and symptoms of depression respectively, and the severity of fear of falling was correlated with symptoms of depression and anxiety ${ }^{89}$. The association between fear of falling and depression is also seen in Chinese communities (crosssectional study of 100 care home residents $)^{90}$. People with depression and fear of falling appear to be most likely to restrict their activity (InChianti study - cross-sectional study of 926 Italians aged $65+)^{91}$.

Although several trials have suggested that falls prevention programmes may reduce depression in fallers ${ }^{92-94}$, and exercise is considered effective 
treatment for depression ${ }^{95}$ a recent systematic review ${ }^{96}$ and a large, well conducted randomised controlled trial ${ }^{97}$ failed to find any robust evidence that a multifactorial falls prevention programme can reduce depressive symptoms in fallers.

The story gets more complicated; treatment with antidepressants approximately doubles the risk of falling ${ }^{98-100}$ and is associated with a twofold increase in fragility fractures ${ }^{101-103}$. There is some weaker evidence (cross-sectional study of 301 adults living in long term care settings having fallen in the previous week) that newer anti-depressants (serotonin and noradrenalin reuptake inhibitors (SNRIs)) are not associated with falls ${ }^{104}$. In summary, depression may cause falls, and may be caused by falls, especially in those fallers with fear of falling or functional decline. Falls prevention interventions are not effective treatments of depression in people who fall, and anti-depressants may increase falls risk, as well as the risk of fracture.

The optimal management of depression in people who fall is unclear, though careful attention to other modifiable falls risk factors is advisable when starting anti-depressants in people at risk of falling ${ }^{105} 106$.

\subsubsection{Fall related injuries}

Approximately 30 to 50 percent of falls result in minor soft tissue injuries that do not require medical attention ${ }^{107}$, although falls are a major cause of trauma in older people ${ }^{108}$. Although falls in older people usually result in relatively low impact energies, typically consisting of a fall from the stairs or the standing position ${ }^{109} 110$, the effects of the fall can still be serious because of other factors such as osteoporosis and diminished protective reflexes. In community dwelling older people, an estimated $1 \%$ of falls result in hip fractures; $3-5 \%$ result in other types of fractures, and an 
additional $5 \%$ produce serious soft tissue injuries ${ }^{1411}$. Rates of fracture resulting from a fall are as high as $10 \%$ in high risk populations (e.g. those attending a falls service), with overall injurious falls being as high as $51 \%{ }^{60}$. Injurious falls are also high (38\%) amongst vulnerable populations such as those living in care homes and other geriatric care settings ${ }^{444961}$.

\subsubsection{Falls and mortality}

(See 4.1.5 for search methods)

Falls are the leading cause of mortality due to injury in people aged over 75 in the United Kingdom ${ }^{5112113}$. In Finnish community dwelling older people, death rates from falls were $51 / 100,000$ in $1995^{114}$ and increased to $55 / 100000$ in $2002^{115}$. However, it should be noted that falls related mortality in Finland is one of the highest in Europe. Amongst European Union (EU) countries, the UK has one of the lowest rates of fall related deaths (standardised mortality ratio 33$)^{116}$.

Although people over 60 years of age make up $19 \%$ of the EU population, they account for $28 \%$ of injury-related deaths ${ }^{116}$. The injury mortality rate (age-standardised) in EU-15 is about 39 deaths per 100,000 people, while in EU-25 it is about 45 deaths per 100,000 people $^{116}$.

In the United States, death from falls overtook deaths from road traffic accidents between 1990-1998, accounting for 9,604 deaths per 100,000 aged $65+$ in $1998^{117}$; for the oldest old (>85 years) the rate was 109 per 100,000 in $1998^{118}$.

In Australia in 1998, there were 1,114 deaths from falls-related incidents for people aged more than 65 years ${ }^{119}$.

\subsubsection{The impact of falls on hospital services}

In 1999 there were over 647,721 fall related $A \& E$ attendances in the UK for people aged $>60$ years $^{5}$. This is a rate of nearly $40 / 1000$ people attending 
emergency departments per year because of a fall. International rates of injurious falls (Table 1.1) range from 0.55-1.00 per person-year 294647 , with serious injurious falls rates in the region of 32 per 1000 person-years ${ }^{55}$. The rate of injurious falls appears to be increasing (adjusted OR 1.08 (95\% CI 1.03-1.12)), according to a Finnish study of routine health service data from $1991-1999^{120}$. This makes falls an issue for secondary care services as well as primary care. Indeed, falling in hospital in-patients is also common and serious ${ }^{121-123}$, but is out with the remit of this work.

The impact of falls on hospital services is difficult to estimate, as Hospital Episode Statistics (HES) data do not specifically code falls (which is appropriate given that a fall is usually a non-specific presentation of some other disease process). But by way of example, HES data for the year ending 2005/6 showing some common conditions and also falls-related conditions are shown in Table 1.2.

These data illustrate that falls related hospital admissions have a similar impact on hospital resource use to conditions such as stroke, and probably a greater impact than traditionally high profile conditions such as acute myocardial infarction.

Costs relating to hospital and nursing home care are greater in people who fall, increasing annual hospital related costs by $\$ 11,042$ (United States, 1996) compared to matched non-fallers; this relationship was stronger for those with recurrent or injurious falls ${ }^{124}$. 
Table 1.2 Hospital Episode Statistical data by health resource

group, $2005 / 6^{125}$

\begin{tabular}{|l|l|l|l|l|l|}
\hline HRG code & $\begin{array}{l}\text { Mean } \\
\text { Age }\end{array}$ & $\begin{array}{l}\text { Finished } \\
\text { consultant } \\
\text { episodes }\end{array}$ & $\begin{array}{l}\text { Mean } \\
\text { Length } \\
\text { of } \\
\text { Stay }\end{array}$ & $\begin{array}{l}\text { Median } \\
\text { Spell } \\
\text { Duration }\end{array}$ & Bed days $^{\dagger}$ \\
\hline E31 Syncope or Collapse $>69$ & 79 & 74842 & 5.7 & 2 & 293,914 \\
\hline $\begin{array}{l}\text { H82 Extra-capsular Neck of } \\
\text { Femur Fracture with Fixation }\end{array}$ & 81 & 2983 & 20.6 & 16 & 54,807 \\
\hline $\begin{array}{l}\text { H84 Intra-capsular Neck of } \\
\text { Femur Fracture with Fixation }\end{array}$ & 79 & 4134 & 19.7 & 14 & 71,837 \\
\hline $\begin{array}{l}\text { H36 Closed Pelvis or Lower } \\
\text { Limb Fractures }>69\end{array}$ & 77 & 30137 & 19.5 & 11 & 445,992 \\
\hline $\begin{array}{l}\text { A22 Non-Transient Stroke or } \\
\text { Cerebrovascular Accident }>69\end{array}$ & 78 & 79922 & 25.7 & 13 & $1,126,041$ \\
\hline E11 Acute Myocardial Infarction & 77 & 28643 & 13.3 & 8 & 216,613 \\
\hline
\end{tabular}

\subsubsection{Falls and carer strain}

(See 4.1.5 for search methods)

The previous sections have illustrated the impact of falls on individuals in terms of morbidity, functional decline and depression. Many carers of older people are themselves old, and likely to be at risk of falls and functional decline. However, there are only a small number of papers which describe the impact of falling on carers, all of which point to the increased carer burden in those looking after people who fall.

Japanese carers of people who fall scored higher than those caring for nonfallers on the Zarit Burden Interview ${ }^{126}$. In patients with Parkinson's disease, falls are associated with greater carer burden ${ }^{127} 128$. Falls are often

* A count of the number of HES records, submitted on behalf of English NHS hospital providers that relate to episodes of admitted patient care that ended during the financial year (1 April to 31 March).

${ }^{+}$The sum of all the days that patients in the group occupied hospital beds during the financial year (1 April to 31 March). 
cited as a key driver of admission to long term care, presumably a reflection of the increased carer burden.

\subsubsection{Falls and admission to long term care}

(See 4.1.2 for search methods)

People who fall have greater need of health and social care resources than matched controls who have not fallen ( 1.4 relative risk for hospitalisation, 2.7 relative risk for nursing home admission), and often have some form of limitation in basic (relative risk 1.4 ) or extended (relative risk 1.3 ) activities of daily living ${ }^{129}$. However, the association is just that and it is not correct to infer that falls cause increase health resource use, but are a marker of an underlying ill-health, with the fall being a non-specific manifestation of the underlying co-morbidities.

Rates of institutionalisation in long term care are 2-5 times greater after a single fall compared to those who have not fallen ${ }^{82130}$, and 2-20 times greater for people with recurrent falls ${ }^{131-133}$. Falls rates are 2-5 times higher in those people admitted to long term care compared to age and gender matched controls not admitted to long term care ${ }^{134}$ and those that fall in long term care are at increased risk of death compared to those who do not fall ${ }^{135}$. Much of this will be related to selection bias, though one might argue that the care home environment might play a role, for example, the type of flooring (wooden carpeted versus other types) influence the risk of fracture from a fall (OR 1.8 (95\% CI 1.3-2.4)), highlighting the importance of the physical environment ${ }^{136}$. 


\subsubsection{Falls risk factors}

(See 4.1.7 for search methods)

There are many risk factors for falls. Fall risks factors were reviewed in the NICE guidelines on falls prevention, and this section provides an update on that work.

Table 1.3 summarises falls risk factors at the population level as identified in prospective cohort studies, the gold standard method for identifying risk factors $^{137}$. Some systematic reviews which refer to older cohort studies are also included. The use of falls risk assessment tools for individual patients is considered separately (see section 1.3 .9 .5 ).

The major risk factors for falls include, in approximate descending order of risk, balance deficits, reduced mobility, home hazards, muscle weakness, history of falls, Parkinson's disease, fear of falling, use of an assistive device, frailty, cognitive impairment, arthritis, impaired ADL, depression, vitamin D deficiency, testosterone deficiency, anaemia, diabetes, medication, neuropathy, female gender and visual deficits (Table 1.3).

There are many other important but less well studied risk factors for falls, such as disturbed sleep (odds ratio 1.3 ) $^{38}$ and renal impairment (odds ratio 3.7). Preliminary studies indicate a possible role for genetic factors ${ }^{138} 139$. The number of risk factors appears to be additive, with the risk of falling increased linearly with the number of risk factors ${ }^{14}$.

Other studies have focussed on risk factors for falls in specific populations, though there is considerable overlap. For example, in stroke patients, depressive symptoms, disability, previous falls, and older age are associated with falls, whereas higher cognitive and physical function were protective ${ }^{140}$. Lee et $a^{141}$ examined falls risk factors in individuals in a 
rehabilitation setting and found poor cognitive and physical function to be associated with in-patient falls.

\subsubsection{Cognitive impairment and falls}

Several studies have found that there is a significant association between cognitive impairment and falls ${ }^{142}$. The odds ratio of falling when there is cognitive impairment ( $\leq 26 / 30$ on the mini-mental state examination [MMSE]) has been reported as $5.0(95 \% \text { CI } 1.8-13.7)^{14}$ and $2.2(95 \%$ CI $1.5-3.2)^{143}$. The likely mechanisms behind falls in older people with cognitive impairment include judgemental errors, cerebrovascular disease and psychotropic medication or a combination of factors. However, the only published randomised control trial examining a multifactorial intervention (compared to usual care) to reduce fall in individuals with cognitive impairment (MMSE $\leq 26)$ found no benefit - relative risk $0.92(95 \% \mathrm{CI}$ 0.81 to 1.05$)^{144}$. 
Table 1.3 Published falls risk factors falls in community dwelling older people

\begin{tabular}{|c|c|c|}
\hline Risk Factor & $\begin{array}{l}\text { Source ( } \mathrm{SR}=\text { systematic review, } \mathrm{R}=\text { review, } \mathrm{C}=\text { cohort study, } \mathrm{MA}=\text { meta- } \\
\text { analysis) }\end{array}$ & Approximate measure of effect \\
\hline Balance deficit & $\begin{array}{l}\text { Piirtola } 2006^{145} \text { R, Pluijm } 2006^{146} \text { C, Delbaere } 2006^{147} \text { C, Stalenhoef } \\
2002^{148} \text { C, Clark } 2005^{149} \mathrm{C}\end{array}$ & Odds ratio $\sim 4$ \\
\hline Reduced mobility & Morris $2007^{150} \mathrm{C}$, Tiedemann $2008^{19} \mathrm{C}$ & Odds ratio 3.7 \\
\hline Home hazards & $\begin{array}{l}\text { Lord } 2006^{151} \text { R, Fletcher } 2002^{152} \text { C, Pluijm } 2006^{146} \mathrm{C} \\
\text { Van Bemmel } 2005^{27} \mathrm{C}\end{array}$ & Relative risk 3.6 \\
\hline Muscle weakness & $\begin{array}{l}\text { Otaka } 2008 \mathrm{SR}^{153}, \text { Moreland } 2004 \text { SR, Pluijm } 2006^{146} \mathrm{C} \text {, Stalenhoef } \\
2002^{148} \mathrm{C}\end{array}$ & Odds ratio $\sim 3$ \\
\hline History of falls & $\begin{array}{l}\text { Capon } 2007^{154} \text { C, Morris } 2007^{150} \text { C, Pluijm } 2006^{146} \text { C, } \\
\text { Papaioannou } 2004^{155} \text { C, Stalenhoef } 2002^{148} \mathrm{C}\end{array}$ & Odds ratio $\sim 3$ \\
\hline Parkinson's disease & Fink $2006^{156} \mathrm{C}$, Fletcher $2002^{152} \mathrm{C}$ & Odds ratio 3 \\
\hline Fear of falling & $\begin{array}{l}\text { Scheffer } 2008^{75} \text { C, Delbaere } 2004^{157} \text { C, Pluijm } 2006^{146} \text { C, Delbaere } \\
2006^{147} \text { C, Delbaere } 2004^{157} \text { C, Murphy } 2003^{65} \text { C }\end{array}$ & Odds ratio 3 \\
\hline $\begin{array}{l}\text { Use of an assistive } \\
\text { device }\end{array}$ & Nandy $2004^{158} \mathrm{R}$ & Relative risk 2.6 \\
\hline Frailty & $\begin{array}{l}\text { Ensrud } 2008{ }^{159} \mathrm{C} \\
\text { (Two of: weight loss, the subject's inability to rise from a chair } 5 \text { times } \\
\text { without using her arms, and reduced energy level) }\end{array}$ & $\begin{array}{l}\text { Odds ratio } 2.4 \text { (recurrent falls, } \\
\text { frail vs. non-frail) }\end{array}$ \\
\hline $\begin{array}{l}\text { Cognitive } \\
\text { impairment }\end{array}$ & $\begin{array}{l}\text { Assantachai } 2003^{51} \mathrm{C} \text {, Shaw } 2002^{160} \text { R, Fletcher } 2002^{152} \text { C, } \\
\text { Papaioannou } 2004^{155} \text { C, Van Doorn } 2003^{161} \text { C, Van Schoor } 2002^{162} \text { SR }\end{array}$ & Odds ratio $\sim 2-4$ \\
\hline
\end{tabular}




\begin{tabular}{|c|c|c|}
\hline Risk Factor & $\begin{array}{l}\text { Source ( } \mathrm{SR}=\text { systematic review, } \mathrm{R}=\text { review, } \mathrm{C}=\text { cohort study, MA=meta- } \\
\text { analysis) }\end{array}$ & Approximate measure of effect \\
\hline Arthritis & Reyes-Ortiz $2004^{163} \mathrm{C}$, Assantachai $2003^{51} \mathrm{C}$ & Relative risk 2 \\
\hline Impaired ADL & $\begin{array}{l}\text { Capon } 2007^{154} \text { C, Reyes-Ortiz } 2004^{163} \text { C, Assantachai } 2003^{51} \mathrm{C} \text {, } \\
\text { Perracini } 2002^{164} \text { C, Pluijm } 2006^{146} \text { C, Shumway-Cook } 2005^{165} \mathrm{C}\end{array}$ & Odds ratio 2 \\
\hline Depression & Reyes-Ortiz $2004^{163} \mathrm{C}$, Stalenhoef $2002{ }^{148} \mathrm{C}$ & Odds ratio 2 \\
\hline $\begin{array}{l}\text { Vitamin D } \\
\text { deficiency }\end{array}$ & $\begin{array}{l}\text { Fosnight } 2008^{166} \mathrm{SR} \text {, Faulkner } 2006^{167} \mathrm{C} \text {, Bischoff-Ferrari } 2004^{168} \mathrm{MA} \text {, } \\
\text { Latham } 2003^{169} \mathrm{SR} \text {, Snijder } 2006^{25} \mathrm{C}\end{array}$ & Odds ratio 1.8 \\
\hline $\begin{array}{l}\text { Testosterone } \\
\text { deficiency }\end{array}$ & Orwoll $2006^{170} \mathrm{C}$, Szulc $2003^{171} \mathrm{C}$ & Relative risk 1.8 \\
\hline Anaemia & Duh, $2008^{172} \mathrm{C}$, Penninx $2005^{173} \mathrm{C}$ & Relative risk 1.7 \\
\hline Diabetes & Reyes-Ortiz $2004^{163} \mathrm{C}$, Schwartz $2002^{174} \mathrm{C}$ & Odds ratio 1.7 \\
\hline Medication & Allain $2005^{175} \mathrm{R}$, Hartikainen $2007^{176} \mathrm{SR}$, Landi $2005^{177} \mathrm{C}$ & $\begin{array}{l}\text { Odds ratio } 1.5 \text { (mainly } \\
\text { benzodiazepines } \\
\text { antidepressants, } \\
\text { antipsychotics) }\end{array}$ \\
\hline Neuropathy & Schwartz $2008^{178} \mathrm{C}$ & Odds ratio 1.5 (diabetics) \\
\hline Female gender & Reyes-Ortiz $2004^{163} \mathrm{C}$, Assantachai $2003^{51} \mathrm{C}$, Fletcher $2002^{152} \mathrm{C}$ & Odds ratio 1.5 \\
\hline Visual deficit & $\begin{array}{l}\text { Schwartz } 2008^{178} \mathrm{C} \text {, Coleman } 2007^{179} \mathrm{C} \text {, Lord } 2006^{180} \mathrm{R} \text {, Assantachai } \\
2003^{51} \mathrm{C} \text {, Perracini } 2002^{164} \mathrm{C} \text {, Lord } 2002^{181} \mathrm{C} \text {, Szabo } 2008^{182} \mathrm{C} \text {, } \\
\text { McCarty } 2002^{183} \mathrm{C}\end{array}$ & $\begin{array}{l}\text { Odds ratio } 1.4 \text { (diabetics) } \\
1.5-3.0 \text { other populations }\end{array}$ \\
\hline
\end{tabular}




\subsubsection{Falls screening tools}

Having highlighted that there are multiple risk factors for falls in multiple domains (physical, psychological, environmental etc). The logical progression is to combine these risk factors into a single tool capable of predicting falls in the future.

Many falls risk screening tools have been published for use in a variety of settings. A major limitation in several of the published screening tools is that they rely upon retrospective recall of falls, which has been shown to be unreliable, underestimating the true prevalence of falls ${ }^{26}$. Individuals who are truly at high risk of falling are likely to be at high risk of injurious falls (because of multiple risk factors and recurrent falls); this population are likely to report falls because of associated injury. This differential recall leads to bias, in this case underestimating non-injurious falls.

The search used to identify published falls screening tools is listed in 4.1 .8 ; only multidimensional tools, evaluated prospectively and reporting sensitivity, specificity, likelihood ratios and/or the area under the curve were reviewed.

\subsubsection{Hospital based falls risk screening tools}

Though not of immediate relevance to this study (focussing on community dwelling older people), much of the original work on falls screening tools emerged from hospital settings, and a brief review of such tools is appropriate.

Oliver et $a^{184}$ developed a falls risk screening tool for use in the hospital setting (stroke unit, acute and rehabilitation wards). They identified five risk factors which were associated with a future in-patient fall:

- Patient presented (to hospital) with a fall or had fallen in hospital

- Agitation

- Visual impairment affecting daily function

- Requiring help with toileting

- Transfer and mobility score of 3 or 4 (derived from the Barthel index ${ }^{185}$ ) 
The tool was prospectively validated in a separate in-patient setting. The sensitivity of the tool for predicting a fall in the week after assessment was $92 \%$, the specificity $68 \%$. The authors noted different sensitivity and specificity in two different settings where the tool was validated. In general terms, tools developed for one setting should not be assumed to perform equally well in a different setting, with a different population. Wijnia et al tested the STRATIFY tool in a Dutch nursing home and found that it underperformed (sensitivity $50 \%$, specificity $76 \%$ ) compared to the results seen for STRATIFY in the hospital setting ${ }^{186}$.

Though STRATIFY fulfilled a useful function in highlighting the importance of in-patient falls, there has been a move to more simple approaches since its inception. For example, in 2008 Salameh ${ }^{187}$ found previous fall and 'acute impairing medical' illness to be predictive of a future in-patient fall and the combination of the two had a sensitivity of $64 \%$, specificity $68 \%$. Also in 2008 , Vassallo ${ }^{188}$ found that clinical judgment based on observed wandering had better predictive accuracy indicated by the number of patients correctly classified $(157 / 200,79 \%)$ than either the STRATIFY $(93 / 200,47 \%)$ or the Downton $^{* 189}$ falls risk assessment tool $(100 / 200,50 \%)$ in a geriatric rehabilitation setting. The general consensus appears to be that falls are so common in hospital that screening is not useful ${ }^{190}$, and that falls reduction strategies should be applied the level of the population, rather than on screened and selected individuals. This approach has been tested in a well conducted cluster RCT of a multifactorial falls intervention in Australia, though the results were negative ${ }^{191}$. However, this may be due to the relative ineffectiveness of the intervention rather than the global approach per se; in particular

\footnotetext{
* The Downton falls screening tool has not been formally evaluated but consists of a history of falls, medications (tranquillisers/sedatives, diuretics, anti-hypertensives excluding diuretics, anti-Parkinsonian drugs, and antidepressants), sensory deficits (visual impairment, hearing impairment), limb abnormalities (such as hemiparesis), confusion and an unsafe gait (with or without aids). Each one of these factors scores a point, and scores of three or above identified patients at risk.
} 
strength and balance training was only delivered over a short period, whereas any improvements from such an approach take weeks to manifest.

Other investigators have used the STRATIFY tool in an attempt to predict falls in patients being discharged from hospital. This is a plausible approach, as the items in STRATIFY seem equally likely to predict falls in the primary care setting as in hospital. Smith ${ }^{192}$ tested the STRATIFY tool on people with stroke being discharged but found it performed poorly (sensitivity $11 \%$ and specificity $90 \%$ ) and suggested a disease specific tool. Subsequently, Ashburn ${ }^{193}$ found that fall or near fall in hospital and upper limb dysfunction were the strongest predictors of future fall in people with stroke being discharged from hospital (specificity $70 \%$ and sensitivity $60 \%$ ). Similarly, Mackintosh ${ }^{194}$ found that in people with stroke being discharged from hospital, a history of inpatient falls and poor balance predicted future fall (sensitivity and specificity $>80 \%$ ). Hyndman ${ }^{195}$ found that people with stroke living in the primary care setting who 'stop walking when talking' (a test of the ability to perform dual tasks) had a sensitivity of $53 \%$ and specificity of $70 \%$ for future fall. The dual tasking phenomenon has also been identified as a useful predictor of falls in patients with cognitive impairment ${ }^{196}$.

The PROFET study was one of the seminal falls prevention studies, in which older people attending an emergency department with a primary 'diagnosis' of fall were offered a multidisciplinary assessment ${ }^{197}$. Eligibility was on the basis of a fall, rather than a screening process. In a further analysis of the risk factors predictive of future falls, three of the six risk factors included a fall in the previous year, falling indoors and the inability to rise following a fall ${ }^{198}$, the remaining items were negative predictors - moderate alcohol consumption, a reduced abbreviated mental test score and admission to hospital as a result of the fall. Again, the most powerful predictor of future fall was a history of a previous fall.

\subsubsection{Falls screening tools in residential settings}

The Mobility Interaction Fall (MIF) Chart has been developed for use by a trained assessor in residential community settings ${ }^{199}$. The MIF chart includes an observation of 
the ability to walk and simultaneously interact with a person or an object, a vision test, and a concentration rating. Additionally, staff rated each resident's risk as high or low and reported the resident's history of falls during the past six months. Detailed results are not available, but the investigators reported that the combination of two high risk scores (MIF chart, staff judgment, falls history) was better than any one individual predictor.

Chen et $a l^{200}$ derived a falls risk score to differentiate people at extremely high risk of falling from those at moderate risk of falling, in an institutionalised population with an overall prevalence of $50 \%$ of falls in one year and $30 \%$ prevalence for recurrent falls in one year. Combining balance, cognition, illness severity, age and continence they derived a risk score which at the extremes differentiated patients with an annual falls rate of 3.2 per person, six times greater than those at the lower end of the scale ( 0.5 falls personyear). The assessments do require a trained assessor, but are relatively straightforward, and should be readily applicable in a residential care setting, or other similar setting such as intermediate care. However, the usefulness of identifying the very high risk versus moderate risk individuals is questionable.

\subsubsection{Falls screening tools in the primary care setting}

A screening tool using prospective falls data has been developed by Tromp et $a l^{201}$ in a nested cohort study within the Longitudinal Aging Study Amsterdam (LASA). They recorded falls prospectively using a weekly diary in 1,285 people living in the community, aged over 65. Previous fall, visual impairment (can you recognise someone's face at four metres?), urinary incontinence and use of benzodiazepines were the strongest predictors identified in the risk profile model for any falls (area under curve $(A U C)=0.65$ ), whereas previous falls, visual impairment, urinary incontinence and functional limitations proved to be the strongest predictors in the model for recurrent falls $(A \cup C=0.71)$. The model developed found that a previous fall (OR 2.5) was more strongly associated with future falls than the other three risk factors (OR 1.6 for each of visual impairment, urinary incontinence and functional limitation). The final model developed was a better predictor 
of recurrent falls (AUC 0.71) than a single fall (AUC 0.65). This was a well-conducted study and there appears to be little reason to think that the findings are not externally generalisable.

Stalenhoef et $a l^{202}$ developed a risk model for predicting recurrent falls based on retrospective self reported data. They identified six statistically significant associations with self reported falls (age $\geq 80$, female gender, musculoskeletal symptoms, balance disturbance, chronic neurological disorder and the use of anti-depressants). These factors were used to construct a predictive model, which gave a positive predictive value of $42 \%$ and negative predictive value of $85 \%$. The usefulness of this model is questionable, in particular as the response rate was $60 \%$; they acknowledged that the very old ( $\geq 80$ ) were under-represented in their sample. The use of retrospective monitoring of falls is likely to have led to an underestimate of falls prevalence ${ }^{26}$, and so an underestimate of the positive predictive value.

Stel et $a l^{203}$, again using data from LASA, devised a tree-structured survival analysis to predict falling. Building on the paper by Tromp, discussed above, they focussed on recurrent falls (two falls within six months), with careful follow up over three years (weekly falls calendar posted to the research centre at the end of every three months, with telephone contact if they were unable to complete the fall calendar, if the fall calendar was not returned even after a reminder, or if it was completed incorrectly). The model that they developed identified the importance of a combination of risk factors in identifying future fallers (grip strength, functional limitation and recurrent falls). The baseline screening data was collected through a face to face interview, though the falls diaries were self completed.

Pluijm et $a l^{146}$, building on previous work in LASA identified nine variables which combined gave modest predictive ability to identify recurrent fallers (a score of five or more had $59 \%$ sensitivity and $71 \%$ specificity, AUC 0.71 ). The items included two or more previous falls, dizziness, functional limitation, weak grip strength, low body weight, fear of falling, the presence of dogs/cats in the household, a high educational level, 
drinking 18 or more alcoholic consumptions per week and two interaction terms (high education $x 18$ or more alcohol consumptions per week and two or more previous falls $\mathrm{x}$ fear of falling). Though comprehensive, this dataset offer limited advantages compared to the more simple tools.

The Falls Risk Assessment Tool (FRAT) ${ }^{158}$, was developed in the United Kingdom and can be administered by a non-health care professional. Using the presence of three risk factors as a cut off point, it had good specificity, identifying $92 \%$ of people who did not have a fall ( $14 \%$ reported falls in the previous six months), but poor sensitivity, identifying only $42 \%$ of individuals who did have a fall; the positive predictive value was $57 \%$. The methodology used in monitoring falls is questionable, as fall rates were based upon retrospective recall at six months. Retrospective recall of falls has been shown to be of limited accuracy; Cummings et $a l^{26}$ carried out a study on falls reported by individuals using prospective, weekly follow up and contrasting with retrospective recall by the same individuals at three, six or twelve months of participants. At three months, $32 \%$ of falls were forgotten, $26 \%$ at six months and $13 \%$ at one year; Hale et al ${ }^{204}$ found similar results using comparable methodology. For the FRAT, recall bias may have resulted in an under-estimate of falls prevalence, thus reducing the positive predictive value. It is possible that a higher positive predictive value may be seen in practice.

Ensrud $^{159}$ showed that a frailty score (consisting of weight loss, inability to rise from a chair five times without using arms, and reduced energy level) predicted recurrent falls over one year (AUC 0.61), fractures (AUC 0.64) as well as other frailty related outcomes (death, institutionalisation).

The key characteristics of falls screening tools for use in the primary care are summarised in Table 1.4. 
Table 1.4 Predictive value of published screening tools used in primary care

\begin{tabular}{|c|c|c|c|c|}
\hline Study & $\begin{array}{l}\text { Uses previous } \\
\text { fall in tool? }\end{array}$ & Sensitivity & Specificity & AUC \\
\hline Stalenhoef et $\left.a\right|^{202}$ & No & $64 \%$ & $71 \%$ & 0.73 \\
\hline $\begin{array}{l}\text { Tromp et } a l^{201} \\
\text { Recurrent falls }\end{array}$ & Yes & & & 0.71 \\
\hline Pluijm et al $^{146}$ & Yes & & & 0.71 \\
\hline FRAT $^{158}$ & Yes & $42 \%$ & $92 \%$ & $\begin{array}{l}\text { Youden's } \\
\text { index } 0.39 ; \\
\text { AUC } 0.70^{205}\end{array}$ \\
\hline $\begin{array}{l}\text { Tromp et } a l^{201} \\
\text { Any fall }\end{array}$ & Yes & $54 \%$ & $79 \%$ & 0.65 \\
\hline Stel et $a l^{203}$ & Yes & - & - & - \\
\hline $\begin{array}{l}\text { Ensrud }^{159} \\
\text { Recurrent falls }\end{array}$ & No & & & 0.61 \\
\hline
\end{tabular}

With the exception of the Stalenhoef tool, which was specifically developed to able to identify people at high risk of falls from routinely available primary care data, the screening tools with the best predictive proprieties include previous fall as a 'risk factor'. It can be argued that identifying people who have fallen is more case-finding than screening per se, though from a practical perspective, the distinction is not as important as having a tool which is easy to use and has robust predictive properties.

\subsubsection{Physical assessment scales}

A variety of physical assessments have been tested for their ability to predict future falls - the Tinetti balance and gait scale ${ }^{206}$, Physiological Profile Assessment (PPA) ${ }^{147} 207$, Timed Get Up and Go Test (TUGT) ${ }^{208}$, Global Rating of Fall Risk (GLORF) ${ }^{209}$, the Modified Gait Abnormality Rating Scale (MGARS), Physical Performance Test (PPT) ${ }^{210}$, Berg balance,

\footnotetext{
* For a two disease, two outcome measure (diagnostic testing) scenario, the area under the curve is equivalent to (Youden's index +1 )/2, where Youden's index equals sensitivity + specificity
} 
$A B C$ and reaction time $e^{211}$, and a variety of functional mobility assessments ${ }^{19}$, as detailed in Table 1.5.

Table 1.5 Physical assessments of falls risk and reported predictive properties

\begin{tabular}{|c|c|c|c|c|}
\hline Item & Study & Sensitivity & Specificity & $\begin{array}{l}\text { Area } \\
\text { under } \\
\text { the } \\
\text { curve }\end{array}$ \\
\hline History of falls & Nordin $^{209}$ & $58 \%$ & $76 \%$ & 0.66 \\
\hline GLORF & Nordin 209 & $56 \%$ & $80 \%$ & 0.68 \\
\hline GUGm (high risk) & Nordin 209 & $7 \%$ & $92 \%$ & 0.62 \\
\hline TUGT 15 seconds & Nordin $^{209}$ & $96 \%$ & $32 \%$ & 0.69 \\
\hline $\begin{array}{l}\text { TUGT } 30 \text { seconds } \\
\text { Women with vertebral } \\
\text { fracture }\end{array}$ & Morris $2007^{150}$ & $33 \%$ & $85 \%$ & 0.60 \\
\hline PPA & Laessoe $2007^{212}$ & $50 \%$ & $43 \%$ & \\
\hline $\begin{array}{l}\text { Two positives from } \\
\text { MGARS, history of fall } \\
\text { and PPT }\end{array}$ & $\begin{array}{l}\text { VanSwearingen } \\
1998^{210}\end{array}$ & $90 \%$ & $87 \%$ & \\
\hline Sit-to-stand once $\geq 1 \mathrm{~s}$ & Tiedemann $^{19}$ & $49 \%$ & & \\
\hline $\begin{array}{l}\text { Sit-to-stand five times } \geq \\
12 \mathrm{~s}\end{array}$ & Tiedemann ${ }^{19}$ & $66 \%$ & $55 \%$ & \\
\hline Alternate-step test $\geq 10 \mathrm{~s}$ & Tiedemann $^{19}$ & $69 \%$ & $56 \%$ & \\
\hline Six-metre walk $\geq 6 \mathrm{~s}$ & Tiedemann $^{19}$ & $50 \%$ & $68 \%$ & \\
\hline Stair descent $\geq 5 \mathrm{~s}$ & Tiedemann $^{19}$ & $63 \%$ & $55 \%$ & \\
\hline $\begin{array}{l}\text { Reaction time, total Berg } \\
\text { score and total } A B C \text { score }\end{array}$ & Lajoie,2004 211 & $89 \%$ & $96 \%$ & \\
\hline
\end{tabular}

Aside from the necessity for a trained assessor to undertake these tests, the other main limitation is that they are little better in predicting future fall than a history of previous fall ${ }^{150}$.

\subsubsection{Falls risk assessment tools}

Once individuals have been identified as being at risk of falling on the basis of risk factors or previous falls, there is a need then to identify the specific modifiable factors in that individual that are amenable to intervention. This process of individualised assessment, as opposed to risk stratification, lends itself to a structured assessment scale. Such 
scales are designed for use in individuals, rather than in populations, which can be a source of confusion.

As individual practitioners and units will have their own approach to addressing falls management with their individual clients, depending on local expertise and facilities, there are an enormous number of assessment tools in the published literature. Rather than complete an exhaustive search of these tools, the following section summarises the findings from the 2004 NICE guidelines ${ }^{10}$.

The NICE guidelines state that in community dwelling older people and in extended care settings (intermediate care, residential care, rehabilitation units), the important assessment tools include:

- an assessment of balance and gait (for example, Timed Up and Go Test, Berg Balance Scale)

- a multifactorial assessment addressing home hazards and individual risk factors for falls

- in home care and residential settings, a Minimum Data Set (for example, that developed by InterRAI ${ }^{213}$ ) should be used to guide management.

Such tools are not considered further here.

\subsubsection{Summary - screening tools}

Despite the proliferation of screening tools which have been developed over the last 15 years, many of which are valid, few are better at identifying future falls than a history of a previous fall. This phenomenon is seen in other frailty related conditions, such as fracture ${ }^{214}$, in which the best predictor of future event is to have had the event already. This highlights the difficulty of screening for frailty related outcomes (i.e. identifying individuals at high risk before they have had the event).

The FRAT tool is the only published screening tool based on a UK population, albeit that the evaluation was carried using self-reported recall of falls. 


\subsection{Why do people fall?}

Lord's Physiological Profile Assessment ${ }^{215}$ provides an excellent understanding as to why an individual might fall. As detailed in Figure 1.2, the upright posture is dependant upon five key physiological mechanisms - vision, vestibular system, proprioception, central control and muscle strength. Accumulative defects in these systems, for example because of a disease process such as diabetes, leads to increased falls risk.

Figure 1.2 Schema for assessing falls (adapted from Lord, 2000207)

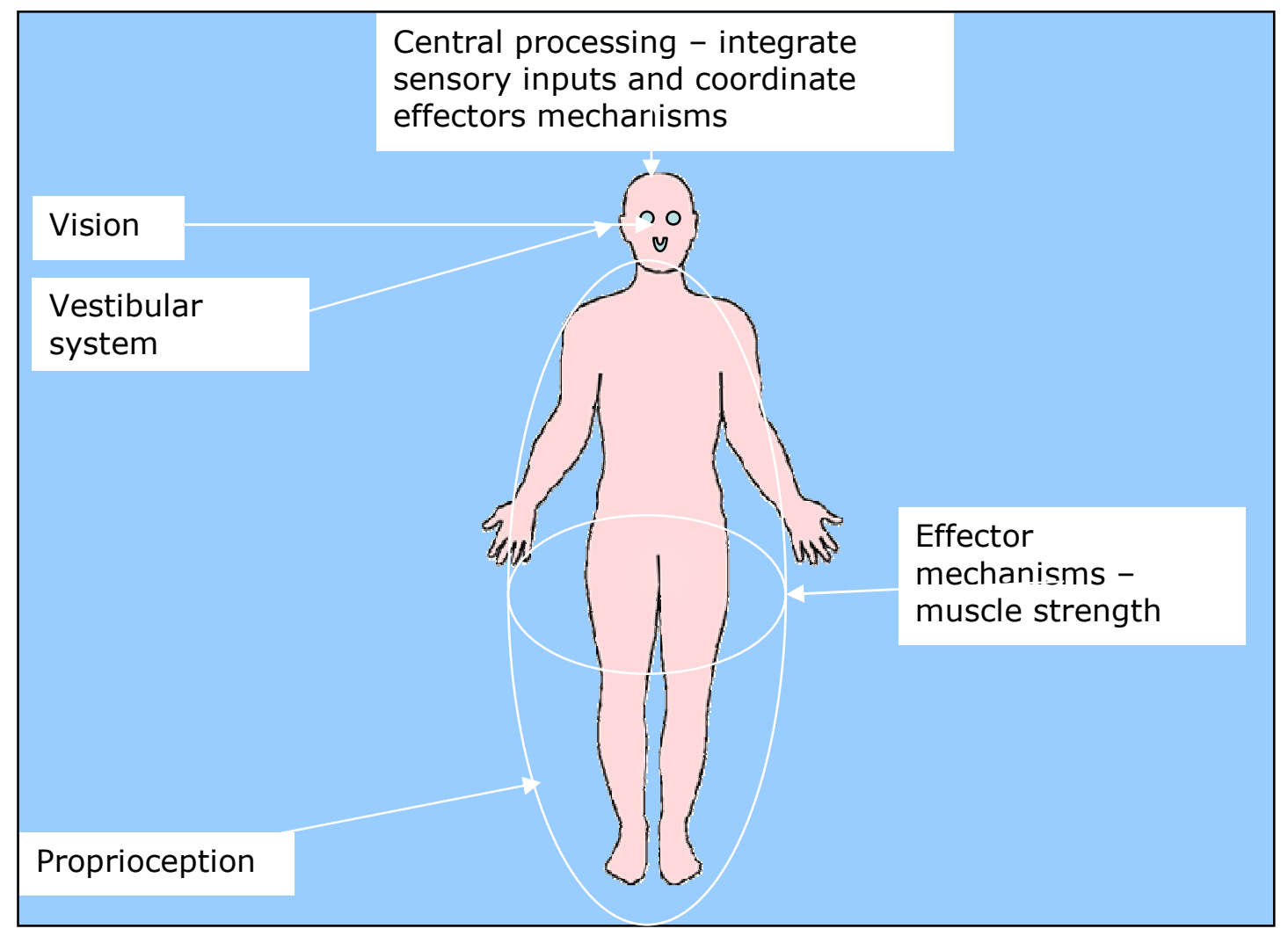

In addition to these intrinsic factors, extrinsic factors play an important part such as environmental hazards and medication. The relative contribution of intrinsic and extrinsic factors will vary from individual to individual, but it is likely that in most people, there will be more than one cause for a fall (see 1.3.8). Figure 1.3 succinctly encapsulates the potential contribution of intrinsic an extrinsic risk factors. 
Figure 1.3 Factors that contribute to the risk of falls

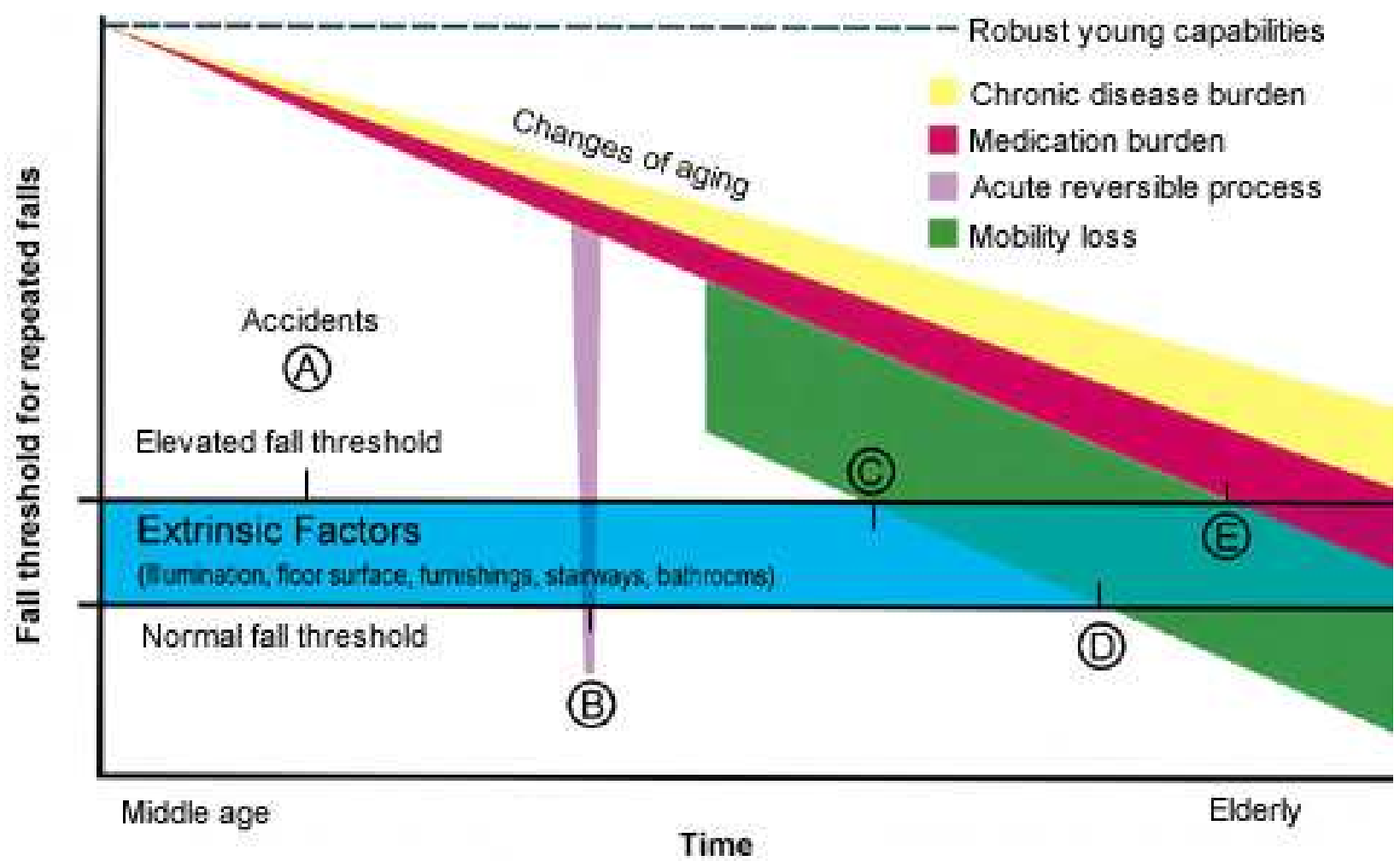

Key:

$A=$ Patient with an accidental fall and no intrinsic or extrinsic risk factors

$\mathrm{B}=$ Patient with acute illness

$\mathrm{C}=$ Patient with moderate illness, loss of mobility and some prescription medications who falls because of an extrinsic factor

$\mathrm{D}=$ Severely ill patient with many medications who falls even without extrinsic factors $\mathrm{E}=$ Elderly patient with numerous age-related changes who falls because of an extrinsic factor

From Steinweg KK. The changing approach to falls in the elderly. Am Fam Physician $1997 ; 56: 1815-22,1823$.

\subsection{Interventions to prevent/reduce falls}

Interventions to reduce falls in older people have been reviewed extensively in recent years; a summary of the most recent reviews is presented here. One of the main reviews influencing the 2004 NICE guidelines ${ }^{10}$ is the Cochrane systematic review on interventions to reduce falls in older people ${ }^{9}$, due to be updated very soon ${ }^{216}$.

The 2003 Cochrane review assessed 62 randomised trials involving 21,668 people. The main outcomes were the number of fallers, or falls. The main findings were that 
multidisciplinary, multifactorial, health/environmental risk factor screening/intervention programmes in primary care both for an unselected population of older people ( 4 trials, 1,651 participants, pooled RR $0.73,95 \%$ CI 0.63 to 0.85 ), and for older people with a history of falling or selected because of known risk factors ( 5 trials, 1,176 participants, pooled RR $0.86,95 \% \mathrm{CI} 0.76$ to 0.98 ), were likely to be effective. This reflects the multifactorial causes of falls discussed in previous sections. However, unifactorial interventions can to be of benefit, namely:

- muscle strengthening and balance retraining, individually prescribed at home by a trained health professional ( 3 trials, 566 participants, pooled relative risk 0.80 , $95 \%$ CI 0.66 to 0.98$)$

- home hazard assessment and modification that is professionally prescribed for older people with a history of falling ( 3 trials, 374 participants, RR 0.66 , 95\% CI 0.54 to 0.81$)$

- withdrawal of psychotropic medication (1 trial, 93 participants, relative hazard ratio $0.34,95 \%$ CI 0.16 to 0.74 )

- cardiac pacing for fallers with cardioinhibitory carotid sinus hypersensitivity (1 trial, 175 participants, weighted mean difference $-5.20,95 \%$ CI -9.40 to -1.00 )

- a 15 week Tai Chi group exercise intervention (1 trial, 200 participants, risk ratio $0.51,95 \%$ CI 0.36 to 0.73$)$.

They concluded 'interventions to prevent falls that are likely to be effective are now available; less is known about their effectiveness in preventing fall-related injuries...' The Cochrane review was integrated into the NICE guidance ${ }^{10}$, which stated that 'all older people with recurrent falls or assessed as being at increased risk of falling, should be considered for an individualised multifactorial intervention.' NICE stipulated that such programmes should consist of 'strength and balance training, a home hazards assessment and interventions, visual assessment and referral and a medication review 
with modifications.' This guidance is consistent with recent Canadian evidence based guidelines ${ }^{217}$.

The NICE guideline group went on to pool data from studies looking at unselected community dwelling older people, recruited on the basis of age and domestic circumstances, but not specifically falls risk factors. The pooled estimates showed that multifactorial interventions are effective in reducing the proportion of fallers in the intervention group (pooled relative risk reduction $0.73,95 \%$ CI $0.63-0.85$ ).

In a targeted population identified on the basis of falls status or known risk factors, the pooled data showed a significant reduction in the proportion of fallers in the intervention groups (RR $0.86,95 \%$ CI $0.76-0.98$ ).

Outside the remit of this PhD, but of interest, the NICE guidance did not find sufficient evidence to be able to recommend multifactorial interventions specifically in extended care settings or for people with cognitive impairment, but instead emphasised the need to provide multifactorial interventions to targeted, high risk populations (irrespective of domicile or cognition).

\subsubsection{Compliance}

A key issue with interventions for frail older people is compliance - or better still, concordance. An intervention which is highly efficient (it works when taken/complied with), but not acceptable to the population for which it is intended, may not be effective in clinical practice.

The NICE guidelines examined this issue in some detail and showed that drop out rates from falls interventions are significant (Table 1.6), with typical rates of around $20 \%$. Some of the drop outs will be unavoidable - mortality, change of residence etc, but some will be related to the acceptability (or not) of the intervention. 
Table 1.6 Adherence to various falls prevention interventions (from NICE guidelines ${ }^{10}$ )

\begin{tabular}{|l|l|l|}
\hline Type of intervention & Drop out rates & Follow up period \\
\hline Tai Chi & $20 \%$ & $7-20$ months \\
\hline Home hazards intervention & $2-28 \%$ & $12-18$ months \\
\hline $\begin{array}{l}\text { Psychotropic medication } \\
\text { withdrawal }\end{array}$ & $68 \%$ & 24 months \\
\hline Cardiac pacing & $9 \%$ & 12 months \\
\hline $\begin{array}{l}\text { Untargeted multidisciplinary } \\
\text { interventions }\end{array}$ & $6-28 \%$ & $12-36$ months \\
\hline $\begin{array}{l}\text { Targeted multidisciplinary } \\
\text { interventions }\end{array}$ & $3-26 \%$ & $3-18$ months \\
\hline
\end{tabular}

Other investigators have highlighted the importance of the language used in encouraging older people to attend such interventions ${ }^{218}$, suggesting a more positive approach, emphasising healthy ageing rather than falls prevention. Programmes using more user friendly strategies may see better adherence. Key enabling factors include 'social support, low intensity exercise, greater education, involvement in decision-making, and a perception of the programmes as relevant and life-enhancing', whilst barriers include 'fatalism, denial and under-estimation of the risk of falling, poor self-efficacy, no previous history of exercise, fear of falling, poor health and functional ability, low health expectations and the stigma associated with programmes that targeted older people ${ }^{\prime 219}$. Herein lies the paradox - those most in need are least likely or able to access the service that may confer benefit ('differential challenge'). We know fall interventions work, but the key issue is getting people at high risk of falls to attend. 


\subsubsection{Published work on falls prevention since the 2003 NICE guidelines}

The search strategy for this part of the literature review is detailed in 4.1.9.

\subsubsection{Tai Chi}

There has been a growing interest in Tai Chi as a potential strategy for falls prevention. Initial trials failed to show any significant difference compared to 'wellness education' $(\text { placebo })^{78}$, though the confidence intervals for falls reduction were consistent with a marked beneficial effect over 48 weeks $(R R=0.75,95 \%$ CI $0.52-1.08, p=0.10)$. A smaller study was unable to show benefit from thrice weekly Tai Chi ${ }^{220}$. Li $2004^{221}$ showed a reduction in falls following on from a programme of Tai Chi, but only in those patients in whom an improvement in functional balance could be demonstrated.

In $2005 \mathrm{Li}^{222}$ showed a reduction in falls ( $7 \%$ vs. $\left.18 \% ; \mathrm{p}=0.03\right)$ compared with the 'stretching-only' control group. After adjusting for baseline covariates, the risk for multiple falls in the Tai Chi group was 55\% lower than that of the stretching control group (risk ratio $0.45 ; 95 \%$ confidence interval, 0.30 to 0.70 ). Compared with the stretching control participants, the Tai Chi participants showed significant improvements following intensive Tai Chi (three times per week). Voukelatos ${ }^{223}$ also showed benefit from once per week Tai Chi classes, the proportion of fallers after 24 weeks was 0.67 $(95 \% \mathrm{CI}=0.49-0.93, \mathrm{p}=0.02)$.

These studies suggest that Tai Chi is a useful intervention to reduce both falls and recurrent falls in community dwelling older people.

\subsubsection{Interventions in specific populations}

Increasingly, investigators have focussed interventions on specific populations.

Clemson ${ }^{224}$ showed a reduction in falls following a multifaceted community-based program, for community dwelling older people who had already fallen in the previous year: relative risk $0.69,95 \%$ CI $0.50-0.96, p=0.025$. Shumway-Cook ${ }^{28}$ was unable to 
show a reduction in falls following a community-based multifactorial intervention in a community dwelling population (Incidence Rate Ratio (IRR) $0.75,95 \%$ CI $0.52-1.09$ ). Weatherall ${ }^{225}$ carried out a meta-analysis and reinforced the prevailing view that multifactorial interventions (OR $0.64,95 \%$ CI $0.47-0.88$ ) are superior to unifactorial interventions in falls prevention (OR $0.81,95 \%$ CI $0.58-1.14$ ). But Gates et al ${ }^{226}$ sparked controversy with their meta-analysis of 19 multifactorial fall prevention programmes in primary care, community, or emergency care settings, which showed no overall benefit (risk ratio for the number of fallers $0.91,95 \%$ CI $0.82-1.02$ ). However, this paper was roundly criticised for its methods - mainly inappropriate trial selection (namely including trials in which the intervention was suboptimal or consisted of advice only), which at present the authors do not appear to have rebutted.

More recent trials have focussed on pragmatic (effectiveness) trials as opposed to explanatory (efficacy) trials. Pragmatic/effectiveness trials concern established clinical services, and evaluate interventions delivered in routine clinical practice. Explanatory/efficacy trials evaluate clearly defined, protocol driven interventions under highly controlled conditions ${ }^{227} 228$. Using the analogy of drug trials, in an efficacy trial of Aspirin, double blinding and careful control of all other conditions are used to ensure the only difference between groups is the drug. In contrast an effectiveness trial will address how Aspirin works in practice, and will be subject to real-life conditions, such as whether trial participants actually take the drug, or abandon it because of side-effects etc.

A recent pragmatic RCT of a multifactorial falls prevention programme in New Zealand also failed to show any evidence of benefit $(n=312$, mean age 81 , IRR $0.9695 \%$ CI 0.70 1.34), which the authors tentatively ascribe to inadequate follow through of referrals to the relevant professionals ${ }^{229}$. Similarly negative findings over 12 months were found in a pragmatic RCT of a multifactorial falls prevention programme delivered to older people attending the emergency department following a fall carried out in the Netherlands $(n=333, \text { OR } 0.86,95 \% \text { CI } 0.50-1.49)^{230}$. These two trials raise concerns about the 
application of the evidence base in clinical practice - the difference between efficacy and effectiveness.

Lord $^{231}$ assessed a group exercise programme in frail older people living in intermediate or sheltered care settings, and showed a reduction in falls rates (IRR $=0.69,95 \%$ $C I=0.48-0.99)$. Suzuki ${ }^{232}$ showed a reduction in fallers from $13.6 \%$ in the intervention group, compared to $54.5 \%(p=0.0097)$ at 20 months in Japanese elders attending a comprehensive geriatric assessment and receiving an exercise intervention, though the numbers were small (52 in total). Weerdesteyn ${ }^{233}$ showed a reduction in falls in people attending a falls service (IRR $0.54,95 \%$ CI $0.34-0.86$ ).

Morgan ${ }^{234}$ suggested that a low intensity exercise programme may be of benefit in the convalescent setting, but only in those with limited baseline function. Nikolaus ${ }^{235}$ reinforced the importance of addressing home hazards in a high risk populations (recently admitted to hospital with functional decline) in reducing falls (IRR $0.69,95 \%$ CI $0.51-0.97)$. Though in a similar Australian population, Latham et al ${ }^{236}$ failed to show any benefit from 10 weeks of high-intensity home-based quadriceps resistance exercise or vitamin D (calciferol 300,000 International Units).

Shaw ${ }^{237}$ evaluated a multifactorial programme in patents with dementia presenting to an emergency department with a falls and showed no reduction in the proportion of fallers (relative risk ratio $0.92,95 \%$ CI 0.81 to 1.05 ). Similar results were seen in cognitively intact older people with recurrent falls (RR for the total number of falls $0.64,95 \%$ CI $0.46-0.90)$ - but no change in the proportion of fallers.

Ashburn ${ }^{238}$ showed a non-significant trend towards a reduction in falls in patients with Parkinson's disease with a history of falling using a personalised exercise strategy.

Campbell ${ }^{239}$ showed that a home safety programme was superior to an exercise programme in reducing falls in people with visual impairment $(\leq 6 / 24)$. Harwood ${ }^{240}$ showed a reduction in falls rates in patients undergoing expedited cataract surgery (IRR $0.66,95 \%$ CI $0.45-0.96, p=0.03)$, though the study was unable to show a significant result for second eye surgery ${ }^{241}$. A larger study $(n=616)$ showed an increase in falls in 
older people attending a geriatric service referred for visual correction (IRR $1.57,95 \%$ CI 1.20-2.05, $p=0.001)^{242}$. The authors posited a variety of explanations for this finding, the most plausible of which were differential reporting bias (those in the control group may have been less motivated to report falls), increased activity or a period of increased risk during a period of adjustment in the visual aid group.

Additional work has looked at refining falls interventions. For example, Barnett ${ }^{77}$ looked at group exercise (including Tai Chi) over one year against falls education and showed a reduction in falls rate $(\mathrm{IRR}=0.60,95 \% \mathrm{CI} 0.36-0.99)$. Other investigators reported benefits such as increased confidence and mobility from enhanced balance training over six weeks, but did not record falls as an end-point ${ }^{243}$.

Other unifactorial interventions however, have not been able to demonstrate a reduction in falls, including 15 weeks of physiotherapy ${ }^{244}, 12$ weeks of physiotherapy ${ }^{245}$ (small trials); Lord $2005^{246}$ and Liu-Ambrose $2004{ }^{247}$ showed a reduction in falls risk (measured using Lord's Physiological Profile Assessment), but not falls. Means ${ }^{248}$ was able to show a reduction in falls following six weeks of exercise, which included an obstacle course. Sakamoto ${ }^{45}$ failed to showed a reduction in falls burden from unipedal standing. But 36 weeks of specific falls prevention directed physiotherapy, including balance training reduced falls (IRR $0.66,95 \%$ CI $0.49-0.90$ ), as did a fitness intervention in apparently low risk individuals recruited from a health insurance company database, $\mathrm{RR}=0.77,95 \%$ CI $0.60-0.97)^{249}$.

Campbell ${ }^{12}$ has suggested that well conducted unifactorial intervention might be effective for primary care based prevention. This was based on a meta-analysis of trials meeting the following relatively stringent criteria:

- participants were randomly allocated to intervention and control groups

- all participants were aged 65 years or older

- the majority lived independently in the community 
- fall events were recorded prospectively using a diary or calendar during the entire trial and monitored at least monthly

- follow up was for 12 months or longer

- at least $70 \%$ of participants completed the trial

- all falls during the trial for at least 50 participants were included in the analysis

- a relative rate ratio with $95 \%$ CI comparing the number of falls in the intervention and control groups was reported.

This meta-analysis identified $14 / 90$ falls prevention trials including 5,968 individuals meeting the above criteria. The meta-regression showed that single interventions were as effective in reducing falls as interventions with multiple components (pooled rate ratios $0.77,95 \% \mathrm{CI} 0.67-0.89$ and $0.78,0.68-0.89$ respectively). A sensitivity analysis, using less stringent selection criteria identified 27 interventions involving 8,380 individuals, but this also failed to shown any trend toward multifactorial programmes being more effective.

\section{$\underline{1.5 .2 .3}$ Vitamin D}

There is a growing body of evidence suggesting a role for vitamin $D$ in reducing falls ${ }^{250-}$ 254 , including in patients with renal impairment ${ }^{255-257}$. A systematic review suggested that vitamin D supplementation is effective in reducing falls by up to $20 \%{ }^{258}$.

\subsubsection{Medication reviews}

Haumschild ${ }^{259}$ and colleagues used a pre-post design to look at a fall-focused pharmaceutical intervention and showed a $47 \%$ reduction in falls in the intervention group. Huang ${ }^{260}$ showed a home hazards assessment combined with a focus on medication safety reduced falls, though this was a small, quasi-randomised study. Zermansky ${ }^{261}$ showed a reduction in the number of falls per person following a pharmacist medication review in a large RCT of care home residents ( $n=661,0.8$ vs. 1.3 falls per patient, $\mathrm{p}<0.0001$ ) $\mathrm{Pit}^{262}$ showed a reduction in the proportion of falls through 
the implementation of a broad based educational programme given to GPs in an Australian cluster RCT ( $n=849$, adjusted OR 0.61, 95\% CI 0.41-0.91). Another educational intervention aimed at primary care, using a review of electronic prescribing records and advice to the prescriber, failed to show any reduction in falls ${ }^{263}$.

\subsubsection{Injurious falls}

NICE and the Cochrane reviewers concluded that there is uncertainty around the effectiveness of multifactorial falls prevention programmes in reducing injurious falls. This is important, as the morbidity and mortality resulting from falls is attributable to injurious falls, rather than fall per se. An intervention which for some reason reduced falls, but had little or no impact upon injurious falls, may not achieve the desired outcome of improving well being and reducing morbidity or mortality.

McClure and colleagues carried out a Cochrane systematic review aimed at identifying population-based intervention effective in reducing falls-related injuries amongst older people ${ }^{264}$. The methodology was robust, though on this occasion study heterogeneity precluded a meta-analysis. Perhaps unsurprisingly, the reviewers did not find any randomised studies addressing this issue at the population level - as opposed to targeted populations described in the previous section. Such large scale randomised trials are extremely unusual, given the practical difficulties and costs of carrying out such studies (see 3.2.3.1.2).

The reviewers did identify six controlled studies addressing injury reduction, including multifactorial educational interventions aimed at health care professionals and individuals ${ }^{265}$ as well as provision of safer environments ${ }^{266-270}$ and in one study, widespread promotion of Tai $\mathrm{Chi}^{271}$. All six studies reported benefits in the intervention groups, ranging from $6-33 \%$ relative risk reduction. The reviewers concluded that though evidence was far from certain, given the methodological limitations of these large scale trials (internal validity, external generalisability, limited comparator groups, uncertain ascertainment and positive publication bias, regression to mean and confounding by secular trends), the studies support the preliminary claim that a population-based 
approach to the prevention of fall-related injury is effective ${ }^{264}$. The most recent study from Tinetti et a $1^{55}$ which was a pragmatic, non-randomised evaluation of falls prevention services in the US, showed a $9 \%$ reduction in serious fall-related injuries. Day et al272 have predicted similar outcome in Australia.

There is a large body of studies addressing fracture reduction specifically, often using pharmacological treatments, but not usually including interventions to reduce falls and fractures combined ${ }^{273}$. These studies have not been addressed in this work.

\subsection{Setting for interventions}

Most falls prevention studies in community dwelling older people have delivered the intervention in the primary care setting, in which the interventions are delivered by staff working in the community, and with general practitioners providing the medical intervention 2829224231249 274-277. The advantage of this model is that treatments are delivered in the context of an established relationship between patients and their carers, rather than the intervention being delivered by secondary care specialists, who may have no long term relationship with the patients. No trials have evaluated a falls prevention programme delivered in a secondary care setting against one in a primary care setting. The consensus appears to be that the components of a successful falls prevention intervention are strength and balance training, home hazards assessment and medical/medication review; the setting in which these components are delivered is of less importance, as long as it is acceptable to the intended participants.

One systematic review has looked at the benefit of day hospital for older people against other forms of comprehensive care. Including papers up until 1999, Forster et al ${ }^{278}$ found that day hospitals are effective in terms of death or poor outcome, disability, and use of resources compared to no comprehensive care, but hold no advantage over other settings. A search on Medline and EMBASE using a similar search strategy did not reveal any additional studies of relevance to falls prevention. 
There is no particular reasons to suspect that a falls programme delivered in a day hospital would have any advantage over a primary care delivered intervention - indeed the opposite is more likely to be true, as care closer to home is likely to see better compliance.

\subsection{Summary of the literature review}

Falls are a common problem for older people, with $24 \%$ of people aged over 65 years falling at least once every year. The method of falls reporting has a critical influence on rates, with more frequent follow up resulting in a greater number of falls being ascertained. Falls incidence is around 1.7 falls per person per annum using such methods.

Fear of falling is an important consequence of falls and has a set of risk factors in common with falls. Interventions to reduce falls are likely to reduce fear of falling as long as there is an improvement in overall function. The management of depression in fallers is more complex, and though there are similarities with fear of falling in the shared risk factors and interventions, pharmacological treatment of depression may increase the risk of falls.

Falls are the leading cause of trauma in older people and a prime cause of fracture; they are also a major cause of mortality in older people. Falls have as similar impact on hospital services to other major conditions such as stroke and myocardial infarction. Falls are a cause of carer strain, though this is poorly studied, and are a leading cause of admission to long term care.

Screening for falls is confounded by the fact that the best predictor of future fall is a previous fall, so most falls screening tools serve a case finding function as much as perform a true screening function. Nevertheless, multifactorial interventions delivered to previous fallers and others at high risk have been effective in reducing falls rates by around $15 \%$. The best evidence is for multifactorial interventions, though targeted unifactorial interventions (including Tai Chi, medication reviews and vitamin D) can be 
equally beneficial. More recent studies have cast doubt on the effectiveness of multifactorial falls prevention programmes (as opposed to the efficacy as demonstrated in clinical trials).

\subsection{Research questions}

The literature review has highlighted that screening for community dwelling older people at high risk of falling can be done, but there is no prospectively evaluated tool that has been tested in the United Kingdom. The first research question then was 'can a falls risk screening tool identify community dwelling older people at high risk of falls and can it identify those at low risk of falling?'

The second research question identified in the literature review concerns the effectiveness, as opposed to the efficacy, of a falls prevention programme - 'does a multifactorial falls prevention programme, delivered in a day hospital, reduce the rate of falls in community dwelling older people identified by a screening process as being a high risk of future falls?'

\subsection{Overview}

This thesis describes two main studies: an evaluation of a falls screening tool (referred to as the cohort study) and a randomised controlled trial (Figure 1.4). Both the cohort study and the RCT share similar methodology regarding ascertaining outcomes.

All participants in the cohort study were asked to complete a screening questionnaire. Those at high risk were first invited to participate in the RCT. If they declined, they were invited to participate in the cohort study, along with those individual as low risk of falls. Prospective data collected from the cohort was used to validate the screening questionnaire (chapter 2). Those screened as being at high risk and entered into the RCT were allocated to a multifactorial day hospital intervention or control (usual care). The primary outcome measure was the rate of falls (chapter 3 ). These form the two main components of this work - developing a screening tool and evaluating a falls prevention 
programme. A concomitant economic analysis has been undertaken but is not discussed in this thesis.

Figure 1.4 Study outline

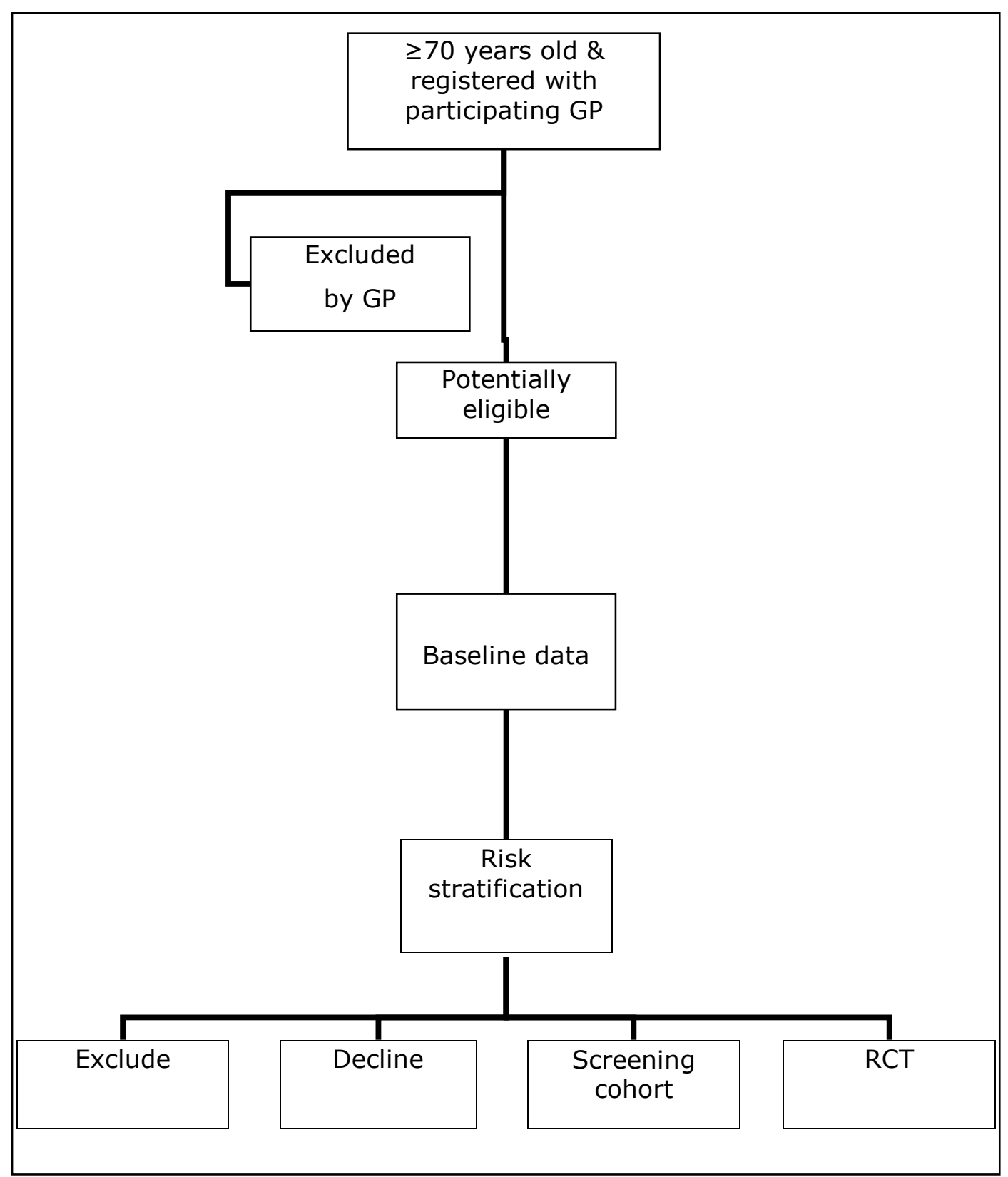




\section{SCREENING}

\subsection{Definitions}

Several different definitions of screening exist, but the essence is to identify a population at an early stage in a disease process, and to then provide an intervention which prevents more serious consequences of the disease manifesting at a later stage.

Screening has been defined as 'applying a test to a defined group of persons in order to identify an early stage, a preliminary stage, a risk factor or a combination of risk factors of a disease. The object of screening as a service is to identify a certain disease or risk factor for a disease before the affected person spontaneously seeks treatment, in order to cure the disease or prevent or delay its progression or onset by (early) intervention' (Council of Europe) ${ }^{279}$.

An alternative definition of screening is 'a public health service in which members of a defined population, who do not necessarily perceive they are at risk of, or are already affected by, a disease or its complications, are asked a question or offered a test to identify those individuals who are more likely to be helped than harmed by further tests or treatment to reduce the risk of disease or its complications' (UK National Screening Committee) $)^{280}$.

Screening is but one method of disease management, which can be considered as having four possible levels of intervention. Primordial prevention is concerned with establishing conditions that minimise the hazards to health by preventing the development of risk factors or underlying conditions leading to causation; these are typically environmental factors (economic, social or behavioural) ${ }^{281}$. An example relating to falls might include reducing socio-economic deprivation, which 
has been linked with an increase in hospital admission rates related to falls $^{282}$. For primordial prevention, interventions are made at the population level.

Primary prevention is directed at specific causal factors, usually at the population level, such as increasing levels of physical activity in the population as a whole. More targeted primary prevention might define a population in whom specific risk factors are known to be prevalent, and provide an intervention. An example related to falls might include giving calcium and vitamin D supplements to prevent falls in care home residents ${ }^{168}$, irrespective of a given individual's vitamin D status. When the risk factor for a disease process is continuous measure, such as vitamin D levels and the risk of falling, there are two possible approaches. Firstly, to introduce population level changes which shift the distribution of the risk factor to the left. This might include supplementing the population's diet with vitamin D - by way of example, margarine has added vitamin $D$. This achieves a greater reduction in the population attributable risk (see 2.4.2). Secondly, prevention could focus on those at highest risk alone (such as individuals with severe vitamin D deficiency). Individuals with very low levels of serum vitamin $D$ will be at the highest risk of developing myopathy or muscle weakness and so have a higher risk of falling, but the greatest population effect is seen by increasing the vitamin D levels of those at intermediate or even low risk. Screening is not required with a population level approach, but the consequence is that low risk individuals are included that may not benefit from the intervention. If an intervention has the potential to cause harm (such as vitamin D induced hypercalcaemia), then the absolute benefit obtained may be reduced. Secondary prevention is directed at slowing the progression of a disease identified at an early stage and preventing more serious consequences, 
such as injury related to falls. A example of secondary prevention might be the use of hip protectors in someone who falls frequently ${ }^{283}$.

Tertiary prevention is used at a late stage in a disease processes and is mainly restorative or adaptive ${ }^{284}$. An example might include rehabilitation following a hip fracture resulting from a fall, either by improving balance and gait (restorative) and/or by improving stability by providing a walking frame (adaptive).

\subsection{Criteria for a successful screening programme}

The most commonly cited criteria against which the suitability of a proposed screening programme may be assessed are those conceived by Wilson \& Jungner in $1968^{285}$ :

- the condition should be an important public health problem

- there should be an accepted treatment

- facilities for diagnosis and treatment should be available

- there should be a recognisable latent or early asymptomatic stage

- there should be a suitable test

- the test should be acceptable to the population

- the natural history of the condition should be understood

- there should be an agreed policy on whom to treat as patients

- the cost of case-finding should be economically balanced in relation to the possible expenditure as a whole

- case-finding should be a continuing process.

It is useful to consider the case for screening for falls on a point by point basis. 


\subsubsection{The condition should be an important public health problem}

Key determinants of the importance of a public health problem include the frequency of the problem, the impact on individuals and the impact upon society, in terms of costs and resource use. For example, synringomyelia (a progressive neurological condition) can have a major impact upon individuals and their carers, but is relatively rare and so not a major public health problem (which is not to say that it is not important). By contrast, falls in older people are common ( $24 \%$ of people aged 65 plus fall each year), may have serious consequences, including fracture ${ }^{286}$ and are a major determinant of health and social costs in the United Kingdom ${ }^{287}$, thus making falls a major public health issue.

\subsubsection{There should be an accepted treatment}

Several studies or reviews have highlighted the efficacy of a multifactorial assessment and intervention falls prevention programme, which can reduce falls in a variety of settings, typically by around $25 \%{ }^{1012} 288$.

\subsubsection{Facilities for diagnosis and treatment should be available}

Most previous studies rely on self reporting of falls, as indeed does clinical practice. There is no 'gold standard' test for falls, other than a good collateral history. Medically verified falls are used to add some degree of validity to self-reporting, but using this technique alone will inevitably lead to under reporting (minor falls may not be reported to the general practitioner). So 'diagnosing' a fall is difficult - indeed from the clinical perspective, falls are not a diagnosis but a symptom of other underlying problems which require a diagnosis.

A variety of facilities or services are available for the identification and management of people who fall. These can be divided into primary care services (falls prevention schemes, general practitioner, intermediate care 
services) or secondary care services (geriatric day hospitals, falls clinics). Often a combination of resources is used in the management of any one individual and as such there is not one single discrete locus for diagnosis and care.

\subsubsection{There should be a recognisable latent stage}

Many cohort studies and case-control studies have identified risk factors for falling14 1534143168201207 289-296. Randomised control trials have demonstrated that intervening on the reversible risk factors can reduce subsequent falls ${ }^{8} 313336$ 297-299. Interventions provided to the high risk individuals have been successful in reducing falls. It is generally accepted that there is a latent stage during which an individual is at risk, for example because of reduced balance and mobility, but has not yet fallen (see 1.4).

\subsubsection{The natural history of the condition should be understood}

The natural history of falls is reasonably well understood, namely an accumulation of intrinsic risk factors, combined with extrinsic risk factors, triggering a fall (see 1.4). In essence, there is a threshold at which we are all at risk of falling. Extrinsic factors (accidents) can overwhelm this threshold and give rise to a fall. Additionally, cumulative intrinsic factors lower the threshold for falling (muscle weakness, reduced balance). Many of these factors are potentially reversible, as is the risk of falling. Different risk factors are associated with different magnitudes of risk.

\subsubsection{There should be a suitable and acceptable test}

This point usually refers to a biological test for a condition, which does not apply to falls. The joint British Geriatrics Society/American Geriatrics Society guidelines advocate the use of the 'get up and go test' to indicate the risk of an individual falling ${ }^{300}$. Screening tools are reasonably good at 
differentiating people at high versus low risk of future fall, typically with a sensitivity of $50-60 \%$ and specificity of $80 \%^{202}$ (see 1.3 .9 .6 ).

\subsubsection{There should be an agreed policy on whom to treat}

There is general guidance on who should be considered for falls reduction strategies (National Service Framework for Older People ${ }^{2}$ and guidance from the National Institute of Clinical Excellence ${ }^{10}$ ) but as people who fall represent such a heterogeneous population, it is not possible to be precise as to who should and who should not be treated. In general terms, an individual with an isolated fall and no other risk factors for falling, such as a gait disturbance, would not be considered for a falls prevention programme $\mathrm{e}^{100}$. Current practice is mainly opportunistic, whereas this thesis will examine the role of a more systematic approach.

\subsubsection{The cost of case-finding should be economically balanced}

Screening and a concomitant cost analysis in the primary care setting for individuals thought to be at risk of falling has not taken place in the United Kingdom.

\subsubsection{Case-finding should be a continuing process}

Current recommendations state that all people over 70 should be asked about falling on an annual basis ${ }^{10} 300$, and assessments offered to those thought to be at high risk.

\subsubsection{Summary}

It appears that there is a theoretical role for screening for people at risk of falling and offering an intervention, but some of the key questions needed to justify a large scale screening programme have yet to be answered. These include having a robust screening tool, and determining the costs of a screening programme and the associated intervention. 


\subsection{Benefits and adverse effects of screening}

In the United Kingdom, screening programmes have centred on noncommunicable diseases with a pre-symptomatic phase, where interventions during the pre-symptomatic phase can prevent progression to overt disease. Examples include cervical cancer, breast cancer and cardiovascular disease. Potential advantages of screening are the prevention of disease, improvement in quality of life (through avoiding illhealth), reduction in mortality and cost savings. Screening has potential disadvantages as well as advantages, such as:

- delay in diagnosing false negatives

- the effects, side effects and psychological distress relating to potentially invasive clinical diagnosis of false positives

- psychological distress where there is no cure for the disease or where the treatment and/or intervention is unacceptable to the individual concerned

- individuals who are positively screened might experience difficulties such as access to insurance, employment or social stigmatisation

- unfavourable cost-benefit relationship of a screening programme Relating to falls, screening may increase fear of falling by alerting people to previously unrecognised risk, for example. The costs of a systematic falls screening programme are not known, so it is possible that the cost may outweigh the benefits.

\subsection{Screening terminology}

\subsubsection{Prevalence and incidence}

The prevalence of a disease is the number of cases in a defined population at a specified point in time whereas the incidence of a disease reflects the 
number of new cases arising in a population in a given period ${ }^{301}$. The two measures provide different and complimentary information. For a chronic condition such as multiple sclerosis, the incidence may be low but the prevalence high. This is because there are relatively few new cases of multiple sclerosis each year, but once contracted it is (usually) permanent, so increasing the prevalence. This is in contrast to short-lived conditions such as the common cold, in which the incidence in one year may be high (we all get colds) and the prevalence low, as at any one time only a relatively few people will be affected.

Point prevalence refers to the prevalence at any given point in time; an alternative measure is period prevalence, which is the number of people affected by a disease in a specified period. Prevalence is influenced by the severity and duration of the illness as well as the incidence and diagnostic accuracy.

Incidence is the number of newly identified cases occurring over a period of time. The incidence rate is given as the number of new cases detected during a defined period of time, divided by the sum of the length of time at which each person is at risk. Incidence rates are often measured in events per person-year.

An alternative measure of incidence is cumulative incidence, which measures the number of new cases divided by the number of disease-free individuals at the beginning of the period (and is a proportion). This measure is useful for comparing risk of disease in different populations.

The third possible measure of incidence is the odds of disease, a measure of the number of new cases in a given period divided by the number of 'disease-free' individuals at the end of the study period. Odds can also be calculated for prevalent cases. 


\subsubsection{Measures of effect and impact on populations}

The population attributable risk (PAR) is the amount of risk that can be reduced if the risk for the exposed group was reduced to that of the risk of the unexposed. The PAR is derived from measures of relative risk. To calculate the relative risk, we need to know the rate (incidence -2.4 .1 ) or the risk in the exposed ( $r_{1}$ - in this case individuals at high risk of falling) and the unexposed ( $r_{0}$-low risk); the rate ratio is $r_{1} / r_{0}$.

An alternative measure of effect is the risk difference, which reflects the excess risk in the exposed population: risk difference $=r_{1}-r_{0}$. It is important to recognise that risk difference assumes causality, which is an over-simplification, as in practice, few diseases have a single causative factor. Risk difference further assumes that removal of the risk factor will reduce risk in the exposed group to the level of risk in the unexposed group, again an over-simplification.

Given the assumptions made in estimating risk differences, a more useful measure of effect is the risk difference percent (also the 'attributable fraction') - the proportion of cases that could have been prevented in the exposed group if they had not been exposed.

Risk difference percent $(\mathrm{RD} \%)=(\mathrm{r} 1-\mathrm{r} 0) / \mathrm{r} 1$

Measures of effect tell us little about the impact upon a population; the impact measures the amount of disease in a population that could be prevented if the exposed became unexposed (assuming causality). The impact of an exposure on a population depends upon the prevalence of the exposure and is called the population attributable risk (PAR): $R-r_{0}$, where $R$ is the rate in the whole population and is given by the weighted sum of $r_{0}$ and $r_{1}$, weighted by the prevalence $(p)$ of the risk factor in the population: $R=p r_{1}+(1-p) r_{0}$. By rearranging the equation PAR $=p\left(r_{1}-r_{0}\right)$. 
As with risk difference, this is more usefully expressed as a percentage the proportion of all cases in the whole population that may be attributable to the exposure: population attributable fraction $(P A F)=p(r 1-r 0) / R$. The PAF can also be estimated from risk ratios (or odds ratios in a case-control study): $p(R R-1) /[p(R R-1)+1]$.

Or, more simply, the PAR equals the attributable risk multiplied by the proportion of the population exposed.

\subsubsection{Sensitivity and specificity}

Sensitivity refers to how good a test is at identifying people who have a disease; specificity reflects how good a test is at identifying those who do not have the disease $\mathrm{e}^{302}$. These are crucial to determining the effectiveness of a screening programme. Taking the screening questionnaire to be used in this study, the aim is to identify those that are at high risk of falling. Ideally, it should be sensitive (correctly identifying all of those that fall) and specific (excluding those that do not fall); this is best represented in a two by two table (Figure 2.1).

Figure 2.1 Sensitivity and specificity

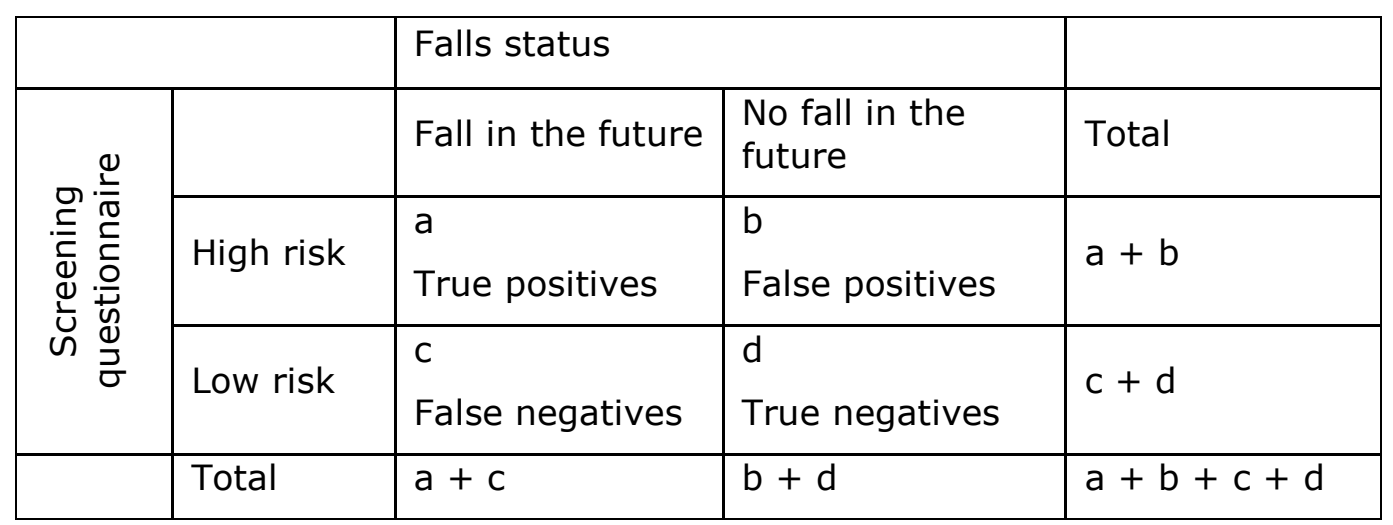

Sensitivity is $a /(a+c)$ and specificity is $d /(b+d)$, both expressed as a percentage. There will inevitably be a trade off between sensitivity and specificity; for example, a test which is always positive will have $100 \%$ 
sensitivity but the specificity would be $0 \%$ and so the test would be clinically useless. Assuming that the intervention is relatively harm-free, the ideal properties of the screening tool would be high sensitivity with less emphasis on specificity. But a reduced emphasis on specificity may result in individuals being assessed that are not going to benefit. A good screening test will have high sensitivity and specificity (above 95\%), but the optimal values for a particular screening test (using a continuous measure) will be determined by a receiver-operator characteristic curve (ROC curve). The ROC curve plots sensitivity against (1-specificity); the area under the curve (AUC) can be calculated, and the higher this value, the more discriminatory the test.

Perhaps more clinically useful in the context of a screening questionnaire are the positive predictive value (PPV) and the negative predictive value (NPV). The crude PPV give the probability of having a falls when the screening tool identifies the individual as being at high risk: $a /(a+b)$. The crude negative predictive value gives the probability of the individual not falling when they are screened as being at low risk: $d /(c+d)$.

As the prevalence of a condition changes, the predictive value of the test will change, even though the sensitivity and specificity remain constant. This is important, as a test with a high PPV in one context will may have a lower PPV in another context where prevalence is lower; it means that screening tests from one setting cannot always be reliably adopted in another where prevalence is different.

\subsection{Development of a screening tool}

The screening tool is a health measurement scale and if it is to be of use in future falls screening programmes, it needs to be valid (it needs to do what it sets out to do) and reliable. The screening tool used in this study is a 
postal questionnaire, designed to select out older people living in the primary care setting who are at high risk of falls over the following year.

\subsubsection{Developing an item pool}

The first step for developing a health outcome measure is to develop an item pool. These items should be known to be associated with the outcome of interest. Where an outcome has been well studied, such items might be drawn from a review of the literature. Where an outcome has been less well studied, the items will need to be generated de novo, typically by using qualitative methods such as key informant interviews, to generate the domains relevant to the outcome.

\subsubsection{Validity}

There are three forms of validity - face validity, content validity and construct validity.

\subsubsection{Face validity}

Face validity 'indicates whether, on the face if it, the instrument appears to be assessing the desired qualities ${ }^{\prime 303}$. This is usually measured subjectively, typically by a panel of experts; the Delphi technique ${ }^{304}$ can be useful in this process. The Delphi process is a structured approach to establishing face validity of items under consideration for an outcome measure. Once the item pool has been generated, the items are collated and sent out to a group of experts in the field. These experts usually include content experts (clinicians), both researchers in the field and practitioners, and should be interdisciplinary. The interdisciplinarity of the group is crucial to ensure that the items selected are valid, relevant and reasonable ${ }^{305}$. The Delphi group should ideally include representatives from various sectors, such as primary and secondary health care ${ }^{306}$ and may include patients or patient representative bodies. Delphi groups are usually quite large, numbering 
many tens or even hundreds of participants. The panel should vote on each item, indicating how valid they felt it was, the results would then be collated and items selected on the basis of their overall ranking.

An alternative to the Delphi technique is the Nominal Group technique, more typically used in constructing guidelines, though equally useful for assessing face validity. The principles are similar to the Delphi technique, in that the group should be interdisciplinary, but the group size is smaller, and should assemble for a face to face meeting ${ }^{307}$. At the meeting, each item would be discussed and then voted on in a structured manner, with each participant being given the opportunity to comment. A disadvantage of the nominal group technique is that more verbose members may dominate proceedings and some stakeholder may not contribute as fully. Once the items have been selected on the basis of their face validity, it is reasonable to then check the items with patients to check face validity from the patient perspective, although patients should be represented on the panel in any case.

\subsubsection{Content validity}

Content validity assesses 'the extent to which the measurement incorporates the domain of the phenomenon under study ${ }^{\prime 281}$. To have acceptable content validity, a tool should include items reflecting the range of concepts relating to the question. For example, if asking about functional health status, the tool should include items not only relating to physical health, but cognition, activities of daily living, social aspects and so on. It is possible to assess the properties of a tool against a gold standard if one exists, comparing the result obtained with the new tool against similar items in the gold standard, known as criterion validity. 


\subsubsection{Construct validity}

Construct validity reflects whether the measurement of the construct adequately represents what is intended by theoretical account of the construct being measured, by using various forms of validity checks. For example, do the observed results from a screening questionnaire confirm the expected results? It would be expected that those that screen as high risk, do in reality fall more often than those screened at low risk.

Other important areas include convergent validity and sensitivity to change.

\subsubsection{Convergent validity}

Convergent validity for an outcome measure is used when the items are being generated de novo, and involve comparing patient's self-reported data for the measure against either spouse or peer-reports for the patient. This data helps establish confidence in the accuracy of the self-reported measure.

Convergent validity can also be examined by looking at the scale's relationship with other outcome measures included in a study. By exploring these relationships further validity for the scale can be established by showing expected relationships with other measures relevant to falls (e.g. fear of faling).

\subsubsection{Sensitivity to change}

For health measurement scales, sensitivity to change is very important does the outcome measure score change as the patient's condition changes or once an intervention has been applied. However, for a screening tool, this property is not so relevant. 


\subsubsection{Reliability}

Reliability examines the concept of reproducibility - the tool should produce similar results for questions asked of the same individual at different times or by different interviewers. Reliability is usually measured as a ratio (score $0-1$ ) of the variability between individuals compared to the overall variability; there are various possible measures of reliability described below.

\subsubsection{Internal consistency}

For large questionnaires, several items may correlate with each other. Using the example of a functional health questionnaire, it is likely that there will be several items assessing physical function. These can be correlated, for example using Cronbach's alpha ${ }^{308}$. Correlations amongst items measuring similar attributes should be in the range of 0.7-0.9309.

\subsubsection{Stability}

The stability of responses to a tool can be assessed between observers (inter-observer reliability) or 'within' observer (the same observer obtaining the same result on different occasions (intra-observer reliability). It can also be assessed by checking to see of the same respondent provides the same answers at different times (test-retest reliability); this however assumes that the item being tested should provide a consistent response over time (not the case with falls for example). There are no clearly defined gold standards by which to measure reliability, but it is generally accepted that measures of reliability should be above $0.7^{302}$.

\subsubsection{Development of the screening tool}

It can be seen from the above sections that the development of a valid and reliable screening tool represents a large body of work, including a literature review, convening an interdisciplinary panel and a series of 
validity and reliability checks, which would require studying a large cohort of participants. Fortunately, previous work in the United Kingdom had already identified a set of items (Table 2.1) suitable for inclusion in a fall screening tool (FRAT ${ }^{158}$ ), which was modified for use in this study. We considered if the existing items were useful and further considered additional possible items.

Table 2.1 Items included in the FRAT

\begin{tabular}{|l|}
\hline History of falling in the previous year, \\
\hline Taking four or more prescribed medications, \\
\hline History of stroke \\
\hline History of Parkinson's disease \\
\hline Reported problems with balance \\
\hline Loss of proximal muscle strength \\
\hline
\end{tabular}

The aim of the screening tool was to gather information from community dwelling older people using a postal questionnaire. The information gathered should differentiate between individuals who go on to fall and those that do not. The questionnaire should be brief, easy to understand and reliable.

\subsubsection{Selection of items for inclusion in the screening tool}

Questions about cognitive impairment (see 3.4.3.1.1) were deemed inappropriate on a postal questionnaire, because of the practical difficulties in obtaining an accurate cognitive assessment by post.

It was felt insensitive to ask a question about depression without additional support, although the geriatric depression scale has been validated for use as a postal questionnaire in older people. However, this comprises a minimum of four items, and is even then only a screening tool rather than a diagnostic tool ${ }^{310}$. We were seeking questions relevant to falls, which 
were concise and valid, and felt that introducing a section screening for depression would not be helpful.

Items asking about a diagnosis risk the introduction of reporting bias. However, self-reporting of many diagnoses has been shown to be valid when compared to medical records ${ }^{311}$; these include diabetes ${ }^{312}$, and other chronic diseases. Important exclusions to this caveat are osteoarthritis and peripheral vascular disease $\mathrm{s}^{313}$. Stroke reported by older people agrees moderately well with GP records (kappa 0.56) in Holland ${ }^{313}$, though other studies have found that it is underreported by patients ${ }^{314} 315$. Diabetes is valid as a self-reported diagnosis, and an increasingly recognised risk factor for falling ${ }^{316}$, but is not as powerful a risk factor as the items selected, and therefore was not included. Stroke and Parkinson's disease were included as self-reported items in the screening tool because of their major impact on falls risk.

Visual acuity is a modest predictor of falls (RR 1.4) but was not included as it is difficult to measure using a postal questionnaire - though it has been successfully used in the LASA study ${ }^{201}$. Furthermore, there is the obvious difficulty that those with impaired vision may not be able to read the questionnaire.

Fear of falling is a strong predictor of falls, but was not included as published tools are lengthy and so not easily incorporated into the planned screening questionnaire ${ }^{317}$.

For the purposes of this study, it was decided to use modify the Falls Risk Assessment Tool, being the only published screening tool used in a UK population; the FRAT contains previous fall, so serves a function of case identification, but also other robust predictors of future fall. However, it has only been validated in a retrospective cohort, it was decided to undertake a 
series of checks to determine the validity, reliability and prospective predictive properties of the tool.

Three extra items were introduced into the FRAT, self-reported mobility limitation as a composite item reflecting balance and muscle strength, rather than self reported problems with balance originally used (see Table 2.2), use of a mobility aid as a further marker of mobility limitation and poor balance and symptoms of dizziness on standing as a marker of postural hypotension. Self-reported mobility was formulated as a Likert scale rating of mobility: not at all/with assistance/around one level of the house/up \& down stairs/to the local shops/unlimited), and for analysis was dichotomised to housebound/not housebound). This item is a composite measure of several well established risk factors predicting future falls (reduced mobility, lower limb disability, activity limitation, gait deficit). Use of a mobility aid was a simple question about whether the individual used a stick or walking frame.

Table 2.2 Risk factors selected for inclusion in the screening questionnaire

\begin{tabular}{|l|l|}
\hline & Item \\
\hline 1 & Fall in the previous twelve months \\
\hline 2 & Taking more than four prescribed medications \\
\hline 3 & Previous stroke \\
\hline 4 & Parkinson's disease \\
\hline 5 & Inability to stand from a chair without using arms to push up \\
\hline 6 & Symptoms of dizziness on standing \\
\hline 7 & Use of a mobility aid \\
\hline 8 & Housebound (mobility impairment) \\
\hline
\end{tabular}

\subsubsection{Format of the screening questionnaire}

The finalised version of the screening questionnaire was designed to be easy for older people to read (font size 14, sans serif, double spaced, one 
double sided sheet with clear instructions to complete both sides) (see appendix 4.2).

The answers to the questions were in the form of a simple yes/no response, except for item 8 , which was on a six point Likert scale. A simple closed response was selected because such questions are easy to complete, define the domain of interest and are easy to standardise, code and analyse ${ }^{318}$. The disadvantage of selecting this style of question is that some participants may just guess, tick any response at random or make errors.

The screening questionnaire had a clear title and instructions and was accompanied by a letter of introduction from the potential participants' general practitioner. A patient information leaflet explaining the study was included. The reverse of the screening questionnaire contained sections for recording demographic data and for the potential participants to indicate their willingness to be contacted. A stamped, addressed envelope was included for return of the questionnaire.

\subsubsection{Determining risk}

Whilst individual risk factors for falls may be more or less powerful in predicting future risk, the combination of risk factors is the key predictor of recurrent falls 14203295 .

Of the risk factors included in this study, falls in the previous year was felt to be robust and reliable ( $90 \%$ of individuals falling in the previous year report this correctly ${ }^{26204}$ ), as well as being a strong predictor (relative risk from previous studies $1.9-2.4$ ). In the predictive model developed by $\mathrm{Stel}^{203}$, a fall in the previous year was the strongest risk factor for future falls ${ }^{203}$. Furthermore, further assessment of people who have already fallen is mandatory following on from the NICE guidance ${ }^{10}$. Given these facts, it 
was felt appropriate to use a previous fall or a combination of any two of the other risk factors as the entry criterion to the study (i.e. defining high risk).

\subsubsection{Validity of screening tool}

Most risk factors for falls have 'face validity'319, and the bulk of the items selected had been assessed by a panel of experts in developing the FRAT. The face validity of the modified FRAT was ascertained through informal consensus by a panel of experts in the field of falls research (Prof Tahir Masud, geriatrician/Prof John Gladman, geriatrician/Prof Denise Kendrick, GP and expertise in injuries/Dr Rob Morris, geriatrician/Dr Avril Drummond, occupational therapist/Prof Rowan Harwood, geriatrician/Dr Carol Coupland, statistician with an interest in injures). The panel felt that the screening questions were sensible, relevant, reasonable and clear. Validity was further assessed amongst primary healthcare workers (DK), physiotherapists (day hospital staff), occupational therapists (AD, day hospital staff) and day hospital patients. All participants in the pilot were asked to comment on the tool screening questionnaire. Further comments were obtained after the screening questionnaire had been used in practice. It was not possible to assess the criterion validity of the modified FRAT, as there is no gold standard tool for predicting future falls in community dwelling older people.

Construct validity is discussed in the main results section, and assessed by determining if those assessed as being at high risk went on to fall more than those at low risk (see section 2.7.5.1).

Convergent and discriminant validity of the tool are best examined by evaluating the tool's relationship with other baseline measures included in the study. By exploring these relationships it should be possible establish 
further validity for the scale by showing expected relationships with other measures. For example, the item asking about mobility could be assessed by comparing response against a standardised measure of mobility, such as a timed walk. However, given the potential burden to participants and added cost, this was not possible.

\subsubsection{Test-retest reliability}

The test-retest reliability properties of the screening questionnaire were determined during the recruitment phase. Twenty high risk and 20 low risk study participants returning the questionnaire were sent a second questionnaire a week later, with a request that it be completed within one week and returned. No attempt was made to follow up any participants who did not send back either the second questionnaire and if the second questionnaire was sent back after two weeks or longer it was discarded.

Sixteen high risk and 12 low risk participants completed the second questionnaire. Reliability was examined using kappa scores for each of the eight items in the screening questionnaire. Mobility was collapsed into two categories for the purpose of analysis (Table 2.3).

Table 2.3 Recoding of mobility in screening questionnaire

\begin{tabular}{|l|l|}
\hline $\begin{array}{l}\text { Mobility response (How far can you } \\
\text { walk, with or without the help of a } \\
\text { stick or frame?) }\end{array}$ & Recoded as \\
\hline Not at all & \multirow{2}{*}{ Housebound } \\
\cline { 1 - 1 } With assistance & \\
\cline { 1 - 1 } Around one level of the house & \multirow{2}{*}{ Not housebound } \\
\cline { 1 - 1 } Up \& down stairs & \\
\cline { 1 - 1 } To the local shops & \\
\hline
\end{tabular}

The kappa scores for each item on the screening questionnaire are shown in Table 2.4. 
Table 2.4 Test-retest reliability scores for screening questionnaire

\begin{tabular}{|l|l|l|l|l|}
\hline Item & $\begin{array}{l}\text { Observed } \\
\text { agreement }\end{array}$ & $\begin{array}{l}\text { Expected } \\
\text { agreement }\end{array}$ & Kappa & Agreement $^{*}$ \\
\hline Fall in last year & $85.2 \%$ & $58.3 \%$ & 0.64 & Good \\
\hline$\geq 4$ medications & $89.3 \%$ & $60.7 \%$ & 0.73 & Good \\
\hline Previous stroke & $92.9 \%$ & $62.5 \%$ & 0.81 & Very good \\
\hline $\begin{array}{l}\text { History of Parkinson's } \\
\text { disease }\end{array}$ & $100 \%$ & & 1.0 & $\begin{array}{l}\text { Perfect (no } \\
\text { discordant } \\
\text { cases) }\end{array}$ \\
\hline Able to stand unaided & $82.1 \%$ & $50 \%$ & 0.64 & Good \\
\hline Dizzy on standing & $82.1 \%$ & $57.7 \%$ & 0.58 & Moderate \\
\hline Requires mobility aid & $89.3 \%$ & $53.1 \%$ & 0.77 & Very good \\
\hline Housebound & $92.0 \%$ & $78.6 \%$ & 0.63 & Good \\
\hline
\end{tabular}

\subsubsection{Summary - development of the screening tool}

The initial development of the screening tool indicates that it is valid and reliable; further evaluation of the predictive properties is detailed in the next section.

\subsection{Evaluation of a falls screening tool - methods}

The cohort study examining the screening tool was carried out in parallel to the randomised controlled trial, and many of the methodological aspects are common to both studies. The methods for the cohort study are presented here, but the methodological considerations are mainly highlighted in chapter 3.

\subsubsection{Study design}

We carried out a cohort study to determine the predictive properties of the screening tool over the course of one year. The study started in 2004 and the last follow up was in 2007.

\footnotetext{
* Agreement according to Altman, 1997
} 


\subsubsection{Population, inclusion and exclusion criteria}

The purpose of the screening tool was to identify older people in the community; accordingly participants were recruited from a primary care setting; this first necessitated recruiting general practices willing to allow access to their patients.

\subsubsection{Recruitment of general practices}

General practices that were registered with the Trent Focus for Primary Care Research, Collaborative Research Network (CRN), were approached by the researchers (DK, SC). The CRN has a Research Practices Board which assesses studies on behalf of the member practices. This study was submitted to the board and approved in June 2004. The CRN then advertised the project to member practices, who then indicated their interest in taking part in the study. The CRN Practices expressing an interest were visited by the study nurse to explain the study, to ensure that they would be able to identify the potential participants and to answer any queries about the study protocol.

Only one CRN practice was registered in the Derby area and declined to participate in this trial. In order to overcome this barrier, the principal investigator at Derby ( $\operatorname{Rr}$ J Youde), wrote to all practices within the Central Derby PCT, inviting them to participate. Two practices were enrolled following this invitation and were included in the trial in the same way as the CRN practices. 


\subsubsection{Recruitment of individual participants}

The individual participant inclusion criteria were kept as broad as possible to try and maximise external generalisability. The criteria were that the individual should be:

- aged 70 or over

- registered on the practice list of one of the participating general practices

- scored two or more on the screening questionnaire (previous fall or two or more other risk factors).

\subsubsection{Exclusion criteria}

The exclusion criteria were kept to the minimum possible however, in order to reduce contamination and in the interests of research governance, some exclusion criteria were necessary. The general practices were asked to exclude individuals if they were:

- residents in nursing or residential homes (the interventions required to reduce falls in care home residents are different from those living in their own homes

or

- patients with terminal illnesses (would not be ethical)

The study nurse excluded potential participants if they met the following criteria:

- individuals already attending one of the day hospitals (it would not be ethical to randomise them to usual care if they had already been referred to the day hospital for a non-falls indication. if attending for falls prevention, these individuals are already receiving an 
intervention and so by definition are not part of the screening population that this study targeted)

- patients under follow up with an existing primary care based falls prevention scheme (these individuals are already receiving an intervention and so by definition are not part of the screening population that this study targeted)

- those unwilling or unable to travel to the day hospital, using transport as provided (not eligible for the intervention arm)

- patients unwilling or unable to provide fully informed consent (would not be ethical).

Individuals who preferred not to participate in the randomised trial were offered the possibility of completing monthly diaries only as part of the screening cohort (section 2.5).

\subsubsection{Recruitment interviews}

Recruitment of individuals was carried out by three researchers (SC, RT, JE). The general practices were provided with recruitment packs, containing a letter of introduction (signed by one of the general practitioners at each practice), a screening questionnaire, a patient information leaflet and a reply-paid envelope. Each pack was in a sealed envelope and the addresses of potential participants were affixed by the practice staff, who then arranged for the invitation to be posted.

On receipt of a completed questionnaire indicating that the individual was willing to participate further in the study, one of the three researchers responsible for recruitment made telephone contact with the potential participant. The telephone conversations followed a standardised format. If the individual was willing to participate, verbal consent was obtained over 
the telephone. On a few occasions, a home visit was required to recruit individuals (for example, where hearing or vision was an issue).

Day hospital and primary care falls prevention service records were checked to ensure that the potential participant was not currently attending the service or under active follow up (exclusion criteria). Active follow up in this context was defined as regular visits with either of the services, or ongoing telephone contact between the service and the participant.

A consent form was then mailed to the individual, who was asked to sign and return the form.

\subsubsection{Outcomes}

\subsubsection{Baseline characteristics}

Participants were described in terms of their age at entry into the study, their gender and their responses to the screening questionnaire (fall in the previous twelve months, taking more than four prescribed medications, previous stroke, Parkinson's disease, inability to stand from a chair without using arms to push up, symptoms of dizziness on standing, use of a mobility aid, housebound/not housebound - see 2.5.4.1). Respondents were categorised as high risk of fall based on the presence of a previous fall or two or more of the other risk factors.

\subsubsection{Primary outcomes}

The primary outcomes were the predictive properties of the falls screening tool, described in terms of prevalence, sensitivity, specificity, positive and negative predictive values and their 95\% confidence intervals (CIs).

\subsubsection{Secondary outcomes}

We asked for self reports of whether the fall was injurious or not but no secondary outcomes were pre-specified in the study protocol for the cohort 
study. However, we subsequently decided to collect 12 month data on quality of life, basic and extended activities of daily living and fear of falling as additional descriptors of the population, and to help with assessing convergent validity.

\subsubsection{Ascertainment}

Prospective monthly falls diaries were used to collect falls outcomes over 12 months, with participants being sent a diary at the beginning of each month, and being prompted to return the diary by inclusion of a stamped addressed envelope sent with the next month's diary. A more detailed discussion on the merits of diary follow up is found in section 3.6.4.

\subsubsection{Sample size}

The initial sample size was based on recruiting approximately 340 individuals, as this has been shown to have sufficient power to determine sensitivity with a confidence interval of $20 \%$ in previous studies ${ }^{158}$. A further power calculation was carried out based on the first six month's data (Table 2.5).

Table 2.5 At least one fall vs. no-fall during six months follow up

\begin{tabular}{|l|l|l|l|}
\hline & Fall & \\
\hline Risk & Yes & No & Totals \\
\hline High & $14(27 \%)$ & $38(73 \%)$ & 52 \\
\hline Low & $4(11 \%)$ & $33(89 \%)$ & 37 \\
\hline Totals & 18 & 71 & 89 \\
\hline
\end{tabular}

The odds ratio for at least one fall over the six months was 3.0 (95\% CI

$0.8-13.8)$, Fisher's exact (2-sided) $p=0.106$. The sensitivity was $14 /(14+4)=78 \%$, the specificity was $33 /(38+33)=46 \%$; the positive predictive value (PPV) was $14 /(14+38)=27 \%$, the negative predictive value 
(NPV) was $33 /(4+33)=89 \%$, with a falls prevalence over the first six months of $18 / 89=20 \%$.

nQuery was used to calculate the sample size; 17 individuals with falls would be needed to be able to demonstrate a sensitivity of $78 \%$ ( $95 \%$ CI $58-98 \%$ ), using a two-sided test with a at 0.05. Assuming the falls prevalence remained constant at $20 \%$, we will need to recruit $(17 / 20 \%=85)$ individuals. Using more narrow confidence intervals (70$90 \%$ ), we would have needed 66 individuals who fell, or a sample size of $(66 / 20 \%=330)$. We initially planned to recruit 330 individuals into the cohort study.

\subsubsection{Analyses}

All analyses were carried out in Stata version 9.

The baseline and fall data were described in terms of proportions, and age using medians and the interquartile range because of the skewed nature of the data. The predictive properties were described using sensitivity, specificity, positive and negative predictive values with their $95 \%$ confidence intervals. The choice of the optimal cut off point for determining high and low risk of falls was examined by calculating the sensitivity and specificity for differing cut off points and by plotting a receiver operating curve. Falls rates were calculated using Poisson regression and comparisons between groups were calculated as incident rate ratios. Quality of life, activities of daily living and fear of falling were compared between those at high and low risk and between fallers and non-fallers. The functional outcomes were continuous data but not normally distributed. Various transformations were tried, but none were suitable. Accordingly, scores were dichotomised on the basis of the median value, and comparisons made using chi square tests and logistic regression. 


\subsubsection{Handling missing data}

Postal questionnaires were used to gather outcome measures. The advantages of postal questionnaires include:

- no interviewer bias ${ }^{309} 320$ (particularly important in any therapy interventions)

- standardised measurement across a large number of participants

- participants are more likely to answer sensitive questions honestly $y^{321}$

- postal questionnaire are relatively cheap ${ }^{322}$.

The disadvantages of postal questionnaires include missing or unclear data, and low response rates, which may introduce bias if responders are different to non-responders ${ }^{323}$. Missing data reduces the effective sample size as regression models require that all cases have complete data.

During the course of the study it became apparent that some of the monthly falls diaries had not been sent to some participants because of clerical error. Stata handles missing data by a process of 'listwise deletion' or 'complete cases only', that is to say only using complete datasets for regression commands. However, this is inappropriate for the falls and functional outcomes as it risks introducing bias. The conventional response to missing data for the Barthel and Nottingham Extended activities of Daily Living (NEADL) scales is to code missing as 'never' or 'not at all' i.e. worst possible outcome ${ }^{324}$. Alternatively, for hierarchical scales such as the NEADL it is reasonable to assume that if an individual fails an easy item they would have failed a more difficult item. An alternative is to replace missing items with the mean for a given subscale, providing there are not too many missing items. Multiple responses to single choice items are treated in the same way as missing items. 
In view of the missing data, we carried out a series of analyses:

- restricting analysis to those participants completing all 12 monthly diaries

- restricting analysis to those participants who had a fall or had complete diaries

- imputing missing data.

A sensitivity analysis was undertaken where missing data on whether a fall occurred or not over the 12 month follow up period was imputed using the multiple imputation procedure in Stata. Variables used in the equation for predicting a missing value for falls were age, gender, (plus a term for the interaction between age and gender where there was evidence of a significant interaction), falls risk (low or high), all eight risk factor variables, the number of returned diaries, plus the Barthel, NEADL, FES and EuroQoL scores. Ten imputed datasets were created. Sensitivity, specificity and predictive value were estimated on each of the 10 imputed datasets and the mean and $95 \%$ confidence intervals of the values for sensitivity, specificity and predictive value were estimated using Rubin's rules.

A second sensitivity analysis was undertaken comparing secondary outcomes by falls risk and by whether a fall occurred or not using the micombine command with the linear regression option. If scores were not normally distributed and no suitable transformation could be found, scores were dichotomised at the median and analysed using logistic regression. 


\subsection{Evaluation of a falls screening tool - results}

\subsubsection{Recruitment}

Recruitment into the cohort study took place in parallel to recruitment in to the RCT. Overall, $2846 / 5312$ (54\%) of people completed at least some parts of the screening questionnaire. Overall study recruitment is shown in Figure $2.2 ; 335$ individuals agreed to participate in the evaluation of the screening tool.

Five individuals replied but supplied insufficient information to allow their risk to be calculated, and did not give additional contact details. Reasons for exclusion included residence in a care home (2) or recent attendance at a falls programme (10). We recruited 335 participants into the cohort study, but due to clerical error, some of the participants did not receive study diaries and have incomplete data. 
Figure 2.2 Overall study recruitment

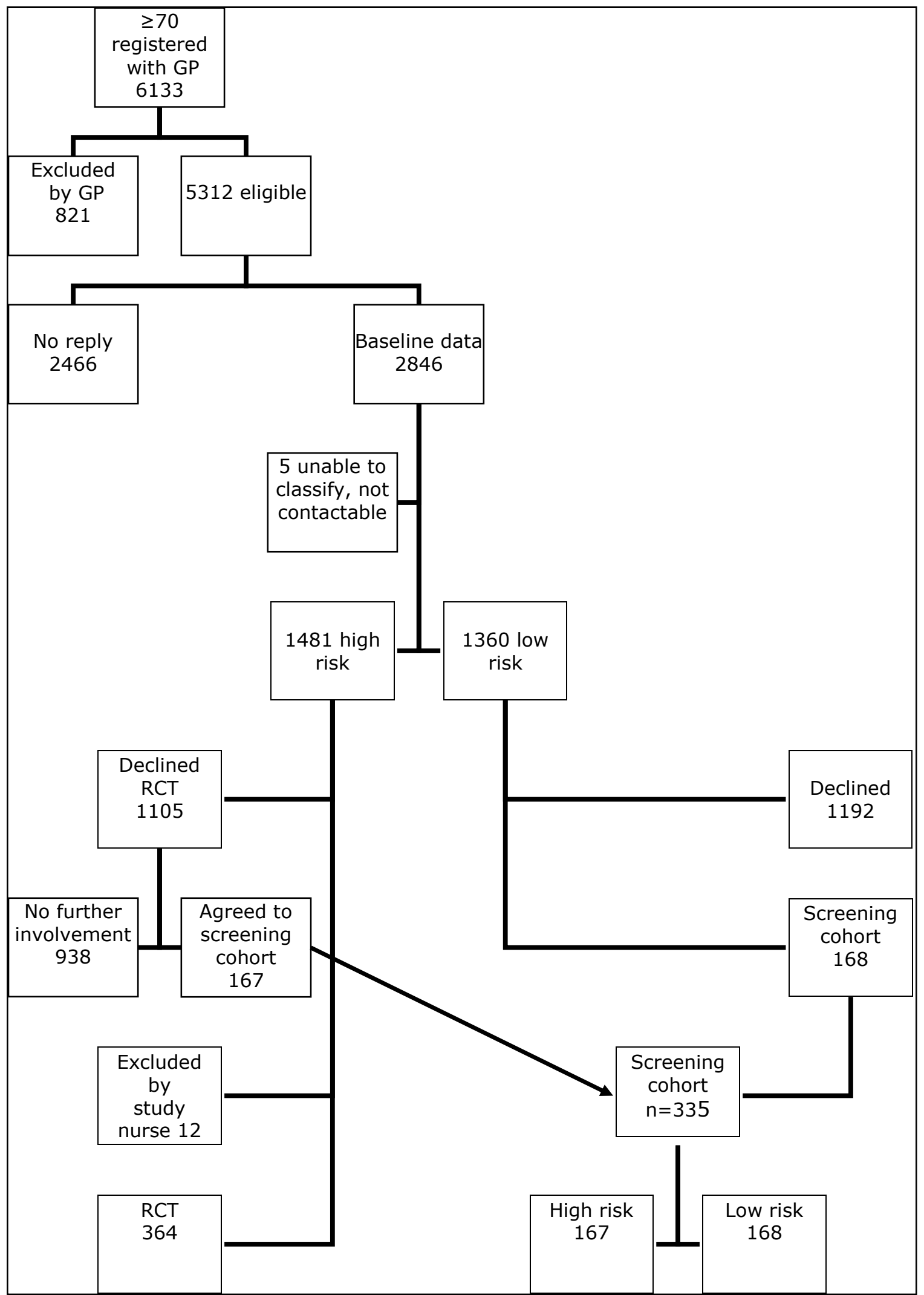


The baseline characteristics for at the key recruitment stages of the trial for the 2841 with data are shown in Table 2.7.

Table 2.6 Characteristics of study population by participation status

\begin{tabular}{|c|c|c|c|c|c|}
\hline Characteristic & $\begin{array}{c}\text { All eligible } \\
n=2841 \\
\text { (some had } \\
\text { incomplete data) }\end{array}$ & $\begin{array}{l}\text { Declined } \\
\mathrm{N}=2130 *\end{array}$ & $\begin{array}{l}\text { Excluded } \\
\mathrm{N}=12^{*}\end{array}$ & $\begin{array}{l}\text { Screening } \\
\text { cohort } \\
\mathrm{N}=335\end{array}$ & $\begin{array}{c}\text { Randomised } \\
\text { Controlled } \\
\text { Trial } \\
\mathrm{N}=364\end{array}$ \\
\hline Age (mean, SD) & $72(24.7), n=2840$ & $78.0(5.9)$ & $80.5(5.7)$ & $77.5(5.6)$ & $78.7,5.6$ \\
\hline Female gender & $1539(56 \%)$ & $1319 / 1994(57 \%)$ & $10(50 \%)$ & $165(50 \%)$ & $218(60 \%)$ \\
\hline $\begin{array}{l}\text { At least one fall in } \\
\text { previous } 12 \\
\text { months }\end{array}$ & $724 / 2776(26 \%)$ & $414 / 2050(20 \%)$ & $18 / 20(90 \%)$ & $76(23 \%)$ & $210(58 \%)$ \\
\hline $\begin{array}{l}\text { Taking more than } \\
4 \text { medications }\end{array}$ & $834 / 2835(29 \%)$ & $544 / 2110(26 \%)$ & $10 / 20(50 \%)$ & $79(24 \%)$ & $192(53 \%)$ \\
\hline History of CVA & $249 / 2832(9 \%)$ & $171 / 2107(8 \%)$ & $4 / 20(20 \%)$ & $20(6 \%)$ & $53(15 \%)$ \\
\hline $\begin{array}{l}\text { Parkinson's } \\
\text { disease }\end{array}$ & $43 / 2838(1.5 \%)$ & $32 / 2113(1.5 \%)$ & $4 / 20(20 \%)$ & $1(0.3 \%)$ & $6(2 \%)$ \\
\hline $\begin{array}{l}\text { Inability to stand } \\
\text { from a chair } \\
\text { without using } \\
\text { arms to push up }\end{array}$ & $1191 / 2825(42 \%)$ & $804 / 2099$ (38\%) & $13 / 20(65 \%)$ & $124(38 \%)$ & $240(66 \%)$ \\
\hline $\begin{array}{l}\text { Symptoms of } \\
\text { dizziness on } \\
\text { standing }\end{array}$ & $936 / 2821(33 \%)$ & $594 / 2093(28 \%)$ & $12 / 20(60 \%)$ & $107(33 \%)$ & $218(60 \%)$ \\
\hline $\begin{array}{c}\text { Use of a mobility } \\
\text { aid }\end{array}$ & $822 / 2828(29 \%)$ & $530 / 2100(25 \%)$ & $17 / 20(85 \%)$ & $87(26 \%)$ & $182(50 \%)$ \\
\hline $\begin{array}{l}\text { Housebound/not } \\
\text { housebound } \\
\text { (mobility } \\
\text { impairment) }\end{array}$ & $448 / 2823(16 \%)$ & $306 / 2099$ (15\%) & $11 / 20(55 \%)$ & $46(14 \%)$ & $83(23 \%)$ \\
\hline High risk of falls & $1481 / 2841(52 \%)$ & $928 / 2121(44 \%)$ & $18 / 20(90 \%)$ & $167(50 \%)$ & $\begin{array}{c}364 \\
(100 \%)\end{array}$ \\
\hline
\end{tabular}

These data show that those that declined to participate were less likely to have fallen and so at overall reduced risk compared to the all those with baseline data, and that the screening cohort lay between the two being at slightly higher risk overall than those declining ( $50 \%$ vs $44 \%$ high risk), but slightly lower risk overall than all those with baseline data ( $50 \%$ vs $52 \%$ high risk). 
Table 2.7 shows the baseline characteristics of the screening population spilt into risk group compared to the RCT population. These data demonstrate that the high risk group in the screening population was characterised by fewer fallers, fewer individuals taking more than four medications and fewer individuals with postural dizziness compared to the RCT population, suggesting a degree of selection bias, inflating the overall risk profile in the RCT population compared to the screening population.

Table 2.7 Characteristics of study population by participation status

\begin{tabular}{|c|c|c|c|}
\hline \multirow{2}{*}{ Characteristic } & \multicolumn{2}{|c|}{$\begin{array}{l}\text { Screening cohort } \\
\qquad N=335\end{array}$} & \multirow{2}{*}{$\begin{array}{c}\text { Randomised } \\
\text { Controlled } \\
\text { Trial } \\
N=364\end{array}$} \\
\hline & $\begin{array}{l}\text { Low risk } \\
n=168\end{array}$ & $\begin{array}{c}\text { High risk } \\
\mathrm{n}=167\end{array}$ & \\
\hline Age (mean, SD) & $75.6(4.0)$ & $79.5(6.4)$ & $78.7,5.6$ \\
\hline Female gender & $76(45 \%)$ & $93(55 \%)$ & $218(60 \%)$ \\
\hline $\begin{array}{c}\text { At least one fall in previous } 12 \\
\text { months }\end{array}$ & $0(0 \%)$ & $80(48 \%)$ & $210(58 \%)$ \\
\hline Taking more than 4 medications & $19(11 \%)$ & $66(40 \%)$ & $192(53 \%)$ \\
\hline History of CVA & $1(1 \%)$ & $20(12 \%)$ & $53(15 \%)$ \\
\hline Parkinson's disease & $0(0 \%)$ & $1(1 \%)$ & $6(2 \%)$ \\
\hline $\begin{array}{l}\text { Inability to stand from a chair } \\
\text { without using arms to push up }\end{array}$ & $21(13 \%)$ & $110(66 \%)$ & $240(66 \%)$ \\
\hline Symptoms of dizziness on standing & $28(17 \%)$ & $81(49 \%)$ & $218(60 \%)$ \\
\hline Use of a mobility aid & $4(2 \%)$ & $87(52 \%)$ & $182(50 \%)$ \\
\hline $\begin{array}{l}\text { Housebound/not housebound } \\
\text { (mobility impairment) }\end{array}$ & $0(0 \%)$ & $47(28 \%)$ & $83(23 \%)$ \\
\hline High risk of falls & 167 & $0 \%)$ & $\begin{array}{c}364 \\
(100 \%)\end{array}$ \\
\hline
\end{tabular}

*Some individuals provided incomplete data

\subsubsection{Data cleaning}

The data collected in the cohort study consisted of monthly diaries. $108 / 335$ diaries were double-entered and the data entry error rate was $34 / 5184(0.66 \%)$. For fall/no fall the error rate was $16 / 1296(1.2 \%)$, for the number of falls the error rate was $3 / 1296(0.2 \%)$, for injurious falls 
$15 / 1296(1.2 \%)$ and for the functional outcomes $31 / 4982(0.62 \%)$. All errors were corrected in the original Access database.

\subsubsection{Data available for analysis}

A total of 3072 diaries were returned. The median number of returned diaries was 10 (IQR 8, 12). 134 participants (41.2\%) returned all diaries, 10 participants died during the 12 month follow up period and were excluded from the final analysis, a further three participants provided baseline data, but no falls diaries (Figure 2.3).

Figure 2.3 Histogram of the number of diaries returned per participant

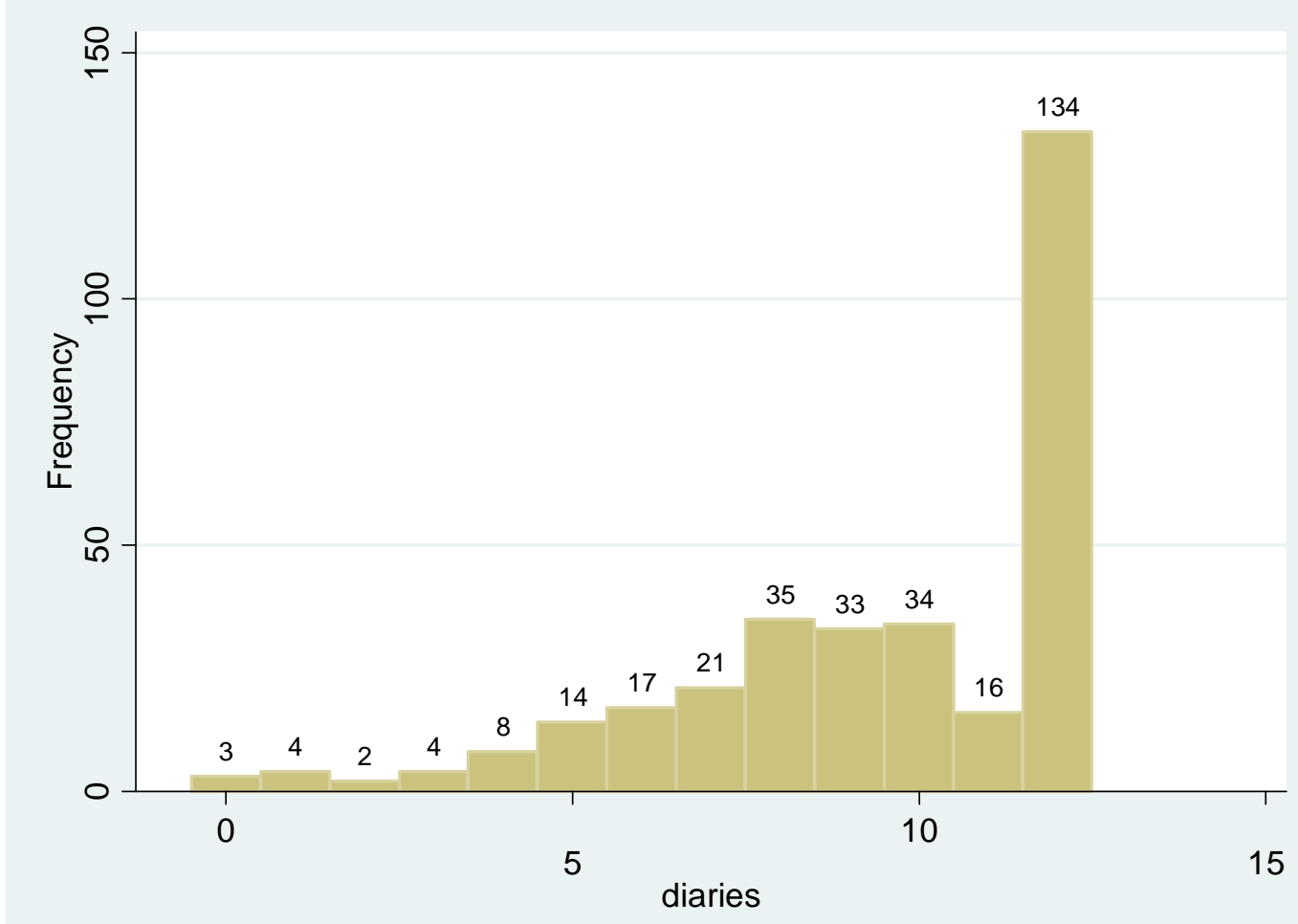

\subsubsection{Baseline characteristics}

The baseline characteristics for those recruited in to the cohort study are shown in Table 2.8, separated by diary return status (complete or incomplete). These data show some significant differences between those with complete compared to incomplete diary returns, with 'incomplete 
returners' being less likely to have had a previous fall ( $20 \%$ vs. $28 \%$ ), previous stroke ( $4 \%$ vs. $10 \%$ ) and less likely to have postural dizziness ( $28 \%$ vs. $40 \%$ ). The proportion of people at high risk was greater in the population returning all diaries compared to those with incomplete diaries ( $55 \%$ vs. $45 \%$ ), which is a potential source of bias.

Table 2.8 Baseline characteristics according to diary returns

\begin{tabular}{|l|l|l|l|}
\hline Characteristic & $\begin{array}{l}\text { Complete } \\
\text { diaries } \mathrm{n}=134\end{array}$ & $\begin{array}{l}\text { Incomplete } \\
\text { diaries } \mathrm{n}=191\end{array}$ & $\begin{array}{l}\text { Significance } \\
\text { test }\end{array}$ \\
\hline Age (mean, SD) & 77.5 & 77.5 & $\mathrm{P}=0.913$ \\
\hline Female gender & $75(56 \%)$ & $90(47 \%)$ & $\mathrm{p}=0.116$ \\
\hline $\begin{array}{l}\text { At least one fall in previous } \\
12 \text { months }\end{array}$ & $37(28 \%)$ & $39(20 \%)$ & $\mathrm{p}=0.013$ \\
\hline $\begin{array}{l}\text { Taking more than four } \\
\text { medications }\end{array}$ & $39(29 \%)$ & $40(21 \%)$ & $\mathrm{p}=0.091$ \\
\hline $\begin{array}{l}\text { History of stroke } \\
\text { Parkinson's disease }\end{array}$ & $13(10 \%)$ & $7(4 \%)$ & $\mathrm{p}=0.026$ \\
\hline $\begin{array}{l}\text { Inability to stand from a } \\
\text { chair without using arms to } \\
\text { push up }\end{array}$ & $56(42 \%)$ & $68(36 \%)$ & $\mathrm{p}=0.258$ \\
\hline $\begin{array}{l}\text { Symptoms of dizziness on } \\
\text { standing }\end{array}$ & $53(40 \%)$ & $54(28 \%)$ & $\mathrm{p}=0.029$ \\
\hline Use of a mobility aid & $37(28 \%)$ & $50(26 \%)$ & $\mathrm{p}=0.774$ \\
\hline $\begin{array}{l}\text { Housebound/not } \\
\text { housebound } \\
\text { (mobility impairment) }\end{array}$ & $18(13 \%)$ & $28(15 \%)$ & $\mathrm{p}=0.755$ \\
\hline High risk of falls & $74(55 \%)$ & $86(45 \%)$ & $\mathrm{p}=0.070$ \\
\hline
\end{tabular}

\subsubsection{Describing the occurrence of falls}

A total of 191 falls were recorded in 3072 returned diaries. The annual falls rate was $746 / 1000$ person-years ( 0.75 per person-year). Table 2.9 shows the number of falls and type of fall by the different diary return groups (those with complete follow up vs. all participants). 
Table 2.9 Number of participants with falls, rate of falls, risk category, recurrent falls and injurious falls by diary return category

\begin{tabular}{|l|l|l|}
\hline & $\begin{array}{l}\text { Returned all diaries } \\
{[\mathrm{n}=134]}\end{array}$ & $\begin{array}{l}\text { All participants } \\
{[\mathrm{n}=322]}\end{array}$ \\
\hline Number at high risk (\%) & $74(55 \%)$ & $158(49 \%)$ \\
\hline $\begin{array}{l}\text { At least one fall in follow up } \\
\text { period } \% \text { \% }\end{array}$ & $47(35 \%)$ & $96(30 \%)$ \\
\hline $\begin{array}{l}\text { Rate of falls per person-year } \\
\text { (Poisson, 95\% CI) }\end{array}$ & $\begin{array}{l}0.35 \\
(95 \% \mathrm{CI} 0.26-0.47)\end{array}$ & $\begin{array}{l}0.39 \\
(95 \% \mathrm{CI} 0.31-0.47)\end{array}$ \\
\hline $\begin{array}{l}\text { Had more than 1 fall in } \\
\text { follow up period (\%) }\end{array}$ & $24(18 \%)$ & $43(13 \%)$ \\
\hline $\begin{array}{l}\text { Had injurious fall in follow up } \\
\text { period (\%) }\end{array}$ & $26(19 \%)$ & $56(17 \%)$ \\
\hline
\end{tabular}

The data in Table 2.9 demonstrate the effect of including those participants with incomplete diary returns, who were at lower risk of falls as shown in Table 2.8, namely an attenuation of adverse falls related outcomes.

\subsubsection{Falls by risk group}

Considering those who returned all 12 diaries $(n=134), 37 / 74(50 \%)$ of those at high risk fell at least once, compared to $10 / 60(17 \%)$ at low risk; odds ratio 5.0 (95\% CI 2.1-12.6, Fisher's exact (2-sided) $p=0.0001$. For all participants surviving at 12 months $(n=322), 66 / 158(42 \%)$ high risk versus $30 / 164(18 \%)$ low risk participants reported at least one fall, odds ratio 3.2 (95\% CI 1.9-5.5), Fisher's exact (2-sided) $p<0.0001$. This is likely to be a biased estimate, as many of those alive at 12 months did not complete all 12 diaries and are at lower risk than those that did complete all twelve diaries.

The rate of falls in the high risk group (using data from all diaries returned) was 1.2 (95\% CI $1.0-1.4)$ compared to 0.3 (95\% CI $0.25-0.46)$ falls per person-year in the low risk group, incidence rate ratio 3.4 (95\% CI 2.54.6), $\mathrm{p}<0.0001$. 


\subsubsection{Predictive properties}

The predictive properties concern events over one year (12 diaries), so those with incomplete diaries were excluded from this analysis. A risk score was calculated by adding individual risk factors to create a continuous risk score (range 0-8). The area under the curve (AUC) was 0.68 and the optimal cut-off was at three or more risk factors, correctly classifying $69.2 \%$ of participants (Table 2.10 ). Although the cut-off $(\geq 2)$ chosen for the entry into the RCT correctly classifies fewer people (65\%), it does have slightly higher sensitivity (79\%), which means that it correctly identified more people at high risk that went on to have a fall. But the trade off is the reduced specificity $(57 \%)$, indicating that fewer people who did not have a fall were correctly identified as being at low risk.

Table 2.10 Predictive properties of the falls risk tool

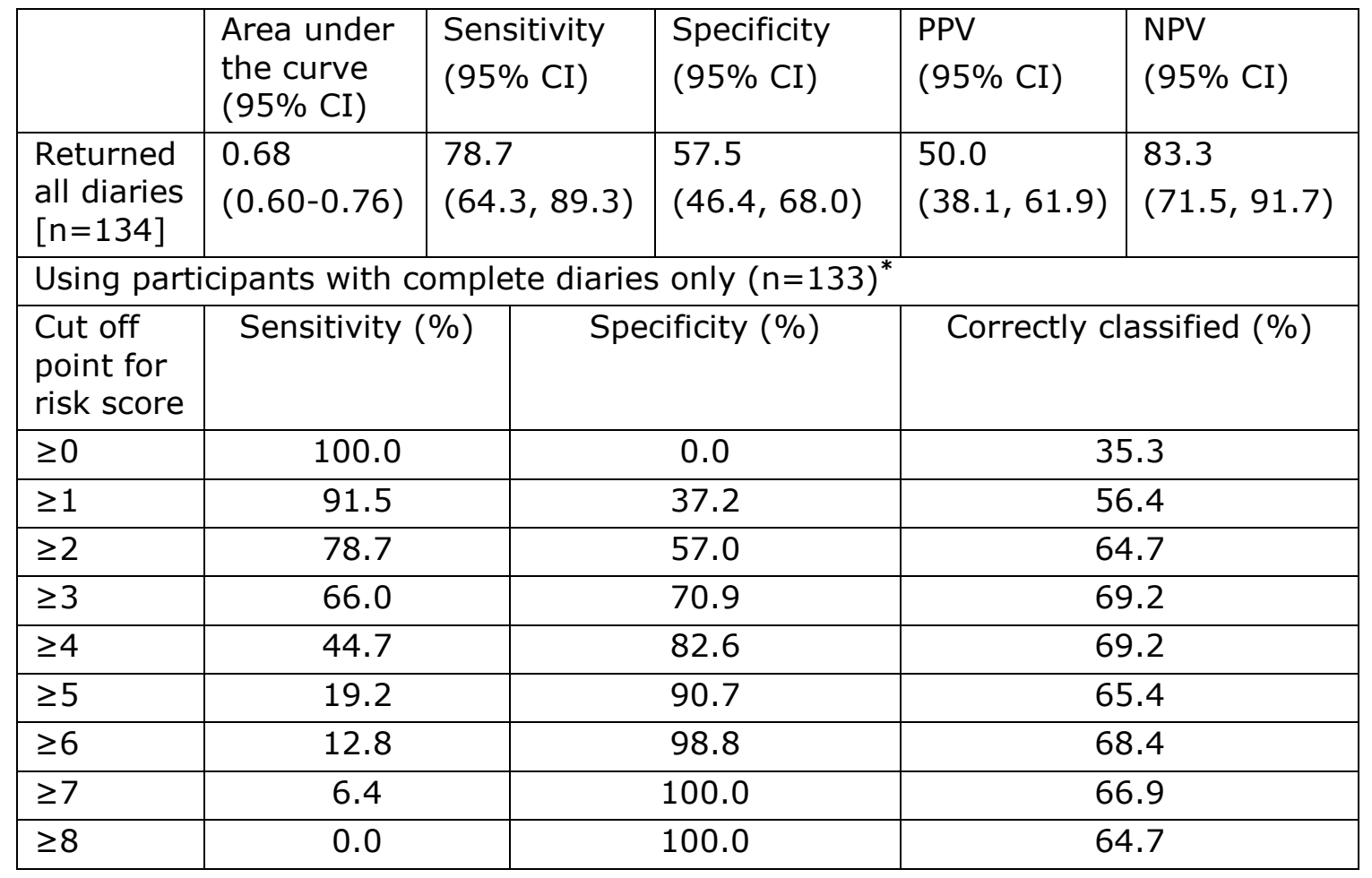

* note 1 person had data missing on dizziness on standing which excluded them from this analysis but not from analysis based on categorised risk score, as response to dizziness would not have altered their risk category 
A ROC analysis using previous fall as the predictor (sensitivity $46 \%$, specificity $85 \%$, PPV 56\%, NPV 79\%) compared to the risk score is shown in Figure 2.4, which shows that previous fall has almost identical ROC characteristics compared to the more complicated risk score. Indeed the confidence intervals for the areas under the curve show that the two models overlap: risk score AUC 0.69 (95\% CI 0.63-0.75) compared to previous fall AUC 0.65 ( $95 \%$ CI $0.60-0.71)$.

Figure 2.4 ROC curves comparing risk score and previous fall only

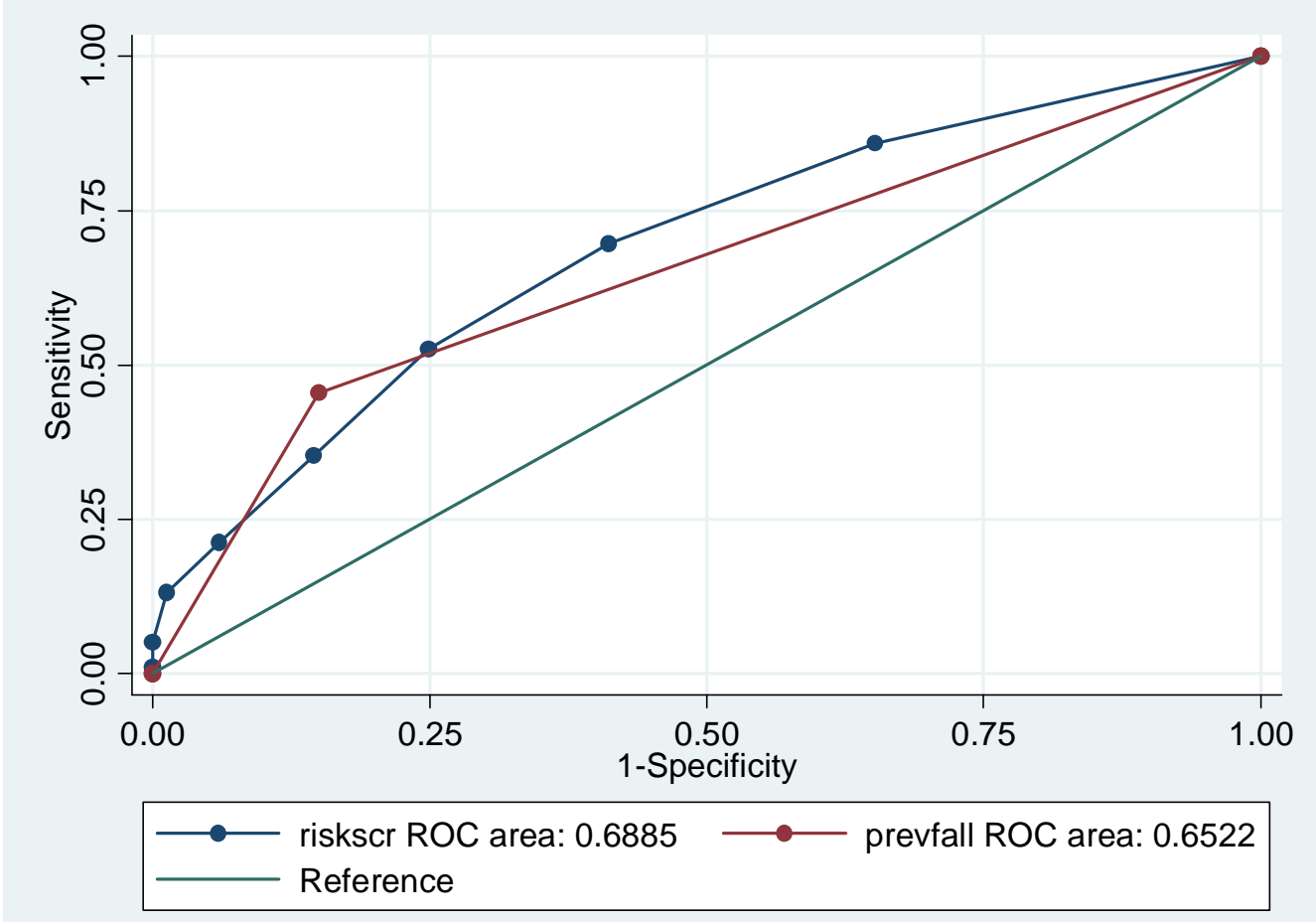

\subsubsection{Sensitivity analyses using imputed data}

Those without complete follow up data were excluded from the primary analysis described above, because of the risk of introducing bias. However, the data from those individuals completing less than 12 diaries was used in a sensitivity analysis carried out on an imputed dataset, the results are shown in Table 2.11. These data illustrate the effect of including those participants without complete follow up data, who were at overall lower risk. Even using the multiple imputation model, which attempts to correct 
for baseline variables, there were fewer falls, with a correspondingly lower positive predictive value. This means that the imputed model is still biased and the data are not representative of the population with complete follow up. So the best estimate available from the cohort study is the primary analysis based on those with complete follow up only, even though with relatively small numbers the confidence intervals are wide. 
Table 2.11 Predictive properties comparing imputed data against original data

\begin{tabular}{|c|c|c|c|c|c|c|}
\hline & $\begin{array}{l}\text { Prevalence } \\
\text { of falls }\end{array}$ & $\begin{array}{l}\text { Sensitivity } \\
(95 \% \mathrm{CI})\end{array}$ & $\begin{array}{l}\text { Specificity } \\
(95 \% \text { CI) }\end{array}$ & $\begin{array}{l}\text { PPV } \\
(95 \% \mathrm{CI})\end{array}$ & $\begin{array}{l}\text { NPV } \\
(95 \% \mathrm{CI})\end{array}$ & $\begin{array}{l}\text { Area under the } \\
\text { curve } \\
(95 \% \mathrm{CI})\end{array}$ \\
\hline $\begin{array}{l}\text { Returned all } \\
\text { diaries } \\
{[n=134]}\end{array}$ & $35.1 \%$ & $\begin{array}{l}78.7 \\
(64.3-89.3)\end{array}$ & $\begin{array}{l}57.5 \\
(46.4-68.0)\end{array}$ & $\begin{array}{l}50.0 \\
(38.1-61.9)\end{array}$ & $\begin{array}{l}83.3 \\
(71.5-91.7)\end{array}$ & $\begin{array}{l}0.68 \\
(0.60-0.76)\end{array}$ \\
\hline $\begin{array}{l}\text { Imputed } \\
\text { data }\end{array}$ & $29.7 \%$ & $\begin{array}{l}68.9 \\
(66.0-71.6)\end{array}$ & $\begin{array}{l}59.1 \\
(57.1-61.0)\end{array}$ & $\begin{array}{l}41.5 \\
(39.2-43.9)\end{array}$ & $\begin{array}{l}81.8 \\
(80.0-83.6)\end{array}$ & $\begin{array}{l}0.64 \\
(0.62-0.66)\end{array}$ \\
\hline \multicolumn{7}{|c|}{ Imputed dataset } \\
\hline $\begin{array}{l}\text { Cut off point } \\
\text { for risk score }\end{array}$ & \multicolumn{2}{|c|}{ Sensitivity (\%) } & \multicolumn{2}{|c|}{ Specificity (\%) } & \multicolumn{2}{|c|}{ Correctly classified (\%) } \\
\hline$\geq 0$ & \multicolumn{2}{|r|}{100.0} & \multicolumn{2}{|r|}{0.0} & \multicolumn{2}{|r|}{29.7} \\
\hline$\geq 1$ & \multicolumn{2}{|r|}{85.4} & \multicolumn{2}{|r|}{35.2} & \multicolumn{2}{|r|}{50.1} \\
\hline$\geq 2$ & \multicolumn{2}{|r|}{68.8} & \multicolumn{2}{|r|}{58.9} & \multicolumn{2}{|r|}{61.8} \\
\hline$\geq 3$ & \multicolumn{2}{|r|}{52.2} & \multicolumn{2}{|r|}{74.7} & \multicolumn{2}{|r|}{68.0} \\
\hline$\geq 4$ & \multicolumn{2}{|r|}{34.3} & \multicolumn{2}{|r|}{85.5} & \multicolumn{2}{|r|}{70.3} \\
\hline$\geq 5$ & \multicolumn{2}{|r|}{20.8} & \multicolumn{2}{|r|}{94.3} & \multicolumn{2}{|r|}{72.5} \\
\hline$\geq 6$ & \multicolumn{2}{|r|}{12.5} & \multicolumn{2}{|r|}{98.7} & \multicolumn{2}{|r|}{73.1} \\
\hline$\geq 7$ & \multicolumn{2}{|r|}{4.2} & \multicolumn{2}{|r|}{100.0} & \multicolumn{2}{|r|}{71.5} \\
\hline$\geq 8$ & \multicolumn{2}{|r|}{0.0} & \multicolumn{2}{|r|}{100.0} & & 70.3 \\
\hline
\end{tabular}




\subsubsection{Secondary outcomes}

Clerical error and loss to follow-up resulted in missing data for some of the functional outcomes, as detailed below:

- EuroQoL (301/325)

- Barthel index of daily living (301/325)

- Nottingham Extended Activities of Daily Living (304/325)

- Falls Efficacy Scale (269/325).

The ADL, FES and QoL scores were not normally distributed and suitable transformations could not be found. They were therefore dichotomised at or above the median value., depending on the number in each group in order to ensure a balanced distribution.

We compared activities of daily living (ADL), fear of falling (FES) and quality of life (QoL) between fallers and non fallers (based on complete diaries) and between those at high and low risk of falls (based on all participants) Table 2.12. These shown that fallers have substantially reduced function, both basic and advanced, increased fear of falling and worse quality of life compared to non-fallers. 
Table 2.12 Functional outcomes by fall or fall risk status (complete diaries)

\begin{tabular}{|c|c|c|c|c|c|c|}
\hline & $\begin{array}{c}\text { Fallers } \\
\text { Median } \\
\text { score }(I Q R)\end{array}$ & $\begin{array}{l}\text { Non } \\
\text { fallers } \\
\text { Median } \\
\text { score } \\
\text { (IQR) }\end{array}$ & $\begin{array}{l}\text { Odds ratio for median score } \\
\text { or above comparing fallers } \\
\text { to non fallers } \\
\qquad(95 \% \mathrm{CI})\end{array}$ & $\begin{array}{l}\text { High risk of } \\
\text { falls } \\
\text { Median score } \\
\quad(\text { IQR })\end{array}$ & $\begin{array}{l}\text { Low risk } \\
\text { of falls } \\
\text { Median } \\
\text { score } \\
\text { (IQR) }\end{array}$ & $\begin{array}{l}\text { Odds ratio for median } \\
\text { score or above } \\
\text { comparing those at high } \\
\text { and low risk of falls } \\
(95 \% \mathrm{CI})\end{array}$ \\
\hline $\begin{array}{c}\text { Barthel } \\
\text { Median } 20\end{array}$ & $\begin{array}{c}19 \\
(18,20)\end{array}$ & $\begin{array}{c}20 \\
(19,20)\end{array}$ & $\begin{array}{c}0.39 \\
(0.19,0.82) \\
P=0.013\end{array}$ & $\begin{array}{c}19 \\
(18,20)\end{array}$ & $\begin{array}{c}20 \\
(20,20)\end{array}$ & $\begin{array}{c}0.18 \\
(0.11,0.30) \\
P<0.001\end{array}$ \\
\hline $\begin{array}{c}\text { NEADL } \\
\text { Median } 61\end{array}$ & $\begin{array}{c}52 \\
(36,63)\end{array}$ & $\begin{array}{c}63 \\
(56,63)\end{array}$ & $\begin{array}{c}0.38 \\
(0.18,0.79) \\
P=0.010\end{array}$ & $\begin{array}{c}52.5 \\
(38.75,61.25)\end{array}$ & $\begin{array}{c}63 \\
(60,66)\end{array}$ & $\begin{array}{c}0.15 \\
(0.09,0.25) \\
P<0.001\end{array}$ \\
\hline $\begin{array}{c}\text { FES } \\
\text { Median } 10\end{array}$ & $\begin{array}{c}15 \\
(10,23.5)\end{array}$ & $\begin{array}{c}10 \\
(10,12)\end{array}$ & $\begin{array}{c}3.42 \\
(1.52,7.71) \\
P=0.003\end{array}$ & $\begin{array}{c}13 \\
(10,24.3)\end{array}$ & $\begin{array}{c}10 \\
(10,10)\end{array}$ & $\begin{array}{c}6.60 \\
(3.8,11.4) \\
P<0.001\end{array}$ \\
\hline $\begin{array}{l}\text { EuroQoL } \\
\text { Median } 6\end{array}$ & $\begin{array}{c}8 \\
(6,9)\end{array}$ & $\begin{array}{c}6 \\
(5,7)\end{array}$ & $\begin{array}{c}3.60 \\
(1.68,7.73) \\
P=0.001\end{array}$ & $\begin{array}{c}7 \\
(6,9)\end{array}$ & $\begin{array}{c}6 \\
(5,7)\end{array}$ & $\begin{array}{c}4.21 \\
(2.60,6.86) \\
P<0.001\end{array}$ \\
\hline
\end{tabular}


Table 2.12 compares activities of daily living, fear of falling and quality of life between fallers and non-fallers (based on participants who returned all diaries or had a fall recorded in at least one returned diary) and between those at high and low risk of falls. The data show that falls risk also identified those with reduced function, increased fear of falling and worse quality of life.

Table 2.13 shows the same outcomes, but also includes the imputed dataset. The findings of falls and falls risk being associated with adverse outcomes holds true in the imputed dataset, albeit with some attenuation of the effect size.

Table 2.13 Functional outcomes according to fall status and falls risk, by diary returns and using imputed data

\begin{tabular}{|c|c|c|c|c|}
\hline & \multicolumn{2}{|c|}{ Fallers vs. non fallers } & \multicolumn{2}{|c|}{ High vs. low risk } \\
\hline & $\begin{array}{c}\text { OR complete } \\
\text { diaries } \\
(95 \% \mathrm{CI})\end{array}$ & $\begin{array}{l}\text { Odds ratio } \\
\text { imputed data } \\
(95 \% \mathrm{CI})\end{array}$ & $\begin{array}{c}\text { OR complete } \\
\text { diaries } \\
(95 \% \mathrm{CI})\end{array}$ & $\begin{array}{l}\text { Odds ratio } \\
\text { imputed data } \\
(95 \% \mathrm{CI})\end{array}$ \\
\hline $\begin{array}{l}\text { Barthel } \\
\text { score }\end{array}$ & $\begin{array}{c}0.39 \\
(0.19,0.82) \\
p=0.013\end{array}$ & $\begin{array}{c}0.77 \\
(0.47,1.27) \\
p=0.306\end{array}$ & $\begin{array}{c}0.18 \\
(0.11,0.30) \\
p<0.001\end{array}$ & $\begin{array}{c}0.18 \\
(0.11,0.30) \\
p<0.001\end{array}$ \\
\hline NEADL & $\begin{array}{c}0.38 \\
(0.18,0.79) \\
p=0.010\end{array}$ & $\begin{array}{c}0.50 \\
(0.31,0.82) \\
p=0.006\end{array}$ & $\begin{array}{c}0.15 \\
(0.09,0.25) \\
p<0.001\end{array}$ & $\begin{array}{c}0.15 \\
(0.09,0.24) \\
p<0.001\end{array}$ \\
\hline FES & $\begin{array}{c}3.42 \\
(1.52,7.71) \\
p=0.003\end{array}$ & $\begin{array}{c}1.99 \\
(1.17,3.38) \\
p=0.011\end{array}$ & $\begin{array}{c}6.60 \\
(3.8,11.4) \\
p<0.001\end{array}$ & $\begin{array}{c}8.51 \\
(5.04,14.39) \\
p<0.001\end{array}$ \\
\hline EuroQoL & $\begin{array}{c}3.60 \\
(1.68,7.73) \\
p=0.001\end{array}$ & $\begin{array}{c}2.04 \\
(1.21,3.45) \\
p=0.007\end{array}$ & $\begin{array}{c}4.21 \\
(2.60,6.86) \\
p<0.001\end{array}$ & $\begin{array}{c}4.49 \\
(2.76, \quad 7.31) \\
p<0.001\end{array}$ \\
\hline
\end{tabular}




\subsection{Discussion}

\subsubsection{Summary}

We recruited 335 older people into the cohort study; the screening population are very similar in terms of baseline characteristics to those who declined to participate.

The modified FRAT, consists of eight simple questions, can be sent out as a postal questionnaire ( $54 \%$ response rate), has reasonable face validity and good to very good test-retest reliability. The construct validity of the tool is demonstrated by the increased number of fallers in the high risk group compared to the low risk group (odds ratio 5).

The predictive properties of the tool are reasonable: sensitivity $79 \%$ and specificity $58 \%$. The positive predictive value of $50 \%$ indicates that for every two people identified as being at high risk, one would go onto to have a fall in the following year. The $83 \%$ negative predictive value means that of those screened as being at low risk, approximately on in six will go on to have a fall, but five out of six will not have a fall.

However, the predictive properties of this relatively simple tool were not significantly better than just using previous fall alone as the predictor for future fall (risk score AUC 0.69 (95\% CI 0.63-0.75) compared to previous fall AUC 0.65 (95\% CI $0.60-0.71)$ ). The positive predictive value using previous fall alone is slightly better than using the screening tool ( $56 \%$ versus $50 \%$ ), but the negative predictive value is lower ( $79 \%$ versus $83 \%)$. Using previous fall as the sole identifier, slightly more than one in two people classified at high risk would go onto fall, but one in five of those classified at low risk would fall - compared to one in six using the screening tool. 
Fallers had reduced function as measured by the Barthel and the NEADL, than non-fallers at twelve months. The magnitude of this effect was similar for both extended and basic activities of daily living (odds ratio 0.4, $p<0.02)$. Fallers also had a three-fold increased in fear of falling (OR 3.3, $p=0.003)$. Linked to the increase in fear of falling and reduced function is the worse quality of life in people who had fallen. We used the EuroQoL to measure quality of life, which comprise five domains (mobility, self-care, daily activities, pain and mood) each with three levels of response (no problem - 0, some/moderate difficulty - 1 and unable/extreme difficulty 2). This study showed a three-four fold worsening of self rated quality of life in fallers (OR 3.6, $p=0.001$ ).

The finding that quality of life was worse in people who have fallen (median 8 versus 6 on a 12 point scale) holds for the mobility domain within the EuroQoL (median 2 versus 1 ) in this study. It appears that we have affirmed the fall-reduced function-fear of falling-reduced quality of life theory in this cohort study. This further supports the construct validity of this screening tool, demonstrating the expected association between falls, reduced function, fear of falling and reduced quality of life.

\subsubsection{Strengths and limitations}

The strengths of this study include the prospective design, the monthly ascertainment of falls, and the collection of an array of secondary outcomes at follow up.

Those at high risk in the screening cohort were slightly less likely to have fallen compared to all those with baseline data. Those at high risk and having fallen who agreed to participate were differentially recruited into the RCT rather than the screening cohort. This makes the screening cohort somewhat unrepresentative. Ideally, the cohort study validating the screening tool should have been carried out prior to the RCT (i.e. in series 
rather than in parallel), but resources (namely time) were insufficient to allow this process. It is not possible to be certain in which direction this bias may have affected the result, but it is reasonable to hypothesise that it led to an underestimate of the true falls prevalence in the high risk group in the screening cohort. This would have the effect of reducing the sensitivity and the positive predictive value of the screening tool.

There is clearly an issue around those participants who returned incomplete diaries, and the comparisons in Table 2.8 and section 2.7.5.1 suggest that they were at slightly lower risk of falls than those that completed the study.

We carried out a sensitivity analyses to determine the robustness of the results based on the smaller sample of 134 participants completing 12 months of follow up. This included all participants alive at 12 months; this slightly underestimated falls prevalence (30\%) (Table 2.11$)$. The complete dataset based on 134 participants is small, with correspondingly wide confidence intervals around the various estimates. The imputed dataset appears to offer biased estimates, and so cannot be used to refine the estimate seen in the original dataset. The analysis of those with complete follow up is consistent with other similar studies (see below).

It would have been possible to increase the number of high risk individuals used to validate the screening tool by including those assigned to the control group of the RCT in the analysis of the predictive properties of the screening tool. However, this was not done as the follow-up diaries used in ascertaining falls outcomes were different in the two studies and there were concerns that the different reporting (more detailed in the RCT) may have led to differential reporting and bias. Also, as discussed above, those participating in the RCT may be in some way different to those at high risk agreeing only to the cohort study, creating further risk of bias. 


\subsubsection{Comparisons with previous studies}

The predictive properties of the screening tool were measured using the area under the curve (AUC 0.68 using the 134 participants with complete follow up). This compares favourably to other falls screening tools -0.65 from Tromp et $a l^{201}, 0.71$ from Pluijm et $a l^{146}$ and $\sim 0.70$ from Nandy et $a l^{158}$. A slightly better score could have been obtained if we had used three or more individual risk factors as the cut off (AUC 0.73).

The finding of reduced basic and extended functional ability in fallers is consistent with previous reports of worse function leading to admission to long term care in people who have fallen ${ }^{129}$; however, as we did not measure function at baseline, we cannot be sure that this relationship is causal. Given that $18 \%$ people who fell had more than one fall, and that nearly $20 \%$ of falls were injurious, it is reasonable to hypothesise that falls cause reduced function. There was also a three-fold increase in fear of falling in fallers compared to non-fallers, which may also have contributed to the reduced function, as has been shown other studies ${ }^{70} 71$.

The worse quality of life measured in people who had fallen is consistent with previous studies ${ }^{70} 71$ 325-328 which have demonstrated a link between fear of falling, functional impairment and a reduction in quality of life in people who have fallen. Indeed $80 \%$ of women asked would rather be dead than experience the loss of independence and quality of life that results from a [fall,] bad hip fracture and subsequent admission to a nursing home $^{329}$. The reduced quality of life is thought to be mediated through a loss of autonomy $y^{330}$, and fear of falling leading to restricted activity and reduced social interaction.

Falls efficacy is the belief that an individual can master falling and so despite having fallen, has the confidence to continue activities; fallers in this study has a substantial increase in fear of falling, measured using the 
Falls Efficacy Scale. Also linked to fear of falling and quality of life are individuals' expectations - people who have fallen may have lower expectations and are 'pleasantly surprised' by their perceived quality of life; one paper examined this theory and did not find evidence to support this adaptive theory in older fallers ${ }^{331}$. In a related sub-study carried out in parallel to this screening study, it was found that low self-efficacy for falls was linked to negative outcome expectation to falls, further casting doubt of the adaptive approach (I Clonis, personal communication).

\subsubsection{Generalisability}

The proportion of people with a fall in the previous 12 months at baseline $(28 \%)$ is in keeping with previous estimates of falls prevalence in UK populations (see 1.2$)$. The fall rate during follow up ( 0.75 falls per personyear) is higher than estimates of falls rates from UK primary care records ${ }^{37}$, which tend to underestimate falls, but below the lower end of the range for international estimates for falls rates in community dwelling older people, mainly based on intervention studies (1.1-1.8 falls per personyear). This suggests that the cohort studied is reasonably representative, at least in comparison to previous studies of fall in community dwelling older people. The subsequent fall prevalence of $35 \%$ over one year, using monthly diaries, is consistent with other studies which have shown that more careful ascertainment results in more falls being recorded, typically reporting annual falls prevalence using weekly or monthly diaries of around $33 \%{ }^{142526}$.

\subsubsection{Interpretation}

We have developed a screening tool which is valid, reliable and generalisable. It is easy to use in the primary care setting, and can be completed by post, with a reasonable response rate (54\%). It could be equally well completed at a routine primary care visit. The predictive 
properties of the tool are as good (sensitivity $79 \%$ and specificity $58 \%$ ), if not better than previously published falls screening tools (FRAT ${ }^{158}$ sensitivity $42 \%$, specificity $92 \%$ ). The tool performs slightly better than just using previous falls to identify those at risk, mainly because of its superior negative predictive value - this has important implications in terms of the cost-effectiveness and acceptability of the subsequent intervention. Falls prevention programmes are expensive, requiring multiple team members delivering an intervention over several weeks, so need to be targeted at those most likely to benefit if they are to be clinically and cost-effective. However, from a practical perspective, using previous fall alone is very simple and has similar predictive properties compared to the screening tool. Aside from the tool's ability to identify those at risk of future fall, it also identifies a cohort at risk of functional decline and reduced quality of life, and so may be useful method of targeting older people in the primary care setting for interventions aimed at maintaining their independence. Such interventions, generally known as comprehensive geriatric assessment, have shown benefit in primary care settings for frail older people with a variety of geriatric syndromes, not just falls $332-334$.

What is not known, at least in the UK setting, is if a multifactorial intervention to prevent falls provided to individuals identified as being at high risk of falls using this screening tool offers any benefit. 


\section{RANDOMISED CONTROL TRIAL}

\subsection{Overview}

In chapter one, the evidence supporting the clinical effectiveness of a multifactorial intervention to reduce the rate of falls was presented. The case was made for screening for falls in the primary care setting, with the aim of identifying individuals who are at risk of falls or who have already fallen but have not presented to health services. Screening methodology and results showing that a screening tool is effective in identifying such high risk individuals was discussed in chapter two. In this chapter, the methodology, results and implications of a randomised controlled trial of a falls prevention programme applied to the high risk population are discussed.

\subsection{Design considerations}

\subsubsection{Evaluating complex interventions}

A multifactorial intervention such as that used to manage people who have fallen, can be considered a complex intervention according to the MRC framework $^{335}$ (note this has been updated since this work was started ${ }^{336}$ ). When evaluating such complex interventions, it is essential that the individual ingredients are clearly defined, so as to allow reproducibility. Furthermore, it is important to try and determine the relationship between the various components - to unpick the 'black box'.

The MRC suggest a series of developmental steps which are required to clearly define the nature of a complex intervention ${ }^{335}$ :

- pre-clinical - exploring the relevant theory

- phase I - modelling the individual components, developing an understanding of their mechanisms and their interdependency 
- phase II - exploratory trial to describe the constant and variable components of the intervention with a view to defining the protocol for a definitive comparison

- $\quad$ phase III - definitive RCT

- $\quad$ phase IV - long term implementation - assessing if the intervention can be delivered successfully in other settings.

This process is long and requires multiple separate studies. The plethora of positive RCTs on falls prevention detailed in section 1.5 suggested that the essential ingredients of falls prevention programmes have been elucidated. However, the purpose of this study is to evaluate the complex intervention in a different population and setting to that which has previously been studied in the United Kingdom (i.e. the screened population, managed in the day hospital) - though several international studies have already carried out this work in a 'high risk populations 1012217224225 .

The definition of the complex intervention intended to be delivered in this study is detailed in section 3.5, but in brief consisted of a medical review, strength and balance training and a home hazards assessment. We attempted to assess whether the intended intervention were being delivered as planned using behavioural mapping and an audit of activity in the falls prevention programme, detailed in appendix 1.1 .

\subsubsection{External comparability}

Given that there have been several previous clinical trials evaluating falls prevention programmes, it is important that the results of this trial can be interpreted in context - in terms of what this trial can add to the literature. A critical appraiser reviewing this trial will examine various aspects of trial conduct to determine if the results are a useful addition to the literature. A variety of critical appraisal tools have been developed which allow the 
appraiser to carry out this process in a systematic manner ${ }^{337}$, and in designing a trial, it is helpful to consider these criteria.

\subsubsection{Internal validity}

Internal validity asks the question 'do these results represent an unbiased estimate of the treatment effect, or have they been influenced in some systematic fashion to lead to a false conclusion? ${ }^{\prime 338}$. Fundamental aspects of the internal validity of a randomised controlled trial concern randomisation and group balance, participant allocation and follow up, blinding, and isolation of the experimental intervention.

\subsubsection{Randomisation}

Randomised controlled trials (RCTs) are considered to be the most rigorous of clinical trials ${ }^{281339}$ because in theory there should be no difference between the control and intervention groups except the treatment being tested. Randomised controlled trials are designed to avoid sampling bias (a form of selection bias), a weakness of case-control and cohort studies, but are still open to non-response bias, a different form of selection bias. This is why it is important to use intention to treat analysis, which analyses individual based on allocation, irrespective of whether or not the participants actually received the allocated treatment ${ }^{340}$. Pre-specified per protocol analyses can be carried out to examine outcomes such as adverse events.

Randomisation should ensure that known and unknown confounding factors are equally allocated between groups. However, because participants are allocated to control or intervention groups randomly, it is possible that baseline imbalances between the groups can arise by chance. It is recommended that important prognostic variables are recorded for each group at baseline ${ }^{341}$, allowing a comparison to be made between groups, 
and then if there are any major imbalance, these can be adjusted for at the analysis stage.

However, it is not clear how such imbalances should be evaluated; testing for statistical significance between the groups might be used, but the question remains, is a statistically significant difference a reflection of a failure of randomisation, or is it a chance finding and should the analyses be adjusted ${ }^{342}$ ? This issue is all the more important when combining trials with various baseline imbalance in a meta-analysis ${ }^{343}$. To overcome this uncertainty in handling baseline imbalances, several groups have suggested the following strategies 342344345 :

1. at the planning stage of a study baseline variables of prognostic value should be identified on the basis of available evidence.

2. these should be fitted in an analysis of covariance or equivalent technique for other data types.

3. other variables should not be added to the analysis unless information from other sources during the course of the trial suggests their inclusion.

Approaches 1 and 2 are supported by other groups - Pocok et $a l^{346}$, Hauck et $a l^{347}$ who suggest adjusting for prognostically important baseline variables, whether they are imbalanced or not. Also supporting this approach, Hernndez et $\left.a\right|^{348}$ further demonstrated that adjusting for baseline covariates improves the power of a clinical trial.

Some investigators have questioned whether randomised studies are always preferable to non-randomised studies. Arguments in favour of nonrandomised studies exist where the effect of the intervention is so obviously dramatic (such as defibrillation for ventricular fibrillation), or 
where the size, duration and cost of a randomised trial outweighs the potential benefits of identifying rare adverse events ${ }^{349}$.

The 'gold standard' RCT is the double-blind placebo controlled drug trial, in which the only variance between groups is the intervention under effect and the placebo is identical in appearance, taste and smell to the intervention. The classic example is a drug trial, in which sugar pills are given in place of the intervention medication; other examples include sham treatments or psychological placebos (e.g. talking versus counselling). Even in these circumstances, it is has been suggested that there is a beneficial effect from a placebo, particularly where the outcome is a continuous measure rather than a binary outcome ${ }^{350}$. Moreover, some placebos lead to better outcomes than others - a clinical trial comparing a pill placebo against a sham treatment placebo found that self-reported pain (using a continuous pain scale) was more effective than the pill placebo ${ }^{351}$. Reasons cited for why the placebo effect might confer benefit are regression to the mean (e.g. the natural history of hypertension is for it to fall after an initial consultation), the effect of time (e.g. operator skill improves, natural history of the condition is one of improvement) and unidentified parallel interventions ${ }^{352}$.

Allocation concealment can be especially difficult when it is not possible to blind participants to the intervention, a common feature of many therapy intervention trials. There the therapist factors: is it the therapist's attitude, charisma or communication skills, or the therapy technique which they are using that is being tested? The participant is not blinded to the fact that they are receiving the intervention, and so may be anxious to please the investigators, thus introduce reporting bias into their replies to outcome measures. 


\subsection{Methods of random allocation}

Random allocation between the arms of a trial aims to ensure that there is no sampling bias introduced by the investigators, but should also ensure that any bias due to unknown effects is addressed. In a blinded RCT, it is imperative that the allocation to the arms of the study is truly concealed, so as not to introduce any bias ${ }^{353}$. This relies upon careful concealment of the allocation groups from the investigators, without which treatment effects may be artificially elevated ${ }^{354}$.

Various techniques have been used to conceal the allocation from the investigator, ranging from the use of sealed envelopes (least reliable and prone to tampering), through to telephone or web-based randomisation sequences. Even the latter are prone to subversion, depending on the nature of the allocation sequence.

The simplest form of randomisation is to toss a coin - heads being one group, tails another. A problem with this method is that it is prone to tampering or it might be possible for the investigator to guess which group the next participants will be allocated, and this in turn could lead to bias.

A more sophisticated approach is to generate a series of random numbers, with even numbers indicating one group and odd numbers the other. Because the list is randomly generated, it is less predictable. Stratified randomisation allocates participants randomly within blocks according to important characteristics, such as age or location.

Block randomisation (or restriction), can be used to try and keep the numbers in each group equal, but allows the investigator to guess the allocation of the last participant in that block. To overcome this, random permutated block sequences can be used ${ }^{355}$; with this technique (Hadamard Randomization), the allocation sequence is contained within 
random block sizes, which make it difficult for an observer to guess the next allocation.

Minimisation is a more refined approach and allows multiple potential confounding factors to be taken into account; but a problem with minimisation is that the group size can be very small ${ }^{356}$.

\subsection{Alternative randomisation procedures}

In un-blinded RCTs, participants allocated to the control group may not be happy, having been made aware during the consent process that a new (as yet unproven) treatment is being offered to the intervention group - this may lead to poor compliance and/or reporting bias. Recognising this dilemma, Zelen proposed an alternative strategy in which participants are consented after they have been randomised ${ }^{357}$. In Zelen's single consent process, those allocated to the intervention are told of alterative therapies, but those in the control group are not told about the intervention; analysis is per the original allocation. In the double consent design, participants are offered the initial randomisation arm treatments, but if they decline, they are then offered the alternative therapy; again analysis is by the original allocation. This technique is designed to help with compliance and adherence to follow up, so reducing sampling bias.

Zelen randomisation is controversial, but has been used in clinical trials such as those looking at screening, where it is especially important to avoid the 'Hawthorne effect', in which the presence of a trial may alter the behaviour of those in the control group. The practicalities of carrying out such research are challenging, and require follow up 'at a distance' such that the control group are not aware they are being monitored; this can be achieved through record linkage studies or registries ${ }^{358}$. Not obtaining consent from the control group (an ethical requirement) does mean that this design is only rarely used. 


\subsection{Public perceptions of randomisation}

Although the general public understand the concept of random allocation, they are not always persuaded of its appropriateness in the context of a clinical trial, which is partly due to difficulties accepting the notion of equipoise $^{359}$. Equipoise is a key factor in deciding if a randomised trial is appropriate - in the investigators mind there should be uncertainty about which treatment option is best. The lay public appear to believe that doctors should always know what is best - so there should be no equipoise in a clinical setting, though this is less of an issue in the context of a clinical trial ${ }^{359}$. This can make recruitment into clinical trials difficult; efforts to inform potential participants about the rationale for randomisation should focus on improving knowledge and understanding rather than clinical aspects of equipoise ${ }^{359}$.

\subsection{Randomisation - internal validity versus external validity} In the previous sections, some of the reasons why a randomised design might be chosen have been highlighted, namely to reduce bias. Another factor which makes RCTs sometimes difficult to interpret more broadly (external validity) is the entry process. There may be differing participation rates from one centre to another, differing practises from one centre to another or one practitioner to another - in other words, elucidating the precise components of a given intervention that can be extrapolated to the wider setting. The entry criteria for an RCT may be more rigorous and not reflect clinical practice, which is where non-randomised studies might have an advantage. The concerns that the public hold about randomisation (section 3.2.3.1.3) may also mean that those entering the trial may not be not representative of the population as a whole.

The external validity of RCTs can be addressed by having pragmatic entry criteria, which as much as possible reflect clinical practice, by using 
multiple centres (which allows comparison across different sites to see if any treatment benefit holds good in different settings) and minimal exclusion criteria.

\section{$\underline{\text { 3.2.3.2 }} \underline{\text { Bias }}$}

Bias is defined as 'any trend in the collection, analysis, interpretation, publication or review of data that can lead to conclusions that are systematically different from the truth ${ }^{281}$. The two main forms of bias are information bias and selection bias ${ }^{360}$. Publication bias refers to the tendency for negative trials not to be published ${ }^{361} 362363364365$, or for the publication to be delayed ${ }^{366}$; this is more of an issue for systematic reviews and meta-analyses than the internal validity of a trial. This is the rationale for international trial registries, discussed in section 3.11.1.

\subsection{Information bias}

Information bias is concerned with the misclassification of information gathered; this can be sub-divided into random and non-random misclassification. Random misclassification can be misclassification of the exposure independent of the outcome or vice versa; this form is nondifferential and the effect is to bias the measure of effect towards the null hypothesis.

Non-random (or differential) misclassification can bias associations in either direction. An example is recall bias, in which respondents either overreport or under-report an exposure; this is a particular problem in casecontrol studies, where cases and control may report exposure differently because of their disease status. Recall bias is best overcome by having objectively verifiable outcome or exposure measures (such as medically verified falls as compared to self reported falls). Recall bias can be further 
minimised by prospectively recording outcomes, rather than relying upon retrospective recall.

A second example is observer bias, in which the investigator interprets or gathers information differently in different groups. Observer bias can be reduced by using standardised outcome assessment measures, ensuring observers are rigorously trained, and through blinding. Blinding reduces bias that may be introduced by an awareness of the allocation group; trial participants can be blinded to the treatment that they are offered (singleblind trial).

Double-blinding is possible, where both the participants and the observers are unaware of treatment allocation; a typical example would be a doubleblind placebo controlled drug trial.

Finally, triple blinding is possible, where participants, observers and the analysts are blinded to allocation, with allocation only being revealed at the end of the analysis. Given the impracticality of blinding participants to allocation in this trial, the option available to reduce bias is to have the analysis blinded to the allocation group. This was achieved by having the allocation group recorded in a numeric code ( 0 or 1$)$ in the study database, rather than by allocation group (intervention or control).

\subsection{Selection bias}

Selection bias can be related to sampling (the initial choice of study participants) or loss to follow up; both are major challenges in longitudinal studies.

Sampling bias is a particular problem in case-control studies if the controls do not represent the population from which the cases are selected. For example, if we compared people who had fallen and attended the day hospital to people who had fallen and not attended the day hospital, there 
would be a high risk of sampling bias. Individuals attending the day hospital might be sicker or more frail than those not attending, and so any difference between the two groups may be related to the population rather than any intervention delivered in the day hospital. Other examples of selection bias include case series or cohort studies reporting a positive effect of a novel intervention compared to a group not receiving the novel intervention - which is in fact related to patient selection. An example would be patients selected for a novel surgical procedure, as the surgeon might choose the fitter patients, less likely to suffer complications which in turn lead to over inflated reported benefit from the intervention. But when equal populations are compared in a randomised controlled trial, the intervention may have minimal benefit or even cause harm.

Non-response bias (or loss to follow up) is a major issue, as nonresponders may be different in many ways (e.g. sicker, possibly dead) than responders. If non-responders are not included, there is a tendency to under-report adverse outcomes. For example, non-responders in this study may be individuals who have fallen and been hospitalised. Equally, nonresponders may be very well and not see the point of replying to questionnaires. In either case, loss to follow up can systematically alter the outcomes of the trial. Different strategies may be employed in the analysis stage to test for the effects of non-response bias (section 3.13.2).

\subsubsection{Precision}

The second aspect concerning the validity of clinical trials alluded to in Guyatt's statement (section 3.2.3) is precision - or the 'estimate of treatment effect', a key determinant of which is random error.

Random error is 'the divergence, due to chance alone, of an observation on a sample from the true population value, leading to a lack of precision in the measurement of an association ${ }^{301}$. Random error is related to 
sampling, as individual samples of a population will always vary and it possible that the samples selected are not representative of the population at large.

In a type I error (or alpha error), the null hypothesis is rejected when it is in fact true - there is no real difference between the study populations. This is related to the statistical significance of the outcome, conventionally measured as a p-value. Conventionally, a $p$-value of $<0.05$ is said to be statistically significant, but in reality, the probability of erroneously rejecting the null hypothesis is a continuous measure. A p-value of 0.04 means that the likelihood of obtaining a positive study result when the null hypothesis is in fact true is 4 in 100 . The level at which one is comfortable in accepting the statistical significance will depend on the actual study outcome and the context of the trial. It is important to be aware that the more statistical tests that are carried out, the greater the possibility of finding a statistically significant result by chance alone. This is why the trial outcomes should be defined in advance, so that accusations of 'datadredging' can be countered.

In a type II error (or beta error), the null hypothesis is accepted when it is in fact false. That is to say that the study result is negative, but the truth is that the true effect is positive. The likelihood of this form of error is related to the power of the study; the probability of a type II error is (1-power). The power of a study should be calculated in advance, using a statistical package (e.g. Stata or nQuery); typical acceptable values for the power of a study would include $80 \%, 90 \%$ or $95 \%$. If a trial is under-powered, and finds that there is no difference between the groups, it would be incorrect to state that the intervention is ineffective; it is the failure to demonstrate an effect ${ }^{367}$. A larger trial may go on to identify the effect. 


\subsection{Sample size (see Table 3.1)}

The eventual sample size of a study will be determined by the precision requirements and the power requirements. Precision is a measure of how wide the confidence intervals will be; power the chances of correctly identifying an effect of the intervention if one really exists. The sample size will be determined by the minimal clinically significant difference between the two arms of a trial that one would want to be able to detect.

Table 3.1 Types of random error

\begin{tabular}{|l|l|l|}
\hline & True situation \\
\hline Test result & Negative trial & Positive trial \\
\hline $\begin{array}{l}\text { Do not reject null } \\
\text { hypothesis (not } \\
\text { significant) }\end{array}$ & $\begin{array}{l}\text { (True result) } \\
\text { Probability }=1-a\end{array}$ & $\begin{array}{l}\text { Type II error } \\
\text { Probability }=\beta\end{array}$ \\
\hline $\begin{array}{l}\text { Reject null hypothesis } \\
\text { (significant) }\end{array}$ & $\begin{array}{l}\text { Type I error } \\
\text { Probability }=a\end{array}$ & $\begin{array}{l}\text { Power } \\
=1-\beta\end{array}$ \\
\hline
\end{tabular}

Aside from statistical considerations, sample size will also be determined by feasibility and financial restrictions. It may be that that the power calculation requires 100,000 participants, but a trial of this size would be logistically difficult to manage (probably resulting in relatively poor quality data collection) but also difficult to fund.

\subsubsection{Confounding}

Confounding exists where there is an alternative factor associated with the outcome which is also associated with the exposure. Confounding is a particular problem in non-randomised clinical trials. Whilst it may be possible to overcome confounding to some extent by measuring all known factors associated with the outcome, there will be factors which are not known that may influence the outcome. It is possible to partially correct for confounding at the design stage (for example, by stratification) and at the 
analysis stage by adjusting for confounding variables but only if the responsible variables have been measured.

Restriction can help to reduce confounding; for example, if smoking was thought to be a confounding factor in a study, then recruitment could be limited to non-smokers; however this strategy reduces the generalisability of any findings to a non-smoking population. Alternatively, matching can be employed (in case-control studies), such that cases and controls are matched according to known confounding factors. The disadvantage of this approach is that not all confounding factors may be known, so there may be residual imbalance.

The best method of reducing confounding is randomisation. By randomly allocating trial participants into control or intervention groups, any confounding factors should be equally distributed between groups and imbalance reduced. It is then possible to compare the baseline characteristics of the groups, in this trial derived from the screening questionnaire, in order to crudely assess if randomisation has been successful (see 3.2.3.1).

\subsection{Trial design}

Give the problems of non-randomised designs in the form of confounding and bias, a randomised control trial design was chosen as the most appropriate method of comparing the intervention with routine practice ${ }^{349}$. This design is particularly strong in its ability to examine benefits and hazards of a specific intervention while avoiding allocation bias that may be seen in non-randomised controlled studies ${ }^{335}$. Within randomised designs, there are two main options - individual or cluster randomised design. Cluster randomised trials are particularly suited to assessing complex interventions, which result in organisational-level changes. According to the 
Medical Research Council (MRC) ${ }^{368}$, a cluster randomised trial is appropriate when:

- the intervention to be studied is itself delivered to and affects groups of people rather than individuals

- the intervention is targeted at health professionals with the aim of studying its impact on patient outcomes

- the intervention is given to individuals but might affect others within that cluster

- if the intervention involves supplying equipment or staff to an administrative unit, then by randomising these units rather than individuals only a subset of the units would receive the equipment or staff.

It might have been possible to randomise different practices to either intervention or control, thus satisfying the first of these criteria. However, the disadvantage of this approach is that different practices may cater for different populations, in terms of socio-economic status, age distribution and other confounding factors which could lead to group imbalance and bias. This can be overcome to some extent by matching practices for confounding variables, but matching has limitations (section 3.2.3.4). The second and fourth of the MRC criteria do not apply to this trial but the third option deserves consideration. Whilst contamination may not take in the sense that individuals can only attend the day hospital 'by invitation', it is possible that increased awareness of falls risk factors in the intervention group may be transferred to controls (who with a conventional RCT may be living in the same street or even same house as a participant in the intervention arm). Against employing a cluster design is the loss of power and so need to increase sample size, leading to increased cost and complexity. Torgerson ${ }^{369}$ recommends that an individual randomised design 
is used unless there are very strong reasons why a cluster design should be employed. Noting the arguments above, it was decided to use an individual randomised design for this trial.

Finally, the collection of numerical data in a randomised controlled trial allows the results to be more easily combined with other studies. This is especially useful for systematic reviews and meta-analyses, which combine the results of a series of smaller studies. For valid information to be obtained then certain methodologies, or design considerations, have to be followed, described in the CONSORT guidelines ${ }^{370}$, reflected in the reporting of the RCT in this study.

\subsection{Recruitment}

\subsubsection{Recruitment of general practices}

GP practices that were registered with the Trent Focus for Primary Care Research, Collaborative Research Network (CRN), were approached by the researchers (DK, SC). The CRN has a Research Practices Board which assesses studies on behalf of the member practices. This study was submitted to the board and approved in June 2004. The CRN then advertised the project to member practices, who then indicated their interest in taking part in the study. The CRN Practices expressing an interest were visited by the study nurse to explain the study, ensure that they would be able to identify the potential participants and answer any queries about the study protocol. These practices were asked to identify men and women, 70 years or older registered with their practice. From this list, those known to be suffering from a terminal illness were excluded using the general practice register or by consulting the general practitioners themselves. These individuals are usually well known to the practices, but it is not possible to be sure that some were not included in 
the invitation list drawn up. Similarly, those known to live in a care home (nursing or residential) were also excluded.

Recruitment of general practices was staggered over 12 months so as to allow a gradual increase in the number of participants at each day hospital. The practices were also contacted towards the end of the study and access to participants records requested to ascertain the outcome data. Participating practises were paid a small fee to reimburse staff for their assistance with the study.

Only one CRN practice was registered in the Derby area and declined to participate in this trial. In order to overcome this barrier, the principal investigator at Derby ( $\mathrm{Dr}$ J Youde) wrote to all practices within the Central Derby PCT, inviting them to participate. Two practices were enrolled following this invitation and were included in the trial in the same way as the CRN practices.

\subsubsection{Recruitment of day hospitals}

Originally, five day hospitals agreed to participate in this study:

- Sherwood Day Hospital, Nottingham City Hospital

- Gibson Day Hospital, Nottingham

- Leengate Day Hospital, Queen's Medical Centre

- Derbyshire Royal Infirmary Day Hospital

- Lincoln County Hospital.

However, two day hospitals closed prior to the study start date (Gibson and Lincoln) due to local service restructuring so had to withdraw.

Each of the participating day hospitals were briefed by the project manager and study nurse on the study and their level of involvement. Regular contact was maintained to ensure that the referral processes from the 
study to the day hospital ran smoothly. Each of the day hospitals agreed to help with an observational audit (see 3.12), which was carried out to assess the features of the falls prevention programmes delivered in each of the day hospitals.

\subsubsection{Recruitment of individual participants}

Detailed information on the inclusion and exclusion criteria are given in section 2.6.3, but are briefly summarised here. Individuals were eligible to participate if they were:

- $\quad$ aged 70 or over

- registered on the practice list of one of the participating general practices

- scored 2 or more on the screening questionnaire (previous fall or two or more other risk factors).

The exclusion criteria were:

- patients already attending one of the day hospitals

- patients under follow up with an existing primary care based falls prevention scheme

- residents in nursing or residential homes

- patients with terminal illnesses

- those unwilling or unable to travel to the day hospital, using transport as provided

- patients unwilling or unable to provide fully informed consent

Individuals who preferred not to participate in the randomised trial were offered the possibility of completing monthly diaries only as part of the screening cohort (2.5). 


\subsubsection{Recruitment interviews}

Recruitment of individuals was carried out by three researchers (SC, RT, JE). The general practices were provided with recruitment packs, containing a letter of introduction (signed by one of the general practitioners at each practice), a screening questionnaire, a patient information leaflet and a reply-paid envelope. Each pack was in a sealed envelope and the addresses of potential participants were affixed by the practice staff, who then arranged for the invitation to be posted.

On receipt of a completed questionnaire indicating that the individual was willing to participate further in the study, one of the three researchers responsible for recruitment made telephone contact with the potential participant. The telephone conversations followed a standardised format. If the individual was willing to participate, verbal consent was obtained over the telephone. On a few occasions, a home visit was required to recruit individuals (for example, where hearing or vision was an issue).

Day hospital and primary care falls prevention service records were checked to ensure that the potential participant was not currently attending the service or under active follow up (exclusion criteria). Active follow up in this context was defined as regular visits with either of the services, or ongoing telephone contact between the service and the participant.

A consent form was then mailed to the individual, who was asked to sign and return the form. On receipt of the consent form, those participating in the RCT were then randomised to either usual care or the day hospital falls prevention programme (see section 3.9 for details). A letter of confirmation was sent out to the participant (both groups) along with their first monthly diary and a generic falls prevention information pack (Slip, trips and broken hips, Department of Health, now out of print). 


\subsection{Cognitive impairment and capacity}

The issue of cognitive impairment in the context of this study is important for two main reasons. Firstly, cognitive impairment is a strong predictor of future falls (section 1.3.8). Secondly, cognitive impairment raises the issue of capacity to consent.

It is possible to measure cognitive impairment without a face-to-face interview; a telephone assessment of cognitive function ${ }^{371}$ was used in the Heart Protection Study as a proxy marker of cognitive impairment ${ }^{372}$. Unfortunately there were insufficient resources in this trial to be able to measure cognitive function in all trial participants. However, most participants attending the day hospital underwent a mini-mental state examination and, assuming there was no failure of randomisation, it is reasonable to extrapolate the findings from this arm of the study to the controls and hence describe the cognitive function of the trial population. The problem with this approach is that individuals with significant cognitive impairment may not actually get to the day hospital (because they forgot the appointment for example) and so the MMSE score of those attending the day hospital may not truly reflect that of the day hospital cohort.

On a more pragmatic note, the recruitment process for the trial excluded individuals with major cognitive impairment, as potential participants needed to be able to read, complete and return the screening questionnaire as well as give verbal consent over the telephone. This means that the trial results will not be generalisable to individuals with significant cognitive impairment.

Aside from measuring cognitive impairment as a possible risk factor for falls, it can also be argued that some measure of cognitive impairment should be undertaken in order to ascertain the individuals' capacity to give consent to participate in the trial. However, cognitive impairment does not 
correlate well with capacity to give consent ${ }^{373}$. People with no cognitive impairment may lack the capacity to participate in a clinical trial, whereas some people with mild-moderate cognitive impairment may have capacity to participate. Capacity requires that an individual can understand, retain and manipulate the information being presented to them ${ }^{374}$. The trial recruitment process catered for these requirements, through a step-wise consent process - understanding the initial invitation, completing the screening questionnaire, telephone discussion about the trial and then a final opportunity to reflect before signing and returning the consent form. Given the degree of active involvement the intervention arm of the trial required, it was felt to be inappropriate to use assent to participate when individuals themselves did not have capacity to give consent.

\subsection{Discussing risk}

A potential problem with screening is that individuals are appraised of their potential risk of an event, which they had not previously considered. It is important that the issue of risk is handled sensitively, so as not to engender excessive fear or anxiety, and using language which is easily understandable to communicate what can be difficult concepts ${ }^{375}$. Methods used to introduce the concept of risk in this study include the provision of the patient information leaflet at the outset, which discusses the risk of falling and the telephone contact made on receipt of the completed questionnaire. The recruitment discussion handled the concept of risk of falling in a matter of fact manner, rather than giving an impression of imminent danger. For example, 'according to the questionnaire that you completed, we think that you might be at risk of falling in the future. Do you worry about falling... ?' In fact, many of the individuals contacted were already aware of their risk of falling from anecdotal information from their friends or relatives. 
Evidence that came to light during the lifetime of the trial suggested that talking to older people about the risk of falling and the dangers of falling is not very helpful and tends to dissuade rather than encourage participation in falls prevention programmes ${ }^{218}$. Rather, a more positive approach is suggested ${ }^{218}$, emphasising the benefits of exercise on general health and well-being, avoiding a focus on falls per se; we adjusted our recruitment interviews accordingly.

Individuals asking advice about reducing their risk of falling during the recruitment discussions were given simple guidance, for example about maintaining activity, increasing awareness of home hazards and in the first instance contacting their general practitioner of they were concerned about their health or medication. They were referred to the falls prevention leaflet and for those with internet access, to the study website (now closed).

There was no attempt to quantify the level of risk for a given individual beyond high or low risk. There is no equivalent of the Framingham tables for coronary heart disease that can generalise risk of falling for an individual. In any event, epidemiological data has limited relevance for a given individual, but describes a population and ascribes a risk or likelihood of an outcome given certain risk factors. Accepted descriptors of risk were not though to be useful in this study, given the high background prevalence of falls (Table 3.2).

Table 3.2 European verbal descriptors of harm ${ }^{376}$

\begin{tabular}{|l|l|l|}
\hline Verbal & Frequency & Probability \\
\hline Very common & Over $10 \%$ & More than 1 in 10 \\
\hline Common & $1-10 \%$ & 1 in 100 to 1 in 10 \\
\hline Uncommon & $0.1-1 \%$ & 1 in 1000 to 1 in 100 \\
\hline Rare & $0.01-0.1 \%$ & 1 in 10000 to 1 in 1000 \\
\hline Very rare & Less than $0.01 \%$ & Less than 1 in 10000 \\
\hline
\end{tabular}


For the purposes of this study, it was felt reasonable to leave the discussion of risk as stated above. Support for participants was provided through ready telephone contact with the study nurse (all participants were provided with contact numbers) and access to a website (http://www.fallsprevention.org - now defunct).

\subsubsection{Retention of study participants}

Aside from monthly postal reminders, telephone contact was maintained with the participants every three months. Additionally, a quarterly study newsletter was dispatched with the diaries and a study website was maintained, with the aim of keeping participants interested in the study and maximising retention ${ }^{377}$. Participants were regularly thanked for their on-going involvement in the study, when contacted by members of the study team and those that were interested will be sent copies of major reports resulting from the trial.

\subsection{Intervention under evaluation}

Randomised controlled trials require that the interventions under evaluation are un-ambiguous, well defined and amenable to measurement. The individual components of the multifactorial intervention delivered in isolation (medical review, strength and balance training and a home hazards assessment) are detailed below.

\subsubsection{Medical assessment and treatment}

The medical assessment included a clinical history (including medications); a full physical examination including visual acuity and orthostatic blood pressure measurement; laboratory tests where indicated; 12-lead ECG and where appropriate a neurovascular assessment (carotid sinus massage and tilt tests). Treatments varied according to the medical diagnoses made and included a medication review, appropriate referral to an optician or 
ophthalmologist for visual impairment and referral to other specialists where necessary.

\subsubsection{Physiotherapy assessment and individualised therapy programme}

The physiotherapy intervention included an assessment of gait, balance, mobility and muscle strength. The original intention was to use the Tinetti method ${ }^{206}$ and measurement of ankle dorsiflexion strength ${ }^{378}$ as standard, but as the different day hospitals had slightly different policies and practice, this was not possible. Interventions included gait re-education and functional training programme using the principles of $\mathrm{Koch}^{379}$, and a muscle strengthening exercise programme based on a modified Dunedin protocol $^{32}$, and where indicated the provision of an appropriate walking aid. Again, local policies and practice varied in the specific interventions delivered. Feet and footwear were assessed for abnormalities that could impair gait and appropriate referrals to a chiropodist or an orthotist were made when necessary. The number and timings of follow up visits at the day hospital for further assessment and therapy varied according to the individualised needs of the participants.

\subsubsection{Occupational therapy assessment and modifications}

The occupational therapy intervention included an interview with the participant using a standardised checklist to investigate home hazards ${ }^{380}$. Where necessary, a home visit was also performed. The aim of a home visit was to identify any potential hazards that may increase the risk of falling, such as poor fitting carpets, poor lighting and access problems. Any interventions necessary were recommended and arranged if the participant gave permission. 


\subsubsection{Control group}

The control group received usual care. Despite increased awareness of the importance of preventing falls and the interventions available, there was relatively little preventative work being carried out at the time the study started. People at risk of falls but who had not presented to the health service because of a fall related issue, receive little, if any intervention. Accordingly, the usual care group did not receive a specific intervention, reflecting usual practice. If they came into contact with a falls prevention service during the course of the study, this was considered usual practice and did not constitute a breach of protocol. This reflects current practice throughout most of the United Kingdom ${ }^{210}$ and so adds to the generalisability of the trial.

Individuals in the usual care group received the same patient information leaflet and falls prevention leaflet as the intervention group, and were asked to complete the diaries on the same monthly basis. No additional treatment was offered.

\subsection{Outcome Measures}

Randomised controlled trials demand that the interventions evaluated are amenable to measurement and that outcome measures are, where possible, standardised, relevant, reliable, valid and sensitive ${ }^{381}$. Using established standardised measures with well defined and comprehensive instructions reduces ambiguity and improves consistency ${ }^{382}$. The use of standardised measures will:

- provide a trial with meaningful results

- allow them to be communicated more easily

- allow them to be compared with other trials 
- allow them to be used in subsequent studies such as meta-analysis and systematic reviews.

Many conventional trials use mortality as the primary outcome measure. However, for falls studies, mortality is not the most important outcome. Frail older people have limited life expectancy and may die during the study, often for reasons unrelated to falls; cardiovascular disease, cancers and other important causes of mortality are common in old age. This is increasingly being seen in cancer trials as survival improves, there is a move away from using mortality as an endpoint, towards using intermediate outcomes, such as disease free survival ${ }^{383}$.

No single trial can feasibly aim to address the common causes of mortality in older people, in contrast to studies involving younger people, where there is usually only a single pathology. However, it is clearly important to be sure that the intervention in question does not increase mortality, and so death is included as a secondary outcome. It is good practice to analyse function and mortality, because no intervention would be judged useful if it prevented disability but, at the same time, reduced survival ${ }^{384}$.

\subsubsection{Baseline demographic and clinical characteristics}

In an adequately sized trial with effective randomisation, any differences in baseline characteristics and possible prognostic factors between the control and intervention groups will arise by chance alone. However, it is important that there is some record of the baseline characteristics of the trial participants to be able to compare the two groups at outset in case of any major discrepancies. Baseline characteristics available for all trial participants include the following:

- age/date of birth

- gender 
- responses from the screening questionnaire

- fall in the previous twelve months

- taking more than four prescribed medications

- previous stroke

- Parkinson's disease

- inability to stand from a chair without using arms to push up (muscle weakness)

- symptoms of dizziness on standing

- use of a mobility aid

- housebound (mobility impairment).

\subsubsection{Primary outcome: rate of falling over a 12 month period post recruitment}

Previous primary care based falls studies report falls related outcomes over a period of one year $9303134-36224$. One year is an appropriate time, as it allows time for the intervention to take effect. Broadly, people who fall can be divided into two categories; first, recurrent fallers who will have many falls over a short period of follow up; second, people who have occasional falls, possibly less than once per year. The intervention needs to show an impact upon both groups of fallers if it is to be successful and subsequently employed in a primary care based prevention strategy.

Falls rate is a fundamental outcome - each fall accumulates risk for fracture, admission, loss of confidence and other adverse outcomes. Using the rate of falls as the outcome measure introduces the element of time, allowing the best use of the data collected (see section 3.14.3); as the population being studied is relatively frail and older, it is likely that significant numbers of participants will drop out over time - typically $20 \%$ 
in trials on similar populations ${ }^{385} 386$. This may be due to a variety of reasons, including death, move to a care home (study end-points), illhealth or because they simply do not want to participate any further. This is especially likely in the day hospital intervention group, who may find the travel to the day hospital tiresome. By using the rate of falls, we are able to capture outcomes over the period of an individual's participation in the study.

Ideally, falls caused by syncopal episodes should also be considered separately $y^{384}$. However, without key witness informants to verify the nature of the fall, it is difficult to ascertain if a fall involved a loss of consciousness. Syncopal falls are frequently associated with amnesia, either antegrade or retrograde, such that the informant may not reliably recall the true nature of the fall ${ }^{387}$. Rather than introduce yet more reporting error, all falls were considered conjointly, irrespective of the aetiology. Published studies record the rate of syncopal falls in community dwelling individuals as $3 \% 388389$, but these figures may well be an underestimate of the true rate of syncopal falls because of associated amnesia.

By contrast, it was possible to ascertain falls associated with major injury and attendance at primary or secondary care services through examining health service records. This enabled discrete analysis of injurious and noninjurious falls.

The definition of a fall used in this study was the most commonly used definition, identified in a recent Cochrane review ${ }^{9}$ of falls interventions 'unintentionally coming to rest on the ground, floor or other lower level; excludes coming to rest against furniture, wall, or other structure'.

This clarifies that falls due to syncope are to be included as a primary outcome measure. The actual definition given to study participants was: 
'We want to know about any falls you have that caused you to land on the ground or a bed or chair, whether you pass out or not. A stumble or near miss does not count'.

\subsubsection{Secondary outcomes}

For this trial, the most appropriate primary outcome was deemed to be a reduction in the rate of falls. It can be argued that falls are only a surrogate for more robust outcome measures, such as fractures. But falls represent more than just a risk of fracture for older people. Falls can be viewed as a syndrome, which encompasses many domains: frailty, multiple comorbidities, fractures, fear of falling and functional decline. The secondary outcomes used in this trial are designed to capture some of these elements.

\subsubsection{Medically validated versus self reported falls}

We examined primary and secondary care records for all participants in the RCT searching for falls related consultations and medically validated falls.

\subsubsection{Proportion of people with single or recurrent falls}

There are advantages to using multiple falls instead of any fall as an endpoint. Isolated falls are more likely to be random, 'one-off' events, whereas recurrent falls are usually associated with underlying neurological or musculoskeletal problems and are a stronger predictor of negative health outcomes ${ }^{30295390}$. We analysed both arms of the trial looking for differences in single versus recurrent (two or more) falls.

\subsubsection{Fall-related injuries}

Falls related injuries clarify the consequences of the fall and are useful comparators. Falls associated with major injuries were analysed separately from non-injurious falls. 
In order to standardise reporting of injuries in such a way as to ensure external comparability, the Severity of Injury Scale ${ }^{391}$ was used to code injuries. This is a relatively simple, internationally recognised injury severity score, detailed below:

- no injury

- $\operatorname{minor}$ (abrasion, contusion)

- moderate to serious (laceration, tissue tear, haematoma, impaired mobility due to injury, fear of subsequent fall and fall injury)

- serious (fracture, multiple fracture, subdural haematoma, head injury).

\subsubsection{Time to first fall}

At best falls prevention programmes can be expected to reduce falls rates by up to one-third, they do not abolish falls completely. However, they may delay the time to the next fall, which may in turn be beneficial to patients. Time to first fall was a pre-specified secondary outcome, as recommended by the ProFANE task force ${ }^{392}$; time to second fall was also calculated as a post hoc analysis.

When carrying out a survival analysis for time to first fall, censoring should consider individuals who do not complete the full follow up period of the study. Individuals may fail to complete the full period of follow up for four possible reasons:

- death directly related to a fall

- death from non-falls related disease

- migration (out of the study)

- they join the study too late to complete the full follow up period (not applicable in this study). 
Accordingly only including the period under follow up is important so as not to bias the results of the survival analysis.

\section{$\underline{\text { 3.6.3.5 }}$ Mortality}

In many cases, mortality and the primary outcome are correlated or 'censoring from mortality' is informative. This is the case with falls, which are associated with a significant 2.6-fold increase in mortality rate ${ }^{131}$. Mortality was checked against primary and secondary care records.

\subsubsection{Disability or activity limitation}

A measure of functional ability is essential in any trial involving older people, as function is a key determinant of quality of life and a useful comparator across studies ${ }^{384}$. The standard measures of disability included in this trial are the Barthel index of activities of daily living and the Nottingham Extended Activities of Daily Living (NEADL) scale. Both the Barthel index and NEADL are well validated measures of functional abilities and can be used as postal questionnaires ${ }^{185}$. The two measures are complementary; the Barthel index is a 10 item scale which assesses basic function, such as mobility, personal care and continence, with scores ranging from 0 (dependant) to 20 (independent). The NEADL assess higher function; it comprises 22 activities of daily living self-report items, divided into four domains: mobility (six activities), kitchen (five activities), domestic (five activities) and leisure (six activities), with scores ranging from 0 (dependant) to 66 (independent).

\subsubsection{Fear of falling}

Several scales are available for measuring fear of falling, but two that have been validated in the United Kingdom include the Falls Efficacy Scale (FESUK) and the Activities-specific Balance Confidence scale (ABC-UK). Previous studies suggest that the FES had the better postal completion rate $(94 \%$ 
versus $86 \%$ ), and both scales are able to detect differences in falls related quality of life measures when compared to non-falling controls ${ }^{393}$. The FES has been validated in the UK as both a face to face and self-completed questionnaire. On a more practical note, the FES is more widely used in the local services and so staff involved in the trial would be more familiar with this measure should the study participants have any queries about the scale. The FES consists of ten items with each item being scored from 1 (most confident) to 10 (least confident).

\subsubsection{Quality of life}

Quality of life measures are important for two main reasons. Firstly, they acknowledge the impact of falls upon quality of life and secondly, they facilitate measurement of cost-utility. The measure used to determine quality of life for this study was the EuroQoL-5D, which is well validated and a useful cross study comparator. The EuroQoL contains five items (mobility, self care, participation, pain and mood), each scored from 1 (no problems) to 3 (extreme problems). It is a key determinant in the economic outcome analyses. The York A1 Tariff scoring algorithm was used to convert EuroQoL scores into a utility score ${ }^{394}$, which is used for economic analyses (not discussed here).

\subsubsection{Institutionalisation, use of services and cost analysis}

The self-reported institutionalisation data (change of residency - move to a care home or sheltered accommodation) were corroborated though reference to primary care records. Health service utilisation was collected in a similar manner, from both primary and secondary care records. Participants also returned monthly information on any assistance that they required:

- help with ADLs (carer, relative, paid/unpaid) 
- meals delivered (funding)

- equipment purchased because of falls (e.g. mobility aid)

- any home adaptations made because of falls and costs.

\subsubsection{Ascertaining outcome measures}

Postal questionnaires were used to collect the outcome data. Postal questionnaires have several advantages over face to face assessment ${ }^{324}$ :

- they reduce the chance of observer bias (misclassification) - a face to face interviewer may be aware of the allocation of the individual in this single-blind trial and so may record outcomes differentially

- they are practical to use for large trials

- they are relatively inexpensive

- they are relatively unobtrusive for the participant (as compared to arranging a follow up interview with an observer).

However, there is a possibility that some participants are unable to complete the questionnaire due to physical limitations, eyesight or inability to read English. Participants who were unable to complete and return the questionnaires were offered the help of the study nurse who would visit them at home. Participants who were sent a questionnaire but who did not return it were contacted by the study nurse and offered a second posting or a visit at home. When questionnaires were returned with questions missing or ambiguous answers given, the independent assessor contacted the participant by telephone and asked about individual questions. These steps should have prevented recall bias arising from higher response rates in those given active treatment, if post alone was used ${ }^{324}$. 


\subsubsection{Primary outcome measure: falls}

Obtaining high-quality reports of falls is resource intensive. Older persons may forget falls, and fall ascertainment based on long-term recall is incomplete. Cummings et $a^{26}$ followed up 325 community dwelling men and women over one year using weekly falls diaries. At one year, $13 \%$ of participants were unable to recall incident falls and a further $7 \%$ recalled falls that were not otherwise corroborated. Failure to recall falls was associated with a statistically, but not clinically significant one-point reduction in the Mini-Mental State Examination. However, there is no better method of recording falls available at the present time.

Most major falls studies have used follow up diaries, supplemented by telephone contacts. For community-dwelling older persons, the gold standard for tracking falls requires asking participants to mail a follow up card weekly or monthly, soliciting non-responders, and characterising each event by directly visiting the participants ${ }^{26} 395$. In this study, it would not have been possible to characterise each event through a direct visit. With nearly 400 trial participants and with an expected rate of falls of 2/year per person $^{36}$, we could have anticipated around 800 events that would have required corroboration. Given the wide geographical spread of participants (Nottinghamshire and Derbyshire) and the limited resources (staff and financial), it would have been difficult to verify each event contemporaneously. However, the study team maintained regular telephone contact with study participants to ensure as well as possible the accuracy of any reported events, checking information where diary record were unclear.

For this study, falls were recorded by giving each participant a diary and reply paid envelope. Participants were asked to record falls in the diary, along with the outcome (saw GP, phoned ambulance, sent to hospital, 
injuries). The diaries were mailed back to the research team at the end of every month. Participants who had not returned the diaries within three days of the end of the month were contacted via telephone by the study nurse to encourage return of the diaries. Those requiring help to complete the diaries were visited at home. Previous falls trials using similar methodology obtained a $90 \%$ response rate, with $20 \%$ of participants requiring telephone contact and $10 \%$ a visit to help complete the diaries (personal communications, Fiona Shaw \& Lesley Day). Falls were monitored until withdrawal from the study, death, admission to care home or the end of 12 months follow up, which ever event occurred first.

\subsubsection{Secondary outcome measures}

The principal method was self-reporting using the monthly diary. This contained a section on falls and the outcomes (carried on as usual, called for help, waited for someone to help, called GP, called ambulance, taken to hospital, nature of any injury). Additionally, there was a section for recording health service utilisation, covering primary care contacts and hospital admissions.

The self-reported falls outcomes were supplemented by recording falls related attendances logged in primary or secondary care records. For hospital admissions, the speciality relating to the admission and the length of stay were obtained. This level of information allowed a more accurate ascertainment of events as well as the costs associated. Information on falls-related drug treatment (such as bone protection therapy) was obtained from the GP records. These data were collected by the project manager (SC) and the study nurse (RT) on standardised forms.

Fall-related injuries data were collected from the diary information, supplemented by telephone interview where appropriate. As above, falls- 
related injuries recorded on primary or secondary care records were also collated.

Disability and quality of life were self reported by study participants using postal questionnaires at one year. They were contained within the end of study booklet. Where participants' responses were unclear, the study nurse contacted the individual by telephone or personal visit to corroborate the data.

Institutionalisation data were available from practice registers when not available directly from participants. Those who changed practice as a result of changing address were traced through the primary care trusts.

Mortality was ascertained from primary care records and cross-referenced against hospital records.

\subsection{Sample size}

Previous falls prevention studies had a baseline falls rate of 1 /year to $3 /$ year per participant ${ }^{90-36}$. A systematic review of falls interventions ${ }^{8}$ identified 22 studies which reported falls outcomes using proportions with one or more falls, and 27 studies which reported rates of falling. In many of the papers reported there seems to be inconsistency between the analysis and sample size calculation. For example, the PROFET study ${ }^{36}$ was powered to detect a reduction in fall rate from 2/year to 1.4 per year, with a sample size of 352; however the analysis was a logistic regression of at least one fall. A paper by Robertson ${ }^{31}$ used proportions for sample size calculations, but negative binomial models for analysis of falls rates.

In the absence of any clear, definitive guidance we powered the study for a reduction in rates of falling. After we had agreed this approach, the Prevention of Falls Network Europe published their paper on reporting falls, suggesting fall data should be summarised as the number of falls, number 
of fallers/non-fallers/frequent fallers, fall rate per person-year, and time to first fall ${ }^{392}$.

The appropriate analysis for rates is Poisson regression analysis, but falls rates typically display 'over-dispersion'. Over-dispersion occurs when the variance is greater than the mean; Poisson analysis is inappropriate in this case (as Poisson analysis assumes that the variance is equal to the mean). When this is the case, the most appropriate analysis is negative binomial regression; this has been suggested as the analysis of choice for falls rates ${ }^{396}$.

\subsubsection{Power calculation and sample size estimates}

With an expected rate of falls of 2/year per person ${ }^{36}$, and an overdispersion parameter of 1.5 , a clinically important risk reduction of $24 \%$ to 1.5 falls/year can be detected with $80 \%$ power and $5 \%$ significance (twosided) in a trial of 160 participants in each arm, giving a trial size of 320 . This assumes a Poisson distribution with over dispersion. If the fall rate was $1 /$ year per person ${ }^{31}$, a risk reduction of $33 \%$ could be detected with this sample size. This sample size calculation was based on the expected outcome from the trial based on previous similar interventions ${ }^{12} 226$.

This sample size also had $80 \%$ power at the $5 \%$ significance level to detect a reduction of one third in the proportion of people with one or more falls, with an expected proportion with one or more falls of $50 \%$ at 12 months. Allowing for an attrition rate of $20 \%$ we planned to recruit a total of 400 participants. To achieve this, we estimated 3125 subjects needed to be screened, of whom $40 \%$ might have been at high risk of falls. Of these 1250 , we estimated $20 \%$ were likely to be ineligible leaving 1000 potential participants of whom it was thought $40 \%$ would agree to take part (see Figure 3.1). 
The most appropriate power calculation asks 'what is the minimum clinically significant difference that we want to be able to detect?' Having opted for a $24 \%$ risk reduction, this trial was at risk of missing a risk reduction less than $24 \%$ because of a type II error. For example, we could have missed a $15 \%$ risk reduction, which would have remained clinically significant. A selection of sample size calculations are shown below; these do not account for the over-dispersion parameter, so are not precise, but do give an indication of the order of magnitude that the sample size would need to be in various scenarios. 
Table 3.3 Sample sizes for different IRRs $($ alpha $=0.05$, beta $=0.2)$

\begin{tabular}{|l|l|l|l|l|}
\hline $\begin{array}{l}\text { Estimated rate in } \\
\text { control group (falls } \\
\text { per person-year) }\end{array}$ & $\begin{array}{l}\text { Estimated rate in } \\
\text { intervention group (falls } \\
\text { per person-year) }\end{array}$ & $\begin{array}{l}\text { Incidence } \\
\text { rate ratio }\end{array}$ & $\begin{array}{l}\text { N per } \\
\text { group }\end{array}$ & Total N \\
\hline 2 & 1.8 & 0.9 & 745 & 1490 \\
\hline 2 & 1.53 & 0.85 & 322 & 644 \\
\hline 2 & 1.224 & 0.8 & 176 & 353 \\
\hline 2 & 0.918 & 0.75 & 110 & 220 \\
\hline 1.8 & 1.62 & 0.9 & 828 & 1655 \\
\hline 1.8 & 1.53 & 0.85 & 358 & 716 \\
\hline 1.8 & 1.44 & 0.8 & 196 & 392 \\
\hline 1.8 & 1.35 & 0.75 & 122 & 244 \\
\hline 1.6 & 1.44 & 0.9 & 931 & 1862 \\
\hline 1.6 & 1.36 & 0.85 & 403 & 806 \\
\hline 1.6 & 1.28 & 0.8 & 220 & 440 \\
\hline 1.6 & 1.2 & 0.75 & 137 & 274 \\
\hline
\end{tabular}

The shaded lines in Table 3.3 indicate the effect size that could be missed with a sample size of 320 at various baseline falls rates. A $10-20 \%$ effect size could have been missed as a result of a type II error.

\subsection{Study design}

The prospective study design is shown in Figure 3.1 . 
Figure 3.1 Prospective plan of the study

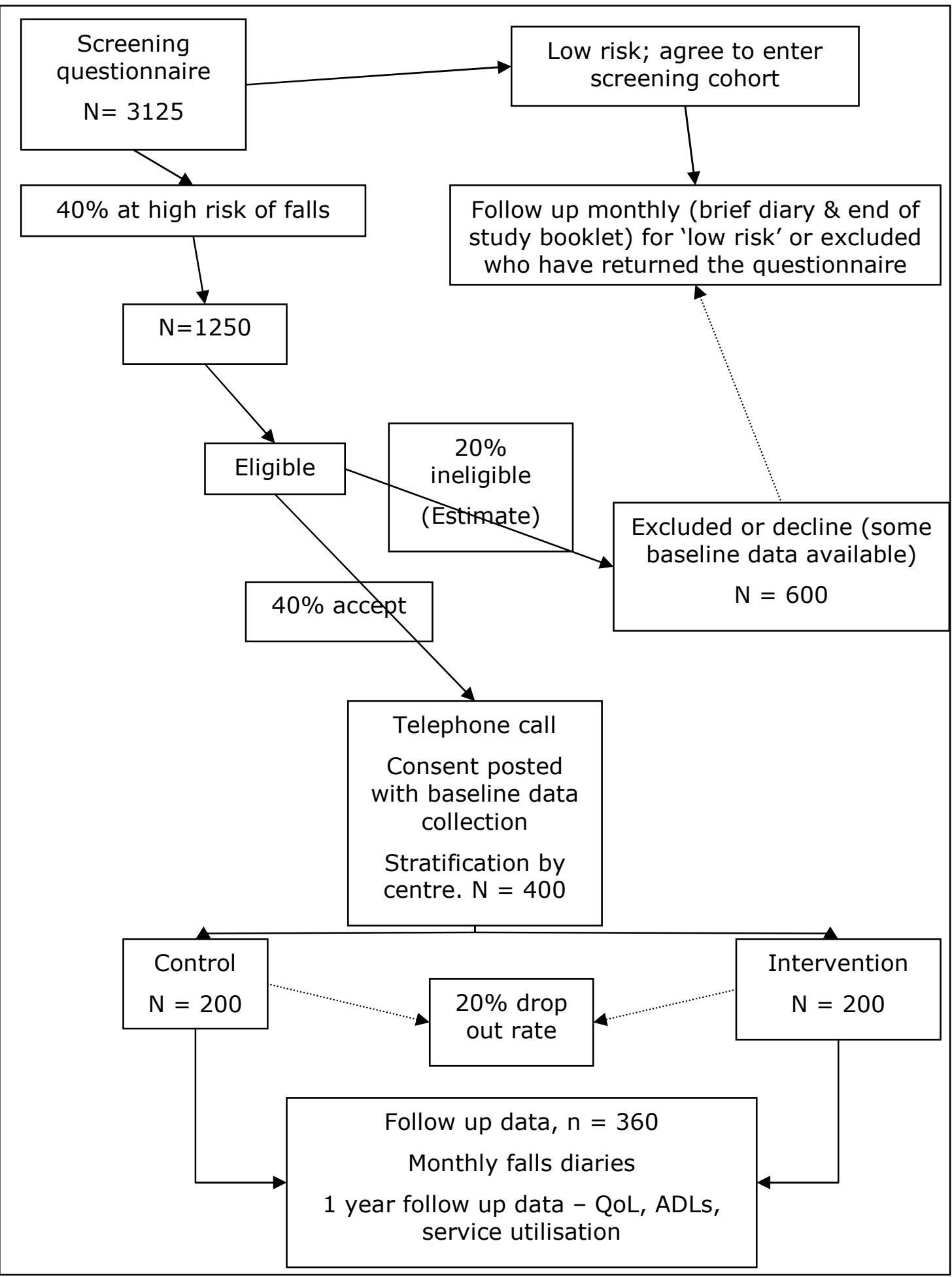




\subsection{Randomisation and stratification}

Stratification was used in this trial to facilitate balanced groups of participants. Participants were stratified by centre (Nottingham versus Derby) only. The block size was of a random size to maximise allocation concealment. The randomised list was produced by the study statistician (CC) and Trent Institute for Health Services Research; none of the other members of the study group had access to the randomisation list. Initially, randomisation was carried out by telephone, and then moved to a web based system (maintained by the Nottingham Clinical Trials Support Unit CTSU), using the same schedule.

\subsection{Blinding}

As discussed in section 3.2.3.2, it was not possible to blind participants to their allocation group, nor the day hospital staff, due to the nature of the intervention. It may have been possible to confer some degree of blinding in this trial by randomising one group to the evidence based intervention (strength and balance training, home hazards assessment and medical review), and the other group to a sham treatment delivered in the day hospital which did not contain these 'ingredients'. However the ethics of offering such a control are unclear. All analysis was carried out by blinded assessors.

\subsection{Research governance and ethical considerations}

Ethical Approval was sought and granted by Nottingham 2 Ethics Committee (reference 04/Q2404/93). The principles of research governance were followed ${ }^{397}$. Under the then new research governance framework, all studies required a formal sponsor. Nottingham City Hospital agreed to sponsor this study, in collaboration with other participating centres. A study agreement was prepared by the research and 
development department at Nottingham City Hospital, detailing shared governance and indemnity arrangements between the main study centres. In order to comply with research governance guidance, participants were first contacted by their general practitioner with a letter inviting them to complete the screening questionnaire and return to the investigators if they were interested in participating in the study. The invitation pack included the screening questionnaire and a patient information leaflet. It was made clear in the documentation that by returning the screening questionnaire, the participants were under no obligation to take part in the study.

The process for obtaining informed consent is described in section 3.4.3. All participants were provided with the contact details and information about the study. It was explained that they were free to withdraw from the study at anytime without giving a reason and that their normal medical care would not be affected. Participants were also reassured that all information would be treated as confidential and stored securely.

All information obtained from participants was coded with a subject number to ensure confidentiality. Identifiable personal details and consent forms were kept in a locked filing cabinet. All computer records and data sets were password protected.

\subsubsection{International Standard Randomised Control Number}

The growth in prospective registration of randomised controlled trials has accentuated the need to distinguish between different trials. Trials are usually referred to by a series of grant numbers, protocol numbers, trial names and acronyms which can make it difficult to determine whether reports, publications or entries in trial registers refer to the same trial or not. To provide an accurate reflection of the research activity in a particular area it is important that each trial is counted only once and that 
unintended duplication between registers is avoided. The International Standard Randomised Control Number (ISRCTN) is a randomly generated, 8-digit number, prefixed by the code ISRCTN that uniquely identifies each trial in the ISRCTN Register.

The ISRCTN should be quoted in all publications relating to the trial, in order to:

- clearly identify the trial and prevent mistaken identity

- help to detect duplication in current registers of trials, and to avoid trial double-counting when assessing a field of research activity

- enable tracking of the trial from inception to completion, and beyond.

The ISRCTN for this trial, registered with controlled-trials.com (http://www.controlled-trials.com/isrctn/) is ISRCTN46584556.

The trial protocol was submitted to Trials, an on-line journal (http://www.trialsjournal.com/content/7/1/5), in January 2006, prior to any of the analyses being performed. This was done to avoid the possibility of retrospective data analysis, i.e. searching for significant outcomes once initial analysis had been undertaken ('fishing expeditions').

\subsection{Process monitoring}

A variety of processes were employed to monitor the interventions delivered to participants attending the day hospital, discussed below.

\subsubsection{Behavioural mapping}

Behavioural mapping is a technique for observing and describing 'environmental influences upon behaviour' ${ }^{1398}$. Behavioural mapping is suitable for the observation of the physiotherapy and occupational therapy activity since the use of a carefully designed chart is 'quick and easy' ${ }^{\prime 398}$. 
This technique has been used in a number of studies on stroke

rehabilitation ${ }^{399-401}$ to determine the amount of time spent in therapy and in other tasks. The results of these studies showed that potentially more time could be spent in therapeutic activities ${ }^{399}$. In an observational study of 15 stroke patients ${ }^{402}$, only $13 \%$ of the working day was spent in therapy. In the comparison of stroke patient's' time use in an intensive rehabilitation unit between a Swiss and Belgian setting ${ }^{400}$ it was found that $45 \%$ and $28 \%$ of the day were spent in therapy in Switzerland and Belgium respectively.

A single observer (Ruth Creamer, $4^{\text {th }}$ year medical student, dissertation project) carried out a behavioural mapping exercise in one of the day hospitals for this study.

\subsubsection{Adherence to programme}

The number of day hospital visits was obtained by a count of 'day hospital logs' which were completed for each attendance, by the day hospital staff. The logs asked about the amount of input according to discipline, and was only available for those in the intervention group (see 4.3).

\subsection{Data handling}

An Access database with password protection was used to store all data. For the purposes of analysis, data were transferred to Intercooled Stata version 9 using Stat Transfer (2001). Original documentation was stored in locked filing cabinets, with identifying information being stored separately.

\subsubsection{Data cleaning}

There are two main threats to the integrity of data, random error and systematic error ${ }^{403}$. Certain data checks can help identify such errors. Logical checks can identify 'non-sensical values' - such as dates of birth in the future. Data double entry of a randomly selected proportion of the data 
can also help to identify errors. Random errors are more difficult to detect, but in theory should be evenly distributed between the two arms in a randomised trial and therefore not result in bias. However, if the random error rate is high, it may reduce the power of the study.

In order to try and avoid systematic error in data recording, we checked random samples of the initial data entry for each person using the database. In addition, we carried out audits of random samples of data entry.

Initial data entry accuracy was maximised through the use of the Access database. Using 'forms' with embedded coding to control the data entry reduced the possibility of errors, though miscoding errors were still possible. Throughout the database, standard responses were used whenever possible. Data accuracy was assessed at different stages throughout the project.

For categorical data, the entries were examined to check that there were no implausible values. For continuous variables, range checks were carried out for plausibility. Wherever there were discrepancies, data were checked against the original records and where these were unclear a consensus was attained between two of the study team. Where it was not possible to verify data, entries were coded as missing.

For calculated values, logical checks were performed to assess robustness.

\subsubsection{Handling missing data}

Missing values are a problem in randomised controlled trials because the sample size can be reduced and if more people drop out from one group than the other, bias may be introduced. There are a variety of accepted methods for handling missing data ${ }^{404}$. 
Missing values in data are due to different reasons. Participants may not have responded because they withdrew consent or they may have died, moved away and it may be impossible to trace them or they may be too ill at the time of the assessment. Even when questionnaires are returned individual items may have been missed. To reduce missing values at the study design stage the following actions were taken:

- the diaries were kept as short as possible and the layout and wording were checked for ease of use before the study started by day hospital attendees

- each question was checked for a wide enough range of response options

- assessments were administered by post, but the study nurse was available to make telephone contact or visit at home those people who needed help

- the study nurse was available to telephone participants who returned the questionnaire with incomplete or inaccurately filled in questions

- copies of the diaries and instructions on completion were stored on the study website.

These measures should have reduced the amount of missing data, but some loss is inevitable. As stated previously, Stata handles missing data by a process of 'listwise deletion' or 'complete cases only', that is to say only using complete datasets for regression commands. However, this is inappropriate for many outcomes as it risks introducing bias. In view of the missing data, we carried out Complete Case Analysis and imputed missing data. 
Multiple imputation (MI) was used to estimate values for non-responders at each time interval. MI is a Monte Carlo simulation technique where each missing data case is replaced by a set of plausible estimates, which are drawn from the predictive distribution of the missing data given the observed data. In contrast to the more naïve approaches, such as mean substitution or last value carried forward, the technique of MI has the advantage that it includes a random component to reflect the fact that imputed values are estimated rather than treating the imputed values as if they are known with certainty ${ }^{405}$. As such, MI is likely to produce more accurate estimates of the standard errors (SE) and variances of the mean utility values at each time-point than other methods of imputation. Rubin's rules are used to combine results from multiple imputed datasets to obtain the estimates. A priori this was our preferred approach for handling missing data because of non-response.

\subsection{Data analysis}

\subsubsection{General considerations}

Statistical significance was tested at the $5 \%$ level; two-sided tests were used. Response bias was ascertained by comparing the proportion of completed diaries returned in the intervention group to the proportion returned in the control group (chi-squared test) and by comparing the baseline characteristics of the responders compared to the non-responders. All primary and secondary outcomes analyses included stratum as a fixed covariate, and the adjusted analyses included all of the baseline variables (age, gender and all eight screening items) as fixed covariates, as discussed in section 3.2.3.1. 


\subsubsection{Assessing population distributions}

Visual inspection of a histogram displaying the data is possibly the best method for assessing normality of a distribution. But it is possible to test that a population fits the normal distribution using a Shapiro-Wilks test, comparing observed observations against those that would be expected if the population fitted a normal distribution. Where there is marked deviation, then assumptions about the normal distribution are not valid. In this case, it may be possible to transform the data; for example if the data is positively skewed, a logarithmic transformation may normalise the data (by reducing the magnitude of the variance). Many other transformations are possible in order to make the data fit a normal distribution (see Kirkwood, Medical Statistics, $2^{\text {nd }}$ edition, 13.3). Stata offers a gladder function which produces a composite pictorial representation of the various possible transformations. The gladder function was used to determine the 'normality' of data, supplemented by formal tests, such as the ShapiroWilks test where necessary.

\subsubsection{Intention to treat analysis}

Intention to treat analysis is the recommended type of analysis for randomised controlled trials 335404406 . Participants were followed up as part of the group to which they were first assigned at randomisation, regardless of whether the participant continued in the trial, complied with the intervention or died.

Intention to treat analysis guards against any attempts to influence the results of the study by excluding aberrant or extreme outcomes. For example older, physically impaired people who are more likely to die are also more likely to have falls. If a greater number of people died from one group then it may be possible that these people were also the ones who found it difficult to attend the day hospital falls prevention programme 
during the time leading up to their death and this would affect the outcomes. Intention to treat analysis addresses this problem by including values for all people. The disadvantage of intention to treat analysis is that it has the tendency to reduce the treatment effects (as not all individuals in the intervention groups will have received the intervention). The converse applies - participants randomised to the control arm should be analysed as controls, even if they subsequently went on to attend the day hospital, for example because they fell and were referred on by their general practitioner. This too will tend to reduce the estimate of the treatment effect.

Per-protocol analysis is carried out according to the intervention actually received by participants. This is sometimes appropriate, for example in drug trials, where it is important to know about adverse affects related to the drug being tested.

\subsubsection{Primary outcome: rate of falling}

For falls incidence rates Poisson regression was used, or if there was over dispersion, then negative binomial regression was preferred, as discussed in section 3.7.

\subsubsection{Model checking}

Statistical models are useful as they provide estimates of an effect which may be generalisable. However for the results of a model to be valid, certain assumptions are made about the data. In order to test these assumptions, various checks were carried out when using various regression models, to ensure that the model assumptions had not been violated (Table 3.4). 
Table 3.4 Techniques used for model checking

\begin{tabular}{|c|c|c|c|}
\hline Model type & Model check & Process & Expected result \\
\hline \multirow{7}{*}{$\begin{array}{l}\text { Logistic, } \\
\text { Poisson } \\
\text { and } \\
\text { negative } \\
\text { binomial } \\
\text { regression }\end{array}$} & Influence & $\begin{array}{l}\text { Cook's distance (measures the aggregate change in the estimated coefficients when each } \\
\text { observation is left out of the estimation) }\end{array}$ & $\begin{array}{l}<(4 / \mathrm{n}) \text { where } \mathrm{n} \text { is the number of } \\
\text { participants }{ }^{407}\end{array}$ \\
\hline & Leverage & & $\begin{array}{l}<(2 p / n), \text { where } p \text { is the number of } \\
\text { independent variables }\end{array}$ \\
\hline & $\begin{array}{l}\text { Goodness of } \\
\text { fit }\end{array}$ & $\begin{array}{l}\text { Deviance residuals - a measure of goodness of fit in a generalised linear model } \\
\text { (approximately normally distributed if the model is correct and may be plotted against the } \\
\text { fitted values or against a covariate to inspect the model's fit) }\end{array}$ & $+/-2$ standard deviations ${ }^{407}$ \\
\hline & $\begin{array}{l}\text { Goodness of } \\
\text { fit }\end{array}$ & Pearson's $\chi^{2}$ goodness of fit test & $\begin{array}{l}\text { Non-significant value indicates } \\
\text { reasonable fit }\end{array}$ \\
\hline & Collinearity & Covariate correlation matrix & $\begin{array}{l}\text { A large positive or negative } \\
\text { correlation may indicate collinearity }\end{array}$ \\
\hline & Collinearity & Add in the square of a continuous variable (age) & Likelihood ratio test \\
\hline & $\begin{array}{l}\text { Goodness of } \\
\text { fit }\end{array}$ & Pregibon's beta (dbeta) - similar to Cook's distance & $\begin{array}{l}\text { No clear guidance! } 0.06 \text { is too } \\
\text { low }^{408} \text { and } 0.2 \text { is high }\end{array}$ \\
\hline \multirow{5}{*}{$\begin{array}{l}\text { Cox's } \\
\text { Proportion } \\
\text { al Hazards }\end{array}$} & $\begin{array}{l}\text { Proportional } \\
\text { hazards }\end{array}$ & Kaplan-Meier curves & $\begin{array}{l}\text { Lines should be parallel and not } \\
\text { cross }\end{array}$ \\
\hline & $\begin{array}{l}\text { Proportional } \\
\text { hazards }\end{array}$ & Schoenfeld residuals - plot residuals against time & Significance test \\
\hline & Linearity & Martingale residuals - plot vs. continuous covariates to detect non-linearity & Visual inspection \\
\hline & $\begin{array}{l}\text { Goodness of } \\
\text { fit }\end{array}$ & Deviance residuals - plot against id to identify outliers & Visual inspection \\
\hline & Collinearity & Add in the square of a continuous variable (age) & Likelihood ratio test \\
\hline
\end{tabular}




\subsubsection{Secondary analyses}

The pre-planned secondary analyses comparing treatment arms are detailed below.

\subsubsection{The proportion of participants with one or more falls}

For the number of participants with one or more fall, odds ratios and $95 \%$ confidence intervals were estimated using logistic regression, using stratum as a fixed covariate and an adjusted analysis using the baseline parameters (age, gender, screening risk factors).

\subsubsection{Time to first fall}

The time to the first fall was estimated using survival analysis (KaplanMeier curves) and comparisons made between groups using Cox proportional hazards regression with stratum as a fixed covariate and an adjusted analysis using the baseline parameters (age, gender, screening risk factors).

\subsubsection{The proportion of people with injurious falls}

For injurious falls, odds ratios and $95 \%$ confidence intervals were estimated using logistic regression, using stratum as a fixed covariate and an adjusted analysis using the baseline parameters (age, gender, screening risk factors).

\subsubsection{The proportion of people institutionalised at 12 months}

For institutionalisation, odds ratios and $95 \%$ confidence intervals were estimated using logistic regression, using stratum as a fixed covariate and an adjusted analysis using the baseline parameters (age, gender, screening risk factors). 
$\underline{3.14 .4 .5}$ Impact on disability, quality of life, fear of falls, and use of health services

These outcomes are all continuous variables (e.g. disability measured on the Barthel scale from 0-20) and were described using means (if normally distributed) or medians (if not normally distributed). Where assumptions for undertaking linear regression were not met, data was transformed and analysed using linear regression, or dichotomised at the median and analysed using logistic regression.

\section{$\underline{3.14 .4 .6}$ Falls-related mortality}

For mortality, odds ratios and $95 \%$ confidence intervals were estimated using logistic regression, using stratum as a fixed covariate and an adjusted analysis using the baseline parameters (age, gender, screening risk factors).

\subsubsection{Pre-specified sub-group analyses}

Subgroup analysis were carried out using age $(70-85,85+)$ and falls history in the last year $(0-1, \geq 2)$. The statistical significance of differences between subgroups was tested using tests for interaction in the regression models.

Not pre-specified, but nevertheless of interest, a per-protocol analysis and a per day hospital analysis was conducted using the same approach. 


\subsection{Results}

\subsubsection{Data Preparation}

\subsubsection{Error rates in data entry}

A random sample of $10 \%$ of screening forms and diaries was double entered to check for accuracy. The error rate was 33/7073 $(0.47 \%, 95 \%$ CI $0.46-0.48 \%)$,) for baseline data items. For falls diaries the error rate was $21 / 2173(0.97 \%, 95 \%$ CI $0.96-0.98 \%)$, and for the functional outcomes $12 / 4900(0.24 \%, 95 \%$ CI $0.23-0.25 \%)$,). All errors were corrected in the Access database.

The error rate for falls records was less than $1 \%$ - which means that any difference between the two groups of $1 \%$ or less may be due to data entry error, but this level of difference is unlikely to be clinically important.

\section{$\underline{\text { 3.15.1.2 Logical checks }}$}

The randomisation list was obtained from the Clinical Trials Support Unit (CTSU), this contained several data items: stratum (Derby $=0$, Nottingham $=1$ ), unique identifier (corresponding to Access database unique identifier), participants' initials, randomisation date, person requesting randomisation, randomisation number, and allocation ( 1 or 0 ). 364 participants were randomised according to the database, which corresponded to the number in the randomisation list when linked in an Access query, with no discrepancies. The randomisation list and internal database record of allocation were identical. A variety of other cross checks were carried out as detailed in appendix 4.4.

GP and hospital records were checked for evidence of any attendance at a Falls Prevention Programme (FPP). An isolated referral to physiotherapy, hospital doctor or occupational therapist was not coded as FPP unless 
explicitly stated as falls prevention therapy and more than one professional involved; a referral to the intermediate care team referral was considered as a FPP.

\subsubsection{Recruitment}

Recruitment into the randomised controlled trial was challenging; the original estimates suggested 3125 individuals would need to be screened to achieve the desired sample size; in fact, over 6000 individuals were screened. Of those not excluded by their general practice, $2846 / 5312$ (54\%) provided some information, with $52 \%$ of those responding classified as being at high risk of future fall. The overall recruitment rate into the RCT was $364 / 6133(6 \%)$ (Figure 3.2). Of those not excluded during recruitment who were at high risk, 364/1481 (25\%) agreed to participate in the RCT; 181 in the control arm and 183 in the intervention arm. One individual in the intervention arm was excluded after randomisation, as they were subsequently discovered to have attended a day hospital falls prevention programme in the year prior to randomisation. 
Figure 3.2 Overall study recruitment

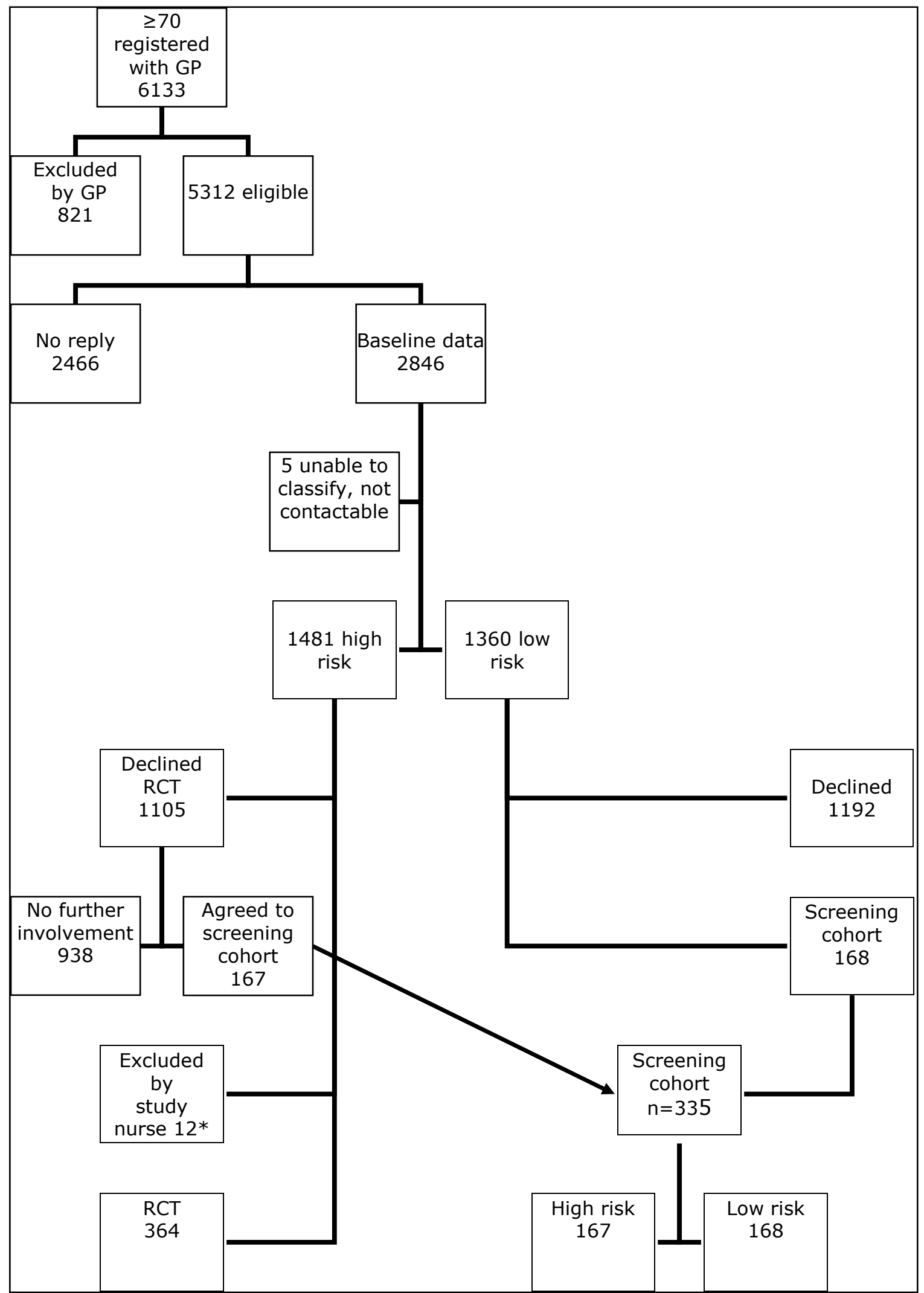

* Reasons for exclusion included residence in a care home (2) or recent attendance at a falls programme (10). 
Participant flow within the RCT is shown in Figure 3.3. Participants were equally randomised between intervention $(n=183)$ and control $(n=181)$ arms.

Figure 3.3 RCT participant flow

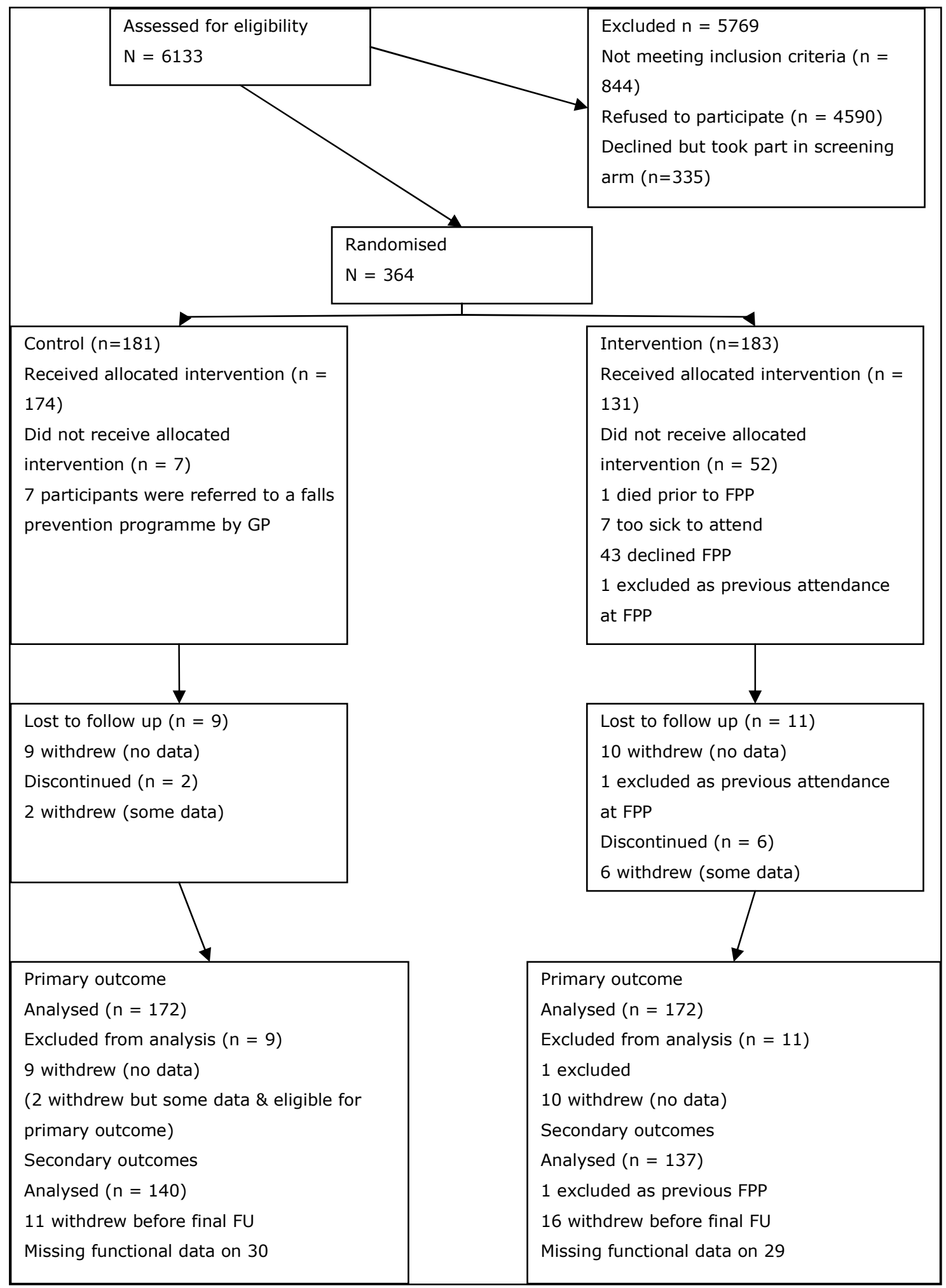


Loss to follow up was similar in both arms of the trial: $11 / 183(6 \%)$ in the intervention arm, compared to $9 / 183(5 \%)$ in the control arm. In both arms losses to follow up were explained by withdrawals, because individuals felt the trial was too burdensome (intervention -9 , control -8 ) or because of ill-health (intervention -1, control - 1), with one person in the intervention arm being excluded after randomisation as they were found to have already attended a falls prevention programme in the previous year. These individuals did not provide any follow up data regarding falls or functional outcomes, though their home circumstances and mortality status at 12 months were known. Losses due to death within the follow up period were the same in both arms (control - 9/181 (5\%), intervention - 9/183(5\%)). More participants discontinued the study in the intervention arm: $6 / 183(3 \%)$ versus $2 / 181(1 \%)$ in the control arm. Again, this was because of the burden imposed by the trial or because of ill-health; however, those that discontinued the trial did provide some follow up data on falls and so are included in the primary outcome analysis.

\subsubsection{Randomisation}

Participants were equally randomised between the two allocation arms and within each of the strata (Table 3.5), although there were five errors in coding stratum, for example individuals resident in Derby stratum were assigned to Nottingham stratum.

Table 3.5 Allocation by stratum

\begin{tabular}{|l|l|l|l|}
\hline & \multicolumn{2}{|l|}{ Randomisation stratum } & \\
\hline $\begin{array}{l}\text { Randomisation } \\
\text { group }\end{array}$ & Derby & Nottingham & Total \\
\hline Control & 61 & 120 & 181 \\
\hline Intervention & 62 & 121 & 183 \\
\hline Totals & 123 & 241 & 364 \\
\hline
\end{tabular}




\subsubsection{Baseline data}

Table 3.6 shows the baseline characteristics of all participants, and then split by allocation. The population recruited to the RCT are similar to those who declined to participate in any aspect of the study in terms of age and gender (Table 2.7), but are at higher falls risk overall - as intended. There was no missing baseline data in those recruited into the RCT.

There are relatively small, but potentially important differences in baseline characteristics comparing the control group to the intervention group, with the intervention group having a slightly 'sicker' profile, although the risk score (sum of the individual risk factors), was the same in both groups. All of the baseline covariates highlighted in bold were included in the adjusted analysis. Stratum was a fixed covariate throughout.

As specified in the protocol and discussed in section 3.2.3.1, we carried out analyses adjusted for the baseline imbalances - in subsequent sections, adjusted analyses refers to adjusting for age, gender and the screening items, crude analysis refers to the inclusion of stratum only as a fixed covariate. 
Table 3.6 Baseline characteristics

\begin{tabular}{|c|c|c|c|c|}
\hline Characteristic & & $\begin{array}{l}\text { All } \\
N=364\end{array}$ & $\begin{array}{l}\text { Control } \\
\mathrm{N}=181\end{array}$ & $\begin{array}{l}\text { Intervention } \\
\mathrm{N}=183\end{array}$ \\
\hline \multirow[t]{2}{*}{ Centre/stratum } & Nottingham & $241(66 \%)$ & $120(66 \%)$ & $121(66 \%)$ \\
\hline & Derby & $123(34 \%)$ & $61(34 \%)$ & $62(34 \%)$ \\
\hline \multirow[t]{3}{*}{ Age (years) } & Mean (SD) & $78.7(5.6)$ & $78.4(5.6)$ & $79.1(5.7)$ \\
\hline & Median (IQR) & $77.8(74.2-82.8)$ & $77.6(73.5-82.9)$ & $78.3(75.0-82.9)$ \\
\hline & Range & $70-101$ & $70-92$ & $70-101$ \\
\hline Female & Frequency (\%) & $218(60 \%)$ & $112(62 \%)$ & $106(58 \%)$ \\
\hline At least one fall in previous 12 months & Frequency (\%) & $210(58 \%)$ & $102(56 \%)$ & $108(59 \%)$ \\
\hline Taking more than 4 medications & Frequency (\%) & $192(53 \%)$ & $89(49 \%)$ & $103(56 \%)$ \\
\hline History of stroke & Frequency (\%) & $53(15 \%)$ & $20(11 \%)$ & $33(18 \%)$ \\
\hline Parkinson's disease & Frequency (\%) & $6(2 \%)$ & $2(1 \%)$ & $4(2 \%)$ \\
\hline $\begin{array}{l}\text { Inability to stand from a chair without using arms to push } \\
\text { up }\end{array}$ & Frequency (\%) & $240(66 \%)$ & $115(64 \%)$ & $125(68 \%)$ \\
\hline Symptoms of dizziness on standing & Frequency (\%) & $218(60 \%)$ & $115(64 \%)$ & $103(56 \%)$ \\
\hline Use of a mobility aid & Frequency (\%) & $182(50 \%)$ & $86(48 \%)$ & $96(52 \%)$ \\
\hline Housebound/not housebound (mobility impairment) & Frequency (\%) & $83(23 \%)$ & $39(22 \%)$ & $44(24 \%)$ \\
\hline $\begin{array}{l}\text { Mini-mental state examination } \\
\text { (median (IQR) }\end{array}$ & & Not available & & $\begin{array}{l}29(28-30) \\
\text { Range } 15-30 \\
n=101 \\
8 / 101(8 \%) \text { had } \\
\text { an MMSE } \leq 24 / 30\end{array}$ \\
\hline Risk score (sum of screening risk factors) & Median (IQR) & $3(2-4)$ & $3(2-4)$ & $3(2-4)$ \\
\hline
\end{tabular}




\subsection{Describing the intervention}

\subsubsection{Behavioural mapping}

The behavioural mapping exercise was carried out at one site only (QMC), as unfortunately additional staffing and funding could not be obtained to complete the process in the other sites.

The results of the behavioural mapping study have been reported elsewhere ${ }^{410}$, but are summarised here in brief.

'23 patients (median age $81.5,37.5 \%$ male) were observed over a total of 35 patient-days at QMC day hospital. $68 \%$ of time was spent in rest, $10 \%$ in physiotherapy, $2 \%$ in occupational therapy. $49 \%$ of patient time was spent alone, $33 \%$ with other patients; the remainder of time with health care professionals. $13 \%$ of time was spent in therapy, which was mainly relevant to falls prevention.

The proportion of time spent in therapy in a day hospital is small, but consistent with previous mapping studies. We have developed a useful tool to describe activity in the day hospital, but further validation work is required.'

\subsubsection{Day hospital attendances and logs}

Four percent (7/181) of the controls group actually attended a day hospital falls prevention programme (FPP), referred by their GP as part of usual care; $131 / 183(72 \%)$ of the intervention group attended.

The median number of recorded attendances at the FPP was $2(0-8)$ in the intervention group. There was significant variation between day hospitals QMC $2(0-10)$, NCHT $6(1-8)$ and DRI $1(0-4), \mathrm{p}=0.025$ (Figure 3.4). 
Figure 3.4 Number of FPP attendances by day hospital

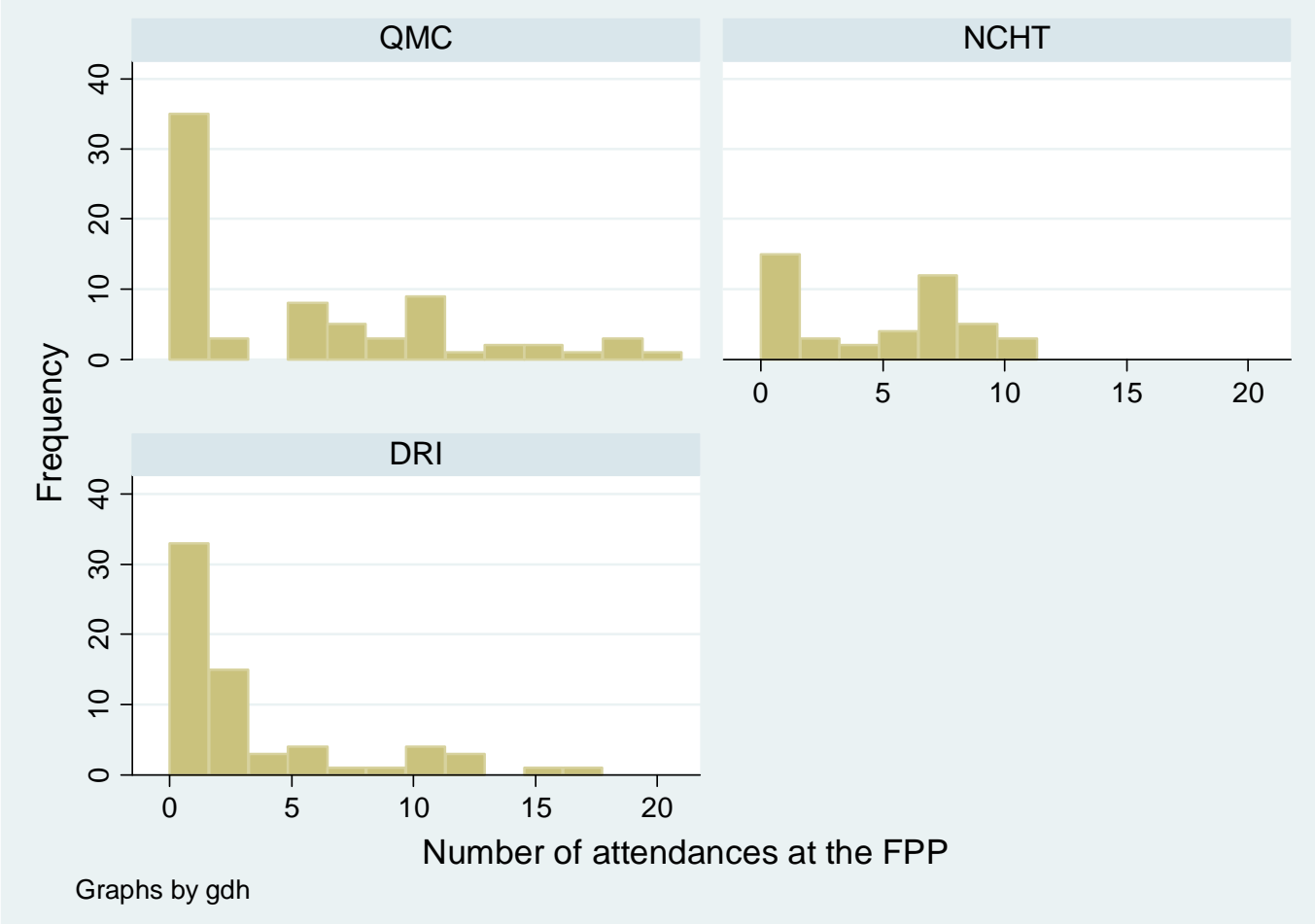

The reasons for non-attendance were not logged systematically, but we did collate comments recorded on the monthly diaries relevant to this issue. The main reasons for non-attendance relate to negative views of treatment ('when attending the Leengate Clinic on 23rd I suffered a pulled muscle. The injury is responding to complete rest and dressing with Ibuleve, but I shall not be able to participate in physiotherapy until I have recovered. To avoid the risk of further injury I shall not attend any more sessions at the clinic. All your papers are enclosed' and not feeling the need to be in the study ('really I feel a big fraud... maybe there are more deserving people than I', '... as I haven't had any falls this month. This is not unusual for me in fact it's normal. Sorry to have wasted your time. It's over a year since I had a fall. However there's no pattern to it, it just occasionally happens.' Some participants did not perceive the therapy to be useful to them ('Withdrawn from Day hospital - did not feel it was beneficial to him, feels too fit to attend. Will continue with diaries.' 
The contribution of individual disciplines to each individuals care in the falls prevention programme was obtained from the day hospital logs. These were completed voluntarily by the day hospital staff, with limited accuracy (no formal training or test of reliability), and often with substantial amounts of missing data (up to one-third missing). It is not possible to be sure if the missing data indicates not seen, or just missing. Nevertheless, the day hospital logs provide some insight into the processes taking place in the different units, as detailed in Table 3.7. Clearly, these data only apply to those individuals who actually did attend the day hospital. The data in Table 2.7 indicate that there are important differences between the three falls prevention programmes, suggesting that the interventions being delivered are not uniform across the three units. 
Table 3.7 Characteristics of each day hospital falls prevention programme

\begin{tabular}{|c|c|c|c|c|}
\hline & $\begin{array}{l}\text { QMC } \\
\text { Median (IQR) }\end{array}$ & $\begin{array}{l}\text { NCHT } \\
\text { Median (IQR) }\end{array}$ & $\begin{array}{l}\text { DRI } \\
\text { Median (IQR) }\end{array}$ & $\begin{array}{l}\text { Significance test } \\
\text { (median test) }\end{array}$ \\
\hline $\begin{array}{l}\text { Attendance rate } \\
\text { (turned up at least once) }\end{array}$ & $45 / 74(61 \%)$ & $38 / 45(84 \%)$ & $48 / 67(72 \%)$ & \\
\hline Number of medical reviews per participant & $8(5-11)$ & $7(2-8)$ & $2(1-6)$ & $P=0.001$ \\
\hline Nature of medical assessment & $\begin{array}{l}\text { Junior staff overseen } \\
\text { by consultant }\end{array}$ & $\begin{array}{l}\text { Junior staff } \\
\text { overseen by } \\
\text { consultant }\end{array}$ & $\begin{array}{l}\text { All patients } \\
\text { assessed initially } \\
\text { by consultant, } \\
\text { varying input } \\
\text { thereafter }\end{array}$ & \\
\hline Number of occupational therapy reviews & $8(4.5-11)$ & $7(1.75-8)$ & $2(1-5.75)$ & $P=0.001$ \\
\hline Duration of occupational therapy input (minutes) & $45(30-7)$ & $92.5(77.5-122.5)$ & $60(48.75-83.75)$ & $P=0.012$ \\
\hline Number of physiotherapy reviews & $8(5-11)$ & $7(2-8)$ & $2(1-5.75)$ & $\mathrm{P}<0.001$ \\
\hline Duration of physiotherapy reviews (minutes) & $255(131.25-367.5)$ & $310(230-435)$ & $65(60-315)$ & $P=0.001$ \\
\hline $\begin{array}{l}\text { Falls incidence rate } \\
\text { (per person-year) }\end{array}$ & $1.77(1.44-2.14)$ & $1.83(1.42-2.32)$ & $1.56(1.26-1.92)$ & \\
\hline
\end{tabular}




\subsubsection{Describing the primary outcome}

Falls were ascertained through the monthly diaries, 172 participants in each group completed at least some falls diaries and so were eligible for primary outcome analysis. In total 3749 monthly falls diaries were returned, 1908 in the control group and 1841 in the intervention group. The median number of diaries returned was 12 (IQR 12-12) in both groups. There was no significant difference between the two arms in the median number of diaries returned (Mann-Whitney p-value 0.61).

Table 3.8 Diary returns by allocation group

\begin{tabular}{|l|c|c|}
\hline & $\begin{array}{l}\text { Control } \\
(\mathrm{n}=181)\end{array}$ & $\begin{array}{l}\text { Intervention } \\
(\mathrm{n}=183)\end{array}$ \\
\hline Number of diaries returned & 1908 & 1841 \\
\hline Median (IQR) number of diaries returned & $12(12-12)$ & $12(12-12)$ \\
\hline Number returning 12 diaries & $138(76 \%)$ & $136(74 \%)$ \\
\hline Number returning 11 diaries & $8(4 \%)$ & $3(2 \%)$ \\
\hline Number returning 10 diaries & $3(2 \%)$ & $4(2 \%)$ \\
\hline Number returning 9 diaries & $3(2 \%)$ & $4(2 \%)$ \\
\hline Number returning 8 diaries & $2(1 \%)$ & $1(1 \%)$ \\
\hline Number returning 7 diaries & $4(2 \%)$ & $6(3 \%)$ \\
\hline Number returning 6 diaries & $7(4 \%)$ & $2(1 \%)$ \\
\hline Number returning 5 diaries & $2(1 \%)$ & $1(1 \%)$ \\
\hline Number returning 4 diaries & $1(1 \%)$ & $2(1 \%)$ \\
\hline Number returning 3 diaries & $1(1 \%)$ & $3(2 \%)$ \\
\hline Number returning 2 diaries & $1(1 \%)$ & $6(3 \%)$ \\
\hline Number returning 1 diaries & $2(1 \%)$ & $4(2 \%)$ \\
\hline Number returning 0 diaries & $9(5 \%)$ & $11(6 \%)$ \\
\hline
\end{tabular}

In total, 677 falls were reported over 304.55 person-years; the overall falls rate was 2.2 (95\% CI 2.1-2.4) falls per person-year. The proportion of non-fallers and recurrent fallers is shown in Table 3.9. 
Table 3.9 Proportion of fallers by allocation

\begin{tabular}{|l|l|l|}
\hline Number of falls & $\begin{array}{l}\text { Control group } \\
\mathrm{n}=172\end{array}$ & $\begin{array}{l}\text { Intervention group } \\
\mathrm{n}=172\end{array}$ \\
\hline None & $82(48 \%)$ & $86(50 \%)$ \\
\hline 1 fall only & $37(22 \%)$ & $41(24 \%)$ \\
\hline 2 or more falls & $53(31 \%)$ & $45(26 \%)$ \\
\hline
\end{tabular}

There were 417 falls over 156.7 person-years ( 2.7 falls per person-year) in the control group compared to 260 falls over 151.2 person-years ( 1.7 falls per person-year) in the intervention group. Individual falls rates (number of falls per person/time under follow up) are shown in Figure 3.5, the extreme outlier in the control group was id=389, who had 107 falls over 11 months of follow up.

Figure 3.5 Box and whisker plot of individual falls rate by allocation

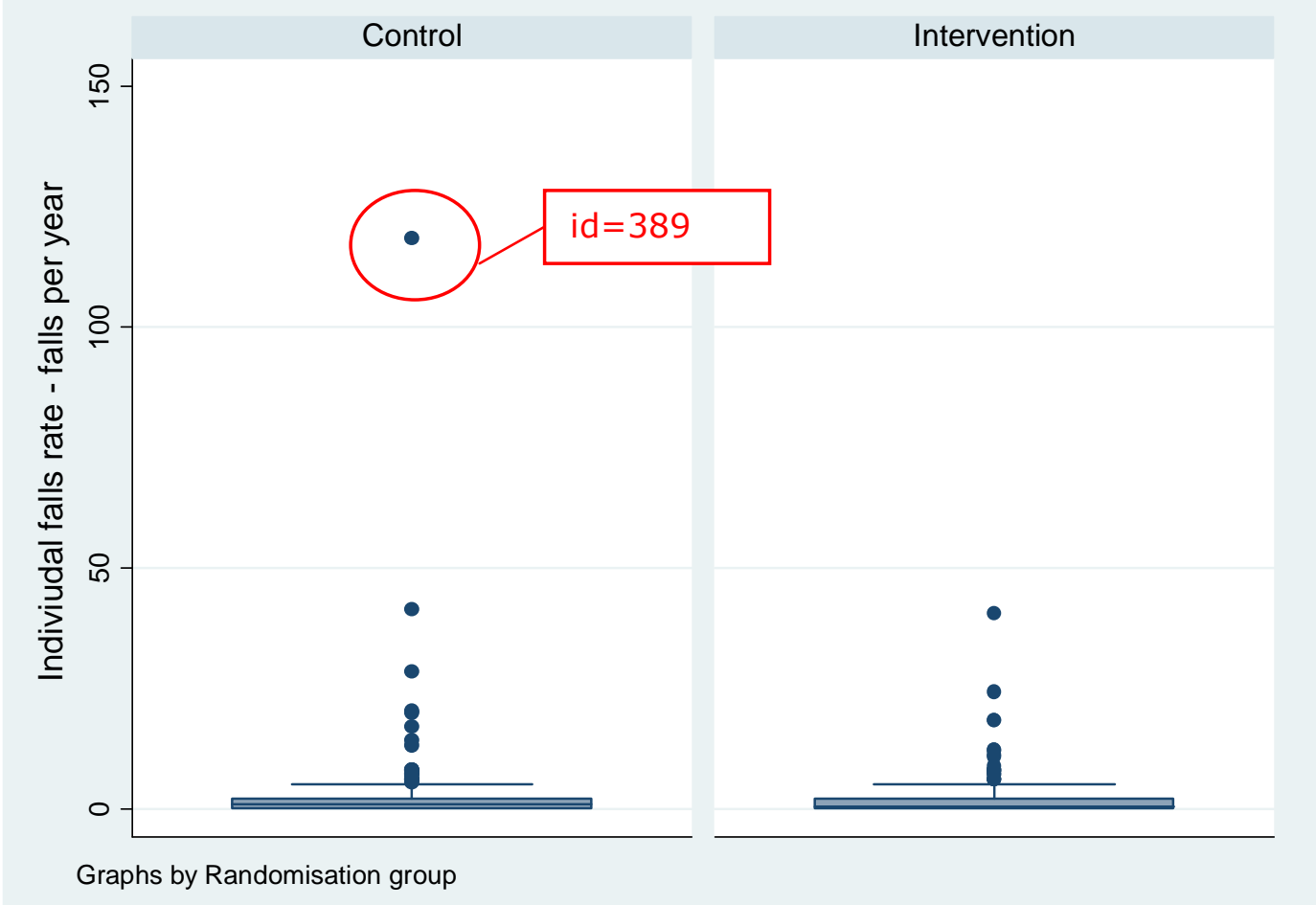

The crude incidence rate ratio adjusted for stratum, using Poisson regression to compare the intervention group against the control group was 0.65 (95\% CI $0.55-0.74), p<0.0001$. However, the goodness of fit test was 
highly significant $(p<0.0001)$, indicating that the Poisson model was a poor fit for the data. The crude analysis excluding the outlier id=389 gave an incidence rate ratio of $0.86(95 \%$ CI $0.73-1.01), p=0.075$ but Pearson's goodness of fit test remained highly significant $(p<0.0001)$, indicating that these data, even with the outlier removed, do not fit a Poisson model.

Using a negative binomial regression model, the crude incidence rate ratio was $0.64(95 \%$ CI $0.43-0.95) p=0.025$. The deviance residual scores are shown in Figure 3.6. These scores should normally lie within $+/-2$ standard deviations ${ }^{407}$, which is the case of most participants except the participant with id 389, who had 107 falls over 12 months of follow up. Further regression diagnostic tests shown in appendix 4.5.1 all indicated a relatively poor model fit for this participant, who still had high leverage and influence.

Figure 3.6 Scatterplot of deviance residuals against study id

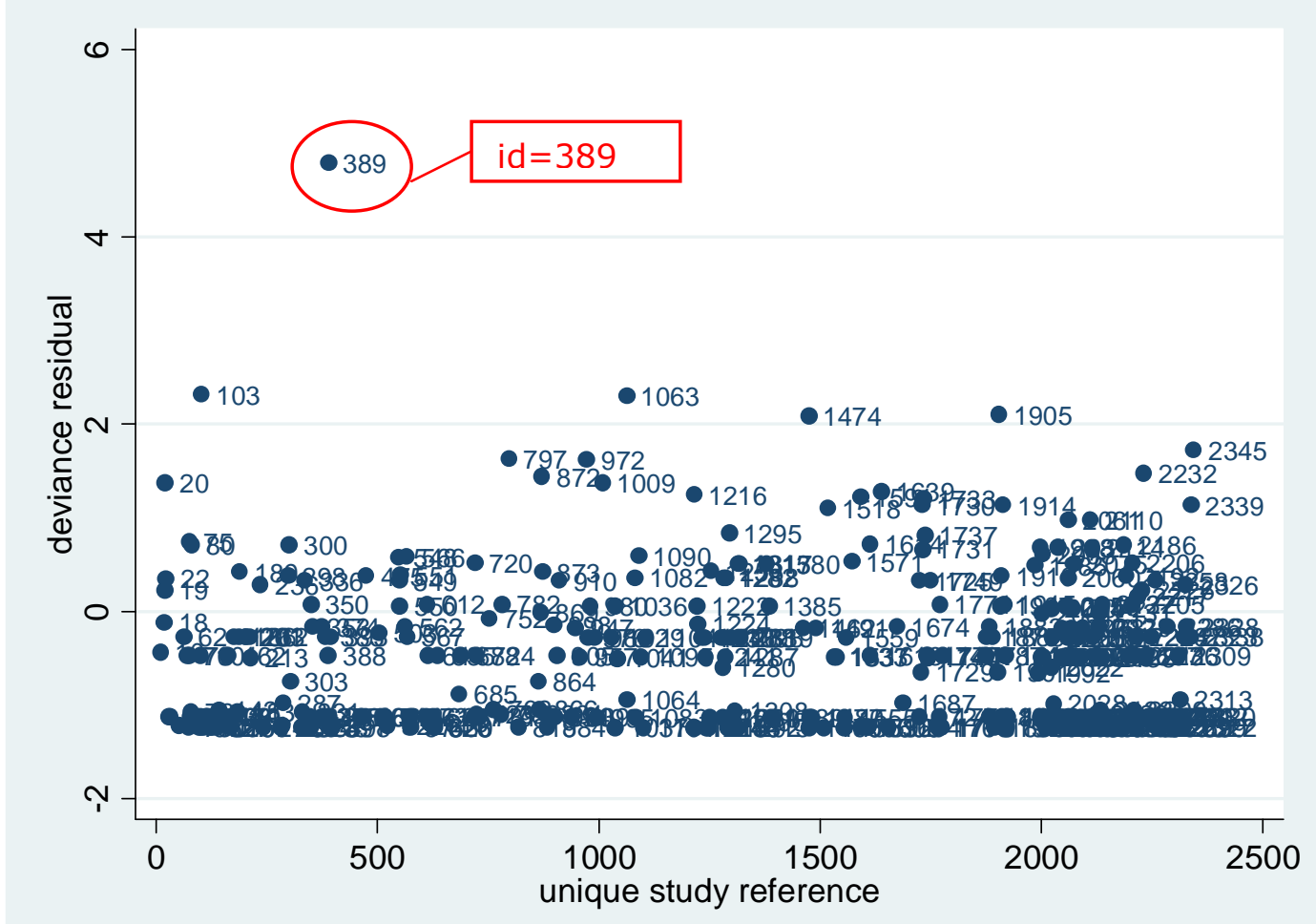


A sensitivity analysis was carried out excluding id 389; other investigators have excluded extreme outliers when analysing fall rates ${ }^{411}$. The rate of falls in the control group excluding id 389 was 2.0 compared to 2.7 falls per person-year when id 389 was included. The overall falls rate fell from 2.2 (95\% CI 2.1-2.4) including id 389, to 1.9 (95\% CI 1.8-2.1) without id 389. The resultant incidence rate ratio (IRR) comparing control and intervention groups was 0.86 ( $95 \%$ CI $0.59-1.25), p=0.424$. This time the Generalised Linear Model (GLM) diagnostics showed a better fit (Cook's $<0.2$, leverage $<0.15$ and dbeta $<2.5)$ for all participants, and although these values are still relatively high, no individual stood out other than id 389. Introducing age-squared showed no evidence of non-linearity, likelihood ratio test $p=0.987$.

The negative binomial regression to be the most appropriate analysis for the data, and excluding id 389 appears reasonable - the extreme rate of falls in this individual are best shown in Figure 3.6. All analyses concerning rates described below exclude id 389 .

\subsubsection{Adjusted analysis}

Given that adjusting for baseline imbalances had been pre-specified in the study protocol ${ }^{412}$ and all of the baseline covariates are prognostically important for falls (see 3.2.3.1), an adjusted analysis was carried out using all of the baseline covariates. The adjusted analysis included all of the screening items, age and gender, as well as stratum.

Using the adjusted negative binomial regression model, the IRR was 0.73 (95\% CI $0.51-1.03), p=0.071$. The regression diagnostics did not suggest that the assumptions for the model had been violated (Cook's $<0.14$, and leverage <0.24). Introducing 'age squared' as a parameter gave a likelihood ratio test of $p=0.681$, indicating no evidence of a non-linear relationship with age, which was therefore retained as a (centred) 
continuous variable. Table 3.10 summarises the key analyses for the primary outcome.

Table 3.10 Summary of the primary outcome analyses

\begin{tabular}{|c|c|c|}
\hline & Unadjusted & Adjusted \\
\hline \multicolumn{3}{|c|}{ Results with participant id $=389$ retained } \\
\hline Poisson regression & $\begin{array}{l}0.65 \text { (95\% CI 0.55- } \\
0.74), p<0.0001\end{array}$ & \\
\hline $\begin{array}{l}\text { Negative binomial } \\
\text { regression }\end{array}$ & $\begin{array}{l}0.69(95 \% \text { CI } 0.46- \\
1.02), p<0.001\end{array}$ & \\
\hline \multicolumn{3}{|c|}{ Results with participant id $=389$ excluded } \\
\hline Poisson regression & $\begin{array}{l}0.86 \text { (95\% CI } 0.73- \\
1.01), p=0.075\end{array}$ & \\
\hline $\begin{array}{l}\text { Negative binomial } \\
\text { regression }\end{array}$ & $\begin{array}{l}0.86(95 \% \text { CI } 0.73- \\
1.01), p=0.075\end{array}$ & $\begin{array}{l}0.73(95 \% \text { CI } 0.51- \\
1.03), p=0.071\end{array}$ \\
\hline
\end{tabular}

\subsubsection{Sub-group analyses}

Two sub-group analyses were pre-specified, by age category $(70-84,85+)$ and by previous fall status and two additional unplanned subgroup analyses were performed (gender and stratum) - Table 3.11. These analyses look for a differential effect within each parameter - for example, examining if the effect of the intervention is different depending on whether or not the individual has had a previous fall. If there was evidence of a differential effect, indicated by a large or small incidence rate ratio for the interaction parameter (effect in previous fallers divided by effect in those without previous fall), and a significant $p$-value result in the 
likelihood ratio test for the interaction, then it would have been appropriate to report the results by sub-groups.

Table 3.11 Sub-group analyses

\begin{tabular}{|l|l|l|}
\hline Sub-group analysis & $\begin{array}{l}\text { Incidence rate ratio for the } \\
\text { interaction }(95 \% \mathrm{CI})\end{array}$ & $\begin{array}{l}\text { Likelihood ratio } \\
\text { test p-value }\end{array}$ \\
\hline $\begin{array}{l}\text { Age category*allocation } \\
\text { (70-84 vs. } 85+\text { ) }\end{array}$ & $1.3(0.5-3.4)$ & 0.572 \\
\hline $\begin{array}{l}\text { Previous fall*allocation } \\
\text { (previous fall vs. no previous fall) }\end{array}$ & $0.7(0.4-1.5)$ & 0.384 \\
\hline $\begin{array}{l}\text { Gender*allocation } \\
\text { (male vs. female) }\end{array}$ & $0.8(0.4-1.6)$ & 0.574 \\
\hline $\begin{array}{l}\text { Stratum*allocation } \\
\text { (Derby vs., Nottingham) }\end{array}$ & $1.7(0.8-3.5)$ & 0.144 \\
\hline
\end{tabular}

None of these analyses show significant evidence of a differential effect according sub-group.

\subsubsection{Per-protocol analysis (post-hoc)}

Attendance at, and engagement with a FPP, whether delivered by primary care or in the day hospital, was arbitrarily designated as more than one attendance at the day hospital FPP or evidence from primary care records of multidisciplinary input into falls management. Irrespective of RCT allocation, 134/344 (39\%) individuals attended some form of FPP. The rate of falls in those attending a FPP was 2.1 (95\% CI 1.9-2.4) fall per personyear, compared to 2.3 (95\% CI $2.1-2.5)$ in those not attending a FPP. The incidence rate ratio for falls by attendance at a FPP was 0.39 (95\% CI $0.11-1.40)$, which is a potentially clinically important effect size, but the likelihood ratio test was $p=0.134$, so it is not statistically significant.

\subsubsection{Secondary analyses}

The pre-specified and post hoc secondary analyses are presented in Table 3.12. With respect to the model checking for these analyses, Parkinson's 
disease exerted significant leverage, but a sensitivity analysis excluding those with high leverage values, did not substantially alter the result. For uncommon events, such as death during follow up and admission to a care home, the model was a poor fit for those who had the event, but otherwise robust. The Cox proportional hazards model tests showed crossover over time and some collinearity with baseline characteristics, making the model unreliable; this was not a pre-specified analysis.

Table 3.12 Secondary outcome analyses

\begin{tabular}{|c|c|c|c|c|}
\hline \multirow[t]{2}{*}{ Outcome } & \multicolumn{2}{|c|}{ Descriptive data } & \multirow{2}{*}{$\begin{array}{l}\text { Crude analysis } \\
\text { Effect size } \\
\text { (95\% CI), } \\
\text { significance }\end{array}$} & \multirow{2}{*}{$\begin{array}{l}\begin{array}{l}\text { Adjusted } \\
\text { analysis }\end{array} \\
\text { Effect size } \\
(95 \% \mathrm{CI}), \mathrm{p}- \\
\text { value }\end{array}$} \\
\hline & Control & Intervention & & \\
\hline $\begin{array}{l}\text { Proportion of } \\
\text { people falling over } \\
12 \text { months (OR) }\end{array}$ & $\begin{array}{l}73 / 138 \\
(53 \%)\end{array}$ & $\begin{array}{l}69 / 136 \\
(51 \%)\end{array}$ & $\begin{array}{l}0.90 \\
(0.56-1.46) \\
p=0.672\end{array}$ & $\begin{array}{l}0.91 \\
(0.54-1.53) \\
p=0.725\end{array}$ \\
\hline $\begin{array}{l}\text { The proportion of } \\
\text { participants with } \\
\text { two or more falls } \\
\text { (OR) }\end{array}$ & $\begin{array}{l}38 / 138 \\
(28 \%)\end{array}$ & $\begin{array}{l}38 / 136 \\
(28 \%)\end{array}$ & $\begin{array}{l}1.01 \\
(0.59-1.72) \\
p=0.969\end{array}$ & $\begin{array}{l}0.98 \\
(0.51-1.76) \\
p=0.933\end{array}$ \\
\hline $\begin{array}{l}\text { The proportion of } \\
\text { people with self- } \\
\text { reported injurious } \\
\text { falls (OR) }\end{array}$ & $\begin{array}{l}55 / 138 \\
(40 \%)\end{array}$ & $\begin{array}{l}56 / 136 \\
(41 \%)\end{array}$ & $\begin{array}{l}1.05 \\
(0.64-1.70) \\
p=0.856\end{array}$ & $\begin{array}{l}1.08 \\
(0.64-1.82) \\
p=0.778\end{array}$ \\
\hline $\begin{array}{l}\text { The proportion of } \\
\text { people } \\
\text { institutionalised at } \\
12 \text { months (OR) }\end{array}$ & $\begin{array}{l}1 / 170 \\
(<1 \%)\end{array}$ & $\begin{array}{l}3 / 166 \\
(<1 \%)\end{array}$ & $\begin{array}{l}3.1 \\
(0.3-30.2) \\
P=0.328\end{array}$ & $\begin{array}{l}4.8 \\
(0.3-73.1) \\
P=0.260\end{array}$ \\
\hline $\begin{array}{l}\text { Mortality at } 12 \\
\text { months (OR) }\end{array}$ & $\begin{array}{l}9 / 181 \\
(5 \%)\end{array}$ & $\begin{array}{l}9 / 182 \\
(5 \%)\end{array}$ & $\begin{array}{l}1.0 \\
(0.4-2.6) \\
P=0.994\end{array}$ & $\begin{array}{l}0.8 \\
(0.3-2.4) \\
P=0.705\end{array}$ \\
\hline $\begin{array}{l}\text { Mortality rates in } \\
\text { person -years } \\
\text { (IRR) } \\
\text { (post-hoc) }\end{array}$ & $\begin{array}{l}0.05 \\
(95 \% \mathrm{CI} \\
0.03-0.10)\end{array}$ & $\begin{array}{l}0.05 \\
(95 \% \text { CI } \\
0.03-0.10)\end{array}$ & $\begin{array}{l}0.89 \\
(0.34-2.30) \\
p=0.804\end{array}$ & $\begin{array}{l}0.7 \\
(0.3-2.0) \\
p=0.543\end{array}$ \\
\hline
\end{tabular}


None of the secondary outcomes described in Table 3.12 showed any strong evidence of a differential effect in a per protocol analysis based on attendance at a fall prevention programme.

\subsubsection{Proportion of people with medically verified injurious falls}

Primary care recorded falls data were abstracted from primary care records, injuries are coded according to the Severity of Injury Scale, and are shown in Table 3.13. Data are only available for those individuals who have a consultation with their GP documented.

Table 3.13 Verified severity of injury during GP fall consultation

\begin{tabular}{|l|l|l|}
\hline Abbreviated injury rating & Controls $\mathrm{n}=22$ & Intervention $\mathrm{n}=18$ \\
\hline No injury & $9(41 \%)$ & $6(33 \%)$ \\
\hline Minor (abrasion, contusion) & $10(45 \%)$ & $9(50 \%)$ \\
\hline $\begin{array}{l}\text { Moderate (laceration, tissue tear, } \\
\text { haematoma, impaired mobility due to } \\
\text { injury, fear of subsequent fall and fall } \\
\text { injury) }\end{array}$ & $2(9 \%)$ & $3(17 \%)$ \\
\hline $\begin{array}{l}\text { Serious (fracture, multiple fracture, } \\
\text { subdural haematoma, head injury) }\end{array}$ & $1(5 \%)$ & $0(0 \%)$ \\
\hline Total & 22 & 18 \\
\hline
\end{tabular}

Pearson chi squared test for trend ( 3 degrees of freedom) $p=0.690$.

There was no significant difference between the two groups when primary care verified injurious fall was dichotomised (no injury vs. injury) in the crude analysis (OR $1.4(95 \%$ CI $0.4-5.3), p=0.601)$, or in the adjusted analysis (OR $2.6(95 \% C I \quad 0.3-22.1), p=0.387)$.

Secondary care recorded falls data were abstracted from secondary care records, and injuries were coded according to the Severity of Injury Score. Again, data are only available for those individuals who have a documented fall-related hospital attendance.

24/135 (18\%) in the intervention group had a verified ED attendance compared to $24 / 137(18 \%)$ in the control group; the figures for falls- 
related ED attendances were 13/24 (55\%) for both groups - 11 of which were associated with an injury in both (Table 3.14).

Table 3.14 Verified severity of injury at ED attendance

\begin{tabular}{|l|l|l|}
\hline & Controls $\mathrm{n}=24$ & Intervention $\mathrm{n}=24$ \\
\hline None & $13(54 \%)$ & $13(54 \%)$ \\
\hline Minor & $4(17 \%)$ & $5(21 \%)$ \\
\hline Moderate & $3(13 \%)$ & $5(21 \%)$ \\
\hline Serious & $4(17 \%)$ & $1(4 \%)$ \\
\hline
\end{tabular}

Pearson chi squared test for trend ( 3 degrees of freedom) $p=0.492$.

Nor were there any significant differences in the ED visits with an injurious fall when ED verified injurious falls were dichotomised (no injury vs.

injury): in the crude analysis the odds ratio was 1.0 (95\% CI $0.3-3.1$, $\mathrm{p}=0.991$, and in the adjusted analysis the odds ratio was 1.3 (95\% CI 0.2 8.0), $p=0.760$.

\section{$\underline{3.16 .6 .2}$ Time to first fall}

The median time to first fall in days was 271 in the control group, compared to 292 in the intervention group. The crude hazard ratio was 0.9 (95\% CI $0.7-1.3), p=0.625$; the adjusted hazard ratio was 0.9 ( $95 \%$ CI $0.7-1.3$ ), $p=0.622$ (Figure 3.7). 
Figure 3.7 Time to first fall by allocation - unadjusted analysis

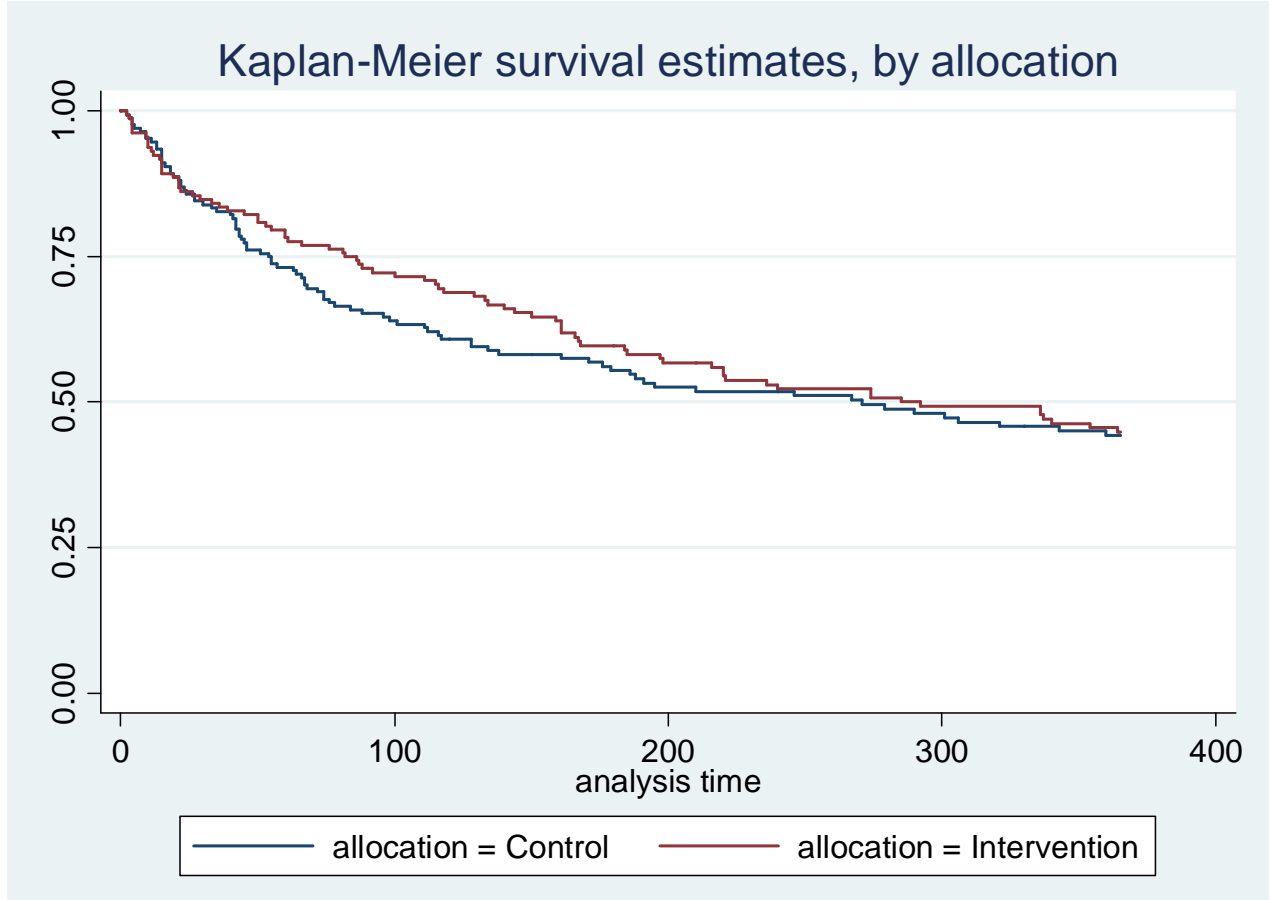

\subsubsection{Second fall outcomes (not pre-specified)}

$38 / 73(52 \%)$ of controls who had one fall had at least one more fall versus $38 / 69(55 \%)$ of those in the intervention group had a second fall, crude odds ratio 1.1 (95\% CI $0.6-2.2), p=0.717$, adjusted odds ratio 0.9 (95\% CI $0.4-2.0), \mathrm{p}=0.826$.

The median time to second fall after the first fall was 55 days in the control group compared to 87 days in the intervention group (Figure 3.8). The crude hazard ratio for time to second fall was 0.9 (95\% CI 0.5-1.2), $\mathrm{p}=0.248$. The adjusted hazard ratio was 0.7 (95\% CI $0.5-1.1), p=0.103$. 
Figure 3.8 Time to second fall - unadjusted analysis

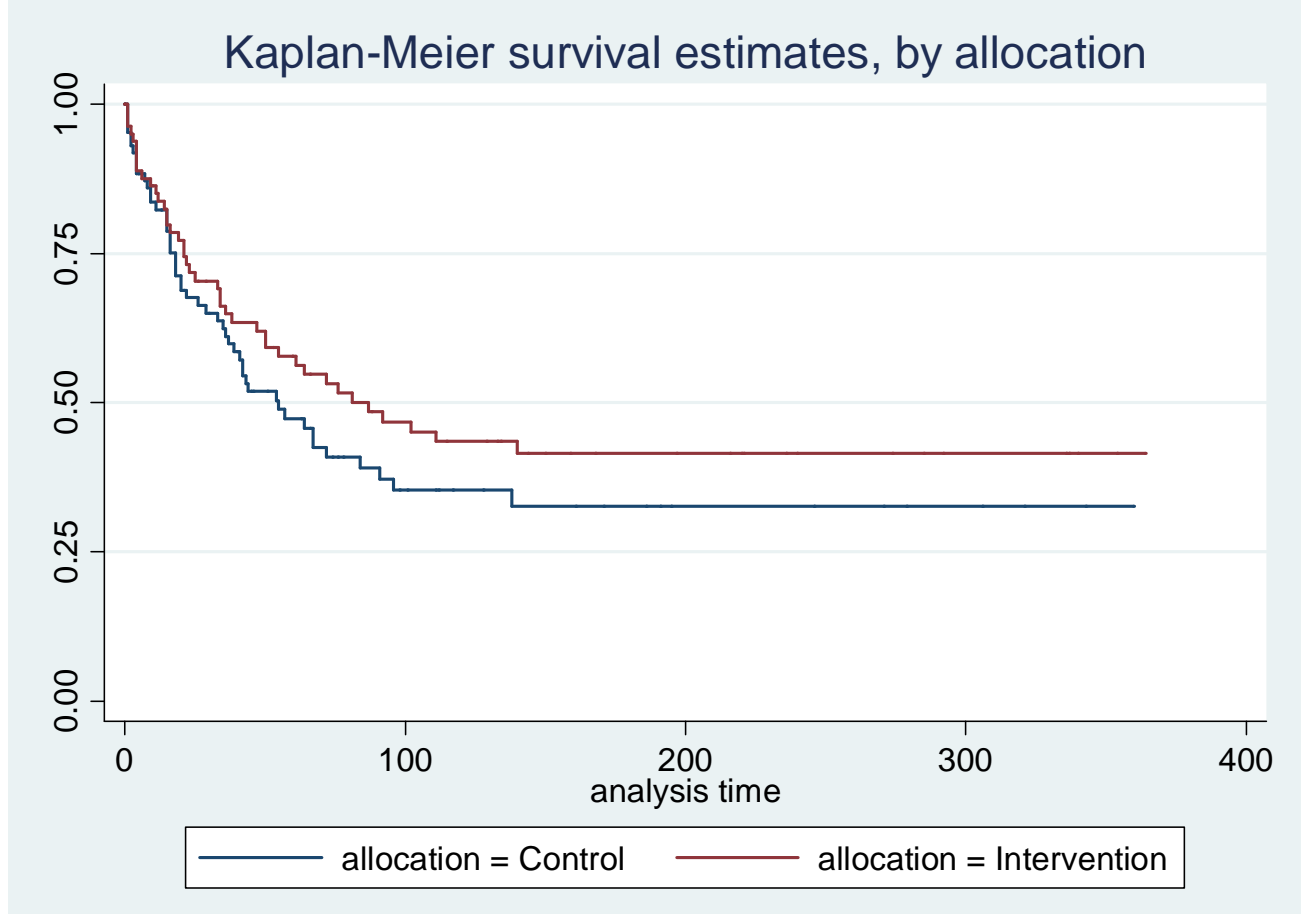

\subsubsection{Impact on disability, quality of life and fear of falls}

There data missing on functional outcomes for 38 controls and 46 in the intervention group. In view of the missing data, a multiple imputation model was run including all of the baseline covariates. 10 datasets were created using the multiple imputation command (ICE) in Stata, with missing data being generated with a random component, but which incorporates the known baseline parameters.

Personal ADLs were measured using the Barthel score, with a possible range of scores from 0 (extremely dependant) to 20 (independent). The Barthel scores were negatively skewed and no transformations rendered the score near normal. The Barthel scores were dichotomised at the median (19/20). The median (IQR) scores for both groups were identical 19 (17-20). The results for the original and imputed datasets are detailed in Table 3.15. 
Extended activities of daily living (outdoor mobility, domestic tasks, social interaction etc) were measured using the Nottingham Extended Activities of Daily Living score, with a possible range of 0 (severely restricted) to 66 (independent). Again the distribution was very skewed, so the results were dichotomised at the group median (56 out of 66 ). Table 3.15 shows the adjusted and imputed estimates.

Fear of falling was assessed using the Falls Efficacy Scale, this is a ten item scale asking about the level of fear of falling in a variety of daily activities; each item is graded from 1-10, with ten indicating the most fear (least confidence) and the maximum score possible is 100 . The FES data was similarly skewed and so was dichotomised at the group median (17/100) see Table 3.15.

Quality of life was measured using the five item EuroQoL, scored 1, 2 or 3 with higher values indicting worse quality of life. Skewed data again demanded non-parametric analysis around the group median of 8 (6-9) see Table 3.15. 
Table 3.15 Imputed data compared to original data

\begin{tabular}{|c|c|c|c|c|c|c|}
\hline Outcome & $\begin{array}{l}\text { Control } \\
\mathrm{N}=172 \\
\text { [number of missing values] }\end{array}$ & $\begin{array}{l}\text { Intervention } \\
\mathrm{N}=172 \\
\text { [number of missing } \\
\text { values] }\end{array}$ & $\begin{array}{l}\text { Adjusted odds } \\
\text { ratio (95\% CI), } \\
\text { significance }\end{array}$ & $\begin{array}{l}\text { Imputed - } \\
\text { control } \\
\mathrm{N}=1720\end{array}$ & $\begin{array}{l}\text { Imputed - } \\
\text { intervention } \\
\mathrm{N}=1720\end{array}$ & $\begin{array}{l}\text { Imputed data } \\
\text { adjusted odds } \\
\text { ratio }(95 \% \mathrm{CI})\end{array}$ \\
\hline $\begin{array}{l}\text { Barthel score } \\
\text { Median (IQR) }\end{array}$ & $\begin{array}{l}19(17-20) \\
{[29]}\end{array}$ & $\begin{array}{l}19(17-20) \\
{[35]}\end{array}$ & $\begin{array}{l}1.4(0.8-2.4) \\
p=0.184\end{array}$ & $19(17-20)$ & $19(18-20)$ & $\begin{array}{l}1.38(0.80-2.36) \\
p=0.248\end{array}$ \\
\hline $\begin{array}{l}\text { NEADL score } \\
\text { Median (IQR) }\end{array}$ & $\begin{array}{l}56(43.75-61) \\
{[34]}\end{array}$ & $\begin{array}{l}53(43-62) \\
{[45]}\end{array}$ & $\begin{array}{l}1.0(0.5-1.8) \\
p=0.884\end{array}$ & $54(43-61)$ & $51(40.7-61)$ & $\begin{array}{l}0.82(0.45-1.52) \\
p=0.532\end{array}$ \\
\hline $\begin{array}{l}\text { FES score } \\
\text { Median (IQR) }\end{array}$ & $\begin{array}{l}18(10-41) \\
{[29]}\end{array}$ & $\begin{array}{l}16(10-38) \\
{[37]}\end{array}$ & $\begin{array}{l}0.8(0.4-1.3) \\
p=0.312\end{array}$ & $19(10-41.4)$ & $17(10-39)$ & $\begin{array}{l}0.75(0.43-1.31) \\
p=0.312\end{array}$ \\
\hline $\begin{array}{l}\text { EuroQoL } \\
\text { (median (IQR) }\end{array}$ & $\begin{array}{l}8(6-9) \\
{[38]}\end{array}$ & $\begin{array}{l}7(6-8) \\
{[27]}\end{array}$ & $\begin{array}{l}0.5(0.3-0.9) \\
p=0.027\end{array}$ & $8(6-9)$ & $7.5(6-9)$ & $\begin{array}{l}0.74(0.41-1.35) \\
p=0.334\end{array}$ \\
\hline
\end{tabular}


These original data show no significant differences between the two arms of the RCT in terms of Barthel, NEADL and FES scores, but a slightly benefit in the EuroQoL score (OR 0.3-0.9). However, the advantage in terms of quality of life was not seen in the sensitivity analysis based on the imputed dataset.

\section{$\underline{3.16 .6 .5}$ Health service resource use}

Participants were asked to record any visits to their general practitioner (GP) in their monthly diary returns, along with the duration of the visit. These reports were not constrained to falls alone, but reflected all care needs. As with many of the secondary outcomes, the distribution was heavily skewed and could not be adequately transformed into a normal approximation, and data were dichotomised about the group median (see Table 3.16).

We also collected verified GP attendances from primary care records. The self reported visits and verified GP visits were only moderately well correlated $(r=0.62)$; an analysis of variance revealed $r^{2}$ to be 0.66 , adjusted $r^{2} 0.62, p<0.0001$. This is perhaps best shown in Figure 3.9, a Bland-Altman plot of the difference of paired variables versus their average; the mean difference was -1.34 visits ( $95 \%$ CI -1.86 to -0.82 ), suggesting that GP records underestimate the true burden of falls. 
Figure 3.9 Bland-Altman plot of mean difference versus average score for self reported and verified GP visits

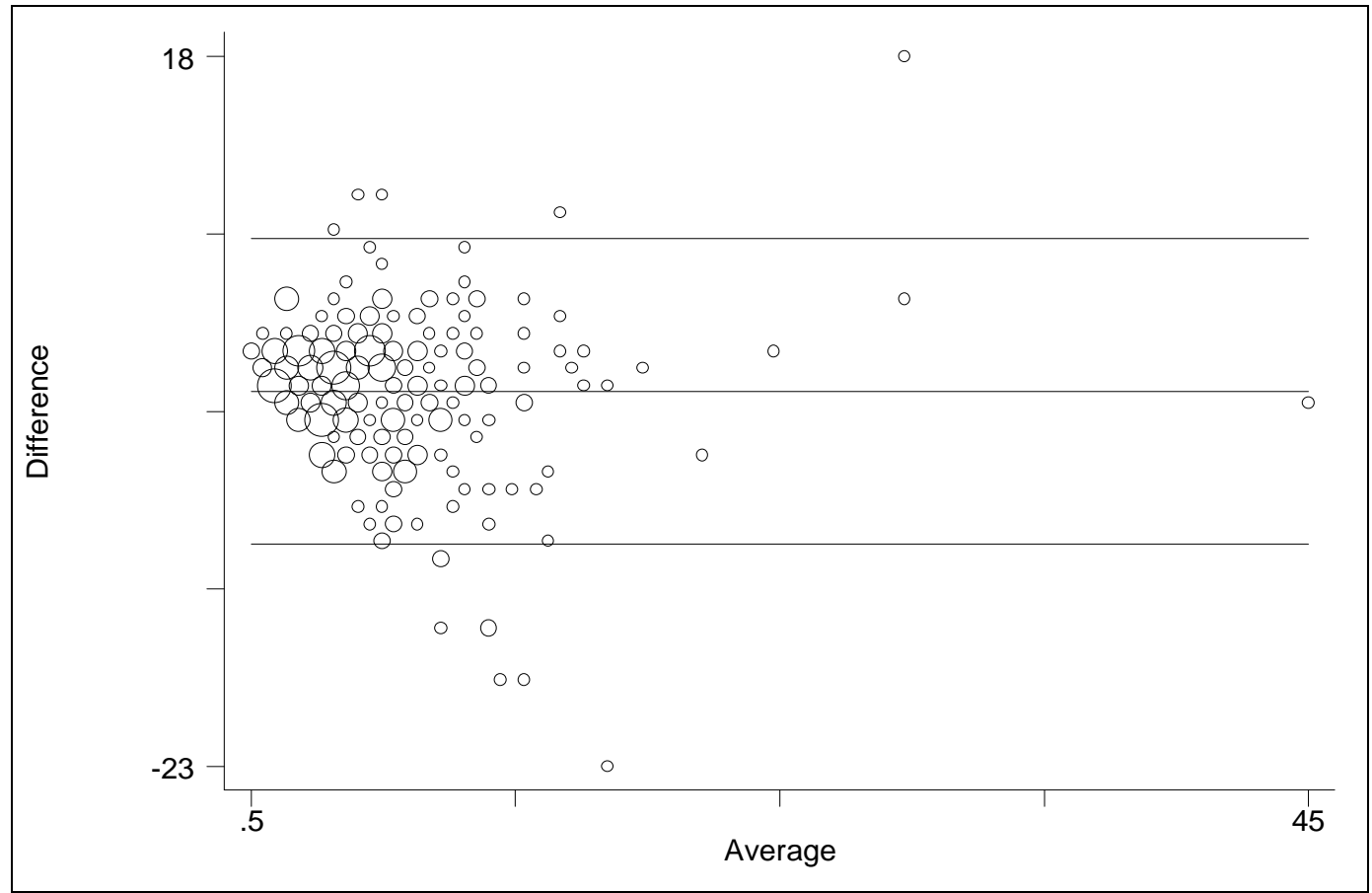

Table 3.16 shows health service use over follow up, not limited to falls related activity alone but including all contacts with the health service documented on primary or secondary care administration systems. 
Table 3.16 Health service resource use

\begin{tabular}{|c|c|c|c|c|c|c|c|}
\hline \multirow[t]{2}{*}{ Outcome } & \multicolumn{3}{|c|}{ Medians (Interquartile range) } & \multicolumn{2}{|c|}{$\begin{array}{l}\text { Number (\%) above the } \\
\text { median }\end{array}$} & \multirow{2}{*}{$\begin{array}{l}\text { Crude odds } \\
\text { ratio } \\
(95 \% \mathrm{CI}) \text {, } \\
\text { significance }\end{array}$} & \multirow{2}{*}{$\begin{array}{l}\text { Adjusted } \\
\text { odds ratio } \\
\text { (95\% CI), } \\
\text { significance }\end{array}$} \\
\hline & All & Control & Intervention & Control & Intervention & & \\
\hline $\begin{array}{l}\text { Self-reported visits to the GP } \\
\text { over } 12 \text { months } n=238\end{array}$ & $\begin{array}{l}5 \\
(3-8)\end{array}$ & $5(3-8)$ & $5(3-7)$ & $\begin{array}{l}72 / 151 \\
(48 \%)\end{array}$ & $\begin{array}{l}63 / 135 \\
(47 \%)\end{array}$ & $\begin{array}{l}1.1(0.7-1.8) \\
p=0.703\end{array}$ & $\begin{array}{l}1.2(0.7-2.0) \\
p=0.524\end{array}$ \\
\hline $\begin{array}{l}\text { Verified GP attendances over } 12 \\
\text { months } n=270\end{array}$ & $\begin{array}{l}5 \\
(3-9)\end{array}$ & $\begin{array}{l}6 \\
(3-8)\end{array}$ & $5(3-9)$ & $\begin{array}{l}69 / 137 \\
(50 \%)\end{array}$ & $\begin{array}{l}60 / 133 \\
(45 \%)\end{array}$ & $\begin{array}{l}0.8(0.5-1.3) \\
p=0.389\end{array}$ & $\begin{array}{l}0.8(0.5-1.3) \\
p=0.381\end{array}$ \\
\hline $\begin{array}{l}\text { Verified non-ED hospital visits } \\
\text { over } 12 \text { months or death } n=334 *\end{array}$ & $\begin{array}{l}0 \\
(0-0), \text { range } 0-5\end{array}$ & $\begin{array}{l}0 \\
(0-0)\end{array}$ & $\begin{array}{l}0 \\
(0-0)\end{array}$ & $\begin{array}{l}36 / 169 \\
(21 \%)\end{array}$ & $\begin{array}{l}39 / 165 \\
(24 \%)\end{array}$ & $\begin{array}{l}1.1(0.7-2.0) \\
p=0.607\end{array}$ & $\begin{array}{l}1.1(0.6-1.8) \\
p=0.805\end{array}$ \\
\hline $\begin{array}{l}\text { Verified ED visit over } 12 \text { months } \\
\text { or death } n=334\end{array}$ & \multicolumn{3}{|c|}{ Number not recorded } & $\begin{array}{l}32 / 169 \\
(19 \%)\end{array}$ & $\begin{array}{l}40 / 165 \\
(24 \%)\end{array}$ & $\begin{array}{l}1.3(0.8-2.3) \\
p=0.288\end{array}$ & $\begin{array}{l}1.3(0.7-2.2) \\
p=0.413\end{array}$ \\
\hline $\begin{array}{l}\text { Verified falls-related hospital } \\
\text { visit** over } 12 \text { months or death } \\
n=75\end{array}$ & \multicolumn{3}{|c|}{ Number not recorded } & $\begin{array}{l}6 / 36 \\
(17 \%)\end{array}$ & $\begin{array}{l}7 / 39 \\
(18 \%)\end{array}$ & $\begin{array}{l}1.1(0.3-3.8) \\
p=0.852\end{array}$ & $\begin{array}{l}1.0(0.2-4.8) \\
p=0.997\end{array}$ \\
\hline $\begin{array}{l}\text { Verified fracture over } 12 \text { months } \\
\text { follow-up or until death } n=364\end{array}$ & $\begin{array}{l}0 \\
(0-0), \text { range } 0-1\end{array}$ & $\begin{array}{l}0 \\
(0-0)\end{array}$ & $\begin{array}{l}0 \\
(0-1)\end{array}$ & $\begin{array}{l}3 / 181 \\
(2 \%)\end{array}$ & $\begin{array}{l}6 / 183 \\
(3 \%)\end{array}$ & $\begin{array}{l}2.0(0.5-8.0) \\
p=0.329\end{array}$ & $\begin{array}{l}1.4(0.3-6.7) \\
p=0.618\end{array}$ \\
\hline
\end{tabular}

*Excludes visit to the day hospital as part of the falls prevention programme

**The correlation between self-reported with verified ED visits was poor $(r=0.10)$ - verified visits only reported 
The self-reported cumulative duration of visits to the GP was 56 (IQR 30100) minutes for controls and 55 (IQR 30-90) minutes for those in the intervention group, with no significant differences between the groups (Mann-Whitney $\mathrm{p}=0.644$ ).

Self reported visits to the district nurse (DN) were captured using the monthly diaries - either visits to the surgery or home visits, with a median of 4 (IQR 2-7) visits over one year, irrespective of allocation, and no significant differences between the groups even after adjusting for baseline imbalances - adjusted odds ratio (splitting at the median) 0.7 (95\% CI $0.4-1.2), p=0.211$

The cumulative duration of DN visits was similar between the groups: median 35 minutes (IQR 15-85) in the controls versus 30 minutes (IQR 1570) in the intervention group (Mann-Whitney $p=0.690$ ). The crude odds ratio (splitting at the median) was 1.0 (95\% CI $0.6-1.0), p=0.958$, and the adjusted odds ratio 0.9 (95\% CI $0.5-1.6), p=0.832$.

\subsubsection{Social services resource use}

Self reported social services resource use was collected from the monthly diaries. The data for this domain was poorly completed, with replies from around $15 \%$ of RCT participants. $9 / 25$ (36\%) individuals in the intervention group stated that they received meals on wheels, compared to $11 / 30$ $(37 \%)$ in the control group. Pearson's chi ( 1 d.f) $p=0.959$; adjusted odds ratio $0.5(95 \%$ CI $0.1-2.4), p=0.406$.

Participants were asked if they received any regular support in performing their daily activities; this was the case for 41 in the intervention group as opposed to 46 in the control group, but missing responses make the denominator uncertain and render the data unhelpful. Similarly, 60 in the control group as opposed to 66 in the intervention group had made some 
form of home adaptation; the median number of adaptations in the control group was 1 (IQR 1-2) compared to 2 (IQR 1-3) in the intervention group, (Mann-Whitney $\mathrm{p}=0.319$ ). Finally, 96 in the intervention group compared to 98 in the intervention group had purchased some form of assistive technology, at a median total cost of $£ 14$ and $£ 10.75$ respectively, MannWhitney $\mathrm{p}=0.690$.

\subsection{Summary of the findings from the randomised controlled trial}

Three hundred and sixty-four community-dwelling older people at high risk of falling were randomised into a pragmatic, multicentre trial evaluating falls prevention programmes in three different day hospital in the East Midlands. Twenty five percent of those eligible consented to participate, representing $6 \%$ of the population aged $70+$ registered with participating general practices.

One hundred and eighty-one were allocated to the control group and 183 to the intervention, of whom seven and 131 respectively attended a falls prevention programme. Losses to follow up were similar in both groups $(5 \%)$, less than originally anticipated. Complete follow up data was available for $138 / 181(76 \%)$ in the control group and $136 / 183(74 \%)$ in the intervention group. There were slight imbalances in baseline characteristics between the two groups, and subsequent analyses were adjusted for prognostically important baseline variables. Most (92\%) of those attending the day hospital were cognitively intact.

The primary outcome of the trial was the rate of falls; the unadjusted incidence rate ratio using negative binomial regression was $0.64(0.43-$ $0.95), p=0.025$, in favour of the intervention.

Regression diagnostics identified a significant outlier in the data, whether by deviance residuals, Cook's distance, leverage or dbeta values; the 
individual had an extreme number of falls (107 over 12 months). A sensitivity analysis excluding this individual showed a much better fit for the negative binomial regression model, but the benefit in favour of the intervention was reduced - IRR $0.86(0.59-1.25), p=0.424$. An adjusted analysis including the baseline variables known to affect falls outcomes and excluding the outlier gave an adjusted IRR of $0.73(0.51-1.03), \mathrm{p}=0.071$, and this is the most appropriate summary measure of effect to describe this trial result.

A variety of sub-group analyses (age, gender, previous fall status, stratum or per protocol) failed to demonstrate a significant difference in the effect of the intervention by any particular sub-group.

There were no significant differences between the groups using the intention to treat analysis in terms of the proportion of fallers, recurrent fallers, medically verified falls, injurious falls, time to first fall or time to second fall. There was a suggestion of benefit in delaying the time to a second fall ( 55 days control vs. 87 days intervention), associated with a clinically important reduction in the hazards ratio of 0.7 (95\% CI $0.5-1.1$ ) in the adjusted model, but this was not statistically significant $(p=0.103)$. In a wide array of secondary outcomes, there were no significant differences between the groups, including institutionalisation, mortality, basic or extended activities of daily living, and fear of falling. Although there was evidence of benefit using the EuroQoL (odds ratio 0.5 (0.3-0.9), $p=0.027$, this was not demonstrated in a sensitivity analysis using an imputed dataset to compensate for missing data - adjusted odds ratio 0.7 $(0.41-1.35), p=0.334$.

There were no significant differences between the groups in terms of health and social care resource use - self reported and validated GP visits, selfreported visits to the district nurse, self-reported and validated hospital 
attendances, or self-reported use or purchase of meals on wheels, home adaptations or other assistive technology.

\subsection{Discussion}

Although the initial analysis appears to show a statistically significant and clinically important trial result, the appropriate analysis shows no conclusive evidence of benefit. The findings are consistent with a $49 \%$ reduction in the rate of falls, or a $3 \%$ increase - adjusted IRR $0.73(0.51$ 1.03), $p=0.071$. The best estimate is for a $27 \%$ reduction in the rate of falls. Such a reduction is clinically important, but the probability of finding this level of effect when the null hypothesis is in fact true (that there is no difference between those randomised to the intervention and those in the control group $)$ is $7 / 100(p=0.07)$.

There are several possible explanations as to why this trial that pointed at a clinically important reduction in the rate of falls should have been unable to do so with a high level of confidence - inadequate power and chance, bias, insensitive outcomes, reverse causation or an inadequate intervention.

\subsubsection{Inadequate power and chance}

The $p$-value relating to the null hypothesis - that there was no difference between the two groups in this trial was 0.07 ; it is conventional to infer the presence of genuine differences between groups to require this probability to be either less than $5 \%$ or $1 \%$ in order to reject the null hypothesis of no difference. The trial was planned to detect a clinically important risk reduction of $24 \%$ assuming a baseline fall rate of 2 per person-year, 320 person-years of follow up and $80 \%$ power. The assumptions for the sample size calculations were reasonably accurate as the study recruited 304 person-years and fall rates were 2.2 (control) and 1.9 (intervention). The 
slight disparity in the person-years of follow up calculated in the original power calculation and that seen in the trial (320 vs. 304 person-years), may well account for the lack of power to reject the null hypothesis. This study was designed using $80 \%$ power, and although this is commonly used in trial planning, it means that there was a one in five chance of dismissing a real effect of a $24 \%$ reduction in the rate of falls if one existed (type II error).

Two other recent falls prevention trials have shown no evidence of benefit, because of a lack of power. Hendriks et $a^{230}$ studied a high risk population attending the emergency department with a fall. They powered their trial to show a $20 \%$ difference in the proportion of fallers ( $52 \%$ versus $32 \%$, alpha 0.05 , beta $90 \%$ ) with 164 participants in each arm. 258 participants were eligible for the primary outcome (proportion of falls at one year), and the odds ratio was $0.86(0.50-1.49), p=0.59$. They concluded that the intervention was ineffective, but in fact could have missed even a $30 \%$ reduction in falls, again because of a type II error.

Elley et $a^{229}$ carried out a RCT to look at the effectiveness of a nurse specialist coordinating a falls prevention programme for high risk community dwelling older people. They also powered their trial to show a $20 \%$ difference on the proportion of fallers ( $52 \%$ versus $32 \%$, alpha 0.05 , beta $90 \%$ ) with 105 participants in each arm. 312 participants were eligible for the primary outcome (rate of falls over one year), and the incidence rate ratio was $0.96(0.70-1.34)$, using Poisson analysis. They concluded that the intervention was ineffective, but in fact could have missed a clinically important $15 \%$ reduction in falls rates because of a type II error. The population attributable fraction $(=p(R R-1) /[p(R R-1)+1]$, see section 2.4.2) reflects the attributable risk multiplied by the proportion of the population exposed ( $35 \%$ prevalence measured prospectively in the 
screening cohort): $0.35 *(0.73-1) /[0.35 *(0.73-1)+1]=10 \%$. This suggests that $10 \%$ of all falls in people aged 70 or older could be prevented using the modified FRAT to identify people at risk and providing a multifactorial falls prevention programme if the estimate of effect seen in this study is correct. This compares to an estimated $9 \%$ reduction in serious fall-related injuries anticipated at the population level in the $\mathrm{US}^{55}$ and Austrialia ${ }^{272}$ and could have considerable public health impact. In 2005-06, the acute care of 68,416 patients with hip fracture in England cost the NHS an estimated $£ 781$ million $^{413}$. Assuming that $80 \%$ of hip fractures are related to falls (probably an underestimate), then a $10 \%$ reduction in the number of falls could result in 5473 fewer hip fractures per annum (10\%x80\%x68416). This represents 5473 individuals who would avoid a fracture, up to 82095 (5473 x15) hospital bed days saved, or a $£ 62$ million saving $(£ 781 M * 5473 / 68416)$. Whilst the cost of this would need to be balanced against the cost of a falls prevention programme, it illustrates the potential impact of a $10 \%$ reduction in falls, and how important the $27 \%$ estimated reduction in falls seen in this trial could be.

\subsubsection{Bias}

Participants were aware of their allocation, and thus differential reporting cannot be excluded as a cause of bias. For example, those in receipt of falls services might be more likely to recall and hence notify falls, whereas those receiving less input might be less likely to recall falls; this might have attenuated the effect. But a series of validated analyses (medically verified falls, hospital admissions etc) also failed to show any difference between the groups in terms of their reporting of these outcomes, which makes reporting bias unlikely.

There were imbalances in baseline covariates which may have been a source of bias, with the intervention group being slightly sicker than the 
control group, but adjusted analyses did not substantially alter the crude outcomes.

Monthly diary data were entered by a research nurse blinded to the allocation, but it is not possible to exclude some form of manipulation or tampering which may have systematically affected the results. However, the double entry checks did not reveal any obvious evidence of systematic bias, with error rates of less than $1 \%$ recorded.

Design bias might have been a possibility - the usual care group could have accessed falls prevention programmes, thus attenuating the effect of systematically implementing a falls prevention programme; however, given that only $7 / 181$ in the control group accessed any form of falls prevention programme, this is unlikely, though may have slightly reduced the intervention effect.

It is possible that those screened into the study were in some way fundamentally different from people who would otherwise have been referred routinely to a falls prevention programme, either because of differing falls rates, or because of their characteristics (Table 2.7 ) - such as willingness to participate. Certainly the age and gender of those in the screening arm and the RCT were similar to those that declined to participate in the trial, though clearly their falls risk factor profile was different, as could have been their motivation to attend. Those at high risk agreeing to participate in the RCT may be different in some unknown way compared to those at high risk who only agreed to participate in the screening cohort. As discussed in section 2.8.2, this may have led to an overall higher risk group in the RCT compared to the screening cohort. 


\subsubsection{Confounding}

The use of a randomised controlled trial design should have prevented unknown confounding factors from exerting a significant effect upon the trial outcome, but it is possible that some confounding occurred which has not been measured, and so cannot be accounted for.

\subsubsection{Insensitive outcomes}

The outcomes used in this trial (falls, functional outcomes, fear of falling and quality of life) have been used in a wide variety of similar trials and have been able to demonstrate a difference between groups, whether this be in self reported falls, fear of falling or function. Insensitive outcomes are not a good explanation for the lack of effect seen in this trial.

\subsubsection{Reverse causation}

A possible explanation is reverse causation - namely that the intervention increased falls, possibly mediated through an increase in activity. Against this is the absence of any difference between the two groups in terms of functional outcomes, in particular mobility related outcomes in both the Barthel and mobility sub-section of the NEADL make this theory implausible. Additionally, both groups reported similar scores for fear of falling.

\subsubsection{Inadequate intervention}

That the intervention tested was insufficiently potent to affect falls related outcomes in this population is a further possible explanation. Although the post-hoc sub-group analysis limited to those who attended the falls prevention programme showed a large effect size - incidence rate ratio $0.39(95 \%$ CI $0.11-1.40), p=0.149$ this was not statistically significant (likelihood ratio test $p=0.185$ ). Adherence to the allocated intervention was limited, with only $37 \%$ of those allocated to the intervention attending six 
or more sessions of the falls prevention programme. Previous trials showing an effect from falls prevention programmes had adherence rates, measured by compliance with follow-up, of around $80 \%$ (section 1.5.1). This suggests that lack of adherence to the evidence based intervention in this trial may be an explanatory factor in the failure to demonstrate an effect from the intervention. Reasons for non-attendance included time and travel arrangements, and participants not perceiving themselves to benefit from the falls prevention programme.

When individuals attended the FPP more than one visit, on the whole they received appropriate interventions ( $~ 60$ minutes occupational therapy, 300 minutes physiotherapy and a series of medical reviews), though the 'dose' of these interventions was probably sub-optimal. More recent evidence suggests that at least 50 hours of exercise are required to see clinically important reductions in falls rates ${ }^{414}$ which may be best achieved by community-based peer-led exercise programmes ${ }^{415}$. The inadequate intervention in this study compared to what has previously been described in 'positive' studies may well have contributed to the lack of effect.

The absence of a clearly defined, uniform intervention in the three day hospitals is a weakness of this study, but it still remains a valid examination of falls prevention programmes as commonly configured in England and Wales, as discussed further in 3.18.9.

Appendix 4.6 details a meta-analysis comparing efficacy (explanatory) trials to effectiveness (pragmatic) falls prevention trials. Whilst imperfect in terms of methodology, the meta-analysis lends support to the theory that there is a discrepancy between efficacy trials and their delivery in clinical practice (trials of effectiveness). 


\subsubsection{Summary}

This trial in isolation does not demonstrate beyond reasonable doubt that a multifactorial falls prevention programme delivered in day hospitals to predominantly cognitively intact older people living in the primary care setting identified as being at high risk of falls using a postal screening questionnaire, is beneficial. A smaller, yet clinically important benefit cannot be excluded, but would need a larger, adequately powered trial: a clinically meaningful $15 \%$ reduction in falls would need a trial with 644 participants with alpha set at 0.05 and 1 -beta at 0.80 . Likely explanations for the lack of effect include inadequate power, cross over in the control arm, poor compliance and a sub-optimal intervention in the intervention arm.

The totality of evidence from other trials suggests that falls prevention interventions, sufficiently intensive and properly delivered, can reduce falls rates $^{1012} 217224225$. The results from this trial are consistent with the results from other published trials, as shown in the meta-analysis in appendix 4.6, although there was significant heterogeneity (fixed effect estimate $\mathrm{I}^{2}$ statistic $69 \%, p<0.0001)$. The best estimate of effect size in this trial $(27 \%)$ is similar to that seen in other trials, although in the particular circumstances of this trial the findings are compatible with there being no difference, and so the null hypothesis cannot be confidently rejected.

\subsubsection{External validity}

The bulk of the published evidence would have led one to expect this trial to have shown a benefit; most RCTs, meta-analyses and systematic reviews have all pointed to the benefits of a structured falls prevention programme in high risk populations ${ }^{10} 12217224225$, although not specifically in a day hospital setting. More recent evidence has focussed on more pragmatic interventions ${ }^{229}$, which have found no evidence of benefit, with 
the authors highlighting the issue of compliance being one of the main detractors. The findings of this trial are compatible with the evidence presented in the meta-analysis by Gates et $a^{226}$; which found that fall prevention services may reduce falls by up to $20 \%$, but the findings were also compatible with a slight increase in falls ( 0.91 (95\% confidence interval 0.82 to 1.02 ).

\subsubsection{Generalisability}

The falls rates seen in this study were broadly in keeping with what might be expected in England; 2 per person-year in a high risk population compared to $1.1-1.8$ falls per person-year 2829 in all community dwelling older people. Falls clinics, broadly equivalent to the day hospital based falls prevention programme evaluated in this RCT, are commonplace across England and Wales ${ }^{416}$. It has been estimated that there are 298 falls clinics throughout England and Wales (SDO report, $2007^{416}$ ), 96\% of which are based in community hospitals or acute hospitals. Most of these falls clinics $(228 / 231,99 \%)$ offer a multifactorial intervention similar to that described in this RCT. This suggests that the results of this RCT are generalisable to falls services throughout England and Wales.

\subsubsection{Implications}

This is the only RCT to date examining falls prevention services as commonly configured in England and Wales; the results of this trial in isolation do not conclusively support falls prevention services delivered in a day hospital setting to a screened population of older people identified as being at high risk of a future fall. A clinically meaningful reduction in falls cannot be excluded as a type II error may account for the findings. This trial also highlights the issue of compliance, with only $37 \%$ of those randomised to the intervention receiving six or more sessions of falls prevention therapy. It also highlights the importance of adhering to the 
evidence based 'recipe' for falls prevention - had a more intensive intervention been provided then this trial may have been more conclusive. The introduction of the screening element is an important difference compared to usual falls prevention programmes, which tend to be more reactive, and so patients attending are more self-selecting - and so adherence may be better. This is supported by differential recruitment into the RCT rather than the screening arm of individuals with a previous fall. There are important implications for falls services - if they are to achieve the reductions in falls seen in efficacy trials, services should strive to reproduce the evidence based interventions in practice. This will involve findings innovative methods to encourage participants to continue attendance for the full programme of strength and balance training, and 'marketing' the programmes in such a way that participants will not be dissuaded from attending. The work from Yardley et $a l^{218}$ and Horne et $a l^{417}$ is informative in this regard, demonstrating the importance of emphasising the positive aspects of falls prevention services (healthy ageing, improving quality of life), as opposed to the negative (you will continue to fall if you don't come).

Some authors have suggested that clinical trials in areas where there is a high pre-trial probability of finding a positive outcome might be stopped early, before the conventional limits of significance have been achieved in order not to violate the principle of individual as opposed to collective equipoise ${ }^{418}$. In the context of this trial, it can therefore be argued that it could have been stopped early (before convention statistical significance was reached), but no provision for this was made in the study protocol. That these trial findings are in keeping with previous similar trials as shown in the meta-analysis provides further reassurance that there is benefit from 
a falls prevention programme provided to populations at high risk of falls more generally (RR $0.86,95 \%$ CI $0.76-0.98))^{10}$.

The argument for interpreting this trial supports the efficacy of falls prevention interventions is supported by the meta-analysis data, Bayes theorem and Stein's paradox ${ }^{419}$. Bayes theorem would interpret the trial in the context of the a priori findings (most falls prevention trials are positive), and so perhaps have a lower threshold for declaring a positive effect. Stein's theory expands on the regression towards the mean theory, namely that the best estimate of 'truth' is the combination of estimates. Using these paradigms, one could argue that the most plausible interpretation in the general context of high risk populations for this trial is that there was a $27 \%$ reduction in falls in favour of the intervention. But nevertheless, with regards to the specific research question this trial set out to answer, the findings do not support the role of falls prevention services delivered in the day hospital to a screened population.

There are also implications for the research agenda. One area which needs to be addressed in more detail is around encouraging participation, compliance and adherence. This is a programme of qualitative work, looking at how individuals deemed to be risk of future falls perceive themselves, what sorts of interventions they will find acceptable, where the interventions should be located and how the interventions can be sustained in the longer term? It also needs to address health professionals' perceptions of patient risk and the rigour with which evidence based interventions are applied. The implication is that although there are multiple RCTs of falls preventions, that some of the critical developmental work, as described in the MRC framework for developing complex interventions ${ }^{335}$, at least concerning day hospital delivered programmes, has not been fully elucidated. Once the falls prevention programme has 
been refined, and piloted for acceptability, there may then be a role for a larger, adequately powered RCT addressing the effectiveness and costeffectiveness of falls prevention programmes in a screened population. It is important to assess the feasibility and biological plausibility of interventions before proceeding to interpret RCTs or even meta-analyses ${ }^{420}$.

\subsubsection{Overall evidence}

The primary aim of this study was to determine if screening for individuals at high risk of falls and offering a day hospital based falls prevention programmes to those at high risk was beneficial.

Wilson \& Jungner's ${ }^{285}$ screening criteria provide a suitable framework to revisit this question in light of the evidence presented:

- The condition should be an important public health problem Falls are a common problem for older people, with $24 \%$ of people aged over 65 years falling at least once every year. Falls are the leading cause of trauma in older people and a prime cause of fracture; they are also a major cause of mortality in older people. Falls have a similar impact on hospital services to other major conditions such as stroke and myocardial infarction (section 1.7).

- There should be an accepted treatment

Multifactorial interventions delivered to previous fallers and others at high risk have been effective in reducing falls rates by around $25 \%$. Whilst this trial is in keeping with the evidence that falls prevention programme are effective, it was unable to show any effect from such a programme delivered in a day hospital to a high risk population.

- Facilities for diagnosis and treatment should be available/ there should be a suitable test 
We have validated a modified version of the FRAT which has reasonable predictive properties: sensitivity $78.7 \%$ and specificity $57.5 \%$. The positive predictive value of $50 \%$ indicates that for every two people identified as being at high risk, one would go onto to have a fall in the following year. The $83 \%$ negative predictive value means that of those screened as being at low risk, approximately one in six will go on to have a fall.

- There should be a recognisable latent or early asymptomatic stage/The natural history of the condition should be understood There is a latent period in which individuals are at risk of falls, but have not fallen, as discussed in section 1.4. Of the 364 identified as being at high risk and include din the trial, 42 had not previously fallen, and there was no evidence of benefit in those who had fallen over those who had not prior to randomisation.

- The test should be acceptable to the population

The modified FRAT was reasonably acceptable to community dwelling older people $-54 \%$ completed and returned the form.

- There should be an agreed policy on whom to treat as patients The identification of high risk individual is encouraged by NICE, though a formal screening programme has not been recommended

- The cost of case-finding should be economically balanced in relation to the possible expenditure as a whole

This is a crucial component of this work, and analysis is in progress

- Case-finding should be a continuing process

The modified FRAT is easy to apply in primary care and could be relatively easily incorporated into routine practice, supported by incentive strategies. 
Current practice of referring people who are at high risk of falls or who have already fallen for a multifactorial falls prevention programme is patchy - in this study only $7 / 181(4 \%)$ of those in the control arm. Having considered the screening criteria above, there now appears reasonable justification to suggest a more proactive approach to preventing falls in older people.

\subsubsection{Recommendations}

Further work on the acceptability and implementation of multifactorial falls prevention interventions is required; once suitable approaches have been found, a further adequately powered RCT may be considered to determine the effectiveness and cost-effectiveness of a systematic screening programme to identify older people at risk of falls, and offer a multifactorial intervention. However, considering the totality of the evidence presented in this thesis, it is not unreasonable to focus additional research efforts on implementation and acceptability alone rather than adding to the evidence base for falls prevention programmes, which would be costly and difficult to justify.

Although this trial in isolation does not provide sufficient evidence to health care commissioners to recommend screening and intervention for falls, in combination with the totality of the evidence it would not be unreasonable to do so. But before embarking on widespread screening, the likely cost of such a programme needs to be estimated. At the very least a more rigorous approach to case-finding should be encouraged. 


\section{APPENDICES}

\subsection{Literature review - search methods}

Databases searched: Ovid MEDLINE(R) 1996 to June Week 4 2008;

EMBASE 1996 to 2008 Week 27; titles were scanned for relevance, then abstracts and full papers examined if relevant. Key references from full papers were hand searched.

\subsubsection{Search terms for falls prevalence and incidence}

\begin{tabular}{|c|l|c|c|}
\hline & & MEDLINE & EMBASE \\
\hline 1 & Accidental Falls/ (Falling/ in EMBASE) & 6818 & 8574 \\
\hline 2 & Prevalence/ & 87841 & 121789 \\
\hline 3 & Incidence/ & 84490 & 84983 \\
\hline 4 & 2 or 3 & 164246 & 196330 \\
\hline 5 & Aged/ & 812946 & 690869 \\
\hline 6 & 1 and 4 and 5 & 458 & 569 \\
\hline 7 & $\begin{array}{l}\text { limit 6 to (English language and humans and (clinical } \\
\text { trial, all or "review")) }\end{array}$ & 78 & 47 \\
\hline 8 & Retained & 17 & 1 \\
\hline
\end{tabular}

4.1.2 Search terms for falls and admission to long term care

\begin{tabular}{|l|l|c|c|}
\hline$\#$ & Searches & MEDLINE & EMBASE \\
\hline 1 & Accidental Falls/ (Falling/ in EMBASE) & 6831 & 8592 \\
\hline 2 & institutionalization/ or long-term care/ & 8436 & 40205 \\
\hline 3 & Aged/ & 813955 & 691890 \\
\hline 4 & 1 and 2 and 3 & 80 & 141 \\
\hline 5 & from 4 keep ... & 13 & 8 \\
\hline
\end{tabular}


4.1.3 Search terms for fear of falling (from $8 / 2 / 2003$ )

\begin{tabular}{|l|l|c|c|}
\hline$\#$ & Searches & MEDLINE & EMBASE \\
\hline 1 & $\begin{array}{l}\text { (old or older* or senior* or elder* or geriatric* or } \\
\text { middle?age*).mp. [mp=title, original title, abstract, } \\
\text { name of substance word, subject heading word] }\end{array}$ & 418539 & 408214 \\
\hline 2 & fear of falling.mp. & 254 & 258 \\
\hline 3 & fall* efficacy scale.mp. & 51 & 51 \\
\hline 4 & 2 or 3 & 275 & 277 \\
\hline 5 & 1 and 4 & 215 & 210 \\
\hline 6 & limit 5 to yr="2003+" & 21 & 20 \\
\hline 7 & from 6 keep... & 15 & 15 \\
\hline
\end{tabular}

\subsubsection{Search terms for falls and depression}

\begin{tabular}{|l|l|c|c|}
\hline$\#$ & Searches & MEDLINE & EMBASE \\
\hline 1 & Accidental Falls/ & 6853 & 8592 \\
\hline 2 & Depression/ & 24093 & 85966 \\
\hline & Add 'Aged' in EMBASE & & 691890 \\
\hline 3 & 1 and 2 (3) & 63 & 353 \\
\hline 4 & Selected & 14 & 10 \\
\hline
\end{tabular}

\subsubsection{Search terms for falls and mortality}

\begin{tabular}{|c|l|c|c|}
\hline & Searches & MEDLINE & EMBASE \\
\hline 1 & Falling/ & 6853 & 8592 \\
\hline 2 & MORTALITY/ & 10059 & 128600 \\
\hline 3 & cohort analysis/ & - & 47086 \\
\hline 4 & 1 and 2 (and 3) & 10 & 20 \\
\hline 5 & from 4 keep 9, 20 & 2 & 2 \\
\hline
\end{tabular}




\subsubsection{Search terms for falls and carer burden}

\begin{tabular}{|c|l|c|c|}
\hline & Searches & MEDLINE & EMBASE \\
\hline 1 & Accidental Falls/ & 6853 & 8592 \\
\hline 2 & Caregivers/ & 9987 & 12512 \\
\hline 3 & carer strain.mp. & 32 & 31 \\
\hline 4 & carer burden.mp. & 59 & 59 \\
\hline 5 & carer stress.mp. & 28 & 33 \\
\hline 6 & 2 or 3 or 4 or 5 & 10027 & 12556 \\
\hline 7 & Aged/ & 815645 & 691890 \\
\hline 8 & 1 and 6 and 7 & 14 & 60 \\
\hline & From 8 keep... & 3 & 0 \\
\hline
\end{tabular}

\subsubsection{Search terms for falls risk factors}

This search uses the search strategy detailed in the NICE guidelines from 2004, focussing on studies from 2004 onwards.

\begin{tabular}{|l|l|c|c|}
\hline & Searches & MEDLINE & EMBASE \\
\hline 1 & Accidental Falls/; Falling in EMBASE & 6922 & 8707 \\
\hline 2 & Cohort Studies/; Cohort analysis in EMBASE & 72021 & 47839 \\
\hline $\begin{array}{l}\text { (Risk* or predict* or screen* or } \\
\text { probability*).mp. [mp=title, original title, } \\
\text { abstract, name of substance word, subject } \\
\text { heading word] }\end{array}$ & 1118147 & 1155411 \\
\hline 4 & Aged/ & 820536 & 699279 \\
\hline 5 & limit 3 to "review articles" & 179497 & 171976 \\
\hline 6 & 1 and 2 and 3 and 4 & 130 & 140 \\
\hline 7 & 1 and 4 and 5 & 377 & 238 \\
\hline 8 & 6 or 7 & 302 & 372 \\
\hline 9 & limit 8 to yr="2002 - 2008" & 31 & 19 \\
\hline & From 9 keep... & & \\
\hline
\end{tabular}




\subsubsection{Search terms for falls risk assessment tools}

This is a sensitive rather than specific search; retained studies were those that included evidence based falls risk factors combined in a screening tool, with prospective follow up and results reported as sensitivity/specificity/area under the curve.

\begin{tabular}{|l|l|c|c|}
\hline & Searches & MEDLINE & EMBASE \\
\hline 1 & Risk Assessment/ & 82404 & 152694 \\
\hline 2 & *Recurrence Risk/ & - & 284 \\
\hline 3 & PREDICTION/ & 66580 & 115940 \\
\hline 4 & "prediction and forecasting"/ & - & 1244 \\
\hline 5 & *Falls Risk Assessment Tool/ & 9 & 1 \\
\hline 6 & Risk Factor/ & 257700 & 194062 \\
\hline 7 & 1 or 2 or 3 or 4 or 5 or 6 & 377516 & 409941 \\
\hline 8 & Prospective Study/ & 166603 & 68568 \\
\hline 9 & Cohort Analysis/ & 72413 & 47839 \\
\hline 10 & Follow Up/ & - & 233211 \\
\hline 11 & 8 or 10 or 9 & - & 318638 \\
\hline 12 & Human/ & 4610101 & 3814687 \\
\hline 13 & Aged/ & 823705 & 699279 \\
\hline 14 & $*$ Falling/ & 6953 & 2309 \\
\hline 15 & 11 and 7 and 13 and 12 and 14 & 32 & 183 \\
\hline 16 & From 15 keep & 37 \\
\hline
\end{tabular}




\subsubsection{Search terms for falls interventions}

This search builds upon the review detailed in the NICE guidelines from 2004. It uses a simplified search strategy, focussing on randomised studies, systematic reviews and meta-analyses from 2003 onwards. Only work on falls prevention in community dwelling older people was selected.

\begin{tabular}{|l|l|c|c|}
\hline & Searches & MEDLINE & EMBASE \\
\hline 1 & Accidental Falls/ (Falling in EMBASE) & 6962 & 8732 \\
\hline 2 & Aged/ & 825311 & 700684 \\
\hline 3 & 1 and 2 & 3998 & 3969 \\
\hline 4 & $\begin{array}{l}\text { limit 3 to (English language and humans and } \\
\text { yr="2003" and (meta analysis or randomized } \\
\text { controlled trial or "review")) } \\
\text { In EMBASE: limit 3 to (human and English } \\
\text { language and "treatment (2 or more terms } \\
\text { high specificity)" and yr="2003 - 2008" and } \\
\text { "Clinical Trial" [Subjects] ) }\end{array}$ & 193 & 196 \\
\hline 5 & From 4 keep & 53 & Nil new \\
\hline
\end{tabular}

\subsubsection{Search terms for day hospital falls interventions}

\begin{tabular}{|l|l|c|c|}
\hline & Searches & MEDLINE & EMBASE \\
\hline 1 & Day Care/ or day hospital.mp. & 639 & 2792 \\
\hline 2 & Ambulatory Care/ & 4579 & 5062 \\
\hline 3 & Ambulatory Care Facilities/ & 2213 & 8160 \\
\hline 4 & 1 or 3 or 2 & 7301 & 15799 \\
\hline 5 & Aged/ & 347226 & 700684 \\
\hline 6 & Accidental Falls/ & 3455 & 8732 \\
\hline 7 & 6 and 4 and 5 & 14 & 74 \\
\hline 8 & From 7 keep... & 0 & 0 \\
\hline
\end{tabular}




\subsection{Screening questionnaire}

\section{Nottingham City Hospital WVS \\ Nhs Trust}

Falls Prevention Study

Screening questionnaire

Thank you for taking the time to complete this questionnaire. It is very brief and should only take a few minutes. Please circle the answer that applies to you.

\section{Risk factors for falls:}

1. Have you fallen or tripped over in the last 12 months? Yes No (We want to know about any falls you have that caused you to land on the ground or a bed or chair, whether you pass out or not. A stumble or 'near miss' does not count.)

2. Do you take more than four different types of tablet each day? (don't count doses of the same tablet more than once)

3. Have you ever had a stroke?

Yes No

4. Do you suffer from Parkinson's disease?

Yes No

5. When you stand up, can you do so without using your arms to push up from the chair or bed, - i.e. using your legs only?

Yes No

6. Do you sometimes get dizzy or light headed on standing? Yes No

7. Do you need a stick or frame to help you walk?

Yes No

8. How far can you walk, with or without the help of a stick or frame? (tick the box that best applies to you)

Not at all

With assistance

Around one level of the house

Up \& down stairs

To the local shops

Unlimited 


\subsection{Sample day hospital log}

\section{Day Hospital Log}

Unique study number:

Hospital number:

Date of notes review:

Completed by:

Number of visits to day hospital:

\section{Visit 1}

1.1 Method of travel:

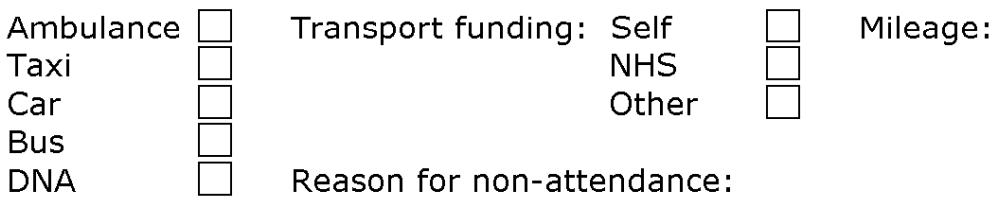

\subsection{Medical consultation}

Investigations (tick all that apply):

\begin{tabular}{|l|l|l|l|}
\hline Haematology $\square$ & Biochemistry $\square$ & ECG $\square$ & ECHO $\square$ \\
\hline 24 hour tape $\square$ & Tilt table test $\square$ & $\begin{array}{l}24 \text { hour BP } \\
\text { monitoring } \square\end{array}$ \\
\hline $\begin{array}{l}\text { Bone } \\
\text { densitometry } \square\end{array}$ & $\begin{array}{l}\text { Plain radiology } \\
\text { (specify) } \square\end{array}$ & Other radiology (specify) \\
\hline CT head $\square$ & & Other investigation (specify) \\
\hline
\end{tabular}

Referral other specialist? $\square$ Which speciality?

\subsection{Occupational Therapist consultation}

How long spent with the patient minutes

Home visit $\square \quad$ Equipment provided

Home modification? $\quad$ Funded by?

\subsection{Physiotherapy consultation}

How long spent with the patient minutes

Equipment provided

minutes

Referral for strength/balance training (how long, how many sessions)

\subsection{Senior nurse consultation}

How long spent with the patient minutes 


\subsection{Data checking}

The variables in Table 4.1 were examined for missing or extreme or implausible results, and any errors corrected. All discrepancies were corrected in the Access database where appropriate.

Table 4.1 Data cross checks

\begin{tabular}{|c|c|c|}
\hline Item 1 & Item 2 & Notes \\
\hline Date of consent & Date randomised & \\
\hline Stratum & Postcode/town & $\begin{array}{l}5 \text { errors; allocation by } \\
\text { stratum was imbalanced with } \\
4 \text { individuals who should } \\
\text { have been in the Nottingham } \\
\text { stratum according to } \\
\text { postcodes being allocated to } \\
\text { the Derby stratum and one in } \\
\text { the reverse direction }\end{array}$ \\
\hline Allocation & Exclusions & $\begin{array}{l}\text { id } 2191 \text { attended } \mathrm{DH} \text { but only } \\
\text { found out after randomisation } \\
\text { so excluded from the analysis }\end{array}$ \\
\hline Cross check DH logs & $\begin{array}{l}\text { GP records } \\
\text { Hospital records }\end{array}$ & \\
\hline Date of entry & $\begin{array}{l}\text { Date of care home } \\
\text { admission } \\
\text { Date of death } \\
\text { Date final diary }\end{array}$ & $\begin{array}{l}\text { Withdrawn } \& \text { no diaries }- \\
\text { date of exit }=\text { date diary } 1 \\
\text { sent }+1 \text { day }\end{array}$ \\
\hline Deaths & $\begin{array}{l}\text { Hospital records } \\
\text { AE records } \\
\text { GP records }\end{array}$ & \\
\hline Fall & $\begin{array}{l}\text { Date of fall } \\
\text { Fall number } \\
\text { Injury } \\
\text { Fall detail } \\
\text { Fall1 vs fall2 dates }\end{array}$ & $\begin{array}{l}\text { Missing dates equally } \\
\text { distributed between groups; } \\
\text { the mid-point date for the } \\
\text { diary month corresponding to } \\
\text { that fall was assigned. }\end{array}$ \\
\hline
\end{tabular}




\subsection{Model checking results}

\subsubsection{Primary outcome - negative binomial regression}

Figure 4.1 Scatterplot of deviance residuals against study id

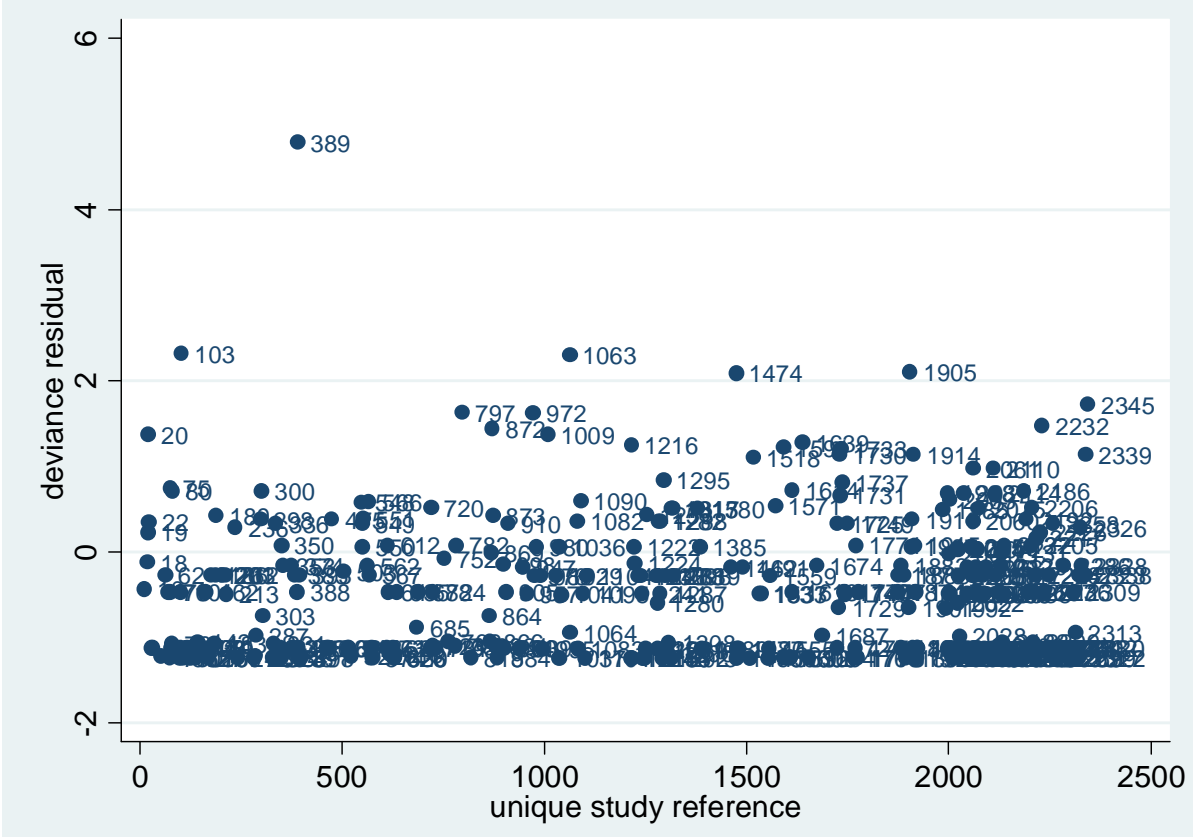

Figure 4.2 Scatterplot of Cook's distance against study id

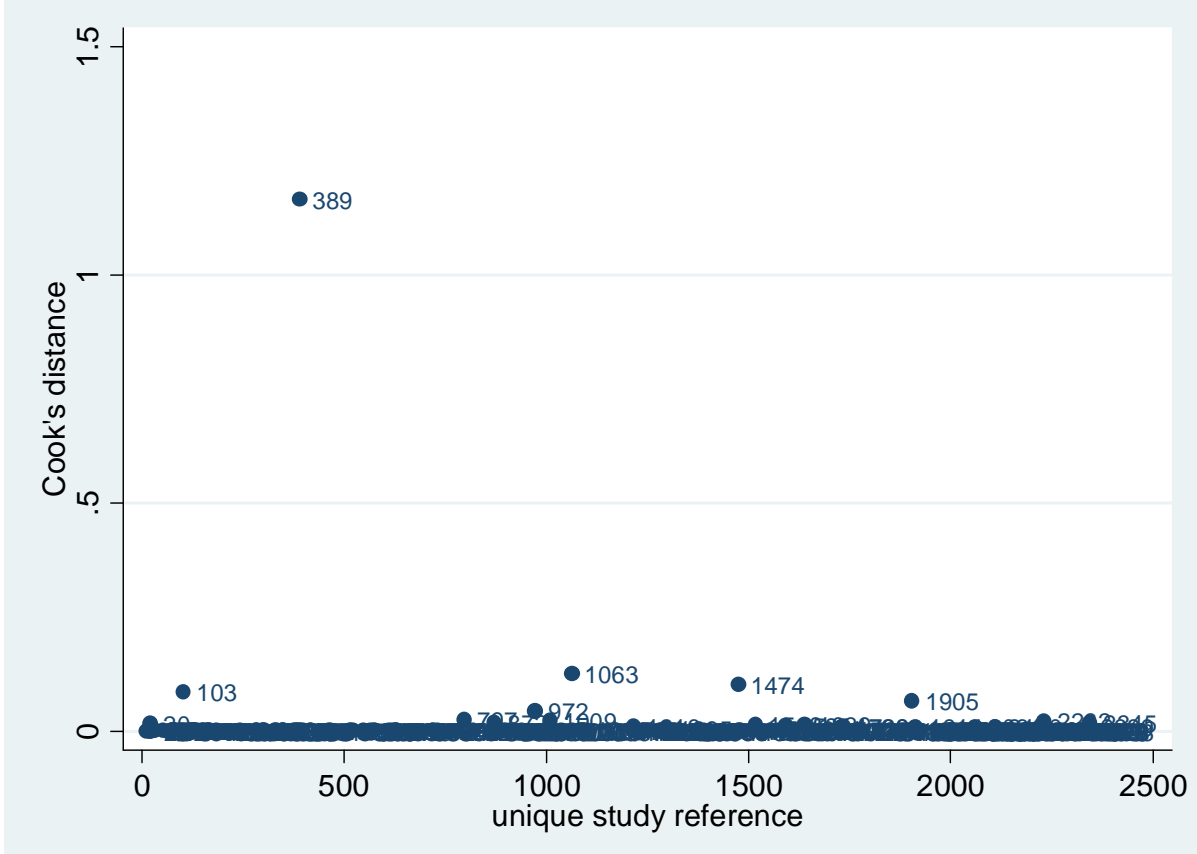


Figure 4.3 Scatterplot of leverage against study id

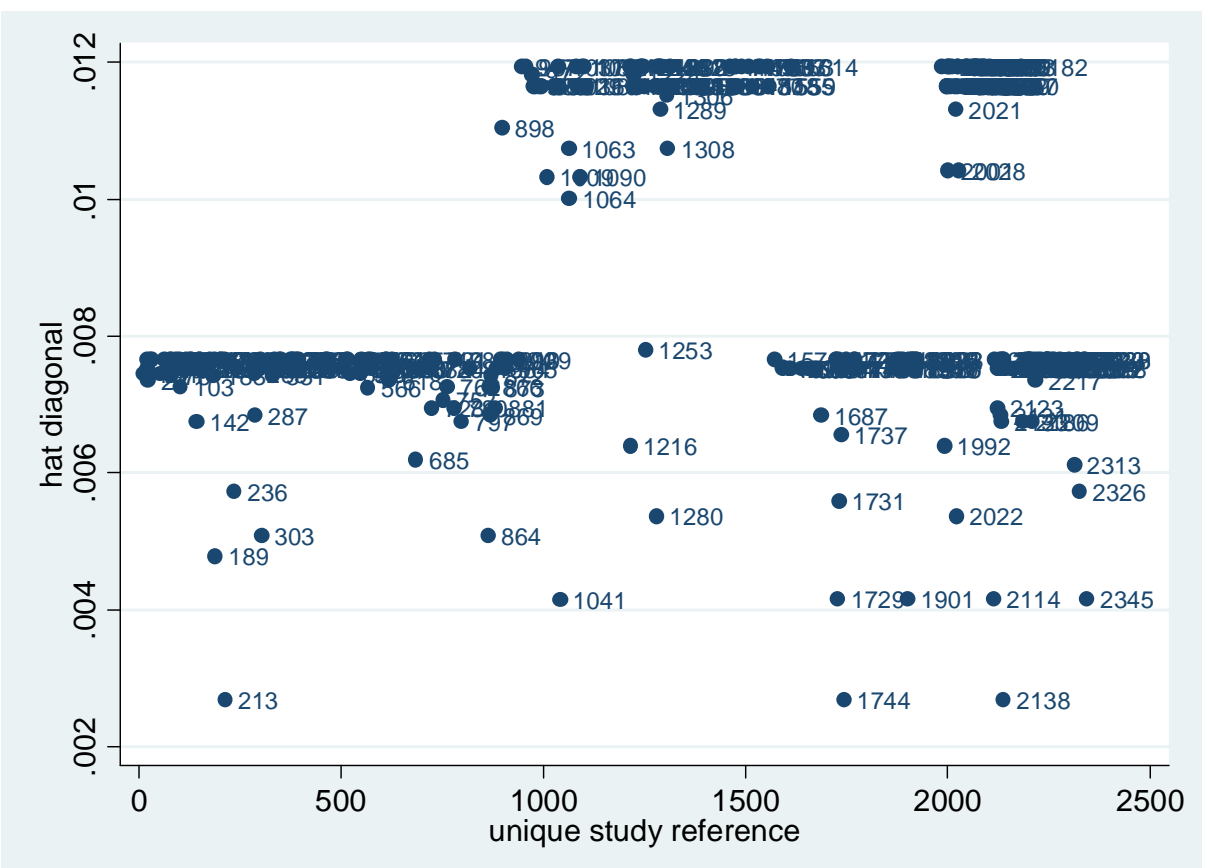

Figure 4.4 Scatterplot of predicted mean number of falls against study id (dbeta)

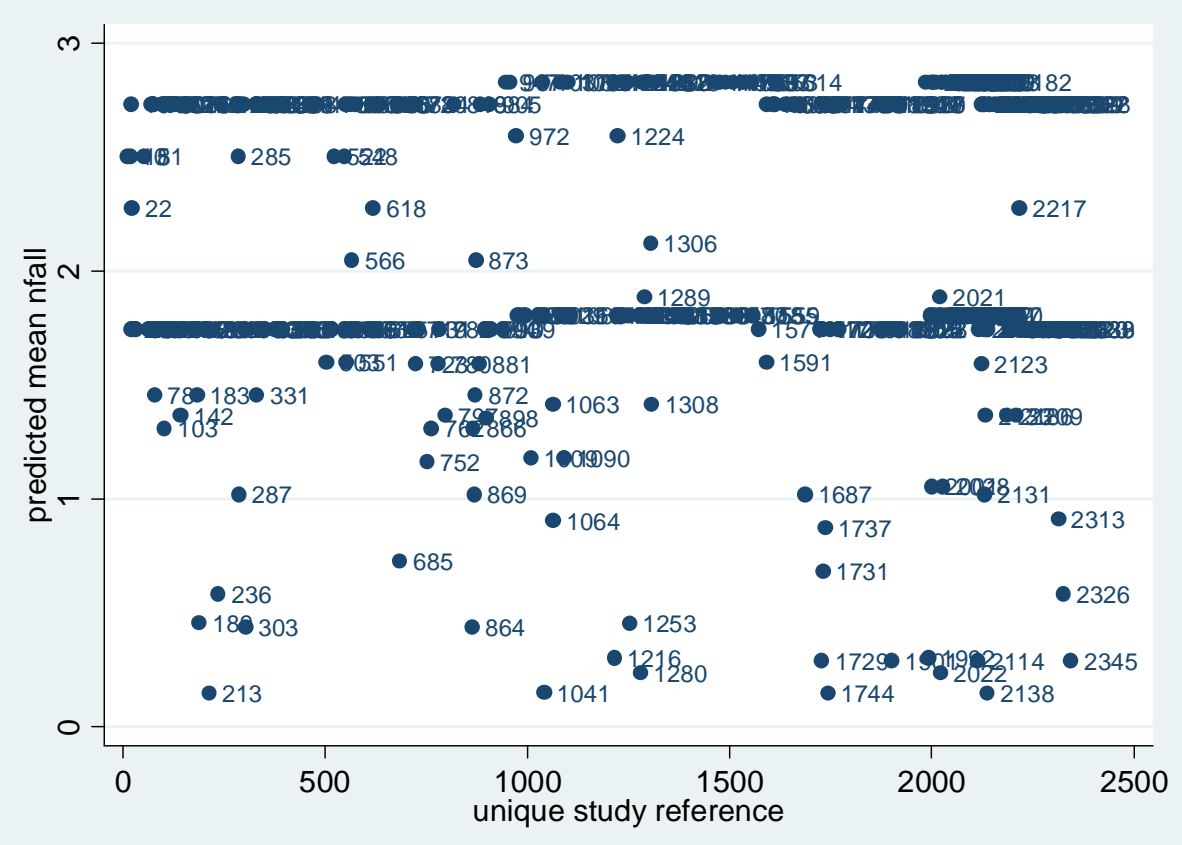




\subsection{Meta-analysis of falls prevention trials}

A limited meta-analysis was carried out to determine the relative benefit if efficacy trials as compared to effectiveness trials. Trials were drawn from the most recent meta-analyses from Campbell ${ }^{12}$ and Gates $^{226}$ as well as including trials published since 2003 logged in Medline.

Search terms included: randomised controlled trial, accidental falls, aged, limited to English language \& humans

Inclusion criteria were: falls over 12 months reported as primary outcome, community dwelling population (including retirement villages), uni or multifactorial intervention, sample size more than 100 in each arm, number of events in control and intervention groups or measure of relative risk with confidence intervals reported.

Each paper was assessed to determine if it was an efficacy/explanatory trial or an effectiveness/pragmatic trial. In this context, pragmatic/effectiveness trials were defined as evaluations of established clinical services, and explanatory/efficacy trials as trials of clearly defined protocol driven interventions. However, few trials report sufficient detail to enable complete clarity in distinguishing the two. This means that the distinction is somewhat subjective; this could have been improved by having a second reviewer classifying each trial, with discussion where there was disagreement. Summary data from the selected trials is shown in Table 4.2. 
Table 4.2 Summary data: RCTs of falls prevention interventions 1994-2008

\begin{tabular}{|c|c|c|c|c|c|c|}
\hline Author/year & Classification & $\mathrm{n}$ & Intervention & Relative risk & \multicolumn{2}{|c|}{$95 \%$ CIs } \\
\hline Campbell 2005 & Efficacy & 391 & Multifactorial & 0.59 & 0.42 & 0.83 \\
\hline Bischoff-Ferrari 2006 & Efficacy & 445 & Unifactorial & 0.77 & 0.51 & 1.15 \\
\hline Cumming 2007 & Efficacy & 616 & Unifactorial & 1.57 & 1.2 & 2.05 \\
\hline Lord 2003 & Efficacy & 551 & Unifactorial & 0.78 & 0.62 & 0.99 \\
\hline Wolf 2003 & Efficacy & 291 & Unifactorial & 0.75 & 0.52 & 1.08 \\
\hline Cumming 1999 & Efficacy & 530 & Unifactorial & 0.64 & 0.5 & 0.83 \\
\hline Stevens 2001 & Efficacy & 1737 & Unifactorial & 1.02 & 0.83 & 1.27 \\
\hline Campbell 1997 & Efficacy & 233 & Multifactorial & 0.6 & 0.47 & 0.78 \\
\hline Clemson 2004 & Efficacy & 310 & Multifactorial & 0.69 & 0.5 & 0.96 \\
\hline Davison 2005 & Efficacy & 313 & Multifactorial & 0.64 & 0.46 & 0.9 \\
\hline Freiberger 2007 & Efficacy & 217 & Multifactorial & 0.77 & 0.6 & 0.97 \\
\hline Lord 2005 & Efficacy & 597 & Multifactorial & 0.9 & 0.69 & 1.17 \\
\hline Shumway-Cook 2007 & Efficacy & 453 & Multifactorial & 0.75 & 0.52 & 1.09 \\
\hline Tinetti 1994 & Efficacy & 301 & Multifactorial & 0.69 & 0.52 & 0.9 \\
\hline Robertson 2001 & Efficacy & 240 & Multifactorial & 0.54 & 0.32 & 0.9 \\
\hline Conroy 2008 & Pragmatic & 344 & Multifactorial & 0.73 & 0.51 & 1.03 \\
\hline Elley 2008 & Pragmatic & 312 & Multifactorial & 0.96 & 0.7 & 1.34 \\
\hline Mahoney 2007 & Pragmatic & 349 & Multifactorial & 0.81 & 0.57 & 1.17 \\
\hline
\end{tabular}


The meta-analysis using the fixed-effect estimate had an $\mathrm{I}^{2}$ statistic of $69.1 \%, p<0.0001$ indicating significant heterogeneity between the studies. Accordingly, a random-effects meta-analysis was carried out (Figure 4.5).

Figure 4.5 Meta-analysis of falls prevention studies using a random-effects model

\begin{tabular}{|c|c|c|c|}
\hline \multicolumn{2}{|l|}{ Study } & \multicolumn{2}{|r|}{$\%$} \\
\hline ID & & ES $(95 \% \mathrm{Cl})$ & Weight \\
\hline Conroy 2008 & $\longrightarrow$ & $0.73(0.51,1.03)$ & 5.09 \\
\hline Elley 2008 & & $0.96(0.70,1.34)$ & 3.95 \\
\hline Mahoney 2007 & & $0.81(0.57,1.17)$ & 4.29 \\
\hline Campbell 2005 & $\rightarrow 1$ & $0.59(0.42,0.83)$ & 6.45 \\
\hline Campbell 1997 & $\rightarrow$ & $0.60(0.47,0.78)$ & 7.95 \\
\hline Clemson 2004 & $\rightarrow$ & $0.69(0.50,0.96)$ & 5.79 \\
\hline Davison 2005 & $\rightarrow \frac{1}{1}$ & $0.64(0.46,0.90)$ & 6.05 \\
\hline Freiberger 2007 & $\rightarrow$ & $0.77(0.60,0.97)$ & 7.02 \\
\hline Lord 2005 & & $0.90(0.69,1.17)$ & 5.54 \\
\hline Shumway-Cook 2007 & $\longrightarrow$ & $0.75(0.52,1.09)$ & 4.57 \\
\hline Tinetti 1994 & $\rightarrow$ & $0.69(0.52,0.90)$ & 6.88 \\
\hline Robertson 2001 & $\rightarrow 1$ & $0.54(0.32,0.90)$ & 4.48 \\
\hline Bischoff-Ferrari 2006 & - & $0.77(0.51,1.15)$ & 3.95 \\
\hline Cumming 2007 & & $1.57(1.20,2.05)$ & 2.63 \\
\hline Lord 2003 & $\rightarrow$ & $0.78(0.62,0.99)$ & 7.02 \\
\hline Wolf 2003 & $\rightarrow$ & $0.75(0.52,1.08)$ & 4.67 \\
\hline Cumming 1999 & $\rightarrow 1$ & $0.64(0.50,0.83)$ & 7.63 \\
\hline Stevens 2001 & $1 \rightarrow$ & $1.02(0.83,1.27)$ & 6.05 \\
\hline Overall (I-squared $=50.8 \%, p=0.007)$ & $\diamond$ & $0.76(0.68,0.83)$ & 100.00 \\
\hline NOTE: Weights are from random effects analysis & & & \\
\hline $\begin{aligned} & 1 \\
&-2.05\end{aligned}$ & & & \\
\hline
\end{tabular}

This meta-analysis, including data from our trial indicates a combined relative risk reduction of $0.76(0.68-0.83)$ in favour of falls prevention strategies delivered to high risk individuals.

A further meta-analysis was carried out separating pragmatic from explanatory trials (Figure 4.6). This shows a similar relative risk reduction of $0.76(0.68-0.83)$ for the explanatory trials, but a reduced effect in pragmatic trials - effect size 0.82 (0.65-0.99). 
Figure 4.6 Meta-analysis comparing pragmatic versus explanatory

\section{falls prevention trials}

\begin{tabular}{|c|c|c|c|}
\hline \multicolumn{2}{|l|}{$\begin{array}{l}\text { Study } \\
\text { ID }\end{array}$} & ES $(95 \% \mathrm{Cl})$ & $\begin{array}{l}\% \\
\text { Weight }\end{array}$ \\
\hline \multicolumn{4}{|l|}{ Pragmatic } \\
\hline Conroy 2008 & & $0.73(0.51,1.03)$ & 5.09 \\
\hline Elley 2008 & & $0.96(0.70,1.34)$ & 3.95 \\
\hline Mahoney 2007 & & $0.81(0.57,1.17)$ & 4.29 \\
\hline Subtotal $(\mathrm{I}$-squared $=0.0 \%, p=0.549)$ & & $0.82(0.65,0.99)$ & 13.33 \\
\hline \multicolumn{4}{|l|}{ 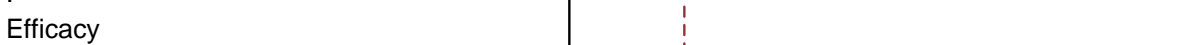 } \\
\hline Campbell 2005 & $\rightarrow 1$ & $0.59(0.42,0.83)$ & 6.45 \\
\hline Campbell 1997 & $\rightarrow 1$ & $0.60(0.47,0.78)$ & 7.95 \\
\hline Clemson 2004 & $\rightarrow$ & $0.69(0.50,0.96)$ & 5.79 \\
\hline Davison 2005 & $\rightarrow \frac{1}{1}$ & $0.64(0.46,0.90)$ & 6.05 \\
\hline Freiberger 2007 & $\rightarrow$ & $0.77(0.60,0.97)$ & 7.02 \\
\hline Lord 2005 & $\frac{1}{10}$ & $0.90(0.69,1.17)$ & 5.54 \\
\hline Shumway-Cook 2007 & $\rightarrow$ & $0.75(0.52,1.09)$ & 4.57 \\
\hline Tinetti 1994 & $\rightarrow$ & $0.69(0.52,0.90)$ & 6.88 \\
\hline Robertson 2001 & $\rightarrow+1$ & $0.54(0.32,0.90)$ & 4.48 \\
\hline Bischoff-Ferrari 2006 & $\longrightarrow$ & $0.77(0.51,1.15)$ & 3.95 \\
\hline Cumming 2007 & & $1.57(1.20,2.05)$ & 2.63 \\
\hline Lord 2003 & $\rightarrow$ & $0.78(0.62,0.99)$ & 7.02 \\
\hline Wolf 2003 & $\rightarrow$ & $0.75(0.52,1.08)$ & 4.67 \\
\hline Cumming 1999 & $\rightarrow+1$ & $0.64(0.50,0.83)$ & 7.63 \\
\hline Stevens 2001 & $i \rightarrow$ & $1.02(0.83,1.27)$ & 6.05 \\
\hline Subtotal $(\mathrm{I}-$ squared $=56.8 \%, p=0.004)$ & $\diamond$ & $0.75(0.66,0.84)$ & 86.67 \\
\hline Overall $(\mathrm{I}$-squared $=50.8 \%, \mathrm{p}=0.007$ ) & $\diamond$ & $0.76(0.68,0.83)$ & 100.00 \\
\hline \multicolumn{4}{|c|}{ NOTE: Weights are from random effects analysis } \\
\hline-2.05 & & 05 & \\
\hline
\end{tabular}

The funnel plot (Figure 4.7) shows a reasonable spread of results, suggesting that publication bias is not a major factor. 
Figure 4.7 Funnel plot of all trials examined in the meta-analysis of falls prevention studies

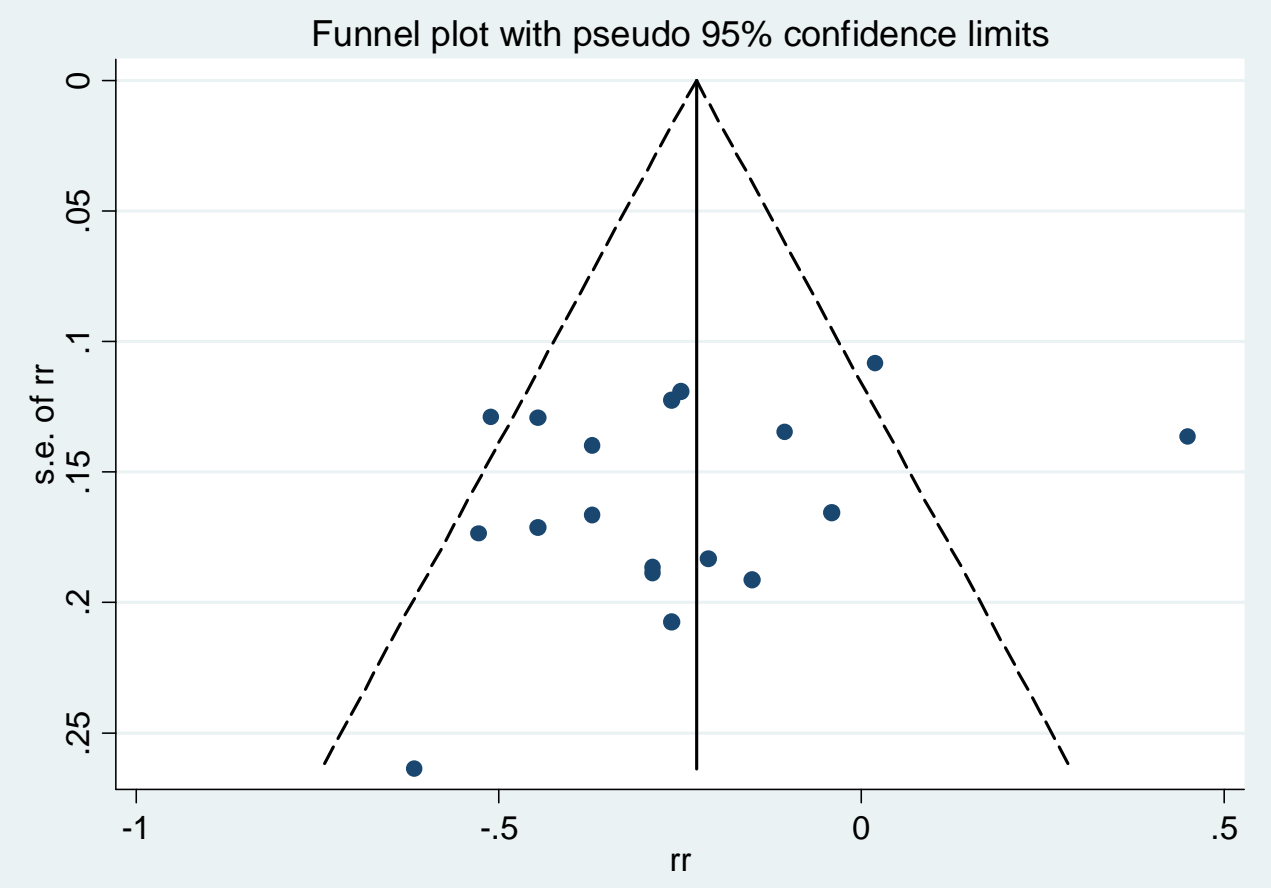

Whilst imperfect in terms of methodology, these findings lend support to the theory that there is a discrepancy between efficacy trials and their delivery in clinical practice (trials of effectiveness). 


\subsection{Publications and presentations arising}

\subsubsection{Publications}

Tahir Masud, Carol Coupland, Avril Drummond, John Gladman, Rowan Harwood, Denise Kendrick, Pradeep Kumar, Rob Morris, Tracey Sach, Rachael Taylor, Jane Youde, Simon Conroy. Multifactorial day hospital intervention to reduce falls in high risk older people in primary care: a multi-centre randomised controlled trial [ISRCTN46584556]. Trials 2006, $7: 5$.

Simon Conroy, Tahir Masud, Carol Coupland, Avril Drummond, John Gladman, Rowan Harwood, Denise Kendrick, Pradeep Kumar, Rob Morris, Tracey Sach, Rachael Taylor, Jane Youde. Early results of a falls screening tool. J Nutr Health Ageing 2005;9(5):381.

Simon Conroy, Tahir Masud, Carol Coupland, Avril Drummond, John Gladman, Rowan Harwood, Denise Kendrick, Pradeep Kumar, Rob Morris, Tracey Sach, Rachael Taylor, Jane Youde. Screening for falls in the community setting. J Nutr Health Ageing 2005;9(5):381.

\subsubsection{Presentations}

Nottinghamshire, Derbyshire \& Lincolnshire Research Alliance grantholder's conference 2006.

Research into Ageing grantholder's conference Birmingham 2005

British Geriatrics Society Falls Conference Manchester 2005

East Midlands Falls Conference 2005 \& 2008 


\section{REFERENCES}

1. Isaacs B. The giants of geriatrics: the challenge of geriatric medicine. Oxford: Oxford University Press, 1992.

2. Department of Health. National service framework for older people: Department of Health, London 2001.

3. Ensrud KE, Ewing SK, Taylor BC, et al. Frailty and risk of falls, fracture, and mortality in older women: the study of osteoporotic fractures. Journals of Gerontology Series A-Biological Sciences \& Medical Sciences 2007;62(7):744-51.

4. Abellan Van Kan A, Rolland Y, Bergman H, et al. The I.A.N.A Task Force on frailty assessment of older people in clinical practice. Journal of Nutrition, Health \& Aging 2008;12(1):29-37.

5. Scuffham $P$, Chaplin $S$, Legood R. Incidence and costs of unintentional falls in older people in the United Kingdom. Journal of Epidemiology \& Community Health 2003;57(9):740-4.

6. Gillespie L. Preventing falls in elderly people. BMJ 2004;328(35):653654.

7. Bazian Ltd. Fall prevention programmes in older people. Evidence-Based Healthcare and Public health. London, 2005:343.

8. Chang JT, Morton SC, Rubenstein LZ, et al. Interventions for the prevention of falls in older adults: systematic review and metaanalysis of randomised clinical trials. BMJ 2004;328(7441):680-.

9. Gillespie LD, Gillespie WJ, Robertson MC, et al. Interventions for preventing falls in elderly people.[see comment][update of Cochrane Database Syst Rev. 2001;(3):CD000340; PMID: 11686957]. Cochrane Database of Systematic Reviews 2003(4): CD000340.

10. National Institute of Clinical Excellence. Falls: the assessment and prevention of falls in older people: NICE, 2004.

11. Skelton $D$, Todd $C$. What are the main risk factors for falls amongst older people and what are the most effective interventions to prevent these falls? How should falls interventions to prevent falls be implemented? In: Network HE, editor: World Helath Organization, 2004.

12. Campbell AJ, Robertson MC. Rethinking individual and community fall prevention strategies: a meta-regression comparing single and multifactorial interventions. Age \& Ageing 2007;36(6):656-62.

13. Feder G, Cryer C, Donovan S, et al. Guidelines for the prevention of falls in people over 65. The Guidelines' Development Group. [see comment]. BMJ 2000;321(7267):1007-11.

14. Tinetti ME, Speechley M, Ginter SF. Risk factors for falls among elderly persons living in the community. New England Journal of Medicine $1988 ; 319(26): 1701-7$.

15. Blake A, Morgan K, Bendall $M$, et al. Falls by elderly people at home: prevalence and associated factors. Age Ageing 1988;17(122):365372.

16. O'Loughlin JL, Robitaille $\mathrm{Y}$, Boivin JF, et al. Incidence of and risk factors for falls and injurious falls among the community-dwelling elderly. American Journal of Epidemiology 1993;137(3):342-54.

17. Clough-Gorr KM, Erpen T, Gillmann G, et al. Multidimensional Geriatric Assessment: Back to the Future Preclinical Disability as a Risk Factor for Falls in Community-Dwelling Older Adults. J Gerontol A Biol Sci Med Sci 2008;63(3):314-320. 
18. Sayer AA, Syddall HE, Martin HJ, et al. Falls, Sarcopenia, and Growth in Early Life: Findings from the Hertfordshire Cohort Study. Am. J. Epidemiol. 2006;164(7):665-671.

19. Tiedemann A, Shimada $H$, Sherrington $C$, et al. The comparative ability of eight functional mobility tests for predicting falls in communitydwelling older people. Age Ageing 2008;37(4):430-435.

20. Chan BKS, Marshall LM, Winters KM, et al. Incident Fall Risk and Physical Activity and Physical Performance among Older Men: The Osteoporotic Fractures in Men Study. Am. J. Epidemiol. 2007; 165(6):696-703.

21. Ganz DA, Bao Y, Shekelle PG, et al. Will my patient fall? JAMA 2007;297(1):77-86.

22. Li W, Keegan THM, Sternfeld B, et al. Outdoor Falls Among Middle-Aged and Older Adults: A Neglected Public Health Problem. Am J Public Health 2006;96(7):1192-1200.

23. Craig R, Mindell J. Chronic diseases: the health of older people. Health Survey for England 2005: The Information Centre, 2007.

24. Wijlhuizen GJ, du Bois $P$, van Dommelen $P$, et al. Effect evaluation of a multifactor community intervention to reduce falls among older persons. International Journal of Injury Control \& Safety Promotion 2007;14(1):25-33.

25. Snijder MB, van Schoor NM, Pluijm SMF, et al. Vitamin D Status in Relation to One-Year Risk of Recurrent Falling in Older Men and Women. J Clin Endocrinol Metab 2006;91(8):2980-2985.

26. Cummings SR, Nevitt MC, Kidd S. Forgetting falls. The limited accuracy of recall of falls in the elderly. Journal of the American Geriatrics Society $1988 ; 36(7): 613-6$.

27. Van Bemmel T, Vandenbroucke JP, Westendorp RGJ, et al. In an observational study elderly patients had an increased risk of falling due to home hazards.

28. Shumway-Cook A, Silver IF, LeMier M, et al. Effectiveness of a Community-Based Multifactorial Intervention on Falls and Fall Risk Factors in Community-Living Older Adults: A Randomized, Controlled Trial. J Gerontol A Biol Sci Med Sci 2007;62(12):14201427.

29. Campbell AJ, Robertson MC, La Grow SJ, et al. Randomised controlled trial of prevention of falls in people aged $>$ or $=75$ with severe visual impairment: the VIP trial. BMJ 2005;331(7520):817.

30. Tinetti $M$, Williams $C$. The effect of falls and fall injuries on functioning in community-dwelling older persons. J Gerontol A Biol Sci Med Sci 1998(53A): M112-M119.

31. Robertson MC, Devlin N, Gardner MM, et al. Effectiveness and economic evaluation of a nurse delivered home exercise programme to prevent falls. 1: Randomised controlled trial. $B M J$ 2001;322(96):697-.

32. Robertson MC ea. Effectiveness and economic evaluation of a nurse delivered home exercise programme to prevent falls. Controlled trial in multiple centres. BMJ 2001(322):701.

33. Clemson L, Cumming RG, Kendig $H$, et al. The Effectiveness of a Community-Based Program for Reducing the Incidence of Falls in the Elderly: A Randomized Trial. J Am Geriatr Soc 2004;52(47):1487-1494.

34. Prudham D, Evans J. Factors associated with falls in the elderly: a community study. Age Ageing 1981(10):141-6.

35. Weatherall M. Multifactorial risk assessment and management programmes effectively prevent falls in the elderly. Evidence-Based Healthcare and Public health 2004;8(5):270-272. 
36. Close JCT et al. Prevention of falls in the elderly trial (PROFET): a randomised controlled trial. Lancet 1999(353):93-7.

37. Gribbin J, Lewis S, Hubbard R, et al. The burden of falls amongst older people in primary care in the United Kingdom. In press.

38. Stone KL, Ewing SK, Lui L-Y, et al. Self-reported sleep and nap habits and risk of falls and fractures in older women: the study of osteoporotic fractures. Journal of the American Geriatrics Society 2006;54(8):1177-83.

39. Volpato S, Leveille SG, Blaum C, et al. Risk Factors for Falls in Older Disabled Women With Diabetes: The Women's Health and Aging Study. J Gerontol A Biol Sci Med Sci 2005;60(12):1539-1545.

40. Kallin K, Gustafson Y, Sandman P-O, et al. Factors Associated With Falls Among Older, Cognitively Impaired People in Geriatric Care Settings: A Population-Based Study. Am. J. Geriatr. Psychiatry 2005;13(6):501-509.

41. Izumi K, Makimoto $K$, Kato $M$, et al. Prospective study of fall risk assessment among institutionalized elderly in Japan. Nurs Health Sci $2002 ; 4(4): 141-7$.

42. Bouwen A, De Lepeleire J, Buntinx F. Rate of accidental falls in institutionalised older people with and without cognitive impairment halved as a result of a staff-oriented intervention. Age \& Ageing 2008;37(3):306-10.

43. Rosendahl E, Gustafson $Y$, Nordin E, et al. A randomized controlled trial of fall prevention by a high-intensity functional exercise program for older people living in residential care facilities. Aging-Clinical \& Experimental Research 2008;20(1):67-75.

44. Ray WA, Taylor JA, Brown AK, et al. Prevention of fall-related injuries in long-term care: a randomized controlled trial of staff education. Archives of Internal Medicine 2005;165(19):2293-8.

45. Sakamoto $K$, Nakamura $T$, Hagino $H$, et al. Effects of unipedal standing balance exercise on the prevention of falls and hip fracture among clinically defined high-risk elderly individuals: a randomized controlled trial. Journal of Orthopaedic Science 2006;11(5):467-72.

46. Kerse N, Butler M, Robinson E, et al. Fall prevention in residential care: a cluster, randomized, controlled trial. Journal of the American Geriatrics Society 2004;52(4):524-31.

47. Jensen J, Nyberg L, Gustafson Y, et al. Fall and injury prevention in residential care--effects in residents with higher and lower levels of cognition. Journal of the American Geriatrics Society 2003; 51(5):627-35.

48. Nowalk MP, Prendergast JM, Bayles CM, et al. A randomized trial of exercise programs among older individuals living in two long-term care facilities: the FallsFREE program. Journal of the American Geriatrics Society 2001;49(7):859-65.

49. Thapa PB, Gideon P, Brockman KG, et al. Clinical and biomechanical measures of balance as fall predictors in ambulatory nursing home residents. Journals of Gerontology Series A-Biological Sciences \& Medical Sciences 1996;51(5): M239-46.

50. Lamoreux EL, Chong E, Wang J], et al. Visual Impairment, Causes of Vision Loss, and Falls: The Singapore Malay Eye Study. Invest. Ophthalmol. Vis. Sci. 2008;49(2):528-533.

51. Assantachai P, Praditsuwan R, Chatthanawaree W, et al. Risk factors for falls in the Thai elderly in an urban community. Journal of the Medical Association of Thailand 2003;86(2):124-30.

52. Johnson SJ. Frequency and Nature of Falls among Older Women in India. Asia Pac J Public Health 2006;18(1):56-61. 
53. Halil M, Ulger Z, Cankurtaran $M$, et al. Falls and the elderly: Is there any difference in the developing world?: A cross-sectional study from Turkey. Archives of Gerontology and Geriatrics 2006;43(3):351-359.

54. Faulkner KA, Cauley JA, Zmuda JM, et al. Ethnic differences in the frequency and circumstances of falling in older community-dwelling women. Journal of the American Geriatrics Society 53(10)(pp 17741779), 2005 Date of Publication: Oct 2005.

55. Tinetti ME, Baker DI, King M, et al. Effect of Dissemination of Evidence in Reducing Injuries from Falls. N Engl J Med 2008;359(3):252-261.

56. Birks YF, Porthouse J, Addie C, et al. Randomized controlled trial of hip protectors among women living in the community. Osteoporosis International 2004;15(9):701-6.

57. Assantachai $P$, Chatthanawaree $W$, Thamlikitkul V, et al. Strategy to prevent falls in the Thai elderly: a controlled study integrated health research program for the Thai elderly. Journal of the Medical Association of Thailand 2002;85(2):215-22.

58. Steinberg $M$, Cartwright $C$, Peel $N$, et al. A sustainable programme to prevent falls and near falls in community dwelling older people: results of a randomised trial. Journal of Epidemiology \& Community Health 2000;54(3):227-32.

59. Izumi K, Makimoto K, Kato M, et al. Prospective study of fall risk assessment among institutionalized elderly in Japan.

60. Hill KD, Moore KJ, Dorevitch MI, et al. Effectiveness of falls clinics: an evaluation of outcomes and client adherence to recommended interventions. Journal of the American Geriatrics Society 2008;56(4):600-8.

61. Nyberg L, Gustafson Y, Janson A, et al. Incidence of falls in three different types of geriatric care. A Swedish prospective study. Scandinavian Journal of Social Medicine 1997;25(1):8-13.

62. Sjosten NM, Salonoja M, Piirtola M, et al. A multifactorial fall prevention programme in home-dwelling elderly people: a randomizedcontrolled trial. Public Health 2007;121(4):308-18.

63. Tinetti ME, Richman D, Powell L. Falls efficacy as a measure of fear of falling. Journal of Gerontology 1990;45(6):P239-43.

64. Bandura A. Self-efficacy: toward a unifying theory of behavioral change.[see comment]. Psychological Review 1977;84(2):191-215.

65. Murphy SL, Dubin JA, Gill TM. The development of fear of falling among community-living older women: predisposing factors and subsequent fall events. Journals of Gerontology Series A-Biological Sciences \& Medical Sciences 2003;58(10): M943-7.

66. Klein BEK, Moss SE, Klein R, et al. Associations of visual function with physical outcomes and limitations 5 years later in an older population: the Beaver Dam eye study. Ophthalmology 2003;110(4):644-50.

67. Whitehead C, Miller M, Crotty M. Falls in community-dwelling older persons followinig hip fracture: impact on self-efficacy, balance and handicap. Clinical Rehabilitation 2003;17(8):899-906.

68. Hatch J, Gill-Body KM, Portney LG. Determinants of balance confidence in community-dwelling elderly people. Physical Therapy 2003;83(12):1072-9.

69. Hellstrom K, Lindmark B, Wahlberg B, et al. Self-efficacy in relation to impairments and activities of daily living disability in elderly patients with stroke: a prospective investigation. Journal of Rehabilitation Medicine 2003;35(5):202-7.

70. Li F, Fisher KJ, Harmer $P$, et al. Fear of falling in elderly persons: association with falls, functional ability, and quality of life. Journals 
of Gerontology Series B-Psychological Sciences \& Social Sciences 2003;58(5):P283-90.

71. Kim H, Hu X, Yoshida $\mathrm{H}$, et al. [Functional status of communitydwelling frail elderly in the Japanese long-term care insurance system]. Nippon Koshu Eisei Zasshi - Japanese Journal of Public Health 2003;50(5):446-55.

72. Becker C, Gebhard F, Fleischer S, et al. [Prediction of mortality, mobility and admission to long-term care after hip fractures]. Unfallchirurg 2003;106(1):32-8.

73. Muche R, Eichner B, Gebhard F, et al. Risk factors and modelling the risk of mortality and socio-functional limitations for elderly people with hip fractures. [German]. European Journal of Geriatrics 5(4)(pp 187-194), 2003 Date of Publication: 2003.

74. Becker C, Gebhard F, Fleischer S, et al. Prediction of mortality, mobility and admission to long-term care after hip fractures. [German]. Unfallchirurg 106(1)(pp 32-38), 2003 Date of Publication: 01 Jan 2003.

75. Scheffer AC, Schuurmans MJ, van Dijk N, et al. Fear of falling: measurement strategy, prevalence, risk factors and consequences among older persons. Age \& Ageing 2008;37(1):19-24.

76. Brouwer BJ, Walker C, Rydahl SJ, et al. Reducing fear of falling in seniors through education and activity programs: a randomized trial. Journal of the American Geriatrics Society 2003;51(6):829-34.

77. Barnett A, Smith B, Lord SR, et al. Community-based group exercise improves balance and reduces falls in at-risk older people: a randomised controlled trial. Age \& Ageing 2003;32(4):407-14.

78. Wolf SL, Sattin RW, Kutner M, et al. Intense tai chi exercise training and fall occurrences in older, transitionally frail adults: a randomized, controlled trial. Journal of the American Geriatrics Society 2003;51(12):1693-701.

79. Turcu A, Toubin S, Mourey F, et al. Falls and depression in older people. Gerontology 2004;50(5):303-8.

80. Jorgensen L, Engstad T, Jacobsen BK. Higher incidence of falls in longterm stroke survivors than in population controls: depressive symptoms predict falls after stroke. Stroke 2002;33(2):542-7.

81. Bergland A, Jarnlo G-B, Laake K. Predictors of falls in the elderly by location. Aging-Clinical \& Experimental Research 2003;15(1):43-50.

82. Gostynski M, Ajdacic-Gross V, Gutzwiller F, et al. Epidemiological analysis of falls among the elderly in Zurich and Geneva. [German]. Schweizerische Medizinische Wochenschrift 129(7)(pp 270-275), 1999 Date of Publication: 20 Feb 1999.

83. Kose N, Cuvalci S, Ekici G, et al. The risk factors of fall and their correlation with balance, depression, cognitive impairment and mobility skills in elderly nursing home residents. Saudi Medical Journal 26(6)(pp 978-981), 2005 Date of Publication: Jun 2005.

84. Lawlor DA, Patel R, Ebrahim S. Association between falls in elderly women and chronic diseases and drug use: Cross sectional study. British Medical Journal 327(7417)(pp 712-715), 2003 Date of Publication: 27 Sep 2003.

85. Scaf-Klomp W, Sanderman R, Ormel J, et al. Depression in older people after fall-related injuries: A prospective study. Age and Ageing 32(1)(pp 88-94), 2003 Date of Publication: Jan 2003.

86. Biderman A, Cwikel J, Fried AV, et al. Depression and falls among community dwelling elderly people: A search for common risk factors. Journal of Epidemiology and Community Health 56(8)(pp 631-636), 2002 Date of Publication: 2002. 
87. Whooley MA, Kip KE, Cauley JA, et al. Depression, falls, and risk of fracture in older women. Study of Osteoporotic Fractures Research Group. Archives of Internal Medicine 1999;159(5):484-90.

88. Stel VS, Smit JH, Pluijm SMF, et al. Consequences of falling in older men and women and risk factors for health service use and functional decline. Age \& Ageing 2004;33(1):58-65.

89. van Haastregt JCM, Zijlstra GAR, van Rossum E, et al. Feelings of anxiety and symptoms of depression in community-living older persons who avoid activity for fear of falling. American Journal of Geriatric Psychiatry 2008;16(3):186-93.

90. Chou KL, Yeung FKC, Wong ECH. Fear of falling and depressive symptoms in Chinese elderly living in nursing homes: fall efficacy and activity level as mediator or moderator? Aging \& Mental Health 2005; 9(3):255-61.

91. Deshpande N, Metter EJ, Bandinelli S, et al. Psychological, physical, and sensory correlates of fear of falling and consequent activity restriction in the elderly: the InCHIANTI study. American Journal of Physical Medicine \& Rehabilitation 2008;87(5):354-62.

92. Shin KR, Shin SJ, Kim JS, et al. [The effects of fall prevention program on knowledge, self-efficacy, and preventive activity related to fall, and depression of low-income elderly women]. Daehan Ganho Haghoeji 2005;35(1):104-12.

93. Means KM, O'Sullivan PS, Rodell DE. Psychosocial effects of an exercise program in older persons who fall. Journal of Rehabilitation Research \& Development 2003;40(1):49-58.

94. Vaapio S, Salminen M, Vahlberg T, et al. Effects of risk-based multifactorial fall prevention on health-related quality of life among the community-dwelling aged: A randomized controlled trial. Health and Quality of Life Outcomes 5, 2007 Article Number: 20 Date of Publication: 26 Apr 2007.

95. Kerse N, Falloon K, Moyes SA, et al. DeLLITE Depression in late life: An intervention trial of exercise. Design and recruitment of a randomised controlled trial. BMC Geriatrics 8, 2008 Article Number: 12 Date of Publication: 2008.

96. Sjosten N, Vaapio S, Kivela SL. The effects of fall prevention trials on depressive symptoms and fear of falling among the aged: a systematic review. Aging \& Mental Health 2008;12(1):30-46.

97. Sjosten NM, Vahlberg TJ, Kivela SL. The effects of multifactorial fall prevention on depressive symptoms among the aged at increased risk of falling. International Journal of Geriatric Psychiatry 23(5)(pp 504-510), 2008 Date of Publication: May 2008.

98. Leipzig R, Cumming R, Tinetti M. Drugs and falls in older people: a systematic review and meta-analysis: II. Cardiac and analgesic drugs. J Am Geriatr Soc 1999;47(1):40-50.

99. Thapa PB, Gideon P, Cost TW, et al. Antidepressants and the risk of falls among nursing home residents.[see comment]. New England Journal of Medicine 1998;339(13):875-82.

100. Weiner DK, Hanlon JT, Studenski SA. Effects of central nervous system polypharmacy on falls liability in community-dwelling elderly. Gerontology 44(4)(pp 217-221), 1998 Date of Publication: 1998.

101. Richards JB, Papaioannou A, Adachi JD, et al. Effect of selective serotonin reuptake inhibitors on the risk of fracture. Archives of Internal Medicine 2007;167(2):188-94.

102. Arfken $\mathrm{CL}$, Lach HW, Birge SJ, et al. The prevalence and correlates of fear of falling in elderly persons living in the community. American Journal of Public Health 1994;84(4):565-70. 
103. Ensrud KE, Blackwell T, Mangione CM, et al. Central nervous system active medications and risk for fractures in older women. Archives of Internal Medicine 163(8)(pp 949-957), 2003 Date of Publication: 28 May 2003.

104. Kallin K, Gustafson Y, Sandman PO, et al. Drugs and falls in older people in geriatric care settings. Aging - Clinical and Experimental Research 16(4)(pp 270-276), 2004 Date of Publication: Aug 2004.

105. Liu B. Relationship between antidepressants and the risk of falls. Geriatrics and Aging 6(7)(pp 45-47), 2003 Date of Publication: Jul 2003.

106. Joo JH, Lenze EJ, Mulsant $\mathrm{BH}$, et al. Risk factor for falls during treatment of late-life depression. Journal of Clinical Psychiatry 63(10)(pp 936-941), 2002 Date of Publication: 01 Oct 2002.

107. Nevitt MC CS, Kidd $S$ et al,. Risk factors for recurrent nonsyncopal falls. A prospective study. JAMA 1989(261):2663-2668.

108. Baker S, Harvey A. Fall injuries in the elderly. Clin Geriatr Med 1985(1):502-12.

109. Kannus $P$, Sievanen $H$, Palvanen $M$, et al. Prevention of falls and consequent injuries in elderly people. The Lancet;366(9500):1885.

110. Ghodsi S, Roudsari B, Abdollahi M, et al. Fall-related injuries in the elderly in Tehran. Injury, Int. J. Care Injured 2003(34 ):809-814.

111. Sattin RW. Falls among older persons: a public health perspective. Annu Rev Public Health 1992(13):489-508.

112. Health Education Authority. Older people - older people and accidents. In: HEA, editor. fact sheet 2. London, 1999.

113. Lilley JM, Arie T, Chilvers CED. Accidents involving Older People: A Review of the Literature. Age Ageing 1995;24(4):346-365.

114. Kannus P, Parkkari J, Koskinen S, et al. Fall-induced injuries and deaths among older adults. JAMA 1999;281:1899-1985.

115. Kannus P, Parkkari J, Niemi S, et al. Fall-Induced Deaths Among Elderly People. Am J Public Health 2005;95(3):422-424.

116. Anonomyous. First Interim Technical Implementation Report: European Network for Safety among Elderly (EUNESE) 2005.

117. Stevens JA, Dellinger AM. Motor vehicle and fall related deaths among older Americans 1990-98: sex, race, and ethnic disparities. Injury Prevention 2002;8(4):272-5.

118. Murphy SL. Deaths: final data for 1998. Natl Vital Stat Rep 2000 48(11):1-105.

119. Cripps R, Jarman J. Falls by the Elderly in Australia: Trends and Data for 1998. Canberra: Australian Institute of Health and Welfare, 2001.

120. Luukinen $\mathrm{H}$, Koski $\mathrm{K}$, Jokelainen J. Temporal changes in the frequency of falling accidents among the elderly during the 1990s: A population-based study. Public Health 2006;120(5):418-420.

121. Haines TP, Bennell KL, Osborne RH, et al. Effectiveness of targeted falls prevention programme in subacute hospital setting: randomised controlled trial.[see comment]. BMJ 2004;328(7441):676.

122. Vassallo M, Sharma JC, Briggs RSJ, et al. Characteristics of early fallers on elderly patient rehabilitation wards. Age Ageing 2003;32(3):338-342.

123. Morse K. Preventing inpatient falls. London: Sage Publications, 1996.

124. Rizzo JA, Friedkin R, Williams CS, et al. Health care utilization and costs in a Medicare population by fall status. Medical Care $1998 ; 36(8): 1174-88$.

125. The NHS Information Centre. Healthcare Resource Group search. In: Health Do, editor. Hospital Episode Statistics, 2008. 
126. Kuzuya M, Masuda Y, Hirakawa Y, et al. Falls of the elderly are associated with burden of caregivers in the community. International Journal of Geriatric Psychiatry 2006;21(8):740-5.

127. Schrag A, Hovris A, Morley D, et al. Caregiver-burden in Parkinson's disease is closely associated with psychiatric symptoms, falls, and disability. Parkinsonism \& Related Disorders 2006;12(1):35-41.

128. Davey C, Wiles R, Ashburn A, et al. Falling in Parkinson's disease: the impact on informal caregivers. Disability \& Rehabilitation 2004;26(23):1360-6.

129. Kiel DP, O'Sullivan P, Teno JM, et al. Health care utilization and functional status in the aged following a fall. Medical Care $1991 ; 29(3): 221-8$.

130. Seematter-Bagnoud L, Wietlisbach V, Yersin B, et al. Healthcare utilization of elderly persons hospitalized after a noninjurious fall in a Swiss academic medical center. Journal of the American Geriatrics Society 2006;54(6):891-7.

131. Donald IP, Bulpitt CJ. The prognosis of falls in elderly people living at home. Age \& Ageing 1999;28(2):121-5.

132. Tinetti ME, Williams CS. Falls, Injuries Due to Falls, and the Risk of Admission to a Nursing Home. N Engl J Med 1997;337(18):12791284.

133. Anpalahan M, Gibson S. Geriatric syndromes as predictors of adverse outcomes of hospitalization. Internal Medicine Journal 2008;38(1):16-23.

134. Saari P, Heikkinen E, Sakari-Rantala R, et al. Fall-related injuries among initially 75- and 80-year old people during a 10-year followup. Archives of Gerontology and Geriatrics 2007;45(2):207-215.

135. Nurmia I, Lüthje $P$, Kataja J. Long-term survival after falls among the elderly in institutional care. Arch. Gerontol. Geriatr 2004(38 ):1-10.

136. Simpson AHRW, Lamb S, Roberts PJ, et al. Does the type of flooring affect the risk of hip fracture? Age Ageing 2004;33(3):242-246.

137. Meta-analysis in context. In: Egger M, Davey Smith G, Altman DG, editors. Reviews in Health Care. London: British Medical Journal Books, 2001.

138. Pajala S, Era P, Koskenvuo M, et al. Genetic factors and susceptibility to falls in older women. Journal of the American Geriatrics Society 54(4)(pp 613-618), 2006 Date of Publication: Apr 2006.

139. Dukas LC, Schacht E, Mazor Ze, et al. A new significant and independent risk factor for falls in elderly men and women: a low creatinine clearance of less than $65 \mathrm{ml} / \mathrm{min}$. Osteoporosis International 2005;16(3):332-8.

140. Kerse N, Parag V, Feigin VL, et al. Falls after stroke: results from the Auckland Regional Community Stroke (ARCOS) Study, 2002 to 2003. Stroke 2008;39(6):1890-3.

141. Lee JE, Stokic DS. Risk factors for falls during inpatient rehabilitation. American Journal of Physical Medicine \& Rehabilitation;87(5):34150; quiz 351.

142. Van Dijk P, Meulenberg O, Van De Sande H, et al. Falls in dementia patients. Gerontologist 1993(33):200-204.

143. Tinetti $M$, Doucette J, Claus $E$, et al. Risk factors for serious injury during falls by older persons in the community. J Am Geriatr Soc 1995(43): 1214-1221.

144. Shaw FE, Bond J, Richardson DA, et al. Multifactorial intervention after a fall in older people with cognitive impairment and dementia presenting to the accident and emergency department: randomised controlled trial. BMJ 2003;326(66):73-. 
145. Piirtola M, Era P. Force platform measurements as predictors of falls among older people - a review. Gerontology 2006;52(1):1-16.

146. Pluijm S, Smit J, Tromp E, et al. A risk profile for identifying community-dwelling elderly with a high risk of recurrent falling: results of a 3-year prospective study. Osteoporosis International 2006:1.

147. Delbaere K, Van den Noortgate N, Bourgois J, et al. The Physical Performance Test as a predictor of frequent fallers: a prospective community-based cohort study. Clinical Rehabilitation 2006;20(1):83-90.

148. Stalenhoef PA, Diederiks JPM, Knottnerus JA, et al. A risk model for the prediction of recurrent falls in community-dwelling elderly: a prospective cohort study. Journal of Clinical Epidemiology 2002;55(11):1088-94.

149. Clark DO, Callahan CM, Counsell SR. Reliability and validity of a steadiness score. Journal of the American Geriatrics Society 2005;53(9):1582-6.

150. Morris R, Harwood RH, Baker R, et al. A comparison of different balance tests in the prediction of falls in older women with vertebral fractures: a cohort study. Age \& Ageing 2007;36(1):78-83.

151. Lord SR, Menz HB, Sherrington C. Home environment risk factors for falls in older people and the efficacy of home modifications. Age \& Ageing 2006;35 Suppl 2:ii55-ii59.

152. Fletcher PC, Hirdes JP. Risk factors for falling among communitybased seniors using home care services.[see comment]. Journals of Gerontology Series A-Biological Sciences \& Medical Sciences 2002;57(8): M504-10.

153. Otaka Y. Muscle and bone health as a risk factor of fall among the elderly. Sarcopenia and falls in older people. Clinical Calcium 2008;18(6):761-6.

154. Capon A, Di Lallo D, Mastromattei $A$, et al. Incidence and risk factors for accidental falls among general practice elderly patients in Latina, Central Italy. Epidemiologia e Prevenzione 2007;31(4):204-11.

155. Papaioannou A, Parkinson W, Cook R, et al. Prediction of falls using a risk assessment tool in the acute care setting. BMC Medicine 2004;2:1.

156. Fink HA, Kuskowski MA, Orwoll ES, et al. Association between Parkinson's disease and low bone density and falls in older men: the osteoporotic fractures in men study.[see comment]. Journal of the American Geriatrics Society 2005;53(9):1559-64.

157. Delbaere K, Crombez G, Vanderstraeten G, et al. Fear-related avoidance of activities, falls and physical frailty. A prospective community-based cohort study. Age \& Ageing 2004;33(4):368-73.

158. Nandy S, Parsons S, Cryer C, et al. Development and preliminary examination of the predictive validity of the Falls Risk Assessment Tool (FRAT) for use in primary care. $J$ Public Health 2004;26(15):138-143.

159. Ensrud KE, Ewing SK, Taylor BC, et al. Comparison of 2 frailty indexes for prediction of falls, disability, fractures, and death in older women. Archives of Internal Medicine 2008;168(4):382-9.

160. Shaw FE. Falls in cognitive impairment and dementia. Clinics in Geriatric Medicine 2002;18(2):159-73.

161. van Doorn C, Gruber-Baldini AL, Zimmerman S, et al. Dementia as a risk factor for falls and fall injuries among nursing home residents. Journal of the American Geriatrics Society 2003;51(9):1213-8. 
162. van Schoor NM, Deville WL, Bouter LM, et al. Acceptance and compliance with external hip protectors: a systematic review of the literature. Osteoporosis International 2002;13(12):917-24.

163. Reyes-Ortiz CA, Al Snih S, Loera J, et al. Risk factors for falling in older Mexican Americans. Ethnicity \& Disease 2004;14(3):417-22.

164. Perracini MR, Ramos LR. [Fall-related factors in a cohort of elderly community residents]. Revista de Saude Publica 2002;36(6):70916.

165. Shumway-Cook A, Ciol MA, Gruber W, et al. Incidence of and risk factors for falls following hip fracture in community-dwelling older adults. Physical Therapy 85(7)(pp 648-655), 2005 Date of Publication: Jul 2005.

166. Fosnight SM, Zafirau WJ, Hazelett SE. Vitamin D supplementation to prevent falls in the elderly: evidence and practical considerations. Pharmacotherapy 2008;28(2):225-34.

167. Faulkner KA, Cauley JA, Zmuda JM, et al. Higher 1,25dihydroxyvitamin D3 concentrations associated with lower fall rates in older community-dwelling women. Osteoporosis International 2006;17(9):1318-28.

168. Bischoff-Ferrari HA, Dawson-Hughes B, Willett WC, et al. Effect of Vitamin D on Falls: A Meta-analysis. JAMA 2004;291(16):19992006.

169. Latham NK, Anderson CS, Reid IR. Effects of vitamin D supplementation on strength, physical performance, and falls in older persons: a systematic review. Journal of the American Geriatrics Society 2003;51(9):1219-26.

170. Orwoll E, Lambert LC, Marshall LM, et al. Endogenous testosterone levels, physical performance, and fall risk in older men. Archives of Internal Medicine 2006;166(19):2124-31.

171. Szulc $P$, Claustrat $B$, Marchand $F$, et al. Increased Risk of Falls and Increased Bone Resorption in Elderly Men with Partial Androgen Deficiency: The MINOS Study. Journal of Clinical Endocrinology and Metabolism 88(11)(pp 5240-5247), 2003 Date of Publication: Nov 2003.

172. Duh MS, Mody SH, Lefebvre $P$, et al. Anaemia and the risk of injurious falls in a community-dwelling elderly population. Drugs \& Aging 2008;25(4):325-34.

173. Penninx BWJH, Pluijm SMF, Lips $P$, et al. Late-life anemia is associated with increased risk of recurrent falls. Journal of the American Geriatrics Society 53(12)(pp 2106-2111), 2005 Date of Publication: Dec 2005.

174. Schwartz AV, Hillier TA, Sellmeyer DE, et al. Older women with diabetes have a higher risk of falls: a prospective study. Diabetes Care 2002;25(10):1749-54.

175. Allain $\mathrm{H}$, Bentue-Ferrer D, Polard $\mathrm{E}$, et al. Postural instability and consequent falls and hip fractures associated with use of hypnotics in the elderly: a comparative review. Drugs \& Aging 2005;22(9):749-65.

176. Hartikainen S, Lonnroos E, Louhivuori K. Medication as a risk factor for falls: critical systematic review. Journals of Gerontology Series A-Biological Sciences \& Medical Sciences 2007;62(10):1172-81.

177. Landi $F$, Onder G, Cesari M, et al. Psychotropic medications and risk for falls among community-dwelling frail older people: an observational study. Journals of Gerontology Series A-Biological Sciences \& Medical Sciences 2005;60(5):622-6. 
178. Schwartz AV, Vittinghoff E, Sellmeyer DE, et al. Diabetes-related complications, glycemic control, and falls in older adults. Diabetes Care 2008;31(3):391-6.

179. Coleman AL, Cummings SR, Yu F, et al. Binocular visual-field loss increases the risk of future falls in older white women. Journal of the American Geriatrics Society 2007;55(3):357-64.

180. Lord SR. Visual risk factors for falls in older people. Age \& Ageing 2006;35 Suppl 2:ii42-ii45.

181. Lord SR, Dayhew J, Howland A. Multifocal glasses impair edgecontrast sensitivity and depth perception and increase the risk of falls in older people. Journal of the American Geriatrics Society 2002;50(11):1760-6.

182. Szabo SM, Janssen PA, Khan K, et al. Older women with age-related macular degeneration have a greater risk of falls: a physiological profile assessment study. Journal of the American Geriatrics Society 2008;56(5):800-7.

183. McCarty CA, Fu CL, Taylor HR. Predictors of falls in the Melbourne visual impairment project. Australian \& New Zealand Journal of Public Health 2002;26(2):116-9.

184. Oliver D, Britton M, Seed P, et al. Development and evaluation of evidence based risk assessment tool (STRATIFY) to predict which elderly inpatients will fall: case-control and cohort studies. BMJ 1997;315(112): 1049-1053.

185. Wade $D$, Collin C. The Barthel ADL index: a standard measure of physical disability? Int Dis Studies 1988;10:64-67.

186. Wijnia JW, Ooms ME, van Balen R. Validity of the STRATIFY risk score of falls in nursing homes. Preventive Medicine 2006;42(2):154-7.

187. Salameh F, Cassuto N, Oliven A. A simplified fall-risk assessment tool for patients hospitalized on medical wards. Israel Medical Association Journal 10(2)(pp 125-129), 2008 Date of Publication: Feb 2008.

188. Vassallo M, Poynter L, Sharma JC, et al. Fall risk-assessment tools compared with clinical judgment: An evaluation in a rehabilitation ward. Age and Ageing 37(3)(pp 277-281), 2008 Date of Publication: 2008.

189. Downton JH. Falls in the Elderly. London: Edward Arnold, 1993.

190. Oliver D. Assessing the risk of falls in hospitals: time for a rethink?[comment]. Canadian Journal of Nursing Research 2006;38(2):89-94; discussion 95-6.

191. Cumming RG, Sherrington C, Lord SR, et al. Cluster randomised trial of a targeted multifactorial intervention to prevent falls among older people in hospital. BMJ 2008:bmj.39499.546030.BE.

192. Smith J, Forster A, Young J. Use of the 'STRATIFY' falls risk assessment in patients recovering from acute stroke. Age and Ageing 2006;35(2):138-143.

193. Ashburn A, Hyndman D, Pickering $R$, et al. Predicting people with stroke at risk of falls. Age and Ageing 2008;37(3):270-276.

194. Mackintosh SF, Hill KD, Dodd KJ, et al. Balance score and a history of falls in hospital predict recurrent falls in the 6 months following stroke rehabilitation. Archives of Physical Medicine \& Rehabilitation 2006;87(12):1583-9.

195. Hyndman D, Ashburn A. Stops walking when talking as a predictor of falls in people with stroke living in the community.[see comment]. Journal of Neurology, Neurosurgery \& Psychiatry 2004;75(7):994-7.

196. Beauchet O, Dubost V, Allali G, et al. 'Faster counting while walking' as a predictor of falls in older adults. Age \& Ageing 2007;36(4):41823. 
197. Close J, Ellis M, Hooper R, et al. Prevention of falls in the elderly trial (PROFET): a randomised controlled trial.[see comment]. Lancet 1999;353(9147):93-7.

198. Close JCT et al. Predictors of falls in a high risk population - results from the prevention of falls in the elderly trial (PROFET). Emer Med J 2003;20(5):421-425.

199. Lundin-Olsson L, Jensen J, Nyberg L, et al. Predicting falls in residential care by a risk assessment tool, staff judgement, and history of falls. Aging Clin Exp Res 2003;15(1):51-9.

200. Chen JS, March LM, Schwarz J, et al. A multivariate regression model predicted falls in residents living in intermediate hostel care. Journal of Clinical Epidemiology 58(5)(pp 503-508), 2005 Date of Publication: May 2005.

201. Tromp AM, Pluijm SMF, Smit JH, et al. Fall-risk screening test: A prospective study on predictors for falls in community-dwelling elderly. Journal of Clinical Epidemiology 2001;54(93):837-844.

202. Stalenhoef PA, Diederiks JPM, Knottnerus JA, et al. The construction of a patient record-based risk model for recurrent falls among elderly people living in the community. Fam. Pract. 2000;17(6):490-496.

203. Stel VS, Pluijm SM, Deeg DJ, et al. A classification tree for predicting recurrent falling in community-dwelling older persons. J Am Geriatr Soc 2003; 51(10): 1356-64.

204. Hale WA, Delaney MJ, Cable T. Accuracy of patient recall and chart documentation of falls. Journal of the American Board of Family Practice 1993;6(3):239-42.

205. Hilden J, Glasziou P. Regret graphs, diagnostic uncertainty and Youden's index. Statistics in Medicine 1996;15:969-986.

206. Tinetti ME. Performance-orientated assessment of mobility problems in elderly patients. J Am Geriatr Soc 1986(34):119-26.

207. Lord S, Sherrington C, Menz H. Falls in older people: risk factors and strategies for prevention.: Cambridge University Press, 2000.

208. Podsiadlo D, Richardson S. The timed up and go: a test of basic functional mobility for frail elder persons. Journal of the American Geriatrics Society 1991(39):142-148.

209. Nordin $E$, Lindelof $N$, Rosendahl $E$, et al. Prognostic validity of the Timed Up-and-Go test, a modified Get-Up-and-Go test, staff's global judgement and fall history in evaluating fall risk in residential care facilities. Age and Ageing 37(4)(pp 442-448), 2008 Date of Publication: 2008.

210. VanSwearingen JM, Paschal KA, Bonino $P$, et al. Assessing recurrent fall risk of community-dwelling, frail older veterans using specific tests of mobility and the physical performance test of function. Journals of Gerontology Series A-Biological Sciences \& Medical Sciences 1998;53(6):M457-64.

211. Lajoie Y, Gallagher SP. Predicting falls within the elderly community: comparison of postural sway, reaction time, the Berg balance scale and the Activities-specific Balance Confidence (ABC) scale for comparing fallers and non-fallers. Archives of Gerontology \& Geriatrics 2004;38(1):11-26.

212. Laessoe $U$, Hoeck HC, Simonsen $O$, et al. Fall risk in an active elderly population--can it be assessed? Journal of Negative Results in Biomedicine 2007;6:2.

213. Steel K, Jonsson PV, Dupasquier JN, et al. Systems of care for frail older persons. InterRAI. Transactions of the American Clinical \& Climatological Association 1999;110:30-5; discussion 35-7. 
214. Kanis JA, Johnell O, Oden A, et al. FRAX ${ }^{\mathrm{TM}}$ and the assessment of fracture probability in men and women from the UK. Osteoporos Int 2008(19):385-3972.

215. Lord SR, Menz HB, Tiedemann A. A Physiological Profile Approach to Falls Risk Assessment and Prevention. PHYS THER 2003;83(3):237252.

216. Gillespie LD RM, Gillespie WJ, Lamb S, Gates S, Cumming RG, Rowe $\mathrm{BH}$,. Interventions for preventing falls in older people living in the community: John Wiley \& Sons, Ltd, 2008.

217. Moreland J, Richardson J, Chan DH, et al. Evidence-based guidelines for the secondary prevention of falls in older adults. Gerontology 2003;49(2):93-116.

218. Yardley $L$, Todd $C$. Encouraging positive attitudes to falls prevention in later life. London: Help the Aged, 2005.

219. Bunn F, Dickinson A, Barnett-Page $E$, et al. A systematic review of older people's perceptions of facilitators and barriers to participation in falls-prevention interventions. Ageing and Society 2008(28):449472.

220. Woo J, Hong A, Lau E, et al. A randomised controlled trial of Tai Chi and resistance exercise on bone health, muscle strength and balance in community-living elderly people. Age \& Ageing 2007;36(3):262-8.

221. Li F, Harmer P, Fisher KJ, et al. Tai Chi: improving functional balance and predicting subsequent falls in older persons. Medicine \& Science in Sports \& Exercise 2004;36(12):2046-52.

222. Li F, Harmer $\mathrm{P}$, Fisher $\mathrm{KJ}$, et al. Tai Chi and fall reductions in older adults: a randomized controlled trial. Journals of Gerontology Series A-Biological Sciences \& Medical Sciences 2005;60(2):187-94.

223. Voukelatos A, Cumming RG, Lord SR, et al. A randomized, controlled trial of tai chi for the prevention of falls: the Central Sydney tai chi trial. Journal of the American Geriatrics Society 2007;55(8):118591.

224. Clemson L, Cumming RG, Kendig $H$, et al. The effectiveness of a community-based program for reducing the incidence of falls in the elderly: a randomized trial. Journal of the American Geriatrics Society 2004;52(9):1487-94.

225. Weatherall M. Prevention of falls and fall-related fractures in community-dwelling older adults: a meta-analysis of estimates of effectiveness based on recent guidelines. Internal Medicine Journal 2004;34(3):102-8.

226. Gates S, Fisher JD, Cooke MW, et al. Multifactorial assessment and targeted intervention for preventing falls and injuries among older people in community and emergency care settings: systematic review and meta-analysis. BMJ 2008;336(7636):130-133.

227. Helms PJ. Real World pragmatic clinical trials: What are they and what do they tell us? Pediatric Allergy and Immunology 2002;13:4-9.

228. Alford L. On differences between explanatory and pragmatic clinical trials. New Zealand Journal of Physiotherapy 2006;35(1):12-16.

229. Elley C, Robertson M, Garrett S, et al. Effectiveness of a falls-andfracture nurse coordinator to reduce falls: a randomized, controlled trial of at-risk older adults. J Am Geriatr Soc 2008;56(8):1383-9.

230. Hendriks $M$, Bleijlevens $M$, van Haastregt J, et al. Lack of effectiveness of a multidisciplinary fall-prevention program in elderly people at risk: a randomized, controlled trial. J Am Geriatr Soc 2008;56(8):1390-7.

231. Lord SR, Castell S, Corcoran J, et al. The effect of group exercise on physical functioning and falls in frail older people living in retirement 
villages: a randomized, controlled trial. Journal of the American Geriatrics Society 2003;51(12):1685-92.

232. Suzuki T, Kim H, Yoshida $H$, et al. Randomized controlled trial of exercise intervention for the prevention of falls in communitydwelling elderly Japanese women. Journal of Bone \& Mineral Metabolism 2004;22(6):602-11.

233. Weerdesteyn $V$, Rijken $H$, Geurts $A C H$, et al. A five-week exercise program can reduce falls and improve obstacle avoidance in the elderly. Gerontology 2006;52(3):131-41.

234. Morgan RO, Virnig BA, Duque $M$, et al. Low-intensity exercise and reduction of the risk for falls among at-risk elders. Journals of Gerontology Series A-Biological Sciences \& Medical Sciences 2004;59(10):1062-7.

235. Nikolaus $T$, Bach $M$. Preventing falls in community-dwelling frail older people using a home intervention team (HIT): results from the randomized Falls-HIT trial. Journal of the American Geriatrics Society 2003;51(3):300-5.

236. Latham NK, Anderson CS, Lee A, et al. A randomized, controlled trial of quadriceps resistance exercise and vitamin $D$ in frail older people: the Frailty Interventions Trial in Elderly Subjects (FITNESS). [see comment]. Journal of the American Geriatrics Society 2003;51(3):291-9.

237. Shaw FE, Bond J, Richardson DA, et al. Multifactorial intervention after a fall in older people with cognitive impairment and dementia presenting to the accident and emergency department: randomised controlled trial.[see comment][erratum appears in BM]. 2003 Mar 29;326(7391):699]. BMJ 2003;326(7380):73.

238. Ashburn A, Fazakarley L, Ballinger $C$, et al. A randomised controlled trial of a home based exercise programme to reduce the risk of falling among people with Parkinson's disease.[see comment]. Journal of Neurology, Neurosurgery \& Psychiatry 2007;78(7):67884.

239. Campbell AJ, Robertson MC, La Grow SJ, et al. Randomised controlled trial of prevention of falls in people aged $>=75$ with severe visual impairment: the VIP trial. BMJ 2005;331(7520):817-.

240. Harwood RH, Foss AJE, Osborn F, et al. Falls and health status in elderly women following first eye cataract surgery: a randomised controlled trial. British Journal of Ophthalmology 2005;89(1):53-9.

241. Foss AJE, Harwood RH, Osborn F, et al. Falls and health status in elderly women following second eye cataract surgery: a randomised controlled trial. Age \& Ageing 2006;35(1):66-71.

242. Cumming RG, Ivers $R$, Clemson $L$, et al. Improving vision to prevent falls in frail older people: a randomized trial. Journal of the American Geriatrics Society 2007;55(2):175-81.

243. Steadman J, Donaldson N, Kalra L. A randomized controlled trial of an enhanced balance training program to improve mobility and reduce falls in elderly patients. Journal of the American Geriatrics Society 2003; 51(6):847-52.

244. Ballard JE, McFarland C, Wallace LS, et al. The effect of 15 weeks of exercise on balance, leg strength, and reduction in falls in 40 women aged 65 to 89 years. Journal of the American Medical Womens Association 2004;59(4):255-61.

245. Helbostad JL, Sletvold O, Moe-Nilssen R. Effects of home exercises and group training on functional abilities in home-dwelling older persons with mobility and balance problems. A randomized study. Aging-Clinical \& Experimental Research 2004;16(2):113-21. 
246. Lord SR, Tiedemann A, Chapman K, et al. The effect of an individualized fall prevention program on fall risk and falls in older people: a randomized, controlled trial. Journal of the American Geriatrics Society 2005;53(8):1296-304.

247. Liu-Ambrose T, Khan KM, Eng JJ, et al. Balance confidence improves with resistance or agility training. Increase is not correlated with objective changes in fall risk and physical abilities. Gerontology 2004;50(6):373-82.

248. Means KM, Rodell DE, O'Sullivan PS. Balance, mobility, and falls among community-dwelling elderly persons: effects of a rehabilitation exercise program. American Journal of Physical Medicine \& Rehabilitation 2005;84(4):238-50.

249. Freiberger $E$, Menz HB, Abu-Omar $K$, et al. Preventing falls in physically active community-dwelling older people: a comparison of two intervention techniques. Gerontology 2007;53(5):298-305.

250. Bischoff HA, Stahelin HB, Dick W, et al. Effects of vitamin D and calcium supplementation on falls: a randomized controlled trial.[see comment]. Journal of Bone \& Mineral Research 2003;18(2):343-51.

251. Dukas L, Bischoff HA, Lindpaintner LS, et al. Alfacalcidol reduces the number of fallers in a community-dwelling elderly population with a minimum calcium intake of more than $500 \mathrm{mg}$ daily. Journal of the American Geriatrics Society 2004;52(2):230-6.

252. Barr RJ, Stewart A, Torgerson DJ, et al. Screening elderly women for risk of future fractures--participation rates and impact on incidence of falls and fractures. Calcified Tissue International 2005;76(4):2438.

253. Jackson C, Gaugris S, Sen SS, et al. The effect of cholecalciferol (vitamin D3) on the risk of fall and fracture: a meta-analysis. Qjm 2007;100(4):185-92.

254. Prince R, Austin N, Devine A, et al. Effects of ergocalciferol added to calcium on the risk of falls in elderly high-risk women. Archives of Internal Medicine 2008;168(1):103-8.

255. Dukas L, Schacht E, Mazor Ze, et al. Treatment with alfacalcidol in elderly people significantly decreases the high risk of falls associated with a low creatinine clearance of $<65 \mathrm{ml} / \mathrm{min}$. Osteoporosis International 2005;16(2):198-203.

256. Bischoff-Ferrari HA, Orav EJ, Dawson-Hughes B. Effect of cholecalciferol plus calcium on falling in ambulatory older men and women: a 3-year randomized controlled trial. Archives of Internal Medicine 2006;166(4):424-30.

257. Gallagher JC, Rapuri PB, Smith LM. An age-related decrease in creatinine clearance is associated with an increase in number of falls in untreated women but not in women receiving calcitriol treatment. Journal of Clinical Endocrinology \& Metabolism 2007;92(1):51-8.

258. Bischoff-Ferrari HA, Dawson-Hughes B, Willett WC, et al. Effect of Vitamin D on falls: a meta-analysis.[see comment]. JAMA 2004;291(16):1999-2006.

259. Haumschild MJ, Karfonta TL, Haumschild MS, et al. Clinical and economic outcomes of a fall-focused pharmaceutical intervention program. American Journal of Health-System Pharmacy 2003;60(10):1029-32.

260. Huang T-T, Acton GJ. Effectiveness of home visit falls prevention strategy for Taiwanese community-dwelling elders: randomized trial. Public Health Nursing 2004;21(3):247-56.

261. Zermansky AG, Alldred DP, Petty DR, et al. Clinical medication review by a pharmacist of elderly people living in care homes--randomised controlled trial.[see comment]. Age \& Ageing 2006;35(6):586-91. 
262. Pit SW, Byles JE, Henry DA, et al. A Quality Use of Medicines program for general practitioners and older people: a cluster randomised controlled trial. Medical Journal of Australia 2007;187(1):23-30.

263. Weber V, White A, McIlvried R. An electronic medical record (EMR)based intervention to reduce polypharmacy and falls in an ambulatory rural elderly population. Journal of General Internal Medicine 2008;23(4):399-404.

264. McClure R, Turner C, Peel N, et al. Population-based interventions for the prevention of fall-related injuries in older people. Cochrane Database of Systematic Reviews 2005(1):CD004441.

265. Poulstrup A, Jeune $B$. Prevention of fall injuries requiring hospital treatment among community-dwelling elderly. European Journal of Public Health 2000(10):45-50.

266. Ytterstad B. The Harstad injury prevention study: community based prevention of fall-fractures in the elderly evaluated by means of a hospital based injury recording system in Norway. Journal of Epidemiology \& Community Health 1996;50(5):551-8.

267. Poulstrup A, Jeune B. Prevention of fall injuries requiring hospital treatment among community-dwelling elderly. European Journal of Public Health 2000(10):45-50.

268. Kempton A, Van Beurden E, Sladden $T$, et al. Older people can stay on their feet: final results of a community-based falls prevention programme. Health Promotion International 2000(15):27-33.

269. Svanstrom L, Ader M, Schelp L, et al. Preventing femoral fractures among elderly: the community safety approach. Safety Science 1996(21):239-46.

270. Lindqvist K, Timpka T, Schelp L. Evaluation of an inter-organizational prevention program against injuries among the elderly in a WHO Safe Community. Public Health 2001(115):308-16.

271. Lin MR, Hwang HF, Wang YW, et al. Community-based Tai Chi and its effect on injurious falls, balance, gait, and fear of falling in older people. Physical Therapy 2006(86):1189-201.

272. Day L, Finch C, Segal L. Reducing Injuries from Falls. $N$ Engl J Med 2008;359(15):1626-.

273. Wells GA, Cranney A, Peterson J, et al. Alendronate for the primary and secondary prevention of osteoporotic fractures in postmenopausal women. Cochrane library: John Wiley \& Sons, Ltd, 2008.

274. Woolf $A D$, Akesson K. Preventing fractures in elderly people. $B M J$ 2003;327(57):89-95.

275. Cumming RG, Thomas M, Szonyi G, et al. Home visits by an occupational therapist for assessment and modification of environmental hazards: a randomized trial of falls prevention. [see comment]. Journal of the American Geriatrics Society 1999;47(12): 1397-402.

276. Stevens M, Holman CD, Bennett N. Preventing falls in older people: impact of an intervention to reduce environmental hazards in the home. Journal of the American Geriatrics Society 2001;49(11):1442-7.

277. Robertson MC, Devlin N, Gardner MM, et al. Effectiveness and economic evaluation of a nurse delivered home exercise programme to prevent falls. 1: Randomised controlled trial.[see comment]. BMJ 2001;322(7288):697-701.

278. Forster A, Young J, Langhorne P. Systematic review of day hospital care for elderly people. BMJ 1999;318(7187):837-841.

279. Council of Europe. Screening as a Tool of Preventive Medicine (Oct. 10, 1994). In: Ministers Co, editor, 1994. 
280. UK National Screening Committee. Second report of the UK national screening committee, 2005.

281. Last J. A dictionary of epidemiology. Fourth ed. Oxford: Oxford University Press, 2001.

282. West J, Hippisley-Cox J, Coupland CAC, et al. Do rates of hospital admission for falls and hip fracture in elderly people vary by socioeconomic status? Public Health 2004;118(8):576.

283. Parker MJ, Gillespie WJ, Gillespie LD. Effectiveness of hip protectors for preventing hip fractures in elderly people: systematic review. BMJ 2006:bmj.38753.375324.7C.

284. Gladman J, Radford K, Walker M. Letter to the editor. Clinical Rehabilitation 2006;20(7):635-636.

285. Wilson J, Jungner G, editors. Principals and practice of screening. Geneva, 1968.

286. Ryynanen OP, Kivela SL, Honkanen R, et al. Incidence of falling injuries leading to medical treatment in the elderly. Public Health $1991 ; 105(5): 373-86$.

287. Scuffham $P$, Chaplin S, Legood R. Incidence and costs of unintentional falls in older people in the United Kingdom. J Epidemiol Community Health 2003;57(67):740-744.

288. Gillespie L, Robertson M, Gillespie W, et al. Interventions for preventing falls in older people living in the community: John Wiley \& Sons, Ltd, 2008.

289. Krauss MJ, Evanoff B, Hitcho E, et al. A Case-control Study of Patient, Medication, and Care-related Risk Factors for Inpatient Falls. J Gen Intern Med 2005;20(2):116-122.

290. Hitcho EB, Krauss MJ, Birge S, et al. Characteristics and Circumstances of Falls in a Hospital Setting. A Prospective Analysis. J Gen Intern Med 2004;19(29):732-739.

291. Graafmans WC, Ooms ME, Hofstee HM, et al. Falls in the elderly: a prospective study of risk factors and risk profiles. Am J Epidemiol 1996(143):1129-36.

292. Koepsell TD, Wolf ME, Buchner DM, et al. Footwear Style and Risk of Falls in Older Adults. J Am Geriatr Soc 2004;52(25):1495-1501.

293. Stalenhoef PA, Crebolder HFJM, Knottnerus JA, et al. Incidence, risk factors and consequences of falls among elderly subjects living in the community: A criteria-based analysis. Eur J Public Health $1997 ; 7(3): 328-334$.

294. Moreland JD, Richardson JA, Goldsmith CH, et al. Muscle Weakness and Falls in Older Adults: A Systematic Review and Meta-Analysis. J Am Geriatr Soc 2004;52(16):1121-1129.

295. Nevitt M, Cummings S, Kidd S. Risk factors for recurrent nonsyncopal falls. A prospective study. JAMA 1989(261):2663-2668.

296. Tinetti M, Inouye S, Gill T, et al. Shared risk factors for falls, incontinence, and functional dependence. Unifying the approach to geriatric syndromes. JAMA 1995(273):1348-53.

297. Kerse N, Butler M, Robinson E, et al. Fall Prevention in Residential Care: A Cluster, Randomized, Controlled Trial. J Am Geriatr Soc 2004;52(26):524-531.

298. Day L, Fildes B, Gordon I, et al. Randomised factorial trial of falls prevention among older people living in their own homes. $B M J$ 2002;325(89):128-.

299. Latham NK, Anderson CS, Lee A, et al. A Randomized, Controlled Trial of Quadriceps Resistance Exercise and Vitamin D in Frail Older People: The Frailty Interventions Trial in Elderly Subjects (FITNESS). J Am Geriatr Soc 2003;51(73):291-299. 
300. American Geriatrics Society BGS, and American Academy of Orthopaedic Surgeons Panel on Falls Prevention. Guideline for the Prevention of Falls in Older Persons. JAGS 2001(49):664-672.

301. Beaglehole R, Bonita R, Kjellstrom T. Basic Epidemiology. 1st ed. Geneva: World Health Organisation, 1993.

302. Altman DG. Practical Statistics for Medical Research. First ed. Boca Raton London New York Washington DC: CHapman \& Hall/CRC, 1999.

303. Streiner D, Norman G. Health measurement scales. Third ed. Oxford: Oxford University Press, 2003.

304. Hasson F, Keeney S, McKenna H. Research guidelines for the Delphi survey technique. Journal of Advanced Nursing 2000;32(4):10081015.

305. Leape L, Brook R. Group judgements of appropriateness: the effect of panel composition. Quality Assur Health Care 1992:151-159.

306. Coulter I, Shekelle P. Impact of varying panel membership on ratings of appropriateness in consensus panels: a comparison of a multiand single disciplinary panel. Health Serv Res 1995:577-91.

307. Delbecq A, Van deVen A. A group process model for problem identification and program planning. Journal of Applied behavioural science $1975 ; 7: 466-91$.

308. Cronbach LJ. Coefficient alpha and the internal structure of tests. Psychometrika 1951(16):297-334.

309. Streiner D, Norman G. Health Measurement Scales, A Practical Guide to Their Development and Use. 2nd Edn. ed. Oxford: Oxford University Press, 1995.

310. Yesavage J, Brink T, Rose T, et al. Development and validation of a geriatric depression screening scale: a prelimnery report. J Psy Res 1983(17):37-49.

311. Bush TL, Miller SR, Golden AL, et al. Self-report and medical record report agreement of selected medical conditions in the elderly. American Journal Of Public Health 1989;79(11):1554.

312. Midthjell $\mathrm{K}$, Holmen $\mathrm{J}$, Bjorndal $A$, et al. Is questionnaire information valid in the study of a chronic disease such as diabetes? The NordTrondelag Diabetes Study. J Epidemiol Commun Health 1992; 46(5):537.

313. Kriegsman DMW, Penninx BWJH, Van Eijk JTM, et al. Self-reports and general practitioner information on the presence of chronic diseases in community dwelling elderly : A study on the accuracy of patients' self-reports and on determinants of inaccuracy. Journal of Clinical Epidemiology 1996;49(12):1407.

314. Tretli S, Lund-Larsen PG, Foss OP. Reliability of questionnaire information on cardiovascular disease and diabetes: Cardiovascular disease study in Finnmark county. J. EPIDEMIOL. COMMUN. HEALTH $1982 ; 36(4): 269$.

315. Colditz GA, Martin P, Stampfer MJ, et al. Validation of questionnaire information on risk factors and disease outcomes in a prospective cohort study of women. American Journal Of Epidemiology $1986 ; 123(5): 894$.

316. Wallace $\mathrm{C}$, Reiber GE, LeMaster J, et al. Incidence of falls, risk factors for falls, and fall-related fractures in individuals with diabetes and a prior foot ulcer. Diabetes Care 2002;25(11):1983-6.

317. Parry SW, Steen N, Galloway SR, et al. Falls and confidence related quality of life outcome measures in an older British cohort. Postgraduate Medical Journal 2001;77(904):103-8.

318. McColl E TR. The use and design of questionnaires. First ed. London: Royal COllege of General Practitioners, 2000. 
319. Colon-Emeric CS, Pieper CF, Artz MB. Can historical and functional risk factors be used to predict fractures in community-dwelling older adults? development and validation of a clinical tool. Osteoporos Int 2002;13(12):955-61.

320. Sackett DL. Bias in analytic research. J Chron Dis 1979(32):51-63.

321. Schwartz N, Strack F, Hippler H, et al. The impact of administration mode on response effects in survey measurement. Appl Cognit Psychol 1991(5):193-212.

322. Siemiatycki J. A comparison of mail, telephone, and home interview strategies for household health surveys. Am J Public Health 1979(69):238-45.

323. Foster K. Evaluating Non-response on Household Surveys. In: Statistics OfN, editor. Government Statistical Service Methodology Series No. 8. London, 1998.

324. Parker C, Dewey M. Assessing research outcomes by postal questionnaire with telephone follow-up. Int. J. Epidemiol. 2000;29(6): 1065-1069.

325. Ory MG, Schechtman KB, Miller JP, et al. Frailty and injuries in later life: the FICSIT trials. Journal of the American Geriatrics Society 1993;41(3):283-96.

326. Legters $K$, Verbus NB, Kitchen $S$, et al. Fear of falling, balance confidence and health-related quality of life in individuals with postpolio syndrome. Physiotherapy Theory \& Practice 2006;22(3):127-35.

327. Michalowska M, Fiszer U, Krygowska-Wajs A, et al. Falls in Parkinson's disease. Causes and impact on patients' quality of life. Functional Neurology 2005;20(4):163-8.

328. Suzuki M, Ohyama N, Yamada K, et al. The relationship between fear of falling, activities of daily living and quality of life among elderly individuals. Nursing \& Health Sciences 2002;4(4):155-61.

329. Salkeld G, Cumming RG, O'Neill E, et al. The cost effectiveness of a home hazard reduction program to reduce falls among older persons. Australian \& New Zealand Journal of Public Health 2000;24(3):265-71.

330. Yardley L, Smith H. A prospective study of the relationship between feared consequences of falling and avoidance of activity in community-living older people. The Gerontologist 2002(42):17-23.

331. Ruthig JC, Chipperfield JG, Newall NE, et al. Detrimental Effects of Falling on Health and Well-being in Later Life: The Mediating Roles of Perceived Control and Optimism. J Health Psychol 2007;12(2):231-248.

332. Stuck $A E$, Siu $A L$, Wieland $G D$, et al. Comprehensive geriatric assessment: a meta-analysis of controlled trials. The Lancet 1993;342(8878):1032-1036.

333. Stuck AE, Egger $M$, Hammer $A$, et al. Home Visits to Prevent Nursing Home Admission and Functional Decline in Elderly People:

Systematic Review and Meta-regression Analysis. JAMA 2002;287(8):1022-1028.

334. Rubenstein $L Z$, Stuck $A E$, Siu $A L$, et al. Impacts of geriatric evaluation and management programs on defined outcomes: overview of the evidence. Journal of the American Geriatrics Society 1991;39(9 Pt 2):8S-16S; discussion 17S-18S.

335. Medical Research Council. A framework for the devleopment and evaluation of randomised control trials for complex interventions to improve health. London: MRC, 2000. 
336. Craig $P$, Dieppe $P$, Macintyre $S$, et al. Developing and evaluating complex interventions: the new Medical Research Council guidance. BMJ 2008;337(sep29_1):a1655-.

337. 10 questions to help you make sense of randomised controlled trials. In: Public Health Resource Unit, editor. Critical Appraisal Skills Programme (CASP) making sense of evidence. England, 2006.

338. Guyatt G, Sackett D, Cook D. Users' guides to the medical literature. II. How to use an article about therapy or prevention. A. Are the results of the study valid? JAMA 1993;270(1):2598-2601.

339. Ellenberg $\mathrm{JH}$. Selection bias in observational and experimental studies. Stat Med 1994(13):557-67.

340. Sibbald $B$, Roland $M$. Understanding controlled trials: Why are randomised controlled trials important? BMJ 1998;316(7126):201-.

341. Altman DG. Better reporting of randomised controlled trials: the CONSORT statement. BMJ 1996;313(7057):570-571.

342. Roberts C, Torgerson DJ. Understanding controlled trials: Baseline imbalance in randomised controlled trials. $B M J$ 1999;319(7203):185-.

343. Trowman R, Dumville JC, Torgerson DJ, et al. The impact of trial baseline imbalances should be considered in systematic reviews: a methodological case study. Journal of Clinical Epidemiology 2007;60(12):1229-1233.

344. Senn SJ. Covariate imbalance and random allocation in clinical trials. Stat Med 1989(8):467-475.

345. The European Agency for the Evaluation of Medicinal Products Evaluation of Medicines for Human Use. Points to consider on adjustment for basleine covariates. In: Products CfPM, editor. London, 2003.

346. Pocock S, Assmann S, Enos L, et al. Subgroup analysis, covariate adjustment and baseline comparisons in clinical trial reporting: current practice and problems. Statist. Med 2002;21:2917-2930.

347. Hauck W, Anderson S, Marcus S. Should We Adjust for Covariates in Nonlinear Regression Analyses of Randomized Trials? Controlled Clin Trials 1998(19):249-256.

348. Hernandez A, Steyerberg E, Dik J, et al. Covariate adjustment in randomized controlled trials with dichotomous outcomes increases statistical power and reduces sample size requirements. Journal of Clinical Epidemiology 2004;57 454-460.

349. Britton A, McKee M, Black N, et al. Choosing between randomised and non-randomised studies: a systematic review. Health Technol Assessment 1998;2(13).

350. Hrobjartsson A, Gotzsche PC. Is the Placebo Powerless?- An Analysis of Clinical Trials Comparing Placebo with No Treatment. $N$ Engl J Med 2001;344(21):1594-1602.

351. Kaptchuk TJ, Stason WB, Davis RB, et al. Sham device v inert pill: randomised controlled trial of two placebo treatments. $B M J$ 2006;332(7538):391-397.

352. Ernst E, Resch KL. Concept of true and perceived placebo effects. BMJ 1995;311(7004):551-553.

353. Torgerson DJ, Roberts C. Understanding controlled trials: Randomisation methods: concealment. BMJ 1999;319(7206):375376.

354. Schulz K, Chalmers I, Hayes R, et al. Empirical evidence of bias: dimensions of methodological quality associated with estimates of effects in controlled trials. JAMA 1995(273):408-412.

355. Bailey $R$, Nelson P. Hadamard randomization: a valid restriction of random permuted blocks. Biometrical Journal 2003;45(5):554-560. 
356. Treasure $T$, MacRae KD. Minimisation: the platinum standard for trials? BMJ 1998;317(7155):362-363.

357. Zelen M. A new design for randomized clinical trials. $N$ Engl J Med 1979;300(22):1242-1245.

358. Torgerson DJ, Roland M. Understanding controlled trials: What is Zelen's design? BMJ 1998;316(7131):606-.

359. Robinson E, Kerr C, Stevens A, et al. Lay public's understanding of equipoise and randomisation in randomised controlled trials. Health Technology Assessment 2005;9(8).

360. Sackett D, Haynes R, Guyatt G, et al. Clincial epidemiology: a basic science for clinical medicine. Second ed. Boston/Toronto/London: Little, Brown and Company, 1991.

361. Simes RJ. Publication bias: the case for an international registry of clinical trials. J Clin Oncol 1986;4(10):1529-41.

362. Dickersin K. The existence of publication bias and risk factors for its occurrence. JAMA 1990;263(10):1385-9.

363. Easterbrook P, Berlin J, Gopalan R, et al. Publication bias in clinical research. Lancet 1991;337(8746):867-72.

364. Sterne J, Gavaghan D, Egger M. Publication and related bias in metaanalysis: power of statistical tests and prevalence in the literature. $J$ Clin Epidemiol 2000;53(11):1119-29.

365. Sutton A, Song F, Gilbody S, et al. Modelling publication bias in metaanalysis: a review. Statistical Methods in Medical Research 2000;9(5):421-45.

366. Stern J, Simes R. Publication bias: evidence of delayed publication in a cohort study of clinical research projects. BMJ 1997;315(7109):640-5.

367. Matthews JNS, Altman DG. Statistics Notes: Interaction 2: compare effect sizes not P values. BMJ 1996;313(7060):808-.

368. MRC. Cluster randomised trials: Methodological and ethical considerations. In: Council MR, editor. MRC clinical trials series. London: Medical Research Council, 2002.

369. Torgerson DJ. Contamination in trials: is cluster randomisation the answer? BMJ 2001;322(7282):355-357.

370. Moher D, Schulz K, Altman D. Revised recommendations for improving the quality of reports of parallel group randomized trials, in CONSORT Group., 2001:1191-1194.

371. Prince M, Macdonald A, Sham P. The development and initial validation of a telephone-administered cognitive test battery (TACT). Int J Methods Psych Res 1999(8):49-57.

372. Heart Protection Study Collaborative Group. MRC/BHF Heart Protection Study of cholesterol lowering with simvastatin in 20536 high-risk individuals: a randomised placebo controlled trial. The Lancet 2002;360(9326):7.

373. Alzheimer's Association. Research Consent for Cognitively Impaired Adults: Recommendations for Institutional Review Boards and Investigators. . Alzheimer Disease \& Associated Disorders $2004 ; 18(3): 171-175$.

374. Beauchamp T, Childress J. Principles of Biomedical Ethics. New York: Oxford University Press, 1979:56.

375. Entwistle VA, Carter SM, Trevena L, et al. Communicating about screening. BMJ 2008;337(sep22_1):a1591-.

376. Krska J, Kennedy E, Milne S. Frequency of counselling on prescription medicines in community pharmacy. Int J Pharm Pract 1995;3:178185. 
377. King M, Nazareth I, Lampe F, et al. Impact of Participant and Physician Intervention Preferences on Randomized Trials: A Systematic Review. JAMA 2005;293(9):1089-1099.

378. Whipple RH ea. Relationship of knee and ankle weakness to falls in nursing home residents. J Am Geriatr Soc 1987(35):13-20.

379. Koch M. An impairment and disability assessment and treatment protocol. Physical Therapy 1994(74):286-94.

380. Tideiksaar R. Preventing falls; home hazard checklists to help older patients protect themselves. Geriatrics 1986(41):26-8.

381. Wade D.T. Measurement in neurological rehabilitation: Oxford Medical Publications, 1992.

382. Gladman J. Some solutions to randomised controlled trials in rehabilitation research. Clinical Rehabilitation 1991(5):9-13.

383. Cuzick J. Primary endpoints for randomised trials of cancer therapy. The Lancet;371(9631):2156-2158.

384. Ferrucci L, Guralnik J, Studenski S, et al. Designing Randomized, Controlled Trials Aimed at Preventing or Delaying Functional Decline and Disability in Frail, Older Persons: A Consensus Report. Journal of the American Geriatrics Society 2004;52(4):625-634.

385. Fleming SA, Blake $\mathrm{H}$, Gladman JRF, et al. A randomised controlled trial of a care home rehabilitation service to reduce long-term institutionalisation for elderly people. Age Ageing 2004;33(4):384390.

386. Cunliffe AL, Gladman JRF, Husbands SL, et al. Sooner and healthier: a randomised controlled trial and interview study of an early discharge rehabilitation service for older people. Age Ageing 2004;33(3):246-252.

387. Parry SW, Steen IN, Baptist M, et al. Amnesia for Loss of Consciousness in Carotid Sinus Syndrome: Implications for Presentation With Falls. Journal of the American College of Cardiology 2005;45(11):1840.

388. Campbell A, Reinken J, Allan B, et al. Falls in old age: a study of frequency and related clinical factors. Age Ageing 1981;10(4):26470.

389. Robbins AS, Rubenstein LZ, Josephson KR, et al. Predictors of falls among elderly people. Results of two population-based studies. Archives of Internal Medicine 1989;149(7):1628-33.

390. Tinetti M, Williams C. Falls, injuries due to falls, and the risk of admission to a nursing home. N Engl J Med 1997(337):1279-1284.

391. Registered Nurses Association of Ontario. Prevention of fall injuries in the older adult. Nursing Best Practice Guideline. Toronto, 2002

392. Lamb SE, Jorstad-Stein EC, Hauer K, et al. Development of a Common Outcome Data Set for Fall Injury Prevention Trials: The Prevention of Falls Network Europe Consensus. Journal of the American Geriatrics Society 2005;53(9):1618-1622.

393. Parry SW, Steen N, Galloway SR, et al. Falls and confidence related quality of life outcome measures in an older British cohort. Postgrad Med J 2001;77(97):103-108.

394. Dolan P. Modelling valuations for EuroQol health states. Med Care 1997;35(11):1095-1108.

395. Tinetti ME, Baker DI, McAvay G, et al. A Multifactorial Intervention to Reduce the Risk of Falling among Elderly People Living in the Community. N Engl J Med 1994;331(118):821-827.

396. Robertson MC, Campbell AJ, Herbison P. Statistical analysis of efficacy in falls prevention trials. Journals of Gerontology Series A-Biological Sciences \& Medical Sciences 2005;60(4):530-4. 
397. Department of Health. Research Governance Framework for Health and Social Care. In: London DoH, editor, 2001.

398. Ittleston W, Proshanky H, Rivlin L. Environmental Pyschology: Man and his physical setting. New York: Holt, Rhinehart \& Winston, 1970.

399. Lincoln N, Gamlen R, Thomason H. Behavioural Mapping of patients on a stroke unit. International disability studies 1989(11):149-154.

400. De Weerdt W, Selz B, Nuyens G, et al. Time use of stroke patients in an intensive rehabilitation unit: a comparison between a Belgian and a Swiss setting. Disability and Rehabiltiation 2000;22(4):181186.

401. Bernhardt J, Dewey $H$, Thrift $A$, et al. Inactive and Alone Physical Activity Within the First 14 Days of Acute Stroke Unit Care. . Stroke 2004(35): 1005-1009.

402. Tinson DJ. How stroke patients spend their days: An observational study of the treatment regime offered to patients in hospital with movement disorders following stroke. Int Disabil Studies 1989(11):45-49.

403. Roberts B, Anthony M, Madigan E, et al. Data management: cleaning and checking. Nursing research 1997(46):350-352.

404. Hollis S, Campbell F. What is meant by intention to treat analysis? Survey of published randomised controlled trials. BMJ 1999(319):670-674.

405. Fox-Wasylyshyn SM, El-Masri MM. Handling missing data in self-report measures. Research in Nursing \& Health 2005;28(6):488-95.

406. Roland M, Dusheiko M, Gravelle $H$, et al. Follow up of people aged 65 and over with a history of emergency admissions: analysis of routine admission data. BMJ 2005;330(7486):289-292.

407. Armitage P, Berry G. Statistical Methods in Medical Research. 3rd Edition ed: Blackwell, 2001.

408. Long MV. Stata Journal 1997(101).

409. Long \& Freese. Stata Journal 2003(128).

410. Creamer R, Drummond A, Standen P, et al. Assessing The Content Of Therapy In A Falls Prevention Programme Using Behavioural Mapping. J Nutr Health Ageing 2006;10(4):333.

411. Liu-Ambrose T, Donaldson B, Ahamed $Y$, et al. Otago Home-Based Strength and Balance Retraining Improves Executive Functioning in Older Fallers: A Randomized Controlled Trial. Journal of the American Geriatrics Society 2008;56(10):1821-1830.

412. Masud T, Coupland C, Drummond A, et al. Multifactorial day hospital intervention to reduce falls in high risk older people in primary care: a multi-centre randomised controlled trial [ISRCTN46584556]. Trials $2006 ; 7(1): 5$.

413. Lawrence $T$, White $C$, Wenn R. The current hospital costs of treating hip fractures. Injury 2005(36):88-91.

414. Sherrington C, Whitney J, Lord S, et al. Effective Exercise for the Prevention of Falls: A Systematic Review and Meta-Analysis. Journal of the American Geriatrics Society 2008;56(12):2234-2243.

415. Layne JE, Sampson SE, Mallio CJ, et al. Successful Dissemination of a Community-Based Strength Training Program for Older Adults by Peer and Professional Leaders: The People Exercising Program. Journal of the American Geriatrics Society 2008;56(12):2323-2329.

416. Lamb S, Gates S, Fisher J, et al. Scoping Exercise on Fallers' Clinics: National Co-ordinating Centre for NHS Service Delivery and Organisation R \& D (NCCSDO), 2007. 
417. Horne M, Speed S, Skelton D, et al. What do community-dwelling Caucasian and South Asian 60-70 year olds think about exercise for fall prevention? Age Ageing 2009;38(1):68-73.

418. Lilford RJ. Equipoise and the ethics of randomisation. $J$ R Soc Med 1995;88:552-559.

419. Efron B, Morris C. Stein's paradox in statistics. Scientific American 1977;236(5):119-127.

420. Woods KL. Commentary: Biostatistics, biological mechanisms and Bayes: lessons from the magnesium trials. Int. J. Epidemiol. 2002;31(1):105-106. 